spers International Journal of Geo-Information

\title{
Innovative \\ Geo-Information \\ Tools for \\ Governance
}

Edited by Yola Georgiadou and Diana Reckien Printed Edition of the Special Issue Published in International Journal of Geo-Information 


\section{Innovative Geo-Information Tools for Governance}





\section{Innovative Geo-Information Tools for Governance}

Special Issue Editors

Yola Georgiadou

Diana Reckien 
Special Issue Editors

Yola Georgiadou

University of Twente

The Netherlands
Diana Reckien

University of Twente

The Netherlands

\section{Editorial Office}

MDPI

St. Alban-Anlage 66

4052 Basel, Switzerland

This is a reprint of articles from the Special Issue published online in the open access journal ISPRS International Journal of Geo-Information (ISSN 2220-9964) from 2017 to 2018 (available at: https: //www.mdpi.com/journal/ijgi/special_issues/geoinformation_governance)

For citation purposes, cite each article independently as indicated on the article page online and as indicated below:

LastName, A.A.; LastName, B.B.; LastName, C.C. Article Title. Journal Name Year, Article Number, Page Range.

ISBN 978-3-03921-337-5 (Pbk)

ISBN 978-3-03921-338-2 (PDF)

Cover image courtesy of Yola Georgiadou.

(C) 2019 by the authors. Articles in this book are Open Access and distributed under the Creative Commons Attribution (CC BY) license, which allows users to download, copy and build upon published articles, as long as the author and publisher are properly credited, which ensures maximum dissemination and a wider impact of our publications.

The book as a whole is distributed by MDPI under the terms and conditions of the Creative Commons license CC BY-NC-ND. 


\section{Contents}

About the Special Issue Editors $\ldots \ldots \ldots \ldots \ldots \ldots$ vii

Yola Georgiadou and Diana Reckien

Geo-Information Tools, Governance, and Wicked Policy Problems

Reprinted from: ISPRS Int. J. Geo-Inf. 2018, 7, 21, doi:10.3390/ijgi7010021 . . . . . . . . . . . . . 1

Rob Lemmens, Juma Lungo, Yola Georgiadou and Jeroen Verplanke

Monitoring Rural Water Points in Tanzania with Mobile Phones: The Evolution of the SEMA App

Reprinted from: ISPRS Int. J. Geo-Inf. 2017, 6, 316, doi:10.3390/ijgi6100316 . . . . . . . . . . . . 11

Johannes Flacke and Cheryl de Boer

An Interactive Planning Support Tool for Addressing Social Acceptance of Renewable Energy

Projects in The Netherlands

Reprinted from: ISPRS Int. J. Geo-Inf. 2017, 6, 313, doi:10.3390/ijgi6100313 . . . . . . . . . . . 31

Maxim Chantillon, Joep Crompvoets and Vassilios Peristeras

The Governance Landscape of Geospatial E-Services-The Belgian Case

Reprinted from: ISPRS Int. J. Geo-Inf. 2017, 6, 282, doi:10.3390/ijgi6090282 . . . . . . . . . . . 50

Josip Lisjak, Sven Schade and Alexander Kotsev

Closing Data Gaps with Citizen Science?Findings from the Danube Region

Reprinted from: ISPRS Int. J. Geo-Inf. 2017, 6, 277, doi:10.3390/ijgi6090277 . . . . . . . . . . . . 75

Jesper Katomero, Yola Georgiadou, Juma Lungo and Robert Hoppe

Tensions in Rural Water Governance: The Elusive Functioning of Rural Water Points in Tanzania

Reprinted from: ISPRS Int. J. Geo-Inf. 2017, 6, 266, doi:10.3390/ijgi6090266 . . . . . . . . . . . 95

Jaap-Willem Sjoukema, Arnold Bregt and Joep Crompvoets

Evolving Spatial Data Infrastructures and the Role of Adaptive Governance

Reprinted from: ISPRS Int. J. Geo-Inf. 2017, 6, 254, doi:10.3390/ijgi6080254 . . . . . . . . . . . 113

Jeroen Verplanke and Yola Georgiadou

Wicked Water Points: The Quest for an Error Free National Water Point Database

Reprinted from: ISPRS Int. J. Geo-Inf. 2017, 6, 244, doi:10.3390/ijgi6080244 . . . . . . . . . . . . 134

Sadra Matmir, Diana Reckien and Johannes Flacke

What do New Yorkers Think about Impacts and Adaptation to Heat Waves? An Evaluation

Tool to Incorporate Perception of Low-Income Groups into Heat Wave Adaptation Scenarios in New York City

Reprinted from: ISPRS Int. J. Geo-Inf. 2017, 6, 229, doi:10.3390/ijgi6080229 



\section{About the Special Issue Editors}

Yola Georgiadou is a professor of geo-information for governance at the Faculty of Geo-Information Science and Earth Observation (ITC) of the University Twente in the Netherlands. Her research is situated at the interface of geo-information technology, policy, and global development. Her current studies include how people enact, organize, and institutionalize (or not) geo-information technology in various domains (water, environment, urban, and land policies) and how infrastructure-the informational, social, and material underpinnings of human action-is built, maintained, and breaks down. Her methods are qualitative. Her normative orientation is "working with the grain" of institutions and organizations. Yola is interested in wicked policy problems, where intense disagreement on values among social actors and high uncertainty regarding spatial facts and cause-effects are manifest. Her latest interdisciplinary research on water governance and digitization in Tanzania foregrounded the interplay between formality and informality in the water sector, as well as the social consequences of the digitization of information flows between citizens and the state and within the state. It showed that digitizing information flows is fraught with insuperable difficulties, when formality and informality compete.

In the past 10 years, she was a collaborator in the research program Linking local action to international climate agreements in the tropical dry forests of Mexico as well as in Using spatial information infrastructure in urban governance networks. She was leader of the research program Sensors, Empowerment, and Accountability in Tanzania (SEMA). These three programs were funded by the Netherlands Organisation for Scientific Research—Science for Global Development (NWO-Wotro). Yola is a past Member of the Executive Committee, International Society Digital Earth (ISDE) - Chinese Academy of Sciences; on the Board of Directors of the Global Spatial Data Infrastructure (GSDI) Association, the Capacity Building Working Group of CODI-Geo, UNECA, Addis Abeba, and on the Advisory Board of SDI and Public Sector Innovation Research, KU Leuven, Belgium. Currently she is a Member of the Editorial Boards for the International Journal Digital Earth (IJDE), for the Journal of Information Technology for Development (JITD), and for the International Journal for SDI Research (IJSDR). She is also member of the NCG sub-commission on Spatial Data Infrastructure (SDI) in the Netherlands and of the NWO-WOTRO Steering Group. 
Diana Reckien is an associate professor of climate change and urban inequalities at the Faculty of Geo-Information Science and Earth Observation, University of Twente, the Netherlands. She specializes in the interface of climate change governance and urban research, with the aim of contributing to justice efforts. One of Dr. Reckien's current research questions is how climate change mitigation and adaptation policies affect and interact with equity and justice, as well as how adaptation and mitigation policies can be set up in order to avoid respective negative side effects. This includes focusing on urban challenges like differential impacts of climate change and adaptive capacity, social vulnerability, and climate change migration. Her other research interests include method development of impact and adaptation assessments, modeling approaches, and ranking - in particular using non-monetary, non-structural, and often psychological damage indicators, employing large comparative studies using social science methods, Geographic Information Systems (GIS), and Fuzzy Cognitive Mapping (FCM). Dr. Reckien's research contributes to the evaluation of success factors of adaptation (plans) in cities, to monitoring and mainstreaming adaptation, and to preventing mal-adaptation. Dr. Reckien is currently the Coordinating Lead Author of the Working Group II Contribution to the IPCC Sixth Assessment Report. She has also been involved in the Second Assessment Report for Climate Change in Cities (ARC3.2; Eds: Rosenzweig, Solecki et al.; Cambridge University Press), for which she led the work on equity and environmental justice. She also serves on the Editorial Board of Renewable and Sustainable Energy Reviews (IF 9.184). Her scientific publication record comprises about 70 publications, including 25 peer-reviewed journal papers, plus multiple book chapters and three Special Issues. Before joining the University of Twente, Dr. Reckien worked as a Senior Climate Impact Scientist at Climate Analytics Berlin (Germany), as an Adjunct Associate Research Scientist at the Center for Research on Environmental Decisions (CRED) at Columbia University's Earth Institute in the City of New York (USA), and as a M.Sc., Ph.D., and Postdoctoral student and researcher at the Potsdam Institute for Climate Impact Research (PIK) (Germany). During parts of that time she also worked as a Social Development Specialist for the Asian Development Bank. Dr. Reckien received her Ph.D. (magna cum laude) in Geography in 2007 from the University of Marburg, Germany, in cooperation with John Moores University, Liverpool, UK. 




\title{
Editorial \\ Geo-Information Tools, Governance, and Wicked Policy Problems
}

\author{
Yola Georgiadou * and Diana Reckien \\ Faculty of Geo-Information Science and Earth Observation, University of Twente, P.O. Box 217, \\ 7500 AE Enschede, The Netherlands; d.reckien@utwente.nl \\ * Correspondence: p.y.georgiadou@utwente.nl; Tel.: +31-53-487-4392
}

Received: 9 January 2018; Accepted: 10 January 2018; Published: 11 January 2018

\section{What You See Depends on Where You Stand}

The emblematic intergovernmental Group of Earth Observations (GEO) sees food, water and energy security, natural hazards, pandemics of infectious diseases, sustainability of key services, poverty, and climate change as societal challenges [1]. In response, GEO is developing an infrastructure of earth observing systems, hardware, and software tools to connect the demand for geo-information with the supply of vast data about the Earth. At the same time, think tanks like the Overseas Development Institute (ODI) observe the complexity and unpredictability of global economic, social, and political developments and develop guidelines to plan and strategize against the odds [2]. We regard the abovementioned societal challenges as wicked policy problems [3] —involving multiple or unknown causes, anticipated and unanticipated effects, and high levels of disagreement among governance stakeholders concerning the nature (and even the existence) of a problem and the appropriateness of solutions. In this Special Issue, we attempt to take the pulse of how we, as geo-information scientists, tackle wicked problems in the global North and South.

To get a sense of the number of published articles on the key themes of the Special Issue, we searched the Web of Science for "Tools" AND "GIS" AND "Governance". Figure 1 shows the distribution of the 87 hits. Searching for Methods or Concepts, instead of Tools, brings about 62 and 23 hits, respectively, with a similar distribution. The upward trend in the number of articles in the last few years testifies to a growing interest in the problem and suggests an emergent integration of the "technical" and "social" research clusters in GIScience, which were operating in isolation in the past [4].

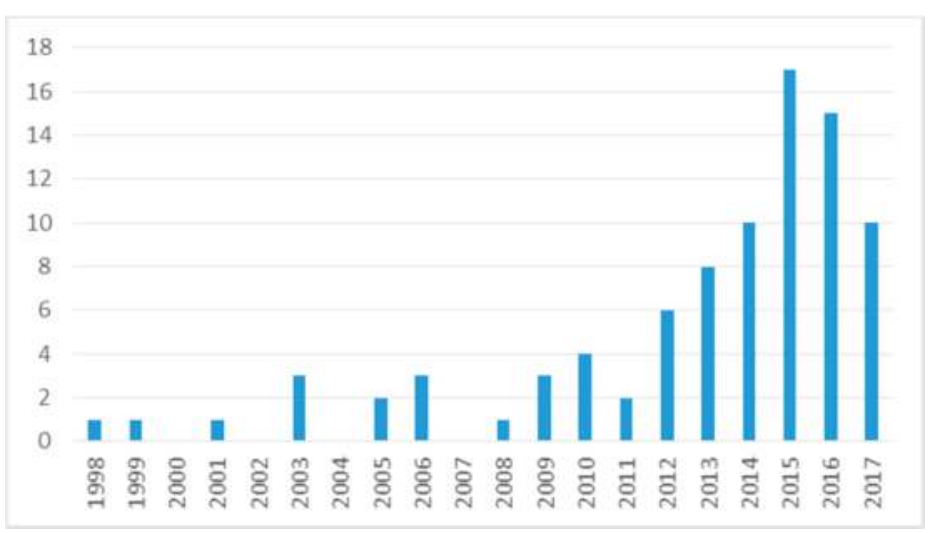

Figure 1. Temporal distribution of hits searching for the topics "Tools" AND "GIS" AND "Governance" in the Web of Science. 
In the past, "technical" research referred to geo-information technology (geo-IT) as revolutionary. Geo-IT would make it easy to identify who owns geo-information, whether it is fit for the purpose at hand, and who can access and integrate it with other information and how. Researchers argued that accessible and integrated data lead to cost savings in the short term, improved service delivery, and more effective policy-making in the medium term, as well as macroeconomic benefits, such as greater competitiveness and innovation, job creation, new firms, and increased Gross Domestic Product (GDP) and tax returns-in other words, better governance-in the long term. The perceived challenge was for independent, verifiable, and repeatable research to provide hard (as opposed to anecdotal) evidence of the positive short-, medium-, and long-term macroeconomic impacts of geo-IT and spatial data infrastructures (SDI). The "social" research sensitized us to contextual issues of importance to geo-IT and SDI implementation, e.g., the need for sustained political support, for legislative backing, for building and maintaining trust, for a level playing field and clear rules, and the need for involving the private sector to help define rules and spot opportunities. The perceived challenge was how to improve institutional arrangements and human capacity so that global innovations in geo-information technology could disappear into the woodwork and become "infrastructure" in specific social contexts. However, prescribing the ideal context of geo-IT implementation only helped to point out "where to go" but not "what actually happens" on the way to the destination [5].

During the same time, public administration scholars were warning against unidirectional causal relations between IT and public administration and spoke about "implications" instead of causal consequences [6]. They argued that autonomous political, legal, economic, and professional developments in and around public administration, and changes in ideas and ideals, are as important to the effects of IT applications on public administration as the technological developments themselves. Moreover, empirical studies in the public sector were indicating that the capacities to collect, store, aggregate, analyze, and present digital data rationalized policy-making processes, but also impinged on their democratic quality. As for the role of information in public policy-making, Van de Donk and Snellen [6] suggested that ideology and interests have always had higher emotional loadings than information for public policy actors:

\begin{abstract}
"The real world of information processing in the domain of public policy making [is] characterised by several types of information (manipulated statistics, high quality research, gossip, editorial comments, evaluation reports, corridor analysis); information pathologies (faulty receptors, failures in communication, information overload, systematic biases) and information politics (manipulation, non-registration, withholding, biased presentation, adding other information, timing, leaking and so on). When looking with an information processing perspective on policy making, it is not surprising at all that one comes up with such a metaphor as a "garbage can"". ( $p .391)$
\end{abstract}

This view may be too pessimistic. If we consider policy-making as a series of steps in a policy cycle [7] it is clear that geo-information tools have played significant roles in some of the policy cycle steps, e.g., in problem recognition, policy monitoring, and policy enforcement [8]. For instance, space imagery influenced problem recognition and agenda setting for the environment. In $A n$ Inconvenient Truth, $\mathrm{Al}$ Gore describes how a single image of the earth from space, taken 50 years ago by a crewmember of the Apollo 8 mission, "exploded into the consciousness of mankind. In fact, within two years of this picture being taken, the modern environmental movement was born. The Clean Air Act, the Clean Water Act, the Natural Environmental Policy Act, and the first Earth Day all came about within a few years of this picture being seen for the first time." Geographic Information Systems (GIS) and Remote Sensing (RS) contribute to policy monitoring, when strategic actors do not shy away from political confrontation, as, for example, the monitoring of deforestation policy in the Brazilian Amazon has shown [9]. Courts of law use remote sensing as evidence in policy enforcement when crimes take place over longer periods of time, when legal disputes relate to objects identifiable from space, when data interpretation by nontechnical experts is possible, and when data authenticity and reliability are certain [10]. 
Political scientists point out that only when the problem is well structured or tame can policy be considered the product of an orderly sequence of steps in a policy cycle (see, e.g., Stone [11]; Sabatier [12]). However, when the problem is moderately structured or wicked, looking at policy-making as steps in a policy cycle and at geo-information tools as collectors, processors, and disseminators of data is not productive. In this case, we need a different conceptual framework for policy-making and for geo-information tools. In Section 2, we start with the general notion of governance to arrive at such a framework, and use it in Section 3 to discuss the authors' contributions. In Section 4, we draw conclusions.

\section{Where Do We Stand?}

Defining a vague term like governance is like trying to nail a pudding to the wall [13]. Yet, vagueness may be the source of the term's popularity, so much so that Pollitt and Hupe [14] refer to governance as a "magic concept". Because magic concepts have a large breadth of scope, they give rise to multiple, overlapping, sometimes conflicting definitions. However, definitions can only fulfil explanatory functions if specified systematically for specific purposes [14]. Definitions of governance can be normative or descriptive.

On the normative side, the most popular is "good governance", a notion that generated such a large catalogue of virtuous characteristics over time that its identity is uncertain. Thus, two decades ago, the foremost attributes for good governance were effectiveness, accountability, transparency, and the rule of law. Currently, the list of recommended qualities of good governance includes "equity, participation, inclusiveness, democracy, widespread service delivery, sound regulation, decentralization, an open trade regime, respect for human rights, gender and racial equality, a good investment climate, sustainable energy use, citizen security, job creation, and a variety of other ends" (p. 17, [15]). Specifying governance as "good governance" serves as a potent myth, a shared frame of reference that enables individuals and organizations to deal with contradictions in everyday life that can never be fully resolved [16]. As such, myths are neither true nor false, but either living or dead [17]. What is of interest is what myths represent, and how myths may or may not contribute to established bases of meaning and experience. Instead of "good governance", Merilee Grindle has been advocating for two decades for "good enough governance" as a platform for critically questioning the long menu of institutional changes and capacity-building initiatives deemed important or essential $[18,19]$. In a recent article, titled Good Governance, R.I.P., she finally declared "good governance" dead [15].

Descriptive definitions of governance separate the performance of governance agents (the means) from the aspirations (goals) of their principals. For instance, Fukuyama (p. 350, [20]) describes "governance as a government's ability to make and enforce rules, and to deliver services, regardless of whether that government is democratic or not." By excluding democracy from the definition, Fukuyama rejects the orthodoxy that democracy and good governance are mutually supportive. Instead, he argues that the "democracy-good governance" link is more of a theory than an empirically demonstrated fact, and that we cannot empirically demonstrate the connection if we define one to include the other. Similarly, De Herdt and De Sardan (p. 4, [21]) describe governance as "an emergent pattern or order of a social system, arising out of complex negotiations and exchanges between "intermediate" social actors, groups, forces, organizations, public and semi-public institutions in which state organizations are only one-and not necessarily the most significant-amongst many others seeking to steer or manage these relations." Choosing this descriptive focus allows them to analyze public authority as the product of a social process.

In this Special Issue, we also define governance descriptively-as the attempts of stakeholders (social actors, groups, organizations, public, and semipublic institutions) to structure policy problems [22]. Thus, we conflate "governance" with a constructivist view of policy-making as "problem structuring" and use Hoppe's typology to distinguish four ideal-types of policy problems (see Table 1). 
Table 1. Four types of policy problems and related tools (adapted from Hoppe [22]).

\begin{tabular}{|c|c|c|}
\hline \multirow{2}{*}{$\begin{array}{c}\text { Spatial } \\
\text { Knowledge }\end{array}$} & \multicolumn{2}{|c|}{ Policy Goals and Values } \\
\hline & Consensus among Stakeholders & Dissensus among Stakeholders \\
\hline $\begin{array}{c}\text { Certain } \\
\text { (facts and } \\
\text { cause-effects) }\end{array}$ & $\begin{array}{l}\text { (1) Tame or structured problems } \\
\text { - Debate on technicalities } \\
\text { - Geo-information tools as problem solver }\end{array}$ & $\begin{array}{l}\text { (3) Moderately structured problems } \\
\text { - Participation to debate goals and values } \\
\text { - Geo-information tools as mediator }\end{array}$ \\
\hline $\begin{array}{l}\text { Uncertain } \\
\text { (facts and } \\
\text { cause-effects) }\end{array}$ & $\begin{array}{l}\text { (2) Moderately structured problems } \\
\text { - Participation to debate cause-effects and } \\
\text { optimize the collection of facts } \\
\text { - Geo-information tools as analyst and/or advocate }\end{array}$ & $\begin{array}{l}\text { (4) Wicked or unstructured problems } \\
\text { - Endless debate } \\
\text { - Geo-information tools as problem recognizer }\end{array}$ \\
\hline
\end{tabular}

At the heart of the typology is the opposed pair of structured (or tame) versus unstructured (or wicked) problems. Problems are structured or tame (box 1) when stakeholders have far-reaching agreement on norms and values, and are certain about the factual and cause-effect knowledge needed to solve them. In contrast, unstructured or wicked problems (box 4) are hotly debated political issues where ethical disagreement and divisiveness in stakeholders' preferences perseveres, while factual and cause-effect knowledge is uncertain. Because stakeholders attempt to solve 'new' problems by mixing solutions to 'old' problems, they are inclined to quickly move a wicked problem into a more structured direction that is more familiar to them and more compatible with existing standard operating procedures. Moderately structured problems appear in two variants-with consensus (box 2) or with dissensus (box 3) regarding stakeholders' goals and values. This definition of governance casts a different light on the uses of geo-information tools depending on how stakeholders frame the policy problem: as a problem recognizer for unstructured problems, as problem analyst and advocate or mediator for moderately structured problems and as problem solver for structured problems (see Table 1). A few indicative examples are in order.

Geo-information tools as problem recognizer: The best-documented example is the detection of the ozone hole by way of remote sensing (RS) [8]. Concern about the detrimental effect of chlorofluorocarbons (CFCs) on the ozone layer stimulated the US Congress to commission NASA to develop the Total Ozone Mapping Spectrometer (TOMS) sensor to monitor the state of the ozone layer. The TOMS sensor was launched in 1978 on-board the NIMBUS satellite and did not report any anomalies until 1986. At that time, NASA confirmed, after re-analysis of the TOMS data, that the ozone hole had been growing since 1978. In response to these findings, the 1987 Montreal Protocol prescribed a $50 \%$ reduction, and four years later, a complete ban on the use of CFCs.

Geo-information tools as analyst and/or advocate: The classical example is John Snow's proto-GIS in 1854 that clustered cholera deaths of people accessing water from the Broad Street well in London [23]. Snow's quantitative analysis, combined with Reverend Henry Whitehead's extensive local knowledge of the community, provided strong evidence in support of his theory of cholera as a water-borne disease. Moreover, his analysis served as an advocacy tool that ultimately led to the endorsement of his theory by local officials. The latter concluded unanimously that the "striking disproportionate mortality in the "cholera area" ... was in some manner attributable to the use of impure water of the well in Broad Street" (p. 182). The pump's handle was removed soon after and the epidemic was contained.

Geo-information tools as mediator: An illuminating example of geo-information tools as mediator between conflicting interests is the Ogiek Peoples Ancestral Atlas, which included their hitherto excluded voices in contests about land. The Ogiek Indigenous People in the Mau Forest in Kenya planned the Atlas to define their ancestral territories within the Mau Forest Complex, and secure their rights and interests against the inflow of migrants. Prior to the Ancestral Atlas, the community had constructed a Participatory 3D Model of the territories. The model reinforced the bonds among the 25 Ogiek clans and their sense of belonging to a single cultural entity, with a unique cultural identity and indigenous knowledge system, instead of belonging to scattered clans [24]. The Ancestral 
Atlas depicted the tacit spatial knowledge of a semiliterate indigenous community, accumulated over generations in intimate interactions between the community and their natural environment.

Geo-information tools as problem solver: Finally, geo-information tools can provide the means to solve highly complex but still tame problems-i.e., when the spatial facts are or can be easily available from remote sensing, censuses, and field observation, the cause-effect links are relatively well understood and stakeholders agree on values and policy goals. Numerous examples of such uses figure in standard RS/GIS textbooks (e.g., Tolpekin and Stein [25]).

In addition to the problem typology, Hoppe [22] discusses how governance stakeholders tend to move from box 4 to box 1, depending on the way of social organizing-either individualist, or hierarchist, or egalitarian-they value most [26]. The three ways of social organizing correspond to the market, hierarchy, or network social coordination, respectively [27]. Each way is supported by (and, in turn, supports) a "cultural bias"; that is, a compatible pattern of perceiving, justifying, and reasoning about nature, human nature, justice, risk, blame, leadership, and governance. For instance, hierarchists tend to frame wicked problems as structured and prefer to move to box 1 sooner rather than later. Egalitarians view wicked problems from the perspective of fairness and are inclined to move to box 3, while individualists attempt to exploit any bit of usable knowledge before moving to box 1 . The question remains as to how several stakeholders with a mix of inclinations (individualist, or hierarchist, or egalitarian) manage to move out of box 4 together? They must either reach some sort of congruence that has elements of most ways of social organizing-i.e., a hybrid way of social organizing-or they must shun the participation of "troublemakers". For instance, Chandran et al. [28] discuss how the hierarchist UN Secretariat of the Convention on International Trade in Endangered Species (CITES) questioned the use of a GIS-based tool developed by the United Nations University, because the tool accorded an excessively important role to egalitarian NGOs (the "troublemakers"), and successfully excluded them from the debate.

In sum, defining governance as the structuring of wicked policy problems requires us to rethink the role of geo-information tools in governance. At the same time, the use of geo-information tools in problem structuring can reveal the degree of hybridity of social organizing, according to [26], or of social coordination, according to Bouckaert, Peters, and Verhoest [27].

\section{Policy Problems and Geo-Information Tools}

Contributors to the Special Issue cover a spectrum of policy problems, from renewable energy, to climate change and bioenergy, to rural water supply and, finally, the coordination of spatial data infrastructures, which underpin efforts to address societal challenges [4]. The geo-information tools they develop and use in their analyses depend on how they frame the policy problem at hand.

Renewable energy is a priority for European countries and cities. Many of them have developed ambitious targets for greenhouse gas reduction; some of them, such as cities in the Netherlands, even aim to become carbon-neutral within the next 20 to 35 years $[29,30]$. However, the implementation of renewable energy systems such as wind turbines or solar farms in The Netherlands has been particularly slow compared with in other European countries. Devine [31] sees two main reasons for this: (a) limited institutional capacities of local decision-makers with respect to the implementation of renewable energy policies; and (b) strong opposition from local communities and individual citizens towards the implementation of large-scale renewable energy projects. Additional economical, institutional, and political factors may play a role [32]. For the city of Enschede, in The Netherlands, Flacke and de Boer [33] framed the problem as moderately structured with goal dissensus; the knowledge that a combination of wind turbines and solar farms can generate more renewable energy is certain, while local stakeholders may value things like aesthetics (the visual impact of turbines in the landscape) more than the government's ambitious targets. The authors developed an interactive planning support tool, named COLLAGE, and deployed it in workshop settings, involving stakeholders in the participatory mapping of wind turbines and solar panels in Enschede. They show that the COLLAGE tool helps to increase citizen awareness for renewable energy, triggers social 
learning about renewable energy, supports improved engagement and participation of the public, and thereby aids local energy governance. The authors show that engaging with local stakeholders and communities early in the planning phase can lower public dissensus and increase the viability, legitimacy, and local relevance of renewable energy strategies. COLLAGE is a good example of a geo-information tool as mediator between groups of stakeholders with diverging goals and values (box 3, Table 1).

Climate change raises equity issues, not only between continents and countries but also between regions, cities, and residents [34,35]. In this century of urbanization, where most people live in cities, the question necessarily turns to who is or will be affected in cities and how. Not only impacts, but also mitigation and adaptation policies are subject to political economy evaluations, with important questions being who can decide to implement adaptation and mitigation and where, to whom, and how it is applied. Low-income residents are among the most vulnerable groups to climate change in urban areas, particularly regarding heat stress. However, their perceptions about heat and the impacts they face often go undocumented, and are seldom considered in decision-making processes delivering adaptation. Matmir et al. [36] evaluate the perceptions of New York City residents concerning past impacts as well as the future need for adaptation to heat waves. Employing online interviews, the authors compare the heat impacts of different income groups and simulate adaptation scenarios. By using online interviews and applying Fuzzy Cognitive Mapping, the authors aim not only to calculate socially useful adaptation options, but also to give low-income groups a voice in the climate change adaptation planning process. The combination of online interviews and Fuzzy Cognitive Mapping is yet another example of a geo-information tool as mediator that includes previously unheard citizens in the policy-making process and reveals consensus or dissensus among income groups (box 3, Table 1).

Bioenergy generation is high on the European political agenda for the circular economy. Bioenergy refers to the reuse of biomass as an excellent raw material for the production of wood pellets for heating. In 2009, the overall supply of biomass in the Danube region (excluding non-EU countries where data was not available) was estimated at 1136.2 petajoules (PJ) with an agricultural contribution of $23 \%$. Lisjak, et al. [37] frame bioenergy generation in the Danube region as a moderately structured problem with knowledge uncertainty. They assume that bioenergy stakeholders-a network of national experts representing each country in the Danube region who act as 'ambassadors' of open data, biomass producers (owners of vineyards and orchards), and biomass utilizers-are convinced of the role of biomass reuse as a common good. The knowledge uncertainty here refers to the lack of spatial facts, e.g., the location of available biomass (piles of branches) and their estimated volume. To produce the lacking spatial facts and close the data gap, the authors developed a smartphone-based geo-information tool: the 'Waste2Fuel' app. An owner of a vineyard or an orchard, standing close to the location of a pile of branches, and armed with the 'Waste2Fuel' app, can select 'Add biomass site', open a data form with fields to input a short description, a contact number, and the estimated volume of the pile, and enter the data. The biomass utilizer will receive this information on her smartphone and organize a pick-up. This kind of geo-information tool is the essence of Citizen Science, "a complement, and even substitute, to data from such traditional sources... Individuals are no longer passive users of data generated by a designated institution on their behalf. On the contrary, they play a far more direct role in the creation and utilisation of content." [37] Citizen Science comes to the rescue when facts are not readily available and citizens are willing to collect them and share them to minimize the uncertainty in factual spatial knowledge [38]. The Waste2Fuel tool and Citizen Science in general are applicable when the collection of discrete facts is the main challenge (box 2, Table 1).

Rural water supply in Tanzania is a wicked policy problem that persists since the country's liberation from colonial rule. Currently, nearly half of rural water points are not functional and about $20 \%$ of newly constructed water points become nonfunctional within one year. Rural citizens-the largest part of a population of 44 million people-soon return to traditional, unimproved water sources and endanger their health and well-being. The problem's wickedness is manifest in the lack of 
spatial facts regarding rural water points and the persistent lack of agreement at different levels of government on how to tackle the problem. In the first of three contributions on rural water supply policy-making in Tanzania, Verplanke and Georgiadou [39] discuss how the Ministry of Water bracketed out the disagreement among different levels of government on how to tackle rural water supply and assumed that the problem was one of data collection only. The Ministry developed the Water Point Mapping System (WPMS) database to support the monitoring of all water points, and improve policy-making and water supply services in rural areas. The focus on the massive data collection for the WPMS database effectively moved the rural water supply problem from box 4 directly to box 2 (Table 1). The authors attributed some of the errors in the database to the bracketing-out of stakeholder disagreement and the discretionary nature of water point mapping. Katomero et al. [40] discuss how the bracketed-out disagreements later reappeared as three pervasive governance tensions, and moved the problem back to box 4 . The first tension is between formal government standards and informal practices used by district water engineers and villagers to classify water points. The second tension is between the new and old administrative hierarchies at the district level. The third tension is between new and existing communication channels at the reporting and receiving ends of information. Finally, Lemmens et al. [41] discuss a mobile phone-based software tool, developed to serve as a boundary object-an object with different meanings and serving different purposes-for different stakeholders debating a wicked problem. The tool helped the researchers to elicit conflicting views of stakeholders over a period of 4 years, and, in the process, assisted them in continuously redesigning the tool. They describe the current architecture of the tool's frontend (the SEMA app) and backend and discuss how the perceptions and use patterns of stakeholders over time affected the tool design and resolved the tension over what to report (by decreasing the discretion of reporters) and who should report (by constraining the reporting "crowd"). As such, the tool acted as a problem recognizer in the context of a wicked policy problem (box 4, Table 1).

The remaining two contributions invert the perspective of the Special Issue in an innovative fashion. Instead of studying how geo-information tools are used in policy-making, the authors discuss what the use of geo-information tools reveals about the hybridity of policy-making, governance, and SDI governance in particular. This kind of research has a family resemblance with previous studies by Anand [42] and Richter [43]. For example, Anand [42] analyses the formal and informal practices in municipal water supply in Mumbai in order to reveal the social production of "hydraulic citizenship", a form of belonging to the city enabled by claims residents make to the city's water infrastructure. Richter (2014) studies formal and informal ways of recording information on land ownership in Indian cities in order to reveal the blurred governance space between urban administration and urban society. Sjoukema et al. [44] examine the governance history of the SDIs in The Netherlands and in Flanders (Belgium), using the evolution of large-scale base maps as SDI proxies and, effectively, as geo-information tools. Their longitudinal study shows that SDI governance has been adaptive, that governance models (individualist, hierarchist, or egalitarian) did not hold up very long, as they were either not meeting their goals, were not satisfying all stakeholders, or were not in alignment with new visions and ideas. They argue that adaptive governance with a broader mix of individualist, hierarchist, or egalitarian policy instruments can better respond to changes. Chantillon et al. [45] focus empirically on Belgium to understand what kinds of social coordination (market, hierarchist, and network) are used for geospatial e-services and data in various regions. They show that Flanders combines hierarchy with network (egalitarian) governance, whereas the Brussels administration prefers a hierarchist way of working. The transposition of the Infrastructure for Spatial Information in the European Community (INSPIRE) Directive stimulated a turn towards a more network-oriented (individualist) governance in the Walloon and the Brussels Capital Regions. They conclude that the current status of social coordination is a weak form of network governance. 


\section{Conclusions}

We have shown that the mainstream view of geo-information tools as contributing to collection, analysis, and dissemination of data may not be so productive when we deal with wicked policy problems. The contributions to the Special Issue show that an alternative view of geo-information tools as problem recognizers, as problem analysts and advocates, as mediators, and as problem solvers is more appropriate, mainly for three reasons: First, the framing of the policy problem (as tame, moderately structured, or wicked) by the researchers themselves becomes more transparent, and increases the researchers' reflexivity. Second, geo-information tools can now be seen as an integral part of a social context, and as interventions in larger political systems, infused with dissensus on policy goals and values, as well as uncertainty regarding spatial knowledge (spatial facts and cause-effect links). Last, but not least, this view enables us to invert the lens and study not only how geo-information tools are used in policy-making and governance, but also what the use of geo-information tools in a certain social context reveals about the hybrid nature of policy-making, governance, and SDI governance in particular.

Author Contributions: The authors jointly conceptualized the contributions to the Special Issue, analyzed them and wrote the paper.

Conflicts of Interest: The authors declare no conflict of interest.

\section{References}

1. Group on Earth Observations (GEO). Geo Strategic Plan 2016-2025: Implementing Geoss; Group on Earth Observations (GEO): Geneva, Switzerland, 2016.

2. Jones, H. Taking Responsibility for Complexity: How Implementation Can Achieve Results in the Face of Complex Problems; Oversees Development Institute (ODI): London, UK, 2011.

3. Rittel, H.W.J.; Webber, M.M. Dilemmas in a general theory of planning. Policy Sci. 1973, 4, 155-169. [CrossRef]

4. Nedovic-Budic, Z.; Crompvoets, J.; Georgiadou, Y. Spatial Data Infrastructures in Context: North and South; CRC Press: Boca Raton, FL, USA, 2011.

5. Georgiadou, Y.; Rodriquez-Pabón, O.; Lance, K.T. Spatial data infrastructure SDI and e-governance: A quest for appropriate evaluation approaches. URISA J. 2006, 18, 43-55.

6. Van de Donk, W.B.H.J.; Snellen, I.T.M. Towards a theory of public administration in an information age? In Public Administration in an Information Age; Snellen, I.T.M., Van de Donk, W.B.H.J., Eds.; Elsevier: Amsterdam, The Netherlands, 1988.

7. Esty, D.C. Environmental protection in the information age. N.Y. Univ. Law Rev. 2004, 79, 115-211. [CrossRef]

8. De Leeuw, J.; Georgiadou, Y.; Kerle, N.; De Gier, A.; Inoue, Y.; Ferwerda, J.; Smies, M.; Narantuya, D. The function of remote sensing in support of environmental policy. Remote Sens. 2010, 2, 1731. [CrossRef]

9. Rajão, R.; Georgiadou, Y. Blame games in the amazon: Environmental crises and the emergence of a transparency regime in Brazil. Glob. Environ. Politics 2014, 14, 97-115. [CrossRef]

10. Purdy, R.; Leung, D. Evidence from Earth Observation: Emerging Legal Issues; Martinus Nijhoff Publishers: Leiden, The Netherlands, 2013; Volume 7, p. 465.

11. Stone, D. Policy Paradox: The Art of Political Decision Making; Revised Edition; W. W. Norton \& Company: New York, NY, USA, 2002.

12. Sabatier, P.A. Theories of the Policy Process; Westview Press: Boulder, CO, USA, 2007.

13. Bovaird, T.; Löffler, E. Evaluating the quality of public governance: Indicators, models and methodologies. Int. Rev. Adm. Sci. 2003, 69, 313-328. [CrossRef]

14. Pollitt, C.; Hupe, P. Talking about government. Public Manag. Rev. 2011, 13, 641-658. [CrossRef]

15. Grindle, M.S. Good governance, R.I.P.: A critique and an alternative. Governance 2017, 30, 17-22. [CrossRef]

16. March, J.G.; Olsen, J.P. Rediscovering Institutions; The Free Press: New York, NY, USA, 1989.

17. Mosco, V. The Digital Sublime: Myth, Power and Cyberspace; The MIT Press: Cambridge, MA, USA, 2004.

18. Grindle, M.S. Good enough governance: Poverty reduction and reform in developing countries. Governance 2004, 17, 525-548. [CrossRef]

19. Grindle, M.S. Good enough governance revisited. Dev. Policy Rev. 2007, 25, 533-574. [CrossRef] 
20. Fukuyama, F. What is governance? Governance 2013, 26, 347-368. [CrossRef]

21. De Herdt, T.; De Sardan, J.-P.O. Real Governance and Practical Norms in Sub-Saharan Africa: The Game of the Rules; Routledge: London, UK, 2015.

22. Hoppe, R. The Governance of Problems; Policy Press: Bristol, UK, 2010.

23. Johnson, S. The Ghost Map: The Story of London's Most Terrifying Epidemic, and How It Changed Science, Cities and the Modern World; Riverhead Books, Penguin Group USA: New York, NY, USA; London, UK, 2006.

24. Rambaldi, G.; Muchemi, J.; Crawhall, N.; Monaci, L. Through the eyes of hunter-gatherers: Participatory 3d modelling among ogiek indigenous peoples in Kenya. Inf. Dev. 2007, 23, 113-128. [CrossRef]

25. Tolpekin, V.; Stein, A. The Core of GIScience: A Systems-Based Approach; University of Twente, Faculty of Geo-Information Science and Earth Observation (ITC): Enschede, The Netherlands, 2012; p. 524.

26. Douglas, M.; Wildavsky, A.B. Risk and Culture: An Essay on the Selection of Technical and Environmental Dangers; University of California Press: Berkeley, CA, USA, 1983.

27. Bouckaert, G.; Peters, B.G.; Verhoest, K. Resources, mechanisms and instruments for coordination. In The Coordination of Public Sector Organizations—Shifting Patterns of Public Management, 1st ed.; Palgrave Macmillan: Basingstoke, UK, 2010; pp. 34-50.

28. Chandran, R.; Hoppe, R.; de Vries, W.T.; Georgiadou, Y. Conflicting policy beliefs and informational complexities in designing a transboundary enforcement monitoring system. J. Clean. Prod. 2015, 105, 447-460. [CrossRef]

29. Reckien, D.; Flacke, J.; Dawson, R.J.; Heidrich, O.; Olazabal, M.; Foley, A.; Hamann, J.J.-P.; Orru, H.; Salvia, M.; De Gregorio Hurtado, S.; et al. Climate change response in Europe: What's the reality? Analysis of adaptation and mitigation plans from 200 urban areas in 11 countries. Clim. Chang. 2014, 122, 331-340. [CrossRef]

30. Heidrich, O.; Reckien, D.; Olazabal, M.; Foley, A.; Salvia, M.; de Gregorio Hurtado, S.; Orru, H.; Flacke, J.; Geneletti, D.; Pietrapertosa, F; et al. National climate policies across Europe and their impacts on cities strategies. J. Environ. Manag. 2016, 168, 36-45. [CrossRef] [PubMed]

31. Devine, W.P. Renewable Energy and the Public: From Nimby to Participation; Earthscan: Milton Park, UK, 2011.

32. Sovacool, B.K.; Lakshmi Ratan, P. Conceptualizing the acceptance of wind and solar electricity. Renew. Sustain. Energy Rev. 2012, 16, 5268-5279. [CrossRef]

33. Flacke, J.; de Boer, C. An interactive planning support tool for addressing social acceptance of renewable energy projects in the Netherlands. ISPRS Int. J. Geo-Inf. 2017, 6, 313. [CrossRef]

34. Reckien, D.; Creutzig, F.; Fernandez, B.; Lwasa, S.; Tovar-Restrepo, M.; Mcevoy, D.; Satterthwaite, D. Climate change, equity and the sustainable development goals: An urban perspective. Environ. Urban. 2017, 29, 159-182. [CrossRef]

35. Reckien, D.; Lwasa, S.; Satterthwaite, D.; McEvoy, D.; Creutzig, F.; Montgomery, M.; Schensul, D.; Balk, D.; Khan, I. Equity, environmental justice, and urban climate change. In Climate Change and Cities: Second Assessment Report of the Urban Climate Change Research Network; Rosenzweig, C., Solecki, W., Romero-Lankao, P., Mehrotra, S., Dhakal, S., Ali Ibrahim, S., Eds.; Cambridge University Press: Cambridge, UK; New York, NY, USA, 2018.

36. Matmir, S.; Reckien, D.; Flacke, J. What do new Yorkers think about impacts and adaptation to heat waves? An evaluation tool to incorporate perception of low-income groups into heat wave adaptation scenarios in New York City. ISPRS Int. J. Geo-Inf. 2017, 6, 229. [CrossRef]

37. Lisjak, J.; Schade, S.; Kotsev, A. Closing data gaps with citizen science? Findings from the Danube region. ISPRS Int. J. Geo-Inf. 2017, 6, 277. [CrossRef]

38. Kusumo, A.N.L.; Reckien, D.; Verplanke, J. Utilising volunteered geographic information to assess resident's flood evacuation shelters. Case study: Jakarta. Appl. Geogr. 2017, 88, 174-185. [CrossRef]

39. Verplanke, J.; Georgiadou, Y. Wicked water points: The quest for an error free national water point database. ISPRS Int. J. Geo-Inf. 2017, 6, 244. [CrossRef]

40. Katomero, J.; Georgiadou, Y.; Lungo, J.; Hoppe, R. Tensions in rural water governance: The elusive functioning of rural water points in Tanzania. ISPRS Int. J. Geo-Inf. 2017, 6, 266. [CrossRef]

41. Lemmens, R.; Lungo, J.; Georgiadou, Y.; Verplanke, J. Monitoring rural water points in Tanzania with mobile phones: The evolution of the SEMA app. ISPRS Int. J. Geo-Inf. 2017, 6, 316. [CrossRef]

42. Anand, N. Pressure: The Politechnics of water supply in Mumbai. Cult. Anthropol. 2011, 26, 542-564. [CrossRef] [PubMed] 
43. Richter, C. Digital Transformations in Indian Cities: Between Paper List and GIS Map; University of Twente, Faculty of Geo-Information Science and Earth Observation (ITC): Enschede, The Netherlands, 2014.

44. Sjoukema, J.-W.; Bregt, A.; Crompvoets, J. Evolving spatial data infrastructures and the role of adaptive governance. ISPRS Int. J. Geo-Inf. 2017, 6, 254. [CrossRef]

45. Chantillon, M.; Crompvoets, J.; Peristeras, V. The governance landscape of geospatial e-services-The Belgian case. ISPRS Int. J. Geo-Inf. 2017, 6, 282. [CrossRef]

(c) 2018 by the authors. Licensee MDPI, Basel, Switzerland. This article is an open access article distributed under the terms and conditions of the Creative Commons Attribution (CC BY) license (http:/ / creativecommons.org/licenses/by/4.0/). 


\title{
Monitoring Rural Water Points in Tanzania with Mobile Phones: The Evolution of the SEMA App
}

\author{
Rob Lemmens ${ }^{1, *}$, Juma Lungo ${ }^{2}$, Yola Georgiadou ${ }^{3}$ and Jeroen Verplanke ${ }^{3}$ \\ 1 Department of Geo-Information Processing, Faculty of Geo-Information Science and Earth Observation, \\ University of Twente, 7514 AE Enschede, The Netherlands \\ 2 Department of Computer Sciences and Engineering, University of Dar es Salaam, 14113 Dar es Salaam, \\ Tanzania; juma.lungo@zalongwa.com \\ 3 Department of Urban and Regional Planning and Geo-Information Management, \\ Faculty of Geo-Information Science and Earth Observation, University of Twente, \\ 7514 AE Enschede, The Netherlands; p.y.georgiadou@utwente.nl (Y.G.); j.j.verplanke@utwente.nl (J.V.) \\ * Correspondence: r.l.g.lemmens@utwente.nl; Tel.: +31-53-4874-529
}

Received: 15 July 2017; Accepted: 16 October 2017; Published: 21 October 2017

\begin{abstract}
Development professionals have deployed several mobile phone-based ICT (Information and Communications Technology) platforms in the global South for improving water, health, and education services. In this paper, we focus on a mobile phone-based ICT platform for water services, called Sensors, Empowerment and Accountability in Tanzania (SEMA), developed by our team in the context of an action research project in Tanzania. Water users in villages and district water engineers in local governments may use it to monitor the functionality status of rural water points in the country. We describe the current architecture of the platform's front-end (the SEMA app) and back-end and elaborate on its deployment in four districts in Tanzania. To conceptualize the evolution of the SEMA app, we use three concepts: transaction-intensiveness, discretion and crowdsourcing. The SEMA app effectively digitized only transaction-intensive tasks in the information flow between water users in villages and district water engineers. Further, it resolved two tensions over time: the tension over what to report (by decreasing the discretion of reporters) and over who should report (by constraining the reporting "crowd").
\end{abstract}

Keywords: rural water supply; information infrastructure; key services; ICT4D; mobile phone; dashboard; Tanzania

\section{Introduction}

Sustaining a functional rural water supply infrastructure has been a challenge in Sub-Saharan Africa [1]. In Tanzania, nearly half of rural water points are not functional [2] and about $20 \%$ of newly constructed water points become non-functional within one year. Rural citizens soon return to traditional, unimproved water sources and endanger their health and well-being [3].

The Ministry of Water monitors the implementation and performance of rural water supply in Tanzania, as an integral part of its mission. In the past, the Ministry calculated the rural water service coverage based on an assumed number of 250 water users per constructed rural water point. In 2009, the Ministry recognized that actual water "coverage rates may very well be lower than those reported by routine data [ ... ]. Without a reliable baseline that takes into account functionality and (more importantly) a means to keep this updated, it is impossible to track the net progress in expanding rural water supply service coverage or, more importantly, to determine actual access rates." [4]. The Ministry's acknowledgement that rural water supply data must include the functionality of water points—"Functional", "Non Functional", and "Functional Needs Repair"—-marks a pivotal moment for the rural water supply sector. In 2010, the Ministry commissioned the Water Point Mapping System 
(WPMS), a web-based, nation-wide information system featuring the entire dataset of geo-tagged water points and their functionality status. However, without an effective updating mechanism, the system cannot track the status of rural water points. Instead, it merely provides a static picture of Tanzanian water points at the time of the original survey.

Nevertheless, the WPMS marked the beginning of an information infrastructure for Rural Water Supply (RWS II) in Tanzania. Development partners, NGOs and researchers started to develop and test dashboards to visualize water points (e.g., the Water Dashboard, see http:/ / opendata.go. tz/en/indicator/a2fab64e-47f7-11e5-847d-0e5e07bb5d8a) and mechanisms that allow district water engineers to update the water point status. Examples are the Big Results Now's (BRN's) updating mechanism based on Google docs and the Ministry of Water's (MoW's) updating mechanism based on pre-formatted and prefilled excel templates [5]. However, only two mechanisms have been developed so far in Tanzania to fill the reporting gap between the villages and the district water departments. The first was the paper-based updating mechanism developed and implemented in a few districts by WaterAid [6]. The second was the mobile phone-based platform, developed by our research team. Both aimed to be interoperable with the WPMS. Both make it possible for water users in villages to inform the District Water Engineer (DWE) about the functionality status of water points. The DWE would then report upwards to the ministry using the BRN or the Ministry of Water (MoW) updating mechanisms.

In this paper, we analyze and discuss the evolution of the mobile phone-based platform, called Sensors, Empowerment and Accountability in Tanzania (SEMA), after the project in which it has been developed. The main research for this paper was done under the Netherlands Organization for Scientific Research (NWO) funded integrated research project: Sensors, Empowerment and Accountability in Tanzania (SEMA); SEMA also means "tell me" in Kiswahili.

Most researchers compare mobile phone-based ICT platforms for improving water supply. For example, Welle, Williams and Pearce conducted the most recent cross-national comparison, which included eight such platforms, in three continents. Some platforms rely on crowdsourcing-water users or their institutional representatives reporting water service failures [7]. Others rely on either the government provider or Non-Government Organizations (NGOs) collecting data regularly. The novelty of our approach consists in observing and conceptualizing the evolution of the design of the front-end of a single platform, the SEMA app, over a long time. Between 2014 and 2017, we deployed three consecutive versions of the SEMA platform in four districts, and fine-tuned the software as we learned lessons from meetings with stakeholders in the rural water supply sector, in-depth interviews with villagers, Community Owned Water Supply Organizations (COWSOs) and district officials in the four districts.

We adapted two concepts from the literature on public services: transaction-intensiveness, discretion [8]. These allowed us to characterize tasks in information flows between citizens and government and judge how amenable they are to digitization. A third concept, "crowd-sourcing", first championed as an effective strategy for open-source economic production, allowed us to model the distributed production of reports on rural water points.

The research question is "how has the usefulness of the SEMA app evolved over time?" and we will address this in terms of its changed functionality and user uptake. The objective of this paper is to show how the development of our mobile phone application has been influenced by the patterns of local organization. The rest of the paper is structured as follows. Section 2 highlights the crisis in the rural water supply and the development of the Rural Water Supply Information Infrastructure (RWS II), with its stakeholders and tasks. Section 3 presents the evolution of the SEMA App, its current architecture and its back-office. Section 4 describes the deployment of the SEMA app in practice and Section 5 discusses the lessons learnt from building the app and testing it with its users. We end with conclusions and recommendations in Section 6. 


\section{Empirical Context-The Rural Water Supply Information Infrastructure (RWS II)}

The emerging RWS Information Infrastructure in Tanzania subsumes water policies and water sector programs, networked information systems, dashboard and updating mechanisms, geo-referenced data, organizational stakeholders and users.

\subsection{Policies and Programs for Rural Water Supply}

In the past 15 years, the Government of Tanzania changed the formal structure of rural water supply substantially, first through the National Water Policy (NAWAPO) [9] and later with the Water Sector Development Program (WSDP) (2006-2025). Under NAWAPO, "consultations and planning starts from the grass roots; implementation is at the most appropriate level, closest to the beneficiaries. User groups are not only responsible for operating, maintaining and sustaining the infrastructure; they are also responsible for planning and managing it for the entire water sector in Tanzania" [4]. Thus, a new village institution, COWSO, was formed to take the full responsibility for operating, maintaining and sustaining water points at the village level. The WSDP consolidates for the first time three sub-sector programs-water resources management, rural water supply, and urban water supply and sewerage-and provides a nation-wide vision and funding. The scale of the WSDP program brings with it a high degree of complexity and inflexibility, with more than 300 implementing agencies involved.

Because of the WSDP's accountability requirements to donors, disbursement of funds must follow a long bureaucratic process of accountability, requiring upwards (vertical) reporting at each level of government, all the way from the village, to the district, and, finally, to the Ministry of Water. This leads to power struggles between different levels of government and a confusion regarding roles and responsibilities [10]. Another power struggle is ongoing between districts and village COWSOs around roles and responsibilities for water services. COWSOs should bear the full cost of Operation and Maintenance (O\&M) and contribute $5 \%$ of the capital investment in rural water schemes, a strategy aiming at a greater sense of local ownership of water schemes. In practice, communities either refuse or cannot afford to contribute the part of the capital investment stipulated in the law [11].

\subsection{Networked Information Systems}

The Water Point Mapping System (WPMS) is part and parcel of the Water Sector Development Program. The World Bank and the Ministry of Water negotiated the blueprint for the WPMS and a local company carried it out from 2010 to 2013. The WPMS is an innovative web-based information system. It aims to make rural water point data accessible to the public and easily updateable by local governments. It provides in digital form the status of the rural water infrastructure to inform national planning and budgeting in the country. The local company performed four tasks: (1) nation-wide baseline data collection of all rural water points; (2) development of the web-based Water Point Mapping System (WPMS); (3) provision of recommendations for the integration of WPMS into the monitoring systems and practices of local governments; and (4) capacity building on the use and updating of the WPMS. The WPMS aims to improve the monitoring of performance of actors-do they fulfill their formal roles and act responsibly? - at different levels of government. Currently, the WPMS is not being used, and setting up a cost-effective updating mechanism for the collected rural water point data remains a significant challenge.

\subsection{Key Stakeholders of Rural Water Supply and Main Actors in SEMA}

District/ward/village officials: According to Section 38 of the National Water and Sanitation Act (2009), the district council (local government authority) has three main roles. First, district officials are responsible for mobilizing citizens and assisting them to form and register COWSOs. The registration of COWSOs is coordinated mainly by District Water Engineers (DWEs). They must prepare and submit quarterly reports to the Ministry of Water (MoW) and to the Prime Minister's Office, Ministry of Regional Administration and Local Government (PMORALG) on the status and progress of the 
COWSO registration process in the district as well as copies of quarterly reports of registered COWSOs. Second, district officials must provide guidelines to COWSOs on the operation and maintenance of water projects and follow-up on their operation and maintenance. The district council must submit weekly reports to MoW and PMORALG on the implementation of new water projects. Ward Executive Officers (WEOs) are accountable to the DWE for water matters concerning their ward-an administrative area made up by a group of two or more villages. Village Executive Officers (VEOs) are accountable to the WEO for water matters concerning their village. Thus, accountability is hierarchically bureaucratic, from the village through the ward and the district up to central government.

Ward Councilors: Ward councilors are elected members of the district council. They represent citizens at the ward level and are elected every five years. They represent citizens' interests at the district council. To be able to know the interests of citizens, councilors need to be informed about the status of affairs in their ward. For this purpose, they organize meetings with citizens of the ward to listen to their suggestions and complaints and inform them on relevant decisions of the district council.

Councilors oversee the district council in three different ways. They: (i) seek information on the plans, budgets and performance of the district; (ii) question the district on either the planning (allocation of resources) or implementation of district plans and budgets; and (iii) participate in decisions to sanction poor performing district staff. In order for councilors to get information on the allocation of resources for water projects, they need to scrutinize district plans and budgets. Councilors have the power to hire and fire district officials and thus can sanction their performance in the implementation of water projects. In practice, however, councilors' sanctioning ability is limited [12].

Citizens: Citizens are responsible for contributing a portion of the capital investment for rural water projects. They participate in the design and planning of rural water projects including the choice of affordable and suitable technology [7]. Citizens attract resources for the investment of water projects. In practice, citizens can play this role both directly and through their representatives such as councilors and/or members of parliament. On the one hand, citizens demonstrate commitment (through contributing part of the capital investment through labor and/or cash) and ability to pay for the operation and maintenance of water projects. On the other hand, citizens can attract resources for water project by influencing councilors and/or members of parliament, who (councilors) have the role to approve district plans and budgets.

Citizens are those who are at the receiving end of the stick when water supply fails. They are represented by their elected officials. They also expect to be served by those officials. They are suffering and enduring the status quo. They find coping mechanisms to live with the status quo. We observe that they are not keen to report with a mobile phone themselves, but rather as active members in COWSOs.

COWSOs: COWSOs are responsible for the operation and management of water projects in rural areas. In principle, COWSO members operate and maintain water projects as volunteers, without payment. A COWSO works closely with the Ward Executive Officer (WEO) and Village Executive Officer (VEO) to ensure that the installed water projects are properly operated and maintained (by trained pump attendants), and to ensure that water users (villagers) pay full operation and maintenance costs (establish and maintain the water funds). Theoretically, COWSOs are required to report to the District Water Engineer (DWE) on a quarterly basis [13], particularly when they receive financial assistance (grants or loans) from the district council, a provision in constitutions of many COWSOs. In practice, the DWE does not receive regular reports from COWSOs, except when they report water point breakdowns.

\subsection{Towards a Changed Infrastructure: Typification of Tasks and Crowdsourcing}

Transaction intensiveness and discretion: We draw on the framework of Pritchett and Woolcock (2004) and the World Bank (2016), who distinguish between discretionary and transaction-intensive elements in key services to citizens, and adapt it to micro-level tasks of decision making. Transaction-intensive tasks require a large number of transactions, involving face-to-face contacts between district officials, village water technicians, COWSO members, and citizens, for example a 
water technician detecting a broken water point and reporting to the COWSO secretary. Discretionary tasks involve decisions based on information that "is important but inherently imperfectly specified and incomplete, and entails extensive professional or informal context-specific knowledge" [6], for examples, a village assembly agreeing to contribute funds for repair of a water point, or a district official approving a COWSO's request for funds are discretionary tasks.

Transaction-intensive tasks are easily amenable to digitization, while discretionary tasks are not because the actor's decisions cannot be mechanized. Non-discretionary and transaction-intensive tasks can easily be codified in computer programs [14]. Tasks that are neither discretionary nor transaction-intensive are lasting dispositions [15], but digitization does not apply to them. They include the systematic preference of villagers to meetings for distribution of food for hunger relief and to attending funerals rather than COWSO meetings. Table 1 shows the relationship between task characteristics and amenability to digitization.

Table 1. Tasks and their amenability to improvement through digitization.

\begin{tabular}{ccc}
\hline & Transaction-Intensive & Non Transaction-Intensive \\
\hline Discretionary & $\begin{array}{c}\text { Less amenable to improvement } \\
\text { through digitization }\end{array}$ & $\begin{array}{c}\text { Not amenable to improvement } \\
\text { through digitization }\end{array}$ \\
\hline Non-discretionary & $\begin{array}{c}\text { Highly amenable to improvement } \\
\text { through digitization }\end{array}$ & Lasting dispositions \\
\hline
\end{tabular}

Crowd-sourcing is a typical way to perform non-discretionary tasks. Tasks that, for instance, are too transaction intensive to digitize due to the limitations of computational power or tasks for which no or not enough digital data exist to answer a question. Feature recognition from photographs is one of these tasks. The human eye is very well equipped to spot anomalies or specific occurrences in pictures more quickly than algorithm driven computers nowadays can. In some cases, knowledge is missing or data are not available to perform a task. In that case, distributing the question at hand to the "crowd" can offer solutions. In many cases, these tasks are the equivalent of mechanical-Turk: simple transactions that together serve a purpose.

To assess which tasks in SEMA could be crowd-sourced, we first conducted a detailed study of the actual flow of information between the water user, who detects the status of a water point, until the district water engineer repairs it [16]. Within the detailed information flow, we identified 88 micro-tasks, which we assembled in six clusters—detecting, reporting, diagnosing, mobilizing funds, purchasing spare parts, and fixing the water point. Our analysis showed that only two of those clusters-i.e., detecting and reporting - had tasks that were transaction-intensive and low in discretion, and therefore amenable to digitization. Therefore, detecting and reporting have been at the core of all successive versions of the SEMA app software.

SEMA uses crowd-sourcing for these tasks through actively approaching COWSO members to report on the status of water points. The question to "simply report" whether a water point is-"Functional", "Non Functional" or "Functional Needs Repair"-is however much more discretionary than it seems. Functionality depends on many aspects. A reporter needs to assess whether water quality, level of improvement/safety, water quantity and accessibility of the water point are in order before a decision can be taken on its functionality status. For a COWSO member these tasks are more discretionary than for water point enumerators. COWSO members are familiar with the context in which the water point is operating. They decide to mark a water point as functional as it has only broken down recently and repairs are under way, or, although it is not currently providing water, the water point customarily provides water again later in the day.

In order for crowd-sourcing to be useful in the case of SEMA the discretionary context needed to be removed as much as possible. If crowd-sourced data on functionality status is frequent and consistent the volume of "binary" (functional/non-functional) reports will present a trend of service delivery over years. In the app design we have, in different deployments, tested how we should 
formulate the tasks for the "crowd" to become as much non-discretionary as possible. For instance, through asking "is the water point providing water today" we get a less discretional answer than asking "is the water point functional today". Likewise, we can ask questions about water quality and quantity. By asking the right questions we reduced discretion and increased the amenability to digitize the reporting on water point functionality.

\section{The SEMA App and Its Back-Office}

\subsection{Evolution of the App}

The SEMA App is a mobile-based software developed by programmers at UDSM and UT for the purpose of enabling ordinary Tanzanian citizens to report on the status of their water points. The evolution of the (front-end) software is characterized by three dimensions, namely technology, routine and performance. By technology we mean the architecture under which the respective versions of the software run, the processing of data, communication and interface between mobile users and databases. The routine dimension is defined by the steps which the users perform to interact with the software when reporting, such as logging onto the system, language selection, etc. The performance dimension gives the quantitative measures of various parameters, including time and cost. Each of these dimensions is presented for various critical moments when the software evolved from one version to another.

\subsubsection{Technology}

The aim of the project was to develop the app for simple feature phones as they are more commonly available than smartphones in our project area, but, as the development on Android phones was more straightforward, this was started first. Later, the development on feature phones was started. Table 2 lists the main elements in the evolvement of three versions of the mobile app.

Table 2. SEMA Mobile App versions and characteristics.

\begin{tabular}{ccccccc}
\hline $\begin{array}{c}\text { SEMA App } \\
\text { Version }\end{array}$ & $\begin{array}{c}\text { Release } \\
\text { Date }\end{array}$ & Technology & Platforms & Performance & Costs & Usability \\
\hline 1 & $\begin{array}{c}\text { January } \\
2014\end{array}$ & Android & $\begin{array}{c}\text { Smart } \\
\text { phone with } \\
\text { Android OS }\end{array}$ & $\begin{array}{c}\text { Internet } \\
\text { requirement }\end{array}$ & $\begin{array}{c}\text { Internet } \\
\text { connection } \\
\text { costs for } \\
\text { reporter }\end{array}$ & $\begin{array}{c}\text { Text } \\
\text { menu-driven }\end{array}$ \\
\hline 2 & $\begin{array}{c}\text { August } \\
2014\end{array}$ & $\begin{array}{c}\text { USSD } \\
\text { simulation } \\
\text { by SMS }\end{array}$ & $\begin{array}{c}\text { All types of } \\
\text { mobile } \\
\text { phones }\end{array}$ & $\begin{array}{c}\text { One-way and slow } \\
\text { communication }\end{array}$ & $\begin{array}{c}\text { SMS costs } \\
\text { for reporter }\end{array}$ & $\begin{array}{c}\text { Free-text } \\
\text { based }\end{array}$ \\
\hline 3 & $\begin{array}{c}\text { February } \\
2015\end{array}$ & USSD & $\begin{array}{c}\text { All types of } \\
\text { mobile } \\
\text { phones }\end{array}$ & $\begin{array}{c}\text { Fast real-time } \\
\text { session based } \\
\text { communications }\end{array}$ & $\begin{array}{c}\text { No cost for } \\
\text { reporter }\end{array}$ & $\begin{array}{c}\text { Coded } \\
\text { menu-driven }\end{array}$ \\
\hline
\end{tabular}

The development on Android continued for two reasons: (1) to keep a working mobile app to test the back office; and (2) to be able to support the use of Android phones in the future in case these become more widely used. After only seven months of its first release, the App developed to its next version (SEMA App Ver.2.0) in August 2014. Updates were now sent through Short Message Service (SMS) [17] using normal text-based phones. In this version, a dialogue style was simulated on the mobile phone, as is common for phone services, such as credit queries and mobile money transactions. While this version makes use of Unstructured Supplementary Service Data (USSD) technology [18], the SEMA App simulated the dialog style only. The major drawback here is that it took up to $30 \mathrm{~min}$ for the reporter to get a reply from the server.

In the third (and current) release of the App (SEMA App Ver. 3.0, see Figure 1), a real USSD is used as opposed to the simulated USSD in the second version; that is, users can now directly dial a short code to start interaction with the back-end system. Furthermore, the USSD gateway was hosted by a 
local Mobile Operator and the communication was accomplished by two major servers (the backend at the university, and the USSD gateway at the local mobile operator). Finally, the current version uses both XML (status data) and JSON (baseline data) file formats/technologies for importing data to the SEMA backend database system. The Extensible Markup Language (XML) and JavaScript Object Notation (JSON) are both data exchange languages, of which the latter is gaining more popularity amongst web developers.
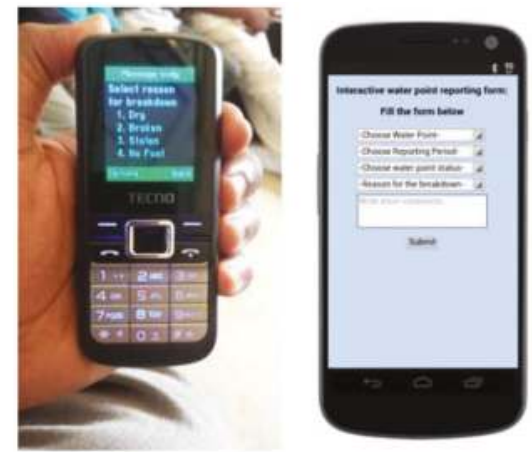

Figure 1. SEMA App version 3.

\subsection{2. (User) Routine}

The SEMA App Ver.1.0 was the Android application which was running only on a smartphone. Due to Internet connectivity issues in the rural areas and the fact that smartphones were beyond reach for ordinary citizens, the app was only tested by researchers and never used by the reporters. However, this allowed us to develop and test menu items and their interaction with the server-side database internally.

The SEMA App Ver. 2.0 had the users trigger the system for reporting by sending a keyword (WATER) to a normal mobile number. This number changed frequently and programmers had to request for a different number from the provider when the previously assigned one could not be used. After sending the keyword successfully, a response message would request users to select a language (English or Kiswahili), and then users would be prompted to log on to the system by providing a password. This (logging on) was repeated every time a user wanted to report status (Very transaction-intensive; unconstrained crowdsourcing). The reporting loop would then allow the reporter to select the status of a water point under report from the following choices: functional, non-functional or need repair (discretion totally under the reporter). Users were also given an option to provide textual description (even more discretion granted to the user).

A variation of the same version (SEMA App Ver. 2.0), reporting was triggered by users sending the keyword (WATER) to a non-mobile number (15573) since in this release; the (simulated) USSD gateway was hosted in a different server. There was no longer an option to select a language, as Swahili was the preference language. The user would then be prompted to enter a password, and in this release, would do that at the first login instance only (Medium-constrained crowdsourcing). The reporting loop allowed the user to make a selection of the status of a Water Point (WP), but the option for textual description was removed.

The current release of the App (SEMA App Ver. 3.0) allows users to directly dial a real USSD code $\left({ }^{*} 150 * 50 * 25 \#\right)$ to trigger the system. No password is required as only (institutional) registered users (by SEMA Administrator) can access the system (highly-constrained crowdsourcing). No language selection option in this release either; Swahili is the only one used. Initially, the App was designed under the assumption that users could systematically distinguish the status of a WP within the three categories, i.e., functional, non-functional and need repair. In this release, users receive a series of 
challenging questions regarding the WP under reporting, and based on the responses the system determines the actual status of the WP. (Low discretion granted to users. The only discretion users have is binary, to answer a "yes" or "no" to the presented questions). Moreover, there is no option for users to give a textual description about the reported WP.

\subsubsection{Performance}

There have also been remarkable milestones of the App over its evolution journey in the context of performance. Initially, it took about three minutes to complete one reporting cycle with SEMA App Ver. 1.0 , which had a cost of TZS 1200/= $(\$ 0.52990)$. The App also supported all mobile operators (Vodacom, Tigo and Airtel). In the subsequent release (Ver. 2.0), it took between two minutes to hours (even days) to complete one reporting cycle, which was highly dependent on the network load at the time of reporting. This was due to the Web API hosting server. The cost for completing one reporting cycle using this (second) version of the App was TZS. 300/= $(\$ 0.13248)$; a remarkable decrease by a fourth from the first release. The App also supported all mobile operators as in the first release. In SEMA App version 3.0, it takes as less as half a minute to complete one reporting cycle, depending on the speed of the reporter in responding to questions. This version supports only Airtel and Vodacom providers, and costs TZS. 92/= $(\$ 0.03974)$ per one cycle of reporting for Vodacom users but is free for Airtel users.

\subsection{Current Architecture}

\subsubsection{Mobile App}

It should be noted that before embarking into re-inventing another mobile app for capturing information system, a survey and thorough evaluation of existing software was conducted to assess their readiness for this context. The evaluated apps included: Akvo FLOW (see http:/ /www.akvo.org) and mWater (see www.mwater.co). These two applications are Android based application that work on smartphones. However, in our context, the users in the rural areas do not own smartphones and Internet access is very limited. Thus, re-using these apps in our context was not appropriate due to the nature of the context.

The intended users of the Mobile app were COWSO members in the rural areas where Internet bandwidth is not available. Therefore, the only possible technologies that can be used in the rural settings were SMS and Unstructured Supplementary Service Data (USSD). However, due to slow communication when SMS is used, USSD was then choses as the most suitable technology in the rural areas. The Mobile application was carefully designed and appropriate technology was chosen. Specially, PHP programming language was chosen as the language for implementing the application where a MySQL database management used system and the system was hosted on Ubuntu Linux operating system powered server. USSD is a Global System for Mobile (GSM) communication technology [19] that is used to send text between a mobile phone and an application program in the network. Specifically, USSD, sometimes referred to as "Quick Codes" or "Feature codes", is a protocol used by GSM cellular telephones to communicate with the service provider's computers. USSD can be used for WAP browsing, prepaid callback service, mobile-money services, location-based content services, menu-based information services, and as part of configuring the phone on the network. USSD messages create a real-time connection during a USSD session and the connection remains open, allowing a two-way exchange of a sequence of data. This makes USSD more responsive than services that use SMS. In our situation, USSD was the appropriate technology because it enables the identification of the users by registering their mobile numbers, assigning a water point to a reporter by mapping a water point record to a mobile number and updating a water point functionality status.

The mechanism of capturing the coordinates of the water point at that time was by using a Trimble GPS receiver that was very much complicated to record, read and data can only be transferred from the GPS to the water points mapping system (see Section 3.2.2) by a few GIS experts. This also was looked at, and an Android Application that works on Smartphone, which captures coordinates and 
water point photos then transfer the data straight to the WPIS API, was developed. Prior to the SEMA project the Ministry of Water had already developed a Water Points Mapping database system and had already envisioned a paper-based updating mechanism, which works in such a way that a COWSO member initiates the process and submits a report to the Village Executive Officer (VEO), the VEO then passes on the report to the Ward Executive Officer (WEO) who submits the same report to the District Water Engineer (DWEs). The DWE then submits the report to the Ministry of Water where the paper report would be transcribed into the WPM database system. The mobile updating mechanisms developed here is an improvement of the already existing practices. It is more efficient because data are passed on electronically, and hence its originality can be tracked.

\subsubsection{Back-Office and Dashboard}

Figure 2 presents a schema diagram of the innovations for implementing a Water Services Information Infrastructure as envisioned in this project. The whole network of the Apps developed was code named Sensors, Empowerment and Accountability (SEMA). At the beginning of the project, it was envisioned that a mobile reporting tool cannot exist on its own, rather it is a part of a larger information infrastructure which involves existing installed base. In Figure 2, the national Water Points Mapping System (WPMS) is represented by the cylindrical icon at the top left corner. This houses all the registered water points of the Ministry of Water. Even though the ultimate goal was to update the WPMS system, this ministry system was not equipped with Web API function, a technology that could have enabled it to be connected with a mobile tool. Hence, it was necessary to build up a staging database system to be integrated with the mobile tool which is represented by the DHIS2 WPMS icon. Water point data then would flow from the reporters who are using the USSD mobile application in the Feature phone, to a USSD gateway at a mobile operator represented by the SEMA USSD APP icon to the DHIS2. Since the DHIS2 database has a Web API feature, this opened up the opportunity for the system to be integrated with other systems such as the national Water Dashboard, Mobile dashboards that can be used by the Ward Executive Officers (WEOs), Village Executive Officer (VEOs) and the Councilors in the wards. In addition, the DHIS2 WPMS can be updated using an Android App for registering new water points. The dashboard also allows to calculate spatial measure, such as the distance from each health facility to the nearest water point and to compute water scarcity in an area by calculating the distance to the nearest water point for each cell in a raster layer.

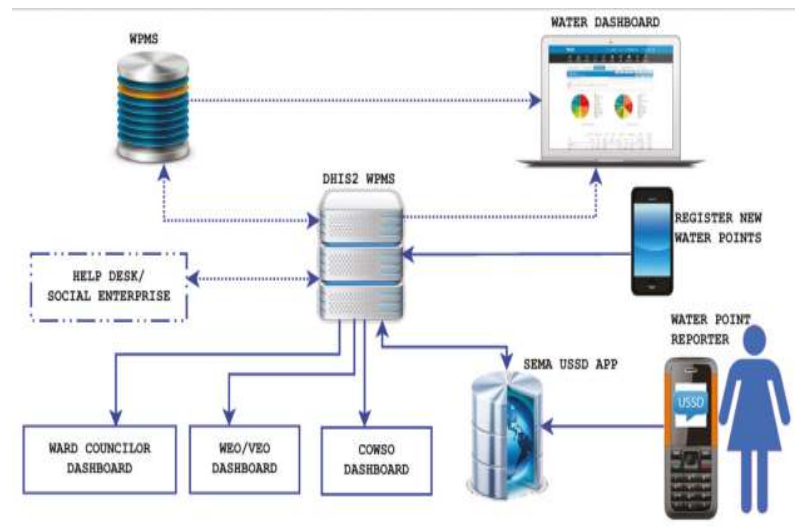

Figure 2. Architecture of the SEMA Water Services Information Infrastructure.

As presented in Figure 3, the dashboard improves the analysis of the data captured in the SEMA infrastructure by implementing advanced features such as water coverage, scarcity analysis and the distance between a nearby water point and other social services such as a health center. 


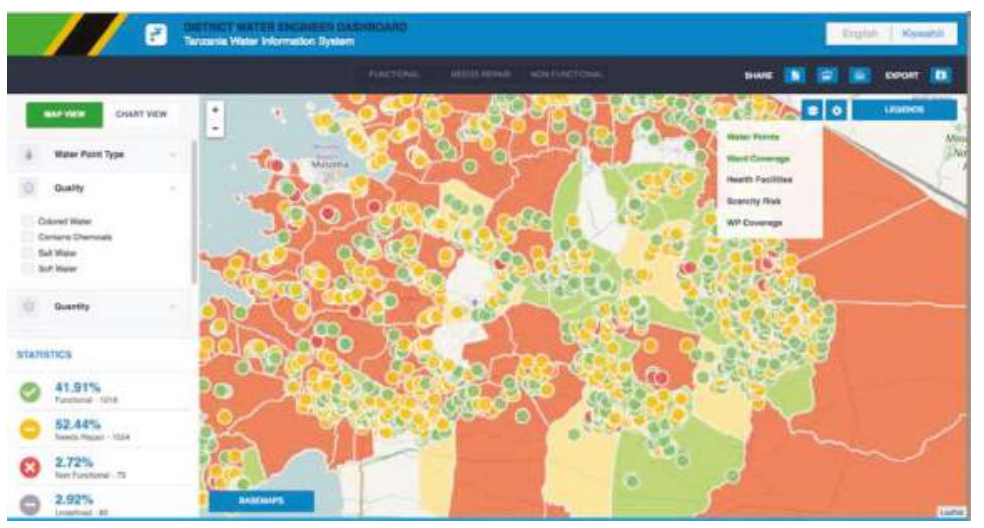

Figure 3. DWE dashboard that make use of the SEMA infrastructure to present data dynamically.

Figure 4 represents a District water engineer's dashboard fetching data from the SEMA App database (i.e., DHIS2 WPMS) dynamically, using lightweight dashboard technologies that can work on smartphones.

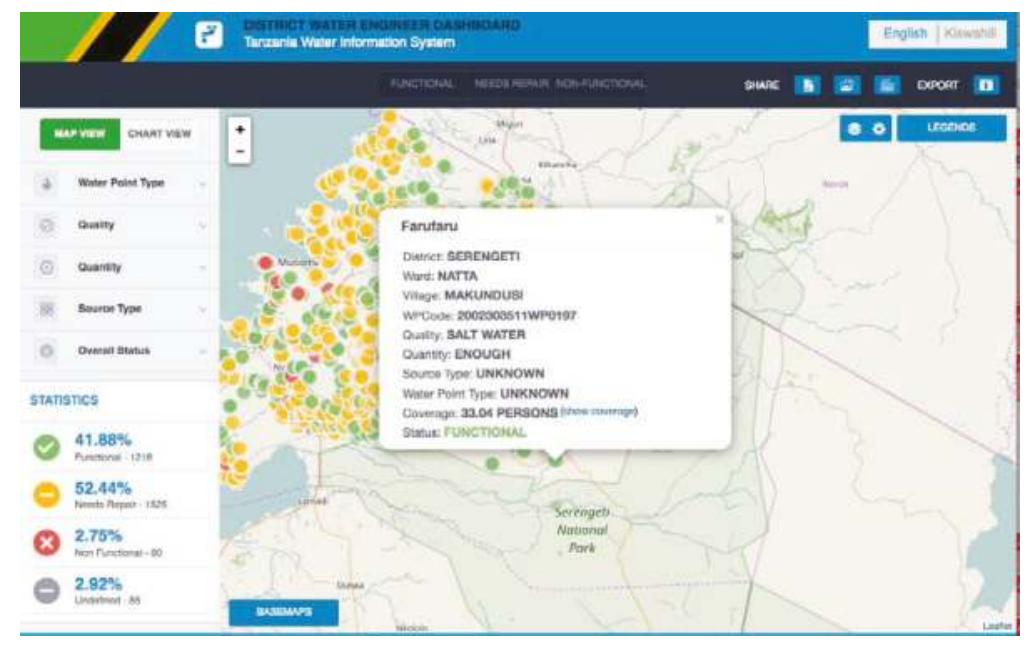

Figure 4. DWE responsive dashboard for Smartphones and Desktops.

The SEMA App infrastructure also has the capacity to produce standardized reports that can be used in official reporting and sharing the data. Figure 5 presents a standard report which lists all water points in the district with their respective status in a particular given period.

The actual deployment of the system is depicted in Figure 6, which shows a description of data flow in the system and can be summarized as follows:

- User dials a short code (the project used ${ }^{*} 150 * 50 * 25 \#$ ) and sends a special text to operator

- Short code operator forwards the message to a USSD URL server

- USSD APP Server processes the message and stores the values to a local database

- SEMA WPIS API Server receives data values as Web API from a local USSD server 


\begin{tabular}{|c|c|c|c|c|c|c|}
\hline \multicolumn{7}{|c|}{$\begin{array}{l}\text { UNITED REPUBLIC OF TANZANIA } \\
\text { MINISTRY OF WATER } \\
\text { List of Water Points }\end{array}$} \\
\hline \multicolumn{7}{|c|}{ Bunda District $\quad$ February 2015} \\
\hline S/N & villlage & WP Name & WP Code & Functional & \begin{tabular}{c|} 
Non: \\
Functional
\end{tabular} & \begin{tabular}{|l} 
Need \\
Repair
\end{tabular} \\
\hline \multicolumn{7}{|c|}{ Mcharo Ward } \\
\hline 1 & Mcharo & Kwa Hoja & 2004303306WP15 & & v & \\
\hline 2 & Mcharo & Kwa Kiboko & 2004303306WP16 & v & & \\
\hline 3 & Mcharo & Kwa Maduhu & 2004303306WP18 & & v & \\
\hline 4 & Mcharo & Kwa Malunde & 2004303306WP17 & & & $\mathrm{v}$ \\
\hline 5 & Mcharo & Kwa Mama Athumani & 2004303306WP14 & & & v \\
\hline 6 & Mcharo & Madaraka Martin & 2004303306 WP13 & & $\checkmark$ & \\
\hline 7 & Mcharo & Madaraka Martin & 2004303306WP13 & & & $\checkmark$ \\
\hline 8 & Mcharo & Nyamaws & 2004303306 WP12 & 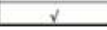 & & \\
\hline
\end{tabular}

Figure 5. SEMA standard report.

These reports can then be accessed by registered users at the Ministry of Water and Irrigation, Regional Water Engineer (RWE), Village Executive Officer (VEO), Ward Executive Officer (WEO) and COWSOs (Community Owned Water Supply Organizations).

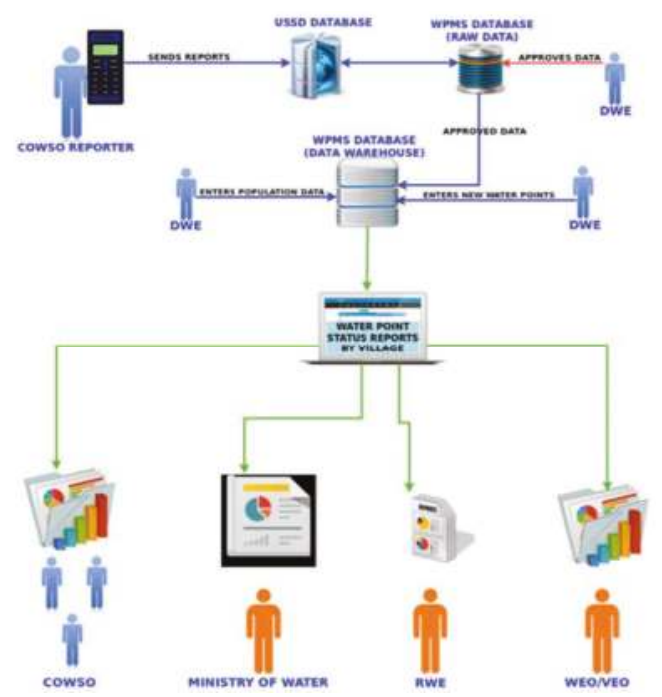

Figure 6. The Mobile reporting system showing the flow of information.

\subsubsection{Context Model}

The aim of context modeling in SEMA is to generate, store, analyze and create value for human-sensed data. A major segment of SEMA deals with analyzing and creating value for data through a proper handling of context. The idea is to improve our understanding of and ability to analyze the content generated by the reporters, also referred to as human sensors, who use a mobile app to report the status of water points. The preferred strategy is to use a combination of semantic and geovisual analytics techniques. A linked-data approach has been put into place for the deployment of a context-based system labeled as SEMAntics (a blend of the words SEMA and Semantics) (see [20]). It uses an ontology which contains concepts and relationships between them, relevant to the domain of SEMA $[21,22]$ and was built through a number of interviews and discussions between project partners and with experts in the field. 
The application of the SEMAntics system is made by formulating competency questions whose answers require the use of contextual relationships. It is important to create a match between concepts of sub-domains within the SEMA ontology such as the urban/rural water sources or formal/informal sectors. The SEMA reporting system focuses on the status of only rural water points, which can be linked with the status of urban water points from other data sources. Figure 7 showcases the linkage of identical concepts in rural and urban domains and derived classes as super concepts.

The innovation in this part of the project is the integrated and formalized capture of technical and social aspects and the integration of geographic information. We built a software prototype, which can answer basic but non-trivial queries such as: "Provide a list of functional rural water points in Bunda district". As in our data sources the water points are not initially classified as "rural", the ontology enforces a hierarchy with super/sub class relationships in such conceptualization and facilitates the answering of such queries, which cannot be easily realized with a traditional GIS-backend. Obviously, as the ontology is expended, more sophisticated query types can be handled. Figure 8 shows for example the conceptualization of administrative responsibilities, which allows us to couple water points to managers.

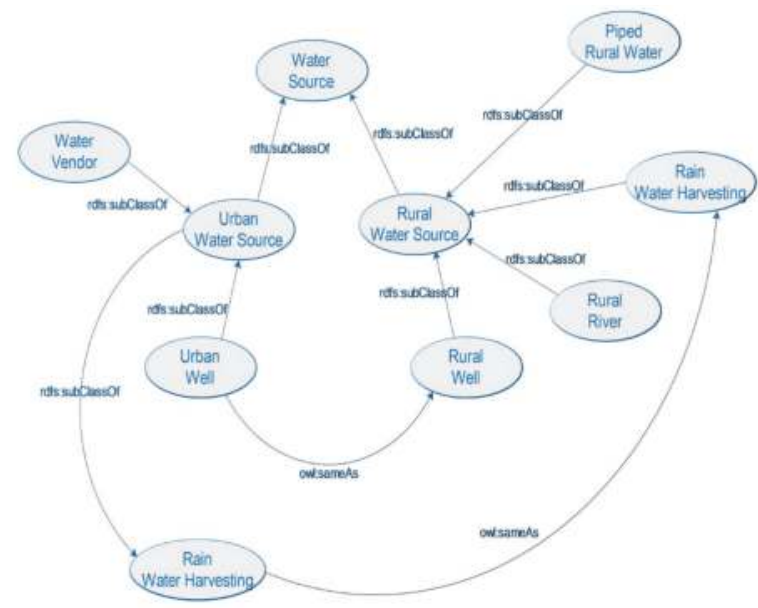

Figure 7. An example of Cross-sectional concepts for SEMA's Water Source Reports.

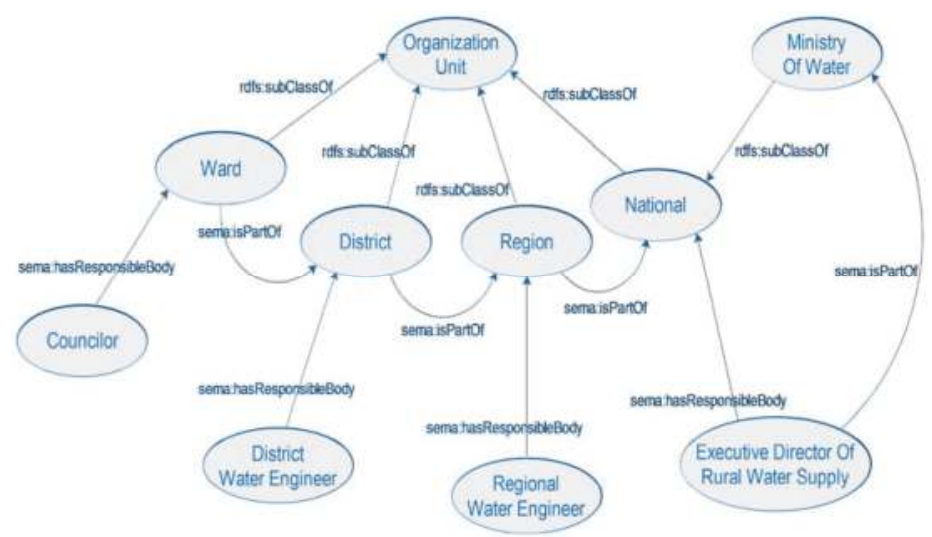

Figure 8. An example of administrative concepts for SEMA's Water Source Reports. 
In the course of our research project it became evident that we cannot expect large amounts of reports as was originally anticipated on, due to the social structures in Tanzania. As a measure to be still able to test our methods, the system has been adapted to specific queries of known users and involve more institutional data. The SEMAntics system has been initially tested in combination with the DHIS2 system, which forms the backbone for the storage and retrieval of (non-contextual) information gathered with the mobile app.

\section{Deployment}

\subsection{Registration of Users}

The reporting technology uses a USSD Technology and a SEMA based DHIS2 platform. Since the application is a USSD based app, it works on both smartphones and feature phones. To be able to report Water Point functionality using the system, a reporter has to be registered in the SEMA system. Information required during registration included: full name of reporters, their mobile numbers and physical home address or location. These details are then assigned to (a) particular water point(s) relating to the reporter.

If the reporter changes a mobile number, loses his/her SIM Card or mobile phone and does not use the same number again, $\mathrm{s} /$ he has to report so that the new number can be registered into the system, otherwise s/he will not be able to report. Reporters are also urged to report if they move from the initial assigned area (relocation, marriage or travel) and are unable to report on water point functionality so that a new reporter can be assigned for those water points.

Once a user is added in the system, upon dialing a short code $* 150 * 50 * 25 \#$, a list of assigned water points would appear on their mobile screen, followed by a series of questions. The reporter is required to answer all the questions accurately, and, at the end, the reporter will get automatic feedback that the submission was successful. The SEMA system allows for users with Airtel and Vodacom mobile numbers to register. For Airtel subscribers, reporting is free of charge while reporting for Vodacom subscribers SMSs are charged at a cost of TZS. 92/=. The platform that is used, DHIS2, allows for broadcast or bulk SMSs module that facilitates sending of SMS to all registered users. This function of the system enables the DWEs to remind reporters to send their monthly due reports as well calling them for training sessions.

\subsection{Training of Users}

Once registration of reporters was completed, the project team conducted village-to-village training for the reporters so as to enable them to be able to use the system (see Figure 9). Training was conducted in all four districts: Bunda, Morogoro Rural, Mufindi and Njombe; by UDSM, UT together with SNV Netherlands Development Organisation. SNV was responsible for coordinating the events, i.e., inception meetings and training workshops. UDSM was responsible for registering users (reporters) in the system and conducting training to reporters on the use of mobile phones for reporting.

These training workshops were preceded by a one-day inception meeting which involved water stakeholders (DWEs, VEOs, WEOs, COWSOs and citizens) in the particular district. The inception meetings were useful in sensitizing people on the importance of water, water conservation and paying for water. It also served as a platform for open discussion to address challenges in the water sector and provide recommendations for improvement.

The workshops were conducted in either or both of the two modes, which are: Training of Trainers (ToT) workshops and one-to-one reporters training. The ToT workshop involved training representative trainers (usually VEOs) who will later be required to train other water point reporters in various villages in the district. Furthermore, during the training the engineers at the DWE office in Bunda were also taught on the use of the District Dashboard part of the system. This dashboard can be used to obtain monthly reports of water point status based on what has been reported. 

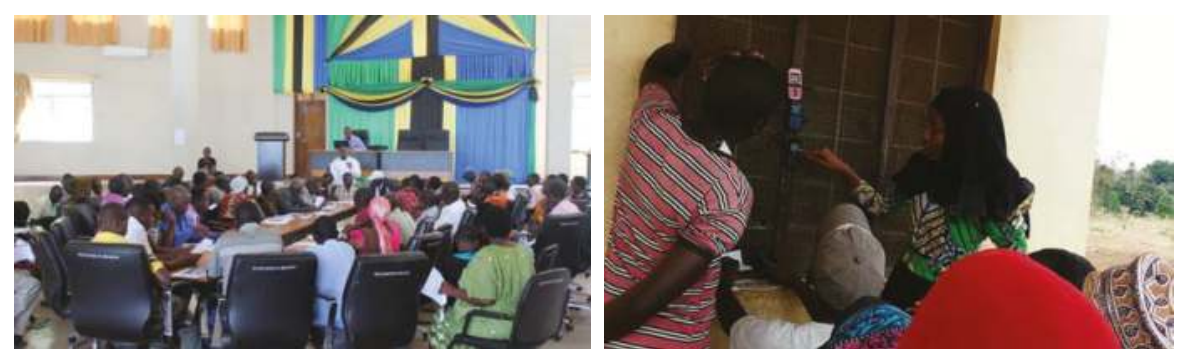

Figure 9. (Left) Trainers' workshop in Bunda in December 2015; and (Right) Training of Reporters in Kolero village in Morogoro.

One-to-one training of reporters focused on training village reporters. This involved project members moving from one village to another, gathering all registered reporters in the area and training them on how to report on the status of water points using their mobile phones. The reporters also had the opportunity to ask questions and address any reporting challenges that they envisage.

The project team has identified, trained and assigned 1899 reporters to the 3078 WPs to facilitate timely reporting of the functionality status of WPs.

\subsection{First Results}

The project team worked with registered reporters from the districts to collect and update the information into the system. We have older data, but they are inconsistent and contaminated with test data. From 2016, we have, at least for Bunda district, a full year of information. From the number of reporters and the number of water points (shown in Table 3), it is evident that in Bunda our reporters were responsible for more water points per person than in the other three districts.

The longer reporters are active, it seems the more new water points are being registered in the WPMS, see Figure 10. It supported our belief in the importance of having intensive interaction with the local population in order to get full insight into the situation on the ground.

Table 3. Registered WP in each district.

\begin{tabular}{ccccc}
\hline & Bunda & Mufindi & Njombe & Morogoro \\
\hline \#WP (SEMA) (March 2017) & 808 & 840 & 748 & 681 \\
\#WPs MoW (July 2015) & 648 & 720 & 712 & 701 \\
\#Villages & 103 & 121 & 46 & 150 \\
\#Registered reporters & 315 & 506 & 542 & 536 \\
Start date of reporting & January 2016 & July 2016 & August 2016 & November 2016 \\
\#Months of reporting & 13 & 6 & 5 & 3 \\
\hline
\end{tabular}

Table 4 shows the Consistency of Reports in terms of the number of reporters that on average report each month. It shows that, for Bunda, more than half of the reporters report each month, but, if we look at the percentage of WPs that are reported each month, we see this is less than half.

Table 4. Percentage of consistency of reporters per district.

\begin{tabular}{cccccccc}
\hline District & \#Reporters & $\begin{array}{c}\text { Consistency } \\
\text { of Reports }\end{array}$ & $\begin{array}{c}\text { \% Airtel } \\
\text { Users }\end{array}$ & \#Reports & $\begin{array}{c}\text { \#Reports per } \\
\text { Reporter }\end{array}$ & $\begin{array}{c}\text { \#Reports } \\
\text { per Month }\end{array}$ & $\begin{array}{c}\text { Consistency of } \\
\text { Reports per } \\
\text { Month per WP }\end{array}$ \\
\hline Bunda & 316 & $54 \%$ & $66 \%$ & 4364 & 25 & 312 & $39 \%$ \\
Mufindi & 506 & $19 \%$ & $5 \%$ & 771 & 8 & 96 & $13 \%$ \\
Njombe & 535 & $12 \%$ & $97 \%$ & 461 & 7 & 66 & $9 \%$ \\
Morogoro & 405 & $31 \%$ & $6 \%$ & 512 & 4 & 128 & $19 \%$ \\
\hline
\end{tabular}




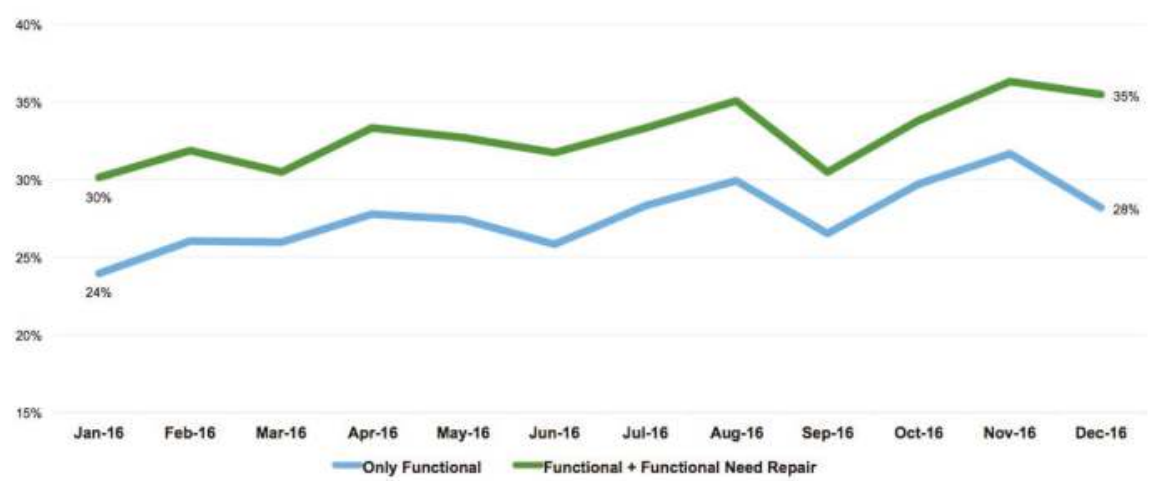

Figure 10. Functionality of water points in Bunda, showing a steady increase over the year 2016.

A breakthrough (or obstacle). Sustainable but still need a helpdesk: Figure 11 is a graph showing what happens if the system and back office do not function. Notice the dip in almost all thin lines in December 2016. In December 2016, the contract of the Helpdesk technical staff was ended. Here, there was no technical support available and reporters were not contacted to make their monthly report. However, people continued to report in the absence of the Helpdesk operators whose primary job was to send monthly reminder as well as assisting to remind the short code to dial.

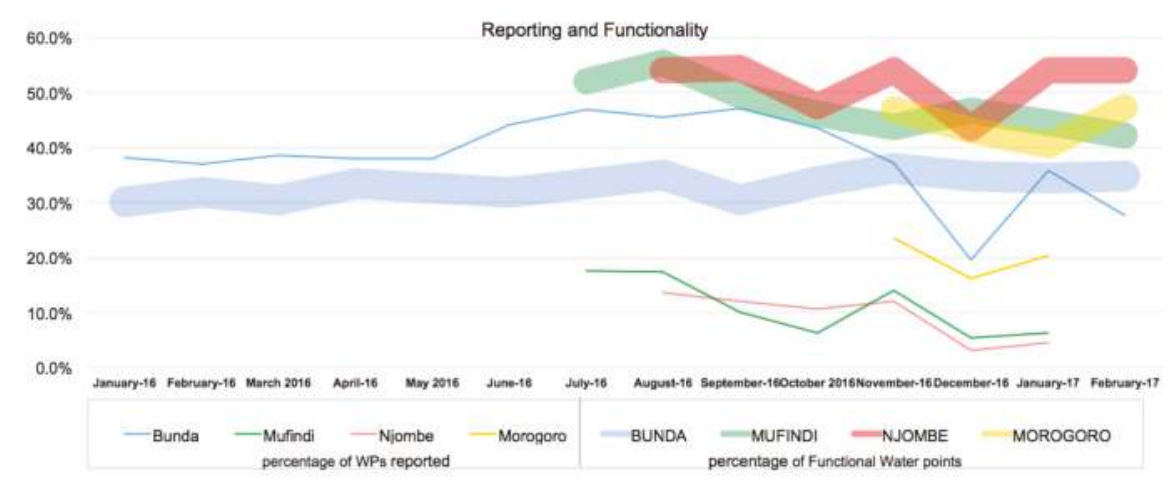

Figure 11. Water Point (WP) Reporting status in the districts.

\subsection{Cost Estimation}

As the result of experiences in the field and having setup the system in practice, we estimate the costs for a working system as in Table 5 . In addition to the technical costs, to cater for database system administration and user support, the salary for two helpdesk officers (also known as system administrators) completes the total cost. The current salary rates are $\$ 625$ per month for a university graduate IT officer. Hence, the total salary costs p.a. is $625 \times 2 \times 12=\$ 15,000$. 
Table 5. Annual cost of SEMA in four districts. The total cost per water point per year is US\$9.95 (at the time of writing 22,049 Tanzanian Shilling).

\begin{tabular}{cc}
\hline Item & Cost in \$ per Year for 2400 Water Points \\
\hline System hosting (SEMA database system) & 2640 \\
Mobile application hosting (USSD App) & 1800 \\
USSD short-code & 2000 \\
Bulk SMS dissemination & 650 \\
Website hosting & 1800 \\
Helpdesk of 2 staff & 15,000 \\
Total & 23,890 \\
\hline
\end{tabular}

\section{Discussion}

\subsection{Lessons Learned-Observations from the Field}

Through the implementation of this project, some valuable take away lessons were noted. Even though the tool can work as expected, many other socio-technical reasons can hamper the reporting behavior of the registered reporters. Some reporters do not own mobile phones, especially female reporters, instead they rely on inserting their SIM cards to others phones and hence the SIM cards are subject to be misplaced frequently. In addition, there were cases of lost SIM Cards due to stolen and broken phones, in which case it takes some time for reporters to restore their mobile numbers and the reporting process gets interrupted. Due to poor network coverage in some villages, reporters needed to travel to reach the network in specific locations. Due to this inconvenience, some reporters end up skipping some reporting periods. As quite some reports were hampered by inconsistent water point names (many relate to the nearest landmark), it is important to involve the reporters in the naming process.

The reporting behavior is very much tied to the fact that a reporter is using the respective water points assigned to them and that they are follow a short training. When a report moves away due to various reasons including marriage, the reporter stops the reporting. Institutionalizing the process and thus guaranteeing continuity needs the involvement of the VEO and/or COWSO leadership and the support by a back-office helpdesk for matters such as re-registration, swapping mobile numbers and reminding the reporters. It was learned further that, developing the back-office system was not a one-off event but evolved as time needs arises. For example, after using the system for sometime, it was requested to add a management report which showed who was reporting for which water point with a respective mobile number. This helped to remind only those who did not report rather than calling for all the reporters.

\subsection{SEMA App in a Changed Rural Water Supply Information Infrastructure}

Delivery of key services entails taking into consideration the numerous implementation requirements of these services. Generally, each type of service requires a number of tasks to be carried out for the service to be efficiently delivered. These tasks depend on the structure of incentives facing providers and recipients, which in turn depends on five key elements of service delivery: resources, information, decision-making, delivery-mechanisms and accountability (Pritchett and Woolcock 2004). Research shows that these elements involve tasks that can be characterised as in Table 1. They may require either numerous (transaction-intensive) or few (non transaction-intensive) processes. Furthermore, the tasks may be based on routine processes in which the actors do not necessarily require exercising intensive judgment (non-discretionary), while on the other hand actors may be required to exercise a high level of judgment (discretionary) [6,23]. We will now translate these characteristics into our case of monitoring water points (see also Table 6 and compare with Table 1). 
Table 6. Tasks and their amenability to improvement through digitization (SEMA case).

\begin{tabular}{ccc}
\hline & Transaction-Intensive & Non Transaction-Intensive \\
\hline Discretionary & Repairing water taps & Setting water coverage targets \\
Non-discretionary & Monitoring water taps & Procedures and Rules \\
\hline
\end{tabular}

We begin with the process of Setting water coverage targets (including water policy), which is a discretionary and non-transaction intensive element of water service provision. Why is it non-transaction intensive? Only a few experts from the respective government agent and Development Partners get together in a closed session and decide what should be the water coverage targets for the next years. Why is it discretionary? These few (smart) people make their decision about water targets based on information that is imperfectly specified and incomplete. They use their judgment and extensive professional and context-specific knowledge, i.e., they use their discretion.

Repairing water taps is a discretionary and transaction-intensive element of water service provision. Why is it discretionary? Expert judgment is required to decide which part is broken, why, where a spare part can be found, how much it costs, how and when to replace it, etc. Why is it transaction-intensive? Thousands of repairmen need to be contacted, mobilized together with resources, and transported to the spot to fix the tap. Repairing water taps is the peskiest element of water service provision.

Procedures and Rules is a non-discretionary and non-transaction intensive element of water service provision. Why is it non-discretionary? No expert judgment is required to follow the already available rules and procedures. Why is it non-transaction intensive? Setting procedures and rules simply entails dictating the one by one procedures of how things should be done, and once they are set and approved, they are simply there to be adhered to.

Monitoring water taps is a non-discretionary and transaction intensive element of water service provision. Why is it non-discretionary? A human observer can normally inspect any of the thousands of water taps and confirm that at the moment of observation it was not functioning. No expert knowledge and difficult judgment is required. Why is $t$ transaction-intensive? Thousands upon thousands of observers are needed to perform this task and to contact dozens of District Water Engineers to inform them about the water tap status. In the context of this project, this "side" of the matrix can easily be "digitized" using an ICT tool, as will be discussed in later sections.

In their literature, Ndaw [24] and Welle [7] presented a number of ICT tools across various countries in the WASH and water sectors, respectively, in which experiences in the use of ICT solutions in the WASH sector are presented. We map the tools (Table 7) onto the elements of key services characterization matrix. Based on this mapping, all tools described in the literature appear to be non-discretionary, while some are transaction-intensive and others are non-transaction intensive.

We observe that there are several tools that provide information directly from village to ministry, while SEMA operates between villagers and district, and as such is going with the grain as meant in $[16,25]$, or, in other words, follows the patterns of local organization.

We conclude that many tools do not seem to have any sort of evolutionary characteristic, with which digital transformation could be achieved. Within the matrix, we also map the initial SEMA App tool (Version 1), in which users had to exercise a lot of discretion in order to report the status of their water points. Gradually, this discretion is removed from the users, leading to subsequent versions of the App (App evolution). Obviously, this is one way to increase the validity and reliability of the data collection. Another way is the involvement of alternative data sources, such as in-situ water sensors, but this is considered to be beyond this project. It should be noted that most of these sensors measure water flow and cannot identify the type of problem in case of malfunctioning water point as is done in our case.

The creation of the SEMA software cannot be seen as just an academic exercise. The SEMA App has been developed in close cooperation with stakeholders, the Ministry of Water being one of the 
most important one, and following the change of needs over time. In addition, the uptake of the software has been supported by training the intended users.

Table 7. Conceptualization of SEMA App versions.

\begin{tabular}{|c|c|c|c|c|}
\hline & $\begin{array}{l}\text { Unconstrained } \\
\text { Crowdsourcing }\end{array}$ & $\begin{array}{l}\text { Medium-Constrained } \\
\text { Crowdsourcing }\end{array}$ & $\begin{array}{l}\text { Highly-Constrained } \\
\text { Crowdsourcing }\end{array}$ & $\begin{array}{l}\text { (Future) Institutionalized } \\
\text { "Crowdsourcing" at MoW }\end{array}$ \\
\hline $\begin{array}{l}\text { Lots of discretion } \\
\text { granted to } \\
\text { reporters }\end{array}$ & & $\begin{array}{c}\text { SEMA V_1.0 } \\
\text {-User reports with } \\
\text { password at every login } \\
\text { instance. } \\
\text {-User reports on whether } \\
\text { WP is F, NF, NR. } \\
\text {-Additional text } \\
\text { description. } \\
\text {-Choice EN/SWA. }\end{array}$ & & \\
\hline $\begin{array}{l}\text { Medium discretion } \\
\text { granted to } \\
\text { reporters }\end{array}$ & & $\begin{array}{c}\text { SEMA V_2.0 } \\
\text {-User reports with } \\
\text { password at first login } \\
\text { instance. } \\
\text {-User reports whether WP } \\
\text { is F, NF, NR. } \\
\text {-Only SWA. }\end{array}$ & & \\
\hline $\begin{array}{l}\text { Low discretion } \\
\text { granted to } \\
\text { reporters }\end{array}$ & $\begin{array}{l}\text { Human Sensor } \\
\text { Web Zanzibar } \\
\text {-Anybody can } \\
\text { report. } \\
\text {-Report on: Yes or } \\
\text { No water. } \\
\text {-Additional text } \\
\text { description. } \\
\text {-Only EN. }\end{array}$ & & $\begin{array}{c}\text { SEMA V_3.0 } \\
\text {-Only users registered by } \\
\text { SEMA administrator can } \\
\text { trigger reporting. } \\
\text {-User reports on elemental } \\
\text { attributes of WP (water } \\
\text { flow, water quality, etc.). } \\
\text {-APP calculates F, NF, NR. } \\
\text {-Only SWA. } \\
\text {-Commercial gateway. }\end{array}$ & \\
\hline $\begin{array}{l}\text { (Future) Zero } \\
\text { discretion granted } \\
\text { to reporters }\end{array}$ & & & & $\begin{array}{c}\text { SEMA V_4.0 } \\
\text {-Only users registered by } \\
\text { MoW can trigger reporting. } \\
\text {-User reports on elemental } \\
\text { attributes of WP (water flow, } \\
\text { water quality, finances, etc.). } \\
\text {-APP calculates F, NF, NR? } \\
\text {-Only SWA. } \\
\text {-MOW verifies the validity } \\
\text { of reports. } \\
\text {-Government (TCRA) gateway. }\end{array}$ \\
\hline
\end{tabular}

\section{Conclusions and Challenges for the Future}

The development of the SEMA App has shed light on socio-technical lessons related to software development, system deployment strategies and organizational change behavior. Software do evolve to address the intended problems and appropriate technology used to develop the software solution matters. In this project, the software technologies adopted to develop the initial solutions of the SEMA App were not appropriate. This calls for a thorough requirements and systems analysis before engaging into the software development process. Specifically, the use of USSD technologies over Android technologies in the rural areas was more appropriate.

The SEMA project has succeeded to reduce the downtime for water point repairs as it facilitated surfacing of the downtime problems per water point in the rural areas. As a result, most of stakeholders were made to understand the magnitude of the problems and hence played their roles and responsibilities accordingly. In this way, the SEMA app amplified the voices of ordinary citizens who wished to hold administrators accountable for the delivery of water services. The application also helped to reduce the bureaucracies involved in data collection and reporting of water services information. In contrast to the approach of using professional surveyors in mapping the water points, this study informs that the baseline list of existing water points in the rural areas can only become be known through involving local communities. In the just four districts involved in this project, the project listed 157 water points, which were not listed in the ministry database. 
The study concluded that not all water points were presented to the professional water points mapping team because the local communities were expecting to get new projects. Furthermore, local beliefs that show strangers their water points would make the water point non-functional and some believed the surveyor were of very high class to be shown aging and poor hygienic water points.

On the question whether rural communities would volunteer to report, this study concludes positive results when engaged to address social problems in their communities. In this project, 1899 reporters were engaged. It is in this process where reporters helped to identify more water points. This helped the District Water Engineers (DWEs) to update and complete their monthly reports as required by the Ministry of Water. The mobile reporting system has reduced the bureaucratic process of reporting functionality status. As previously, they used to write letters to inform the functionality status and allow traceable follow-ups on actions done on the reported WPs in the four districts.

Based on the study results and lessons learned, it is hereby recommended that, when implementing similar project, the project team should take initiatives to ensure that the district technicians are impacted with the essential technical skills by facilitating coaching and mentoring sessions by linking them with experienced technicians. The DWEs were also advised to facilitate the field learning sessions to enable them acquiring the new skills. Further recommendations are that verification of water point reporters confirm their willingness, capability and commitment to reporting water point functionality status should be done together with the project team and DWE team. The coaching and training session to the confirmed reporters on mobile reporting application system should be conducted as one of the project implementation activities. Any missing WPs were identified and added to the project baseline data, and they were also presented to the MoW for them to revise their data.

Acknowledgments: The main research for this paper was done under the NWO-WOTRO funded integrated research project: Sensors, Empowerment and Accountability in Tanzania (SEMA).

Author Contributions: Rob Lemmens, Juma Lungo, Yola Georgiadou and Jeroen Verplanke conducted desk research, fieldwork (including testing the SEMA App) and wrote the paper. Juma Lungo implemented the SEMA App.

Conflicts of Interest: The authors declare no conflict of interest.

\section{References}

1. Giné, R.; Pérez-Foguet, A. Sustainability assessment of national rural water supply program in Tanzania. Natl. Resour. Forum 2008, 32, 327-342. [CrossRef]

2. United Republic of Tanzania. The Water Sector Status Report 2013; Ministry of Water: Dar es Salaam, Tanzania, 2013.

3. UNICEF/WHO. Progress on Sanitation and Drinking Water: 2015 Update and MDG Assessment; UNICEF and The World Health Organization: New York, NY, USA, 2015.

4. United Republic of Tanzania. Water Sector Development Programme (2005-2025); Consolidated Report; Ministry of Water: Dar es Salaam, Tanzania, 2006.

5. MoWI. Updating Manual for CDMT. 2015. Available online: http://www.maji.go.tz/sites/default/files/ New_UPDATING\%20MANUAL\%20CDMT\%20SEPTEMBER\%202015.pdf (accessed on 18 October 2017).

6. WaterAid. The Water Point Mapping Updating Methodology. 2010. Available online: http:/ /www.wateraid.org/ /media/Publications/The-water-Point-mapping-updating-methodology.pdf (accessed on 18 October 2017).

7. Welle, K.; Williams, J.; Pearce, J. ICTs Help Citizens Voice Concerns over Water-Or Do They? IDS Bull. 2016, 47, 41-51. [CrossRef]

8. Pritchett, L.; Woolcock, M. Solutions When the Solution is the Problem: Arraying the Disarray in Development. World Dev. 2004, 32, 191-212. [CrossRef]

9. United Republic of Tanzania. National Water Policy 2002; Ministry of Water: Dar es Salaam, Tanzania, 2002.

10. Tilley, H. Unblocking Results: Rural Water in Tanzania; Overseas Development Institute: London, UK, 2013.

11. Cleaver, F; Toner, A. The evolution of community water governance in Uchira, Tanzania: The implications for equality of access, sustainability and effectiveness. Natl. Resour. Forum 2006, 30, 207-218. [CrossRef] 
12. Braathen, E.; Chaligha, A.; Odd-Helge, F. Local Governance, Finances and Service Delivery in Tanzania: A Summary of Findings from Six Councils; Norwegian Institute for Urban and Regional Research (NIBR): Oslo, Norway, 2005.

13. United Republic of Tanzania. Tanzania Water Supply and Sanitation Act (2009); United Republic of Tanzania: Dar es Salaam, Tanzania, 2009.

14. World Bank. World Development Report 2016: Digital Dividends; The World Bank: New York, NY, USA, 2016.

15. Wacquant, L. Habitus. In International Encyclopedia of Economic Sociology; Becket, J., Milan, Z., Eds.; Routledge: London, UK, 2005.

16. Nganyanyuka, K.; Martinez, J.; Lungo, J.H.; Verplanke, J.; Georgiadou, Y. Working with the grain: How amenable to digital transformation is the monitoring and repair of rural water points in Tanzania. Inf. Technol. Int. Dev. 2017, 13, 103-121.

17. Wikipedia. SMS. 2017. Available online: https://en.wikipedia.org/wiki/SMS (accessed on 18 October 2017).

18. Wikipedia. Unstructured Supplementary Service Data. 2017. Available online: https://en.wikipedia.org/ wiki/Unstructured_Supplementary_Service_Data (accessed on 18 October 2017).

19. Wikipedia. GSM. 2017. Available online: https://en.wikipedia.org/wiki/GSM (accessed on 18 October 2017).

20. Tsega, H.; Lemmens, R.; Lungo, J.; Kraak, M.J. Towards a Smarter System for Human Sensor Web. In Proceedings of the IEEE International Conference on Pervasive Computing and Communications, PerCom'15, St. Louis, MO, USA, 23-27 March 2015; pp. 14-19.

21. Tsega, H.; Lemmens, R.; Lungo, J.; Kraak, M.J. Urban Context Modelling for Human Sensor Web. In Proceedings of the N-AERUS XIV workshop, Enschede, The Netherlands, 12-14 September 2013.

22. Wesselink, A.; Hoppe, R.; Lemmens, R. Not just a tool. Using context in the development of a mobile App for rural water supply in Tanzania. Water Altern. J. 2015, 8, 57-76.

23. Pritchett, L. The World Bank and public-sector management: What next? Int. Rev. Adm. Sci. 2013, 79, 413-419. [CrossRef]

24. Ndaw, M.F. Unlocking the Potential of Information Communications Technology to Improve Water and Sanitation Services; WSP Report on Water \& Sanitation Program; The World Bank: Washington, DC, USA, 2015.

25. Kelsall, T. Going with the Grain in African Development? Dev. Policy Rev. 2008, 26, 627-655. [CrossRef]

(c) 2017 by the authors. Licensee MDPI, Basel, Switzerland. This article is an open access article distributed under the terms and conditions of the Creative Commons Attribution (CC BY) license (http:/ / creativecommons.org/licenses/by/4.0/). 
Article

\title{
An Interactive Planning Support Tool for Addressing Social Acceptance of Renewable Energy Projects in The Netherlands
}

\author{
Johannes Flacke * and Cheryl de Boer \\ Faculty of Geo-Information Science and Earth Observation (ITC), University of Twente, P.O. Box 6, \\ 7500 AE Enschede, The Netherlands; c.deboer@utwente.nl \\ * Correspondence: j.flacke@utwente.nl; Tel.: +31-53-4874-381
}

Received: 17 July 2017; Accepted: 13 October 2017; Published: 19 October 2017

\begin{abstract}
The implementation of renewable energy policies is lagging behind in The Netherlands. While several Dutch cities have ambitious goals for reducing greenhouse gas (GHG) emissions, the implementation of renewable energy projects has been rather slow. The main reasons for this are the limited institutional capacities of local decision-makers, low levels of social acceptance of renewable-energy technologies, and limited opportunities for engagement of communities in decision-making processes. In order to address these issues we have developed an interactive planning support tool named COLLAGE for stakeholder participation in local renewable-energy planning. The goal of this paper is to analyze whether the COLLAGE tool helps to increase community engagement in renewable-energy projects and planning by increasing awareness and addressing social learning issues related to renewable-energy options. We tested the tool in a series of workshops with stakeholders and citizens from the city of Enschede, The Netherlands. The workshop results show that the tool helped involve stakeholders and communities in deciding where to locate renewable-energy facilities. It increased community members' awareness of the benefits of and requirements for renewable energy by disclosing the spatial consequences of overall municipal goals. We conclude that the COLLAGE tool can be an important building block towards new local energy governance.
\end{abstract}

Keywords: renewable energy; social acceptance; energy governance; interactive mapping tools; maptable

\section{Introduction}

Renewable energy is an important cornerstone of global and national climate change policies, such as the Paris Agreement [1] and the EU roadmap towards a competitive, low-carbon economy [2], but its implementation is lagging behind in many European countries, including The Netherlands. While several Dutch cities have developed ambitious goals for reducing greenhouse gas (GHG) emissions, many of them aiming to become carbon-neutral within the next 20 to 35 years [3], the implementation of renewable-energy systems such as wind turbines or solar farms has been very slow in The Netherlands compared with other European countries. In 2014, the share of energy from renewable-energy technology was only $4.4 \%$ of the gross inland energy consumption in The Netherlands, while the average renewable-energy share of the EU-28 countries accounted for $12.5 \%$ of the gross inland energy consumption in 2014, with countries such as Austria (30\%) or Sweden (35\%) having the highest share among the EU countries [4].

Scholars have identified two main reasons for the low development of renewable-energy projects: (a) limited institutional capacities of local decision-makers with respect to the implementation of renewable-energy policies, particularly with respect to wind power [5], due to an emphasis 
on centralized policy-making and an underestimation of issues of spatial and environmental planning; and (b) strong opposition from local communities and individual citizens towards the implementation of large-scale renewable-energy projects, often referred to as the NIMBY ("Not In My Backyard") phenomenon [6]. Wuestenhagen et al. [7] capture both barriers within the concept of social acceptance of renewable, particularly wind-energy innovations, which includes the three interdependent dimensions of socio-political acceptance, community acceptance, and market acceptance. Socio-political acceptance refers to the public acceptance of renewable-energy technologies and policies by key stakeholders and policy actors. Community acceptance, which is typically understood as the NIMBY phenomenon, refers to the specific acceptance of siting decisions and renewable-energy projects by local stakeholders, particularly residents and local authorities. Market acceptance, finally, explains the adoption of innovative products by consumers through a communication process between individual adopters and their environment. Sovacool and Lakshmi Ratan [8] have analyzed how the acceptance of wind- and solar-energy projects depends upon the prevalence of nine interrelated factors: (1) strong institutional capacity; (2) political commitment; (3) favorable legal and regulatory frameworks; (4) competitive installation and/or production costs; (5) mechanisms for information-sharing and feedback; (6) access to financing; (7) prolific community and/or individual ownership and use; (8) participatory project siting; and (9) recognition of externalities or positive public image.

Devine Wright et al. [9] claim that research of social acceptance of renewable energy is skewed towards understanding resistance to technology implementation by reference to the NIMBY concept. While the NIMBY explanation is often seen by policy-makers and investors and as the main obstacle to renewable-energy implementation [10], Breukers and Wolsink [11] argue, that the limited opportunities for communities' engagement in the decision-making process relating to the siting of renewable-energy projects is also part of the problem. Particular local authorities, having a major role in the energy transition due to their existing geographical and political proximity to individual, household and community-level activities and practices [12,13], are important actors in this context. However, public participation and community engagement in the development of renewable-energy projects are often limited to one-directional information campaigns with websites or leaflets in order to convince the public of the advantages of particular renewable-energy locations rather than allowing for an open discussion, e.g., within a public meeting where opponents would have the opportunity to collectively express emotional antagonism and influence other citizens [10]. The close relationship between NIMBYism and limited public engagement is described by Devine Wright as a "rather destructive, self-fulfilling cycle [ ... ] in which local opposition is interpreted by developers and policy-makers as evidence of NIMBYism, which leads to engagement practices whose main goal is to allay NIMBY responses by limiting engagement opportunities" [10] (p. 22).

Breaking such a cycle requires new ways of thinking and practising public engagement that better connects policy-making with local areas directly affected by specific projects. In contrast to traditional, centralized energy systems that are mainly regulated by national and/or state/provincial governments, the implementation of renewable-energy projects requires strong engagement from local communities [14]. Citizens need to understand the relationship between local actions for renewable energy and global or national climate change goals [12]. This is where the involvement of local authorities is crucial, especially in terms of emphasizing the relevance of a collective endeavor. Therefore, a more inclusive process that involves local residents in the development of local renewable-energy policies as well as in the concrete siting of renewable-energy projects in specific localities is needed.

However, it needs to be acknowledged that the development of renewable-energy policies and projects should be understood as a typical wicked problem [15], which is generally seen as "complex, open-ended, and intractable, while both the nature of the 'problem' and the preferred 'solution' are strongly contested" [16] (p. 101) among stakeholders. The choice between different types of renewable energy, such as wind, solar, biogas, etc., all of them having various positive as well as negative impacts, 
leads to complex trade-offs when it comes to decision-making, which are exacerbated by various mental models, perceptions, and preferences of the various stakeholders involved. Scholars need to examine such types of wicked problems "through a panoramic social lens rather than a scientific microscope, and working with it in an open and heuristic process of collective learning, exploration, and experimentation" [17] (p. 2). In other words, engaging with local stakeholders and communities from the very early planning phases onwards is the best way to address and mitigate the wickedness of the development of renewable-energy strategies and projects.

In order to address the issues discussed above, we have developed an interactive planning support tool for stakeholders' and citizens' participation in local renewable-energy planning that we named COLLAGE (Collaborative Location and Allocation Gaming Environment). Implemented on a digital maptable, the COLLAGE tool encourages stakeholders to discuss jointly where to allocate what kind of renewable-energy systems (wind, solar) within the municipal boundaries. While doing so, the model calculates various impacts, benefits and trade-offs of the current allocation and thus allows stakeholders to reflect immediately on the different options. The goal of the COLLAGE tool is to stimulate and substantiate stakeholder discussions towards consensual options and locations, and to raise awareness and facilitate social learning of stakeholders and local communities in relation to the different renewable-energy options. Social learning is understood in this context as a process of iterative reflection that occurs when participants share their experiences, ideas and environments with others during a group activity [18].

In the paper we present the application of the COLLAGE tool in stakeholder workshops in the city of Enschede, The Netherlands. The goal of the paper is to analyze whether and how the COLLAGE tool helps to increase community engagement in renewable-energy projects and planning by increasing awareness and addressing social learning issues relating to renewable-energy options. In Section 2, we describe the framework and functioning of the COLLAGE tool in detail. Section 3 presents details of the case study, the adoption of the COLLAGE tool for the specific case study, and the workshops we conducted. In Section 4, we analyze the results of the mapping sessions during the workshops and compare these to the perceptions of the participants towards renewable energy. We further analyze particular lessons learned by the participants during the workshops and evidence of awareness-raising and social learning. In the final section, we discuss how the COLLAGE tool can be used to support the introduction of new forms of local energy governance [19], that gives local governments and communities a stronger role in the future governance of energy systems.

\section{The COLLAGE Tool}

The COLLAGE tool is a stakeholder-oriented interactive planning support tool implemented on a maptable. A maptable is a large-scale horizontal interactive display that shows digital content in terms of maps and allows users to interact with the content via touching and gestures (Figure 1). Often a second screen is attached to it that is used to either display a 3D scene of the 2D map shown on the maptable or the results and outcomes from the interactive mapping sessions. Due to its horizontal installation, up to 6 participants can gather around the table and interact with the digital content on the interactive screen and with fellow participants [20]. The current version of the COLLAGE tool is implemented in CommunityViz Scenario 360 software [21], an extension to ArcGIS.

Such interactive Planning Support Systems (PSS) have been applied and tested in research, focusing on improving stakeholder participation in planning processes, for the last couple of years [22]. They are seen as particularly useful for initiating and strengthening interaction and collaboration between participants, e.g., stakeholders and citizens. Pelzer et al. [23] researched the added values such interactive PSS provide to urban planning processes. Shrestha et al. [24] showed how such interactive PSS tools support stakeholders in expressing their views, understanding other people's views, and coming to a consensus or a shared understanding of a problem situation. While most studies of the added values of such interactive, maptable-based PSSs for supporting planning processes focus on the participation of domain experts and other stakeholders, the use and usability of such 
systems within decision-making processes involving laypersons or, so to speak, "normal" citizens, is hardly explored.

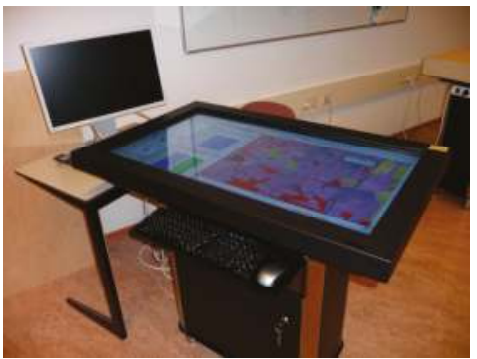

(a)

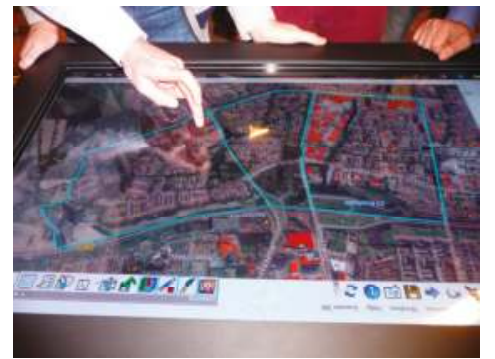

(b)

Figure 1. The interactive maptable: (a) the entire maptable setup including a second screen; (b) participants interacting with the maptable during a workshop session.

The current COLLAGE tool focuses on wind and solar energy technologies, the latter being sub-divided into solar parks, i.e., a large number of solar panels typically mounted on the ground, and solar panels on rooftops. Other renewable-energy technologies such as geothermic energy or biogas installations will be included in future versions of the model. The COLLAGE tool includes several sets of spatial data, such as building footprints, land use and administrative boundaries (Table 1) that were used to generate the layers of spatial information that are shown on the maptable (Table 2) for informing the participants during the participatory mapping process.

Table 1. Complete list of data sets used.

\begin{tabular}{cl}
\hline Data Set & Source \\
\hline Municipal boundaries & Municipality of Enschede \\
Land use & Municipality of Enschede \\
Sun map (building footprints) & Municipality of Enschede \\
Ecologically sensitive areas & Municipality of Enschede \\
Built-up areas & Municipality of Enschede \\
High voltage lines & Municipality of Enschede \\
Canals & Municipality of Enschede \\
Railroad tracks & Municipality of Enschede \\
Gas pipes & Municipality of Enschede \\
\hline
\end{tabular}

The data layer rooftop suitability shows the suitability of each single building for solar panels in five categories from not suitable at all to very suitable. This categorization is taken from the so-called "sun map" (in Dutch: zonnekaart) [25], a classification of rooftops according to their suitability for setting up solar panels that is available for the whole of The Netherlands. The classification of each roof is based on the solar radiation at that location, the angle of the roof and its exposure/orientation.

Table 2. Data layers shown on the maptable.

\begin{tabular}{lll}
\hline Layers of Information & Description/Purpose & Source \\
\hline municipal boundaries & district and neighborhood boundaries & Municipality of Enschede \\
\hline land use & main land use categories & Municipality of Enschede \\
\hline rooftop suitability & suitability for solar panels on roofs & sun map [25] \\
\hline number of solar panels & Max no. of solar panels possible per rooftop & sun map [25] \\
\hline solar park suitability & area suitable for solar parks & derived from base data \\
\hline suitable wind area & area suitable or wind energy installations & derived from base data \\
\hline aerial photograph & webservice, for orientation & Dutch National SDI (PDOK) [26] \\
\hline street names, names of regions and districts & webservice, for orientation & Dutch National SDI (PDOK) [27] \\
\hline
\end{tabular}


The layer suitable wind area demarcates areas in which wind turbines are allowed according to Dutch planning law. The criteria used for demarcating the suitable wind area are given in Table 3. Setting up of solar parks is allowed in agricultural areas and green areas outside the urban core, except those areas that are ecologically sensitive, as well as within industrial areas.

Table 3. Criteria applied for the demarcation of the suitable wind area.

\begin{tabular}{cc}
\hline Data Set & Criteria \\
\hline built-up urban core area & $400 \mathrm{~m}$ distance \\
residential buildings outside the urban core & $400 \mathrm{~m}$ distance \\
ecologically sensitive areas & excluded \\
high voltage lines & $245 \mathrm{~m}$ distance \\
canals & $50 \mathrm{~m}$ distance \\
railroad tracks & $100 \mathrm{~m}$ distance \\
gas pipes & $245 \mathrm{~m}$ distance \\
\hline
\end{tabular}

Functions for navigating (zoom in/out, pan, etc.) allow the users to maneuver interactively through the area. These functions are intuitive to use and can be learned easily by the stakeholders at the beginning of a workshop. While the stakeholders navigate in the map they can allocate different types of renewable-energy sources by selecting a priori defined types of renewable energy and drawing them on the map. While mapping these renewable-energy features, various outcome indicators of impacts, costs or benefits are calculated and visualized in charts on the second screen (Figure 2). In the current version of the model, the following indicators are calculated: total renewable-energy production in Megawatt hours per year (MWh/a); total and per renewable energy type (wind, solar parks, solar rooftops, Figure 2a); renewable-energy production from solar rooftops in MWh/a, divided into residential and non-residential; and the energy mix in percentage of total renewable energy produced (Figure $2 \mathrm{~b}$ ). In both bar charts, the respective goals to be achieved during the workshop are also indicated.

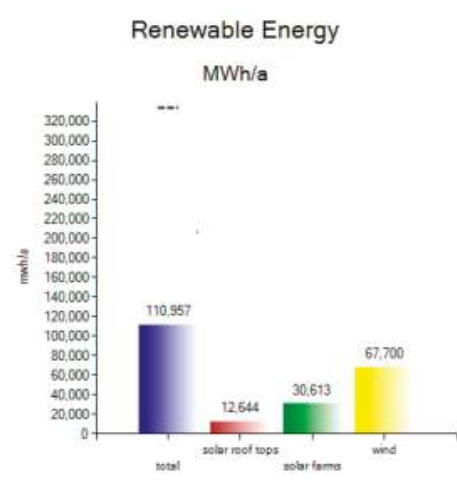

(a)

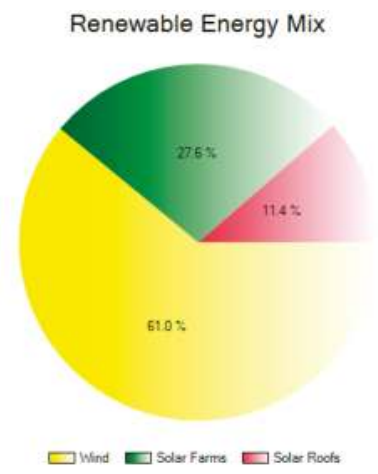

(b)

Figure 2. Charts visualizing the outcome indicators of the mapping sessions: (a) bar chart showing total renewable energy in MWh per type of renewable energy resulting from the current allocations; (b) the resulting mix of renewable energy.

\section{Enschede Case Study}

\subsection{Renewable-Energy Policies in the City of Enschede, The Netherlands}

Enschede is a medium-sized city with around 160,000 inhabitants located on the eastern border of The Netherlands. On 20 June 2014, the city officially became a Covenant of Mayors signatory by 
signing up to the European initiative for local and regional authorities aiming to exceed the Europe 2020 goal of reducing carbon emissions by $20 \%$ by 2020 [28]. In 2016, only $1.2 \%$ of the total electric energy consumption in Enschede was renewable produced from solar energy [29]. However, this share has increased significantly over the years, starting from $0.1 \%$ in 2012 [29].

An evaluation of the potential for renewable energy for Enschede finds that the city has very little space available for the development of renewable energy compared with other Dutch cities [30]. Areas for the installation of wind turbines are rather limited due to the required distance from residential areas and other offsets, as listed in Table 3 (Figure 3). Moreover, due to the airport area in the north of Enschede, only wind turbines up to a tip height of $140 \mathrm{~m}$ are allowed in some of the areas suitable for wind. On the other hand, the potential for development of solar farms is significant. Based on this study, the goals of the city of Enschede with respect to the implementation of renewable energy are to have a share of at least $12 \%$ by the year 2030 and at least $27 \%$ by 2050 of the projected energy need coming from renewable energy produced with the municipal boundaries [28]. This is not a very ambitious goal, but is based on an analysis of what is technically achievable. According to the report, this goal needs to be accompanied by a certain amount of energy saving in order to achieve a reasonable $\mathrm{CO} 2$-reduction [28].

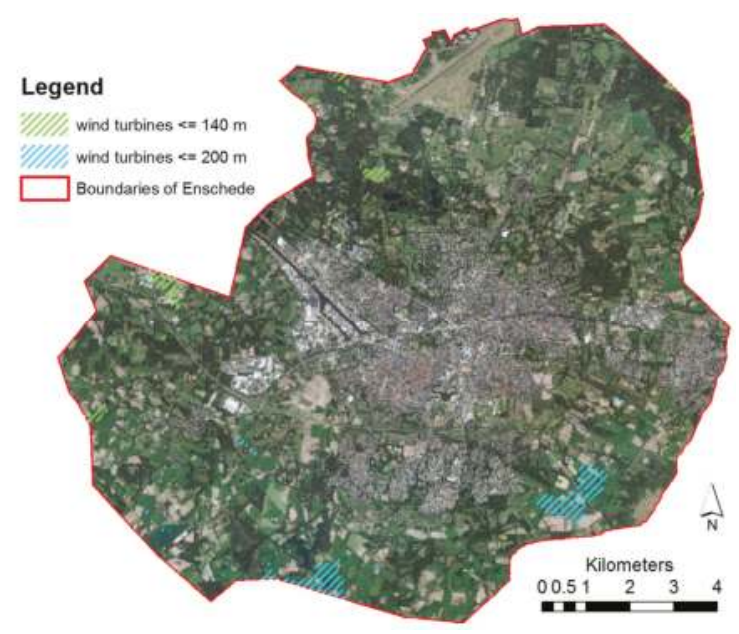

Figure 3. Area suitable for wind turbines in the city of Enschede.

Between October 2016 and March 2017, the city conducted the Enschede wekt op (Enschede wakes up) campaign [31]. The main aims of the campaign were to inform citizens of the local goals for renewable energy, the different forms of renewable energy that could be implemented in order to achieve these goals, and to sensitize and raise popular awareness in relation to these issues and projects. In addition to the information provided via the project website, the campaign conducted various activities and events, such as a town-hall meeting and various public brainstorming sessions. On the website, five scenarios describing potential locations for renewable energy were presented, as developed in advance by the municipality. The results and outcomes of the entire campaign are summarized in a final report [32]. The participatory workshops using the COLLAGE tool were also part of the campaign. Participants could register for the COLLAGE workshops via the project website.

\subsection{The COLLAGE Tool for Enschede}

The specific roll out of the COLLAGE model and tool for the Enschede workshops was developed in close cooperation with the municipality. In the Enschede COLLAGE model participants could 
choose between a total of seven different options for renewable wind and solar energy, all having a different intensity and representing different levels of visual and environmental impacts (Table 4). Solar panels on roofs could be assigned in three different intensities of $100 \%, 60 \%$ and $30 \%$ coverage of the rooftop. Intensive solar parks represent a land use exclusively for solar energy production, while extensive solar parks allow a combined land use of solar energy production and, for example, meadow. The two different types of wind turbines of $193 \mathrm{~m}$ and $134 \mathrm{~m}$ tip height represent the wind turbine models most commonly used in the area and therefore most likely to be known to the participants. The different renewable-energy types and options and their respective energy productivity used for calculating the outcome indicators (see above) are given in Table 4. The outcome indicator total renewable energy is calculated based on the total number of wind turbines times their specific energy productivity; plus the total area of solar parks times their specific energy productivity; plus the total number of solar panels of all selected buildings times specific energy productivity divided by the selected options $(100 \%, 60 \%, 30 \%)$.

Table 4. Renewable-energy options in the COLLAGE tool for Enschede.

\begin{tabular}{ccc}
\hline Type of Renewable Energy & Option & Energy Productivity \\
\hline solar panels on roofs & $100 \%^{1}$ & $240 \mathrm{w}$ per panel \\
& $60 \%{ }^{1}$ & $240 \mathrm{w}$ per panel \\
\multirow{2}{*}{ solar parks } & $30 \%^{1}$ & $240 \mathrm{w}$ per panel \\
& intensive & $835 \mathrm{MWh}$ per ha \\
wind turbines & extensive & $500 \mathrm{MWh}$ per ha \\
& $193 \mathrm{~m}$ turbine & $8300 \mathrm{MWh}$ per turbine \\
& $134 \mathrm{~m}$ turbine & $4800 \mathrm{MWh}$ per turbine \\
\hline \multicolumn{3}{c}{}
\end{tabular}

\subsection{The Enschede COLLAGE Workshops}

Three stakeholder workshops using the COLLAGE tool were conducted in Enschede between November 2016 and January 2017, hosting in total 35 participants. All three workshops addressed different target groups within the citizenry. The first workshop, hosting in total 15 participants, was an open workshop to which all citizens were invited. The second workshop, with 12 participants, focused particularly on citizens that were already somewhat engaged in local energy and/or sustainability initiatives in Enschede. The third workshop involved eight local policy-makers from the different parties represented on the city council of Enschede. The participants of the first workshop had signed up for it via the project website. Participants for the second workshop were recruited using existing contacts to local energy and sustainability groups. For the third workshop, we invited the members of the city council. The first workshop included three groups of five participants each, whilst the other two workshops both included two parallel groups. Each group worked on one maptable, i.e., in total, results from seven groups of stakeholders were used in this analysis.

All workshops were designed for a duration of approximately $2.5 \mathrm{~h}$. During the workshops, the stakeholders were asked to work on a couple of tasks in various sessions. The sequence of workshop sessions and tasks was a priori designed and tested in a series of test workshops. In all sessions, the groups were asked to discuss potential locations for the installation of renewable energy in Enschede, and subsequently to allocate the respective energy options as available in the model (see above). For orientation of the participants the system displayed the goals in terms of renewable-energy production to be achieved during the single sessions based on the $12 \%$ goal of renewable energy for Enschede.

After an introduction to the Enschede wekt op campaign, the workshops' goals and the renewable-energy context in the city, the participants were asked to complete a short exercise on the maptable in order to understand and learn the functioning of the COLLAGE tool. After that, the participants worked in two subsequent sessions of approx. $30 \mathrm{~min}$ on the allocation of renewable 
energy. The first session focused on the allocation of solar panels on rooftops in the urban built-up core of Enschede. Therefore, the participants were asked to select one neighborhood that they were already familiar with. After selection, the system displayed the goal in terms of renewable energy based on the overall goals of the city of Enschede broken down to the share of energy consumption in that neighborhood in 2015, i.e., $12 \%$ of the consumption of electricity in that neighborhood in 2015.

The second session focused on the allocation of solar parks and wind turbines on the outskirts and in rural area of Enschede, thus covering the entire area of Enschede. The goal-setting for this session was in total 330,000 MWh renewable energy for wind and solar. This represented $12 \%$ of the total energy consumption in Enschede in 2015, minus the share that is potentially to be derived from biogas, as this source of renewable energy is also relevant for Enschede but is not yet included in the model. Towards the end of the workshop, the groups reported the results of the sessions, and the main issues discussed, back to the plenary.

All mapping sessions were supported by a moderator and a chauffeur on each maptable, which has proven to be useful when carrying out interactive mapping sessions on a maptable [33]. The moderator facilitates and structures the mapping sessions by guiding the process, asking the right questions and making sure that all members of the group participate actively. The chauffeur is responsible for supporting the mapping when technical issues occur with respect to the table, helping with the handling of the socio-technical tool.

In order to analyze the outcomes of the workshops and the usability and applicability of the tool, we employed a combination of different data collection and analytical methods. All participants answered a questionnaire including questions on their perception of renewable energy, the usability of the tool, and some socio-demographic factors at the end of the workshop. The questionnaire (Appendix A) included 5-point Likert scales and also open-ended questions. For all mapping sessions, screen and voice recording was implemented in order to capture the interactions of the participants with the tool together with their arguments and reasoning. Protocols from workshop observations prepared by a workshop observer were used to support findings from the analysis of the screen captures and voice recordings. SPSS (version 24) was used to analyze the results from the questionnaire. Listening to the recordings of the mapping sessions, we transcribed the main issues mentioned by the various participants.

\section{Results}

This report of the results from the Enschede COLLAGE workshops starts with the perceptions and preferences of the participants towards renewable energy. In considering these factors, we distinguish between the participants who had already installed some type of renewable energy at their own home and those who had not, assuming that participants belonging to the first group have a more positive attitude, in general, towards renewable energy. We then report the results and outcomes of the mapping sessions and conclude with a discussion of the lessons learned from the mapping sessions.

\subsection{Participants' Profile and Perception of Renewable Energy}

The profile of the workshop participants and their perceptions and preferences towards renewable energy is based on a total of 35 questionnaires completed by the participants in the three workshops conducted between November 2016 and January 2017. Of the 35 respondents, 91\% (32 respondents) lived in their own house in Enschede and only two lived in a rented house (1 participant did not provide an answer). A majority of 13 respondents (37\%) lived in district south, followed by 7 participants from Centrum and 6 from Oost, 4 participants each from districts Noord and West, and one participant did not live in Enschede. The vast majority of participants were aged 31-50 years (12 respondents) or 51 to 65 years (10 participants); 2 participants were younger than 18, 5 between 18 and 30 years old, and 6 above 65 years. The self-reported average monthly household income of more than $50 \%$ of the participants was between $€ 3000$ and $€ 3999$ ( 7 respondents) or higher than $€ 4000$ (12 participants). 
Only two participants reported an average monthly household income of less than $€ 2000$ and five had an income of $€ 2000-2999$. Nine respondents did not provide details on their income situation.

The sample of Enschede citizens that participated in the workshops shows a reasonable distribution in terms of age as well as place of residence, as all age groups and districts of Enschede are represented. On the other hand, the sample is rather skewed towards citizens with a higher average income and home owners, both items presumably being correlated to one another. In any case, while the sample used in this study does not allow any conclusions in relation to the city as a whole or inferences based on statistical analysis such as correlations, it is broad enough to analyze qualitatively how the work with the COLLAGE tool affects preferences and knowledge about renewable energy.

The majority of participants in the workshops showed a generally positive attitude towards renewable energy. Almost half of the participants (16 respondents, $45 \%$ ) reported that they had some sort of renewable energy installed already, most of them having solar panels on their homes. Regarding the question of what they personally think the share of renewable energy in Enschede in 2030 should be (in steps of $5 \%$ between $0 \%$ and $100 \%$ ), answers varied between $5 \%$ and $100 \%$, with an average value of $33 \%$ and a median of 30\%, hence far higher than the target set by the city of Enschede. The range of values shows, on the one hand, the diversity of participants' attitudes towards renewable energy, but on the other hand a generally positive attitude towards renewable energy among the majority of participants.

Regarding the participants' perception of the potential benefits of renewable energy, most participants agreed that renewable energy is a good option for reducing GHG emissions ( $97 \%$ agreement) and that renewable energy helps secure the energy supply for the future $(82 \%$ agreement). However, the argument that the costs and benefits of renewable energy should be kept local receives the lowest levels of agreement and $42 \%$ disagreement, revealing that the argument for local engagement in the development and management of renewable-energy projects [30] is not shared among the majority of participants. Comparing the group of participants who had already had some type of renewable (mostly solar) energy source installed with the participants who had not, shows similar attitudes towards the pros and cons of renewable energy in both groups (Figure 4). However, those participants who had already personally invested in renewable installations reveal a slightly more positive attitude for all five arguments tested.

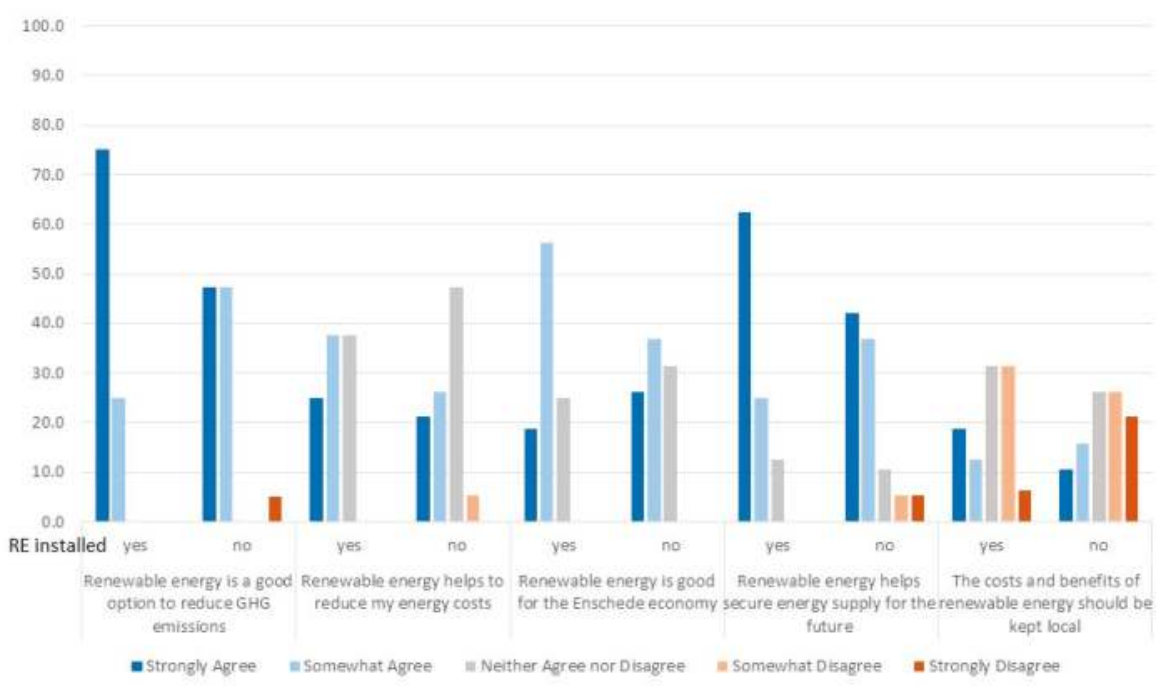

Figure 4. Participants' perception of renewable energy. 
While the participants in the three workshops are very similar in their positive perception of renewable energy as a means of reducing GHG emissions, as well as in their rather reluctant perception of the possibilities of localizing the energy costs and benefits, the policy-makers participating in the third workshop were significantly more positive towards the role of renewable energy for the Enschede economy and for securing the city's future energy supply. Moreover, the participants of the third workshop supported the statement that the costs and benefits of renewable energy should be kept local, while in the other two workshops levels of agreement were significantly lower. We can conclude from this finding that the important issue of costs and (local) benefits from renewable energy is not yet properly addressed in the COLLAGE tool. This might can be improved by adding further outcome indicators such as costs and benefits.

The participants' preference for different renewable-energy options clearly favors solar energy, with a total of $94 \%$ support. Wind energy, on the other hand, is the most debated type of renewable in Enschede. While $51 \%$ of the participants support wind energy to a greater or lesser extent, another $31 \%$ oppose this for Enschede to some extent. Comparing again the group of participants who already have some type of renewable-energy source installed with the participants who have not does not reveal significant differences in perception (Figure 5). Both groups are overwhelmingly positive towards solar energy and show likewise mixed preferences towards wind, with the group not having installations being slightly more positive with a total of $58 \%$ of respondents showing strong or mild agreement compared to $44 \%$ of the other group. The policy-makers from the third workshop were again more open towards wind energy for Enschede, showing $85 \%$ agreement. Interestingly, in contrast to the other two groups, they also see biomass as a potential source of renewable energy for Enschede ( $85 \%$ support).

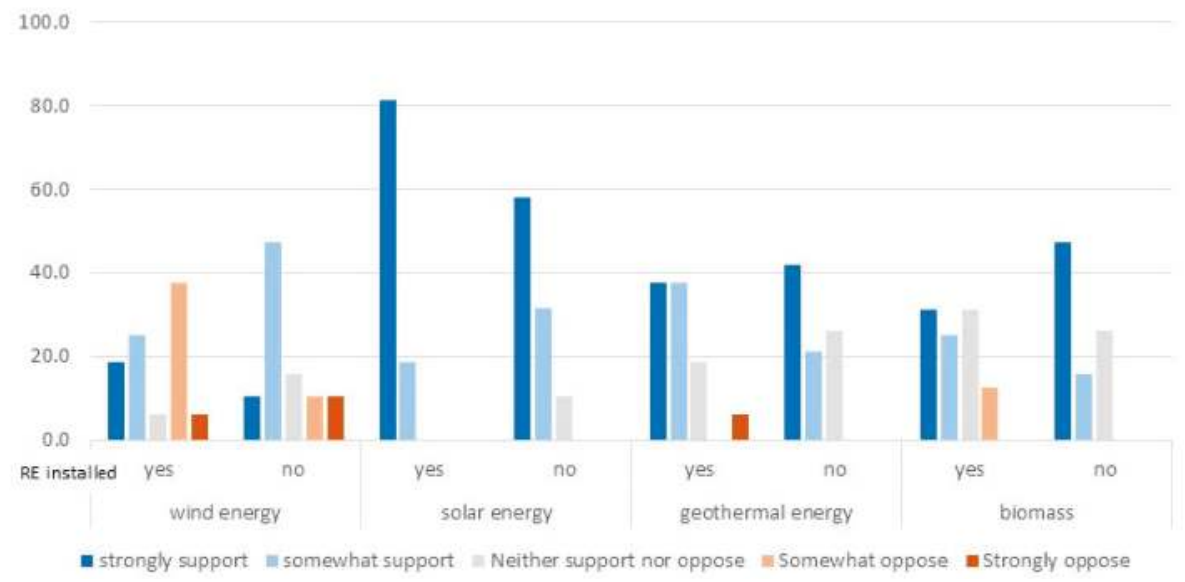

Figure 5. Participants' preference for types of renewable energy.

\subsection{Results of the Collaborative Mapping Sessions}

During the first mapping session, most groups did not achieve the neighborhood goals in terms of renewable-energy implementation by allocating solar panels on suitable roofs. During the second session, focusing on the entire city, all groups managed to achieve the given goal of $330.000 \mathrm{MWh}$ of renewable-energy implementation, mostly via the allocation of several wind turbines and/or large scale solar parks. In relation to this, it needs to be mentioned that during the mapping sessions various groups focused during the second session more on achieving the given goals rather than on an eventually conflicting discussion of potential locations, thereby limiting the relevance of the results as an input to spatial planning of renewable-energy projects. On the other hand, several groups 
acknowledged during the mapping sessions that a mix of various renewable-energy sources was needed for Enschede in order to achieve the goals set, thereby achieving the goal of social learning about renewable energy for Enschede during group activities.

Several groups identified similar locations for wind turbines and solar parks. Areas suitable for solar farms preferred by most groups were the green areas along the highway (A35) that cuts through Enschede in a west-east direction, the abandoned airport area in the north, and the Usseler Ess, a highly contested area on the south-west border of the built-up core that is owned by the municipality and had already been proposed as a solar park. This shows a high level of agreement between the participants in terms of locations for solar parks.

The choice of locations for wind turbines was limited due to the small area suitable for wind turbines in any event, so the allocations of the separate groups were rather similar in this area as well. In general, the majority of groups favored locations for wind turbines within existing industrial areas rather than in agricultural areas in order to preserve the more natural land. Five groups earmarked a cluster of wind turbines in the industrial area of Twence in the west of Enschede and, similarly, 4 groups located wind turbines within the industrial area of Maarsteden. Additionally, 4 of the 8 groups located some wind turbines close to the recreation area Het Ruitbeek in the south of Enschede. In terms of solar rooftops, the main conclusions from the mapping sessions were to use, predominantly and where possible, industrial buildings rather than private housing because of higher efficiency; and to engage with the local housing cooperative for setting up solar, because it owns a large amount of the apartment housing in Enschede.

Other general statements derived from the workshop sessions stated that, in principle, the majority of the participants preferred solar options over wind because of the lower visual impact on the landscape; while some other participants acknowledge, based on the outcomes of the mapping sessions, that a combination of both is the most logical option. Agreement exists among the participants that the municipality should promote participation in the projects that move forward.

\subsection{Lessons Learned}

The analysis of the lessons learned by the participants in the sense of social learning is essentially derived from the recordings of the group discussions during the mapping sessions. One major lesson the participants learned from the workshop sessions was that it is almost impossible to achieve the goals within single neighborhoods and based purely on solar rooftops. They also learned that using solar panels to fill single locations within Enschede, that have already been the subject of lengthy discussions, such as the airport or the Usseler Ess, would not be enough to achieve the targets. Likewise, a solution such as that favored by many groups of putting solar panels along the highways provides only a very small amount of the overall energy needed. Additional issues that were discussed showed that while big roofs are potentially more efficient for setting up solar panels, many roofs are simply not strong enough to hold the necessary construction.

With respect to the implementation of wind turbines, participants learned that a single turbine may provide a significantly higher amount of renewable energy compared to installations of solar rooftops but also compared to the same space covered with solar farms. However, in this context, some participants remarked on the much stronger visual impact of the wind turbines on the landscape, as they can be seen from far away. In summary, the main conclusion derived from the workshops for many participants was that a mix of solar and wind is the most logical option in order to achieve the renewable-energy goals set by the municipality.

Having said this, it became obvious that the choice of locations is crucial while working on achieving the energy goals. Here the COLLAGE tool was perceived as very positive by the overwhelming number of participants. Various forms of social learning were reported by the participants (Figure 6). More than $85 \%$ of all participants stated that the session helped them to get to know the views of others on renewable energy. More than $80 \%$ agreed that they were able to 
share their views on renewable energy with the other participants during the workshops. Finally, almost $75 \%$ claimed that they had learned something about renewable energy during the workshop.

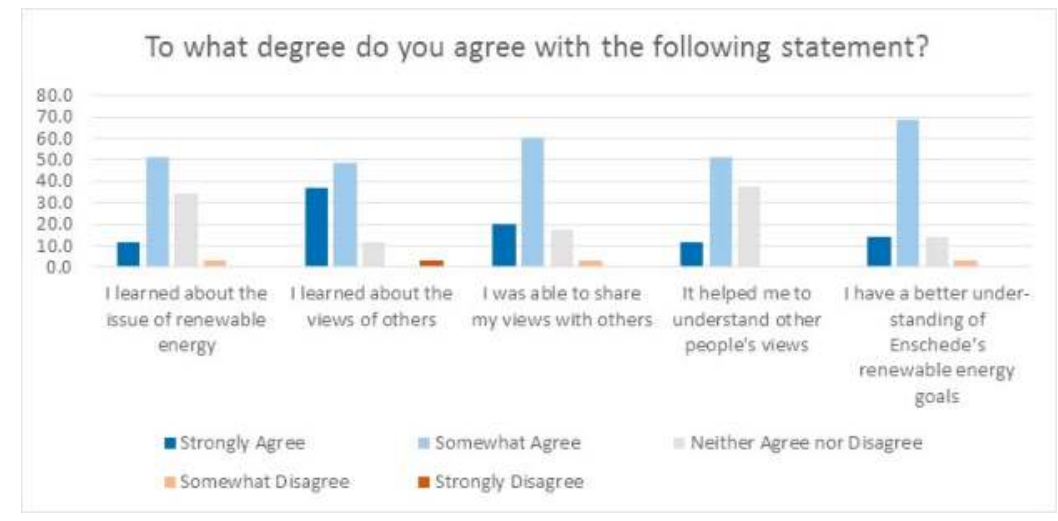

Figure 6. Lessons learnt by the participants.

The main added value of the tool as seen by the participants was that it allows better communication $(27.1 \%)$ and that it helps to obtain more informed results $(33.3 \%)$. Regarding the usability of the tool (Figure 7), the majority of participants claimed that the COLLAGE tools were transparent (74.3\% of agreement along participants), user friendly (62.9\% agreement), and provided a good level of detail $(60 \%)$. In addition, the level of guidance provided by the mediator and the chauffeur during the mapping session was perceived as positive by the overwhelming majority ( $91 \%)$.

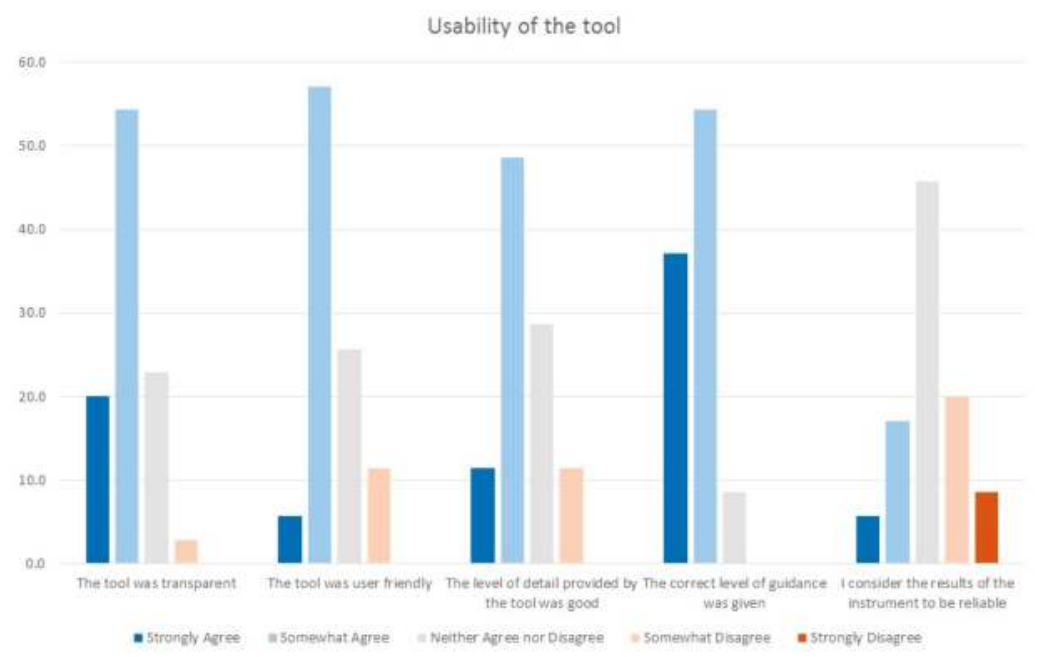

Figure 7. Usability of the COLLAGE tool.

The results of the tool, however, were not perceived as reliable by about $30 \%$ of the participants (Figure 7, final item on the right). This somewhat surprising finding refers mainly to the mapping results on the tables, as can be seen from a number of comments the participants made during the mapping sessions and in response to the open-ended questions in the questionnaire. The main issues 
mentioned with respect to limited reliability were that the tool should also include other types of renewable-energy sources such as biogas, geothermal energy or hydropower in order to be more realistic and, therefore, reliable; and that the role of storage of energy is unclear and also needs to be considered. Moreover, a few participants claimed that, given the limited options for renewable energy available in Enschede (see above), this type of trade-off process should be carried out at the national level given that there are more options available.

In summary, we can conclude that the majority of participants perceived the COLLAGE tool and workshop sessions to be very useful for understanding and learning about requirements, options, and limitations of renewable energy in general as well as for Enschede specifically. On the other hand, the mapping results were perceived as less valuable and reliable, although the process of collaborative mapping was essential for achieving the envisaged goals of social learning about renewable energy.

\section{Discussion and Conclusions}

Rogers et al. [34] found, for the UK, that "community-based renewable-energy projects, with high levels of public participation, are more likely to be accepted by the public than top-down development of large-scale schemes". Other authors $([11,12,14]$ stress the importance of local governments for a successful transition to renewable-energy sources. Taking both arguments together, it becomes obvious from the empirical results obtained during the workshops in Enschede that the COLLAGE tool can be an important building block towards a new local energy governance [19], helping to overcome known barriers of community-related social acceptance as identified by Sovacool and Lakshmi Ratan [8]. Checking against the authors' framework (see Section 1): the COLLAGE tool helps to involve people and communities in the decision to site or permit renewable-energy facilities; and it helps to make community members aware of the benefits of, but also the requirements for, renewable energy by disclosing the spatial consequences of overall municipal goals.

\subsection{Added Value of the COLLAGE for Engaging with Communities in Renewable-Energy Planning}

The COLLAGE tool serves a public dialogue that addresses systematic aspects of future energy systems by providing what Devine-Wright [10] calls "a basis for creating a social contract on technical change". The interactive nature of the tool allows users to explore the consequences of various renewable-energy technologies and the mix of energy sources. In that sense it allows flexibility in experiencing how to achieve a given goal [35]. The spatial approach of the tool, with the flexibility to zoom into various locations, allows citizens to demarcate place-related identities, which often leads to oppositional behavior [10] if they are not considered while siting renewable-energy projects.

Several participants stated at the end of the workshops that they had learned quite a lot about the benefits of renewable energy. They were involved in a general discussion of locations, which could also serve as a basis for further involvement in concrete siting decisions of single renewable-energy projects. Participants indicated that they had gained a better understanding of what it meant for Enschede, and were consequently more willing to accept renewable-energy projects.

An interesting finding is that the participants in the workshops were obviously more ambitious in defining goals for renewable-energy production in Enschede than the city administration was in its sustainability strategy [28], which was based on a study of technical feasibility with respect to renewable energy [30]. The average goal of the workshop participants of 33\% from renewable energy (see above) is based on a total of only 35 participants, and is therefore clearly not representative for the city of Enschede as a whole. However, it should be emphasized that it was far from the case that only pro-renewable energy citizens participated, as the participants also included citizens who were critical of renewable energy. In addition, the mapping results show that the majority of participants were able to envisage the allocation of more space for renewable energy than that which is needed to achieve the $12 \%$ goal in 2030 . One can conclude that conducting such citizen workshops using the COLLAGE tool prior to developing a local renewable-energy strategy or setting particular goals might be a useful 
addition to the usual studies, surveys, or information campaigns, in order to better capture and reflect citizens' perceptions and ideas.

If this approach is taken, stakeholders as well citizens can be involved from the early phase of local energy planning onwards, not merely looking at single project sites but developing an overall city strategy. In the case of the city of Enschede, the workshops' results, as well as the outcomes and findings of other activities conducted during the Enschede wekt op campaign, were summarized in a policy document for the entire city [32]. Based on such a renewable-energy strategy, potential co-operations for single locations or projects might be identified involving local actors as well as potential investors and developers to jointly develop so-called community renewable-energy projects [36]. Walker et al. [37] found, for the UK, that mutual trust between investors and developers of renewable-energy projects and local communities is a crucial prerequisite for a successful implementation of renewable-energy projects. Moreover, mechanisms are needed for partner identification at an early stage and within a stable and supportive policy context [38]. Interactive workshops involving all three groups could serve as a suitable mechanism for achieving such requirements.

\subsection{Limitations of the COLLAGE Tool and Workshops}

A limitation of the model in its current form that became apparent during the workshops is that the participants often focused during the mapping sessions more on achieving the given goals in terms of renewable-energy production than on a critical and eventually conflicting discussion of potential locations for renewable-energy installations. Rather than discussing each single location in detail, it could be observed that some locations were mapped without much discussion in order to reach a certain amount of renewable energy. In the context of serious gaming, Harteveld et al. [39] describe this as the reflection dilemma that occurs when players, in our case the participants, forget the real world and focus on the world that is unravelling on the screen, i.e., the maptable, and this immersion detracts from the potential meaning. A potential way to overcome or at least mitigate this in the COLLAGE model would be to add other indicators to the model, particularly those that do not count only benefits, such as renewable energy produced, but also costs, such as loss of natural area, or other environmental impacts caused by the interventions. A cost-benefit calculation could also be a valuable add-on. If more trade-offs become visible, it will lead in turn to more serious interactions, discussions and mapping activities.

Another limitation of the model is that it can only host a limited number of participants, i.e., large-group participation would not be possible using the model. More maptables could be used to serve larger groups of participants, but that would also require more moderation, facilitation and technical support. Alternatively, the COLLAGE model could be applied in an analogue modus with participants working on large-scale paper maps and placing solar farms and wind turbines onto the map by means of Lego bricks and pawns from a board game. In doing so, potentially larger groups of participants could be involved. With such an analogue COLLAGE approach, the digital divide between different age groups in terms of computer and communication technology literacy could be addressed. In our workshops, we observed that younger participants were on average much faster at learning and applying the COLLAGE tool than the significantly older participants. However, the downside of such an analogue COLLAGE approach would be that all the advantages resulting from the digital approach would be lost, such as zooming into locations on the interactive maptable and the on-the-fly calculation of outcome indicators. Consequently, the goals of analogue COLLAGE workshops would have to be adapted.

Finally, one limitation that became obvious during the mapping sessions was the lack of data included in the model. An obviously useful layer of information would be to know which buildings are constructed in a manner suitable for solar rooftops and which are not. Other layers of data and information that could be added to improve the model would be the spatially different wind capacity or the quality or fertility of the soil on the agricultural land. This would enable a better assessment 
of how much wind can be harvested where and at what cost, hence addressing a further trade-off in addition to those discussed above.

The analysis of workshop results could have benefitted if the participants had been interviewed prior to the workshop as well as afterwards. This was not possible for logistical reasons, as the participants were not asked to give their email addresses while registering for the workshops. With such information, changes in attitudes towards renewable energy could have been attributed much more clearly to the COLLAGE tool and workshop. However, it should be recognized that citizens' environmental positions and attitudes only change slowly and over long periods of time, but not necessarily within a two-hour workshop. We can conclude that stakeholders as well as citizens should ideally be involved in a series of workshops with the COLLAGE tool; not only to fully understand and utilize the benefits of the tool, but also in order to contribute to the concrete development and roll out of the tool for a specific location and context in the sense of a participatory, stakeholder-based modelling process [40] that helps increase the quality, and thereby legitimacy, of the models as well as triggering collaborative learning effects.

\subsection{Further Research Needs}

There is a general consensus among scholars that, in order to increase the implementation of renewable-energy projects for combatting climate change, an improved engagement and participation of the public and stakeholders needs to be achieved $[10,11]$. In this paper we describe the COLLAGE tool that is designed for involving stakeholders in the participatory mapping of renewable-energy locations. Using the city of Enschede in The Netherlands, where we conducted stakeholder workshops for locating wind turbines and solar panels, we have shown that the model helps to increase awareness for renewable energy and triggers social learning about renewable energy among the local stakeholders and citizens.

To fully support local energy governance [19], the tool would need to be extended to include other types of renewable energy. While in Enschede wind and solar are the dominant forms of renewable energy, biogas or geothermal energy can also be elements of a renewable-energy strategy in other cities and countries. Moreover, other outcome indicators resulting from the various allocations of renewable-energy projects and indicating varying impacts, cost and benefits, thereby illustrating potential trade-offs, would need to be added to the model.

In order to enhance the usability of the COLLAGE tool, a potentially useful addition might be to add a 3D visualization on the second screen to the 2D map on the maptable, as not all participants are able to read 2D maps well. Hettinga [41] discussed that when presenting information on renewable-energy measures to be implemented in a 3D environment that is recognizable as their own neighbourhood, participants can better relate the information presented to this environment. In particular, the aesthetic impact of wind turbines on the landscape could be visualized more clearly in a 3D environment.

Acknowledgments: The authors would like to thank the city of Enschede for funding the workshops and providing data, and particularly Ed van't Erve, Hanneke Spoler, Henk Visser and Benny Schulte Lubberink from the city of Enschede for participating in the development of the COLLAGE model and tool. We also thank the citizens of Enschede for actively participating in the workshops. Thanks also goes to Frans van den Bosch, Christian Kempf, Rehana Shrestha, Carissa Champlin, and Inge Kaarbat for helping with the implementation of the workshops; Johannes Flacke thanks Heike Köckler for providing useful comments on a draft version of the paper; and Juliet Wilson for careful proofreading of the manuscript. We thank the anonymous reviewers for providing useful comments in order to improve the paper. Finally, we thank the PGM department of ITC/UT, particular our colleagues and students who participated in the test workshops and thereby helped in developing the COLLAGE tool.

Author Contributions: Cheryl de Boer and Johannes Flacke jointly initiated the study, conceptualized the COLLAGE model and tool and conducted the workshops. Johannes Flacke developed and implemented the COLLAGE tool, analyzed the spatial and statistical results, facilitated the workshop session and wrote the text. Cheryl de Boer moderated the workshops and contributed to the analysis of the workshop results.

Conflicts of Interest: The authors declare no conflict of interest. 


\section{Appendix A}

\section{Questionnaire}

This survey is part of a workshop on renewable energy in Enschede. Your participation will be a great help to us. The responses will be kept anonymous. They will be used to gain a better understanding of the participants' perception of renewable energy in Enschede and the usability of the tools used in the workshop. In addition, summarized data will be provided to the Municipality of Enschede to use to evaluate the workshop session. Please complete this survey before you leave tonight.

Thank you for your participation!

\section{Part 1: Renewable Energy for Enschede}

1. Your general perception of renewable energy. How much do you agree with the following statements?

\begin{tabular}{|c|c|c|c|c|c|c|}
\hline & & $\begin{array}{l}\text { Strongly } \\
\text { Agree }\end{array}$ & $\begin{array}{l}\text { Somewhat } \\
\text { Agree }\end{array}$ & $\begin{array}{l}\text { Neither } \\
\text { Agree nor } \\
\text { Disagree }\end{array}$ & $\begin{array}{l}\text { Somewhat } \\
\text { Disagree }\end{array}$ & $\begin{array}{l}\text { Strongly } \\
\text { Disagree }\end{array}$ \\
\hline 1 & $\begin{array}{l}\text { Renewable energy is a good option } \\
\text { to reduce GHG emissions }\end{array}$ & $\square$ & $\square$ & $\square$ & $\square$ & $\square$ \\
\hline 2 & $\begin{array}{l}\text { Renewable energy helps to reduce } \\
\text { my energy costs }\end{array}$ & $\square$ & $\square$ & $\square$ & $\square$ & $\square$ \\
\hline 3 & $\begin{array}{l}\text { Renewable energy is good for the } \\
\text { Enschede economy }\end{array}$ & $\square$ & $\square$ & $\square$ & $\square$ & $\square$ \\
\hline 4 & $\begin{array}{l}\text { Renewable energy helps secure } \\
\text { energy supply for the future }\end{array}$ & $\square$ & $\square$ & $\square$ & $\square$ & $\square$ \\
\hline 5 & $\begin{array}{l}\text { The costs and benefits of renewable } \\
\text { energy should be kept local }\end{array}$ & $\square$ & $\square$ & $\square$ & $\square$ & $\square$ \\
\hline
\end{tabular}

2. The total energy consumption of Enschede is predicted to be $3.000 .000 \mathrm{MWh}$ in 2030. How much do you think Enschede should plan to produce itself with renewable energy (on a scale from 0-100\%)

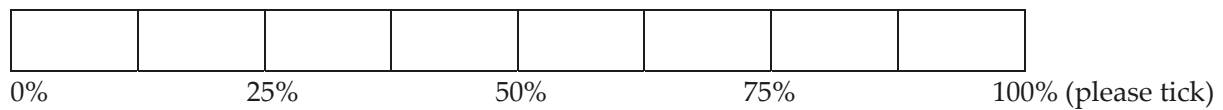

3. What is your opinion on the following renewable energy sources for Enschede?

\begin{tabular}{llllll}
\hline & $\begin{array}{l}\text { Strongly } \\
\text { Support }\end{array}$ & $\begin{array}{l}\text { Somewhat } \\
\text { Support }\end{array}$ & $\begin{array}{l}\text { Neither Support } \\
\text { nor Oppose }\end{array}$ & $\begin{array}{l}\text { Rather } \\
\text { Oppose }\end{array}$ & $\begin{array}{l}\text { Strongly } \\
\text { Oppose }\end{array}$ \\
\hline $\mathbf{1}$ Wind energy & $\square$ & $\square$ & $\square$ & $\square$ & $\square$ \\
\hline $\mathbf{2}$ Solar energy & $\square$ & $\square$ & $\square$ & $\square$ & $\square$ \\
\hline $3 \quad$ Geothermal & $\square$ & $\square$ & $\square$ & $\square$ & $\square$ \\
\hline 4 Biomass & $\square$ & $\square$ & $\square$ & $\square$ & $\square$ \\
\hline 5 Other: & $\square$ & $\square$ & $\square$ & $\square$ & $\square$ \\
\hline
\end{tabular}

4. Do you have any renewable energy systems installed in your house in Enschede already?

$\square$ Yes $\square$ no

If yes, what kind: 
Part 2: The renewable energy workshop and the maptable tool

1. What do you consider to be the most important value of the tool (select one)

$\square$ better communication $\square$ better cooperation $\square$ more efficient work $\square$ more informed result $\square$ none $\square$ Other, namely

2. To what degree do you agree with the following statement?

\begin{tabular}{lllllll}
\hline & $\begin{array}{l}\text { Strongly } \\
\text { Agree }\end{array}$ & $\begin{array}{l}\text { Somewhat } \\
\text { Agree }\end{array}$ & $\begin{array}{l}\text { Neither } \\
\text { Agree nor } \\
\text { Disagree }\end{array}$ & $\begin{array}{l}\text { Somewhat } \\
\text { Disagree }\end{array}$ & $\begin{array}{l}\text { Strongly } \\
\text { Disagree }\end{array}$ & $\begin{array}{l}\text { Don't } \\
\text { Know/na }\end{array}$ \\
\hline $\mathbf{1} \begin{array}{l}\text { I learned about the issue } \\
\text { of renewable energy }\end{array}$ & $\square$ & $\square$ & $\square$ & $\square$ & $\square$ & $\square$ \\
\hline $2 \begin{array}{l}\text { I learned about the views } \\
\text { of others }\end{array}$ & $\square$ & $\square$ & $\square$ & $\square$ & $\square$ & $\square$ \\
\hline $3 \begin{array}{l}\text { I was able to share my } \\
\text { views with others }\end{array}$ & $\square$ & $\square$ & $\square$ & $\square$ & $\square$ & $\square$ \\
\hline $\begin{array}{l}\text { It helped me to } \\
\text { understand other } \\
\text { people's views }\end{array}$ & $\square$ & $\square$ & $\square$ & $\square$ & $\square$ & $\square$ \\
\hline $\begin{array}{l}\text { I have a better } \\
\text { understanding of } \\
\text { Enschede's energy goals }\end{array}$ & $\square$ & $\square$ & $\square$ & $\square$ & $\square$ \\
\hline
\end{tabular}

3. Questions on usability of the tool

\begin{tabular}{lllllll}
\hline & $\begin{array}{l}\text { Strongly } \\
\text { Agree }\end{array}$ & $\begin{array}{l}\text { Somewhat } \\
\text { Agree }\end{array}$ & $\begin{array}{l}\text { Neither } \\
\text { Agree nor } \\
\text { Disagree }\end{array}$ & $\begin{array}{l}\text { Somewhat } \\
\text { Disagree }\end{array}$ & $\begin{array}{l}\text { Strongly } \\
\text { Disagree }\end{array}$ & $\begin{array}{l}\text { Don't } \\
\text { Know/na }\end{array}$ \\
\hline $\mathbf{1} \quad$ The tool was transparent & $\square$ & $\square$ & $\square$ & $\square$ & $\square$ & $\square$ \\
\hline $\mathbf{2} \quad$ The tool was user friendly & $\square$ & $\square$ & $\square$ & $\square$ & $\square$ & $\square$ \\
\hline $3 \quad \begin{array}{l}\text { The level of detail provided } \\
\text { by the tool was good }\end{array}$ & $\square$ & $\square$ & $\square$ & $\square$ & $\square$ \\
\hline $\begin{array}{l}\text { The correct level of guidance } \\
\text { was given }\end{array}$ & $\square$ & $\square$ & $\square$ & $\square$ & $\square$ & $\square$ \\
\hline $\mathbf{5}$ & $\begin{array}{l}\text { I consider the results of the } \\
\text { instrument to be reliable }\end{array}$ & $\square$ & $\square$ & $\square$ & $\square$ & $\square$ \\
\hline
\end{tabular}

4. What was the most important thing that you learned during the workshop?

5. Please provide any general comments about the workshop or the computer tool below. (optional) 


\section{Part 3: About you}

1. Age group: $\square<18$ years $\square 18-30$ years $\square 31-50$ years $\square 51-65$ years $\square>65$ years

2. Where do you live in Enschede? $\square$ Centrum $\square$ Noord $\square$ Oost $\square$ West $\square$ Zuid $\square$ not in Enschede

3. What kind of property do you live in? $\square$ own house $\square$ rented house $\square$ flat/apartment $\square$ Other [Please explain:

4. What was the average gross monthly income of your household in the last year (in euros)?

$\square<1.000 \square 1.001-1.999 \square 2.000-2.999 \square 3.000-3.999 \square>=4000$

\section{References}

1. United Nations Framework Convention on Climate Change (UNFCC). Adoption of the Paris Agreement; UNFCC: Paris, France, 2015.

2. European Commission. The Roadmap for Transforming the EU into a Competitive, Low-Carbon Economy by 2050; European Commission: Brussels, Belgium, 2012.

3. Reckien, D.; Flacke, J.; Dawson, R.J.; Heidrich, O.; Olazabal, M.; Foley, A.; Hamann, J.J.-P.; Orru, H.; Salvia, M.; Gregorio Hurtado, S.; et al. Climate change response in Europe: What's the reality? Analysis of adaptation and mitigation plans from 200 urban areas in 11 countries. Clim. Chang. 2014, 122, 331-340. [CrossRef]

4. Eurostat. Renewable Energy Statistics. Available online: http://ec.europa.eu/eurostat/statistics-explained/ index.php/Renewable_energy_statistics (accessed on 17 July 2017).

5. Breukers, S.; Wolsink, M. Wind energy policies in The Netherlands: Institutional capacity-building for ecological modernisation. Environ. Politics 2007, 16, 92-112. [CrossRef]

6. Devine, W.P. Renewable Energy and the Public: From NIMBY to Participation; Earthscan: Milton Park, UK, 2011.

7. Wüstenhagen, R.; Wolsink, M.; Bürer, M.J. Social acceptance of renewable energy innovation: An introduction to the concept. Energy Policy 2007, 35, 2683-2691. [CrossRef]

8. Sovacool, B.K.; Lakshmi Ratan, P. Conceptualizing the acceptance of wind and solar electricity. Renew. Sustain. Energy Rev. 2012, 16, 5268-5279. [CrossRef]

9. Devine-Wright, P.; Batel, S.; Aas, O.; Sovacool, B.; Labelle, M.C.; Ruud, A. A conceptual framework for understanding the social acceptance of energy infrastructure: Insights from energy storage. Energy Policy 2017, 107, 27-31. [CrossRef]

10. Devine-Wright, P. Public engagement with large-scale renewable energy technologies: Breaking the cycle of NIMBYism. WIREs Clim. Chang. 2011, 2, 19-26. [CrossRef]

11. Breukers, S.; Wolsink, M. Wind power implementation in changing institutional landscapes: An international comparison. Energy Policy 2007, 35, 2737-2750. [CrossRef]

12. Fudge, S.; Peters, M.; Woodman, B. Local authorities as niche actors: The case of energy governance in the UK. Environ. Innov. Soc. Transit. 2016, 18, 1-17. [CrossRef]

13. International Energy Agency (IEA). Cities, Towns \& Renewable Energy: Yes In My Front Yard; IEA: Paris, France, 2009.

14. Mey, F.; Diesendorf, M.; MacGill, I. Can local government play a greater role for community renewable energy? A case study from Australia. Energy Res. Soc. Sci. 2016, 21, 33-43. [CrossRef]

15. Rittel, H.; Webber, M. Dilemmas in a general theorie of planning. Policy Sci. 1973, 4, 155-169. [CrossRef]

16. Head, B. Wicked Problems in Public Policy. Public Policy 2008, 3, 101-118.

17. Xiang, W.-N. Working with wicked problems in socio-ecological systems: Awareness, acceptance, and adaptation. Landsc. Urban Plan. 2013, 110, 1-4. [CrossRef]

18. Armitage, D.; Marschke, M.; Plummer, R. Adaptive co-management and the paradox of learning. Glob. Environ. Chang. 2008, 18, 86-98. [CrossRef]

19. Parag, Y.; Hamilton, J.; White, V.; Hogan, B. Network approach for local and community governance of energy: The case of Oxfordshire. Energy Policy 2013, 62, 1064-1077. [CrossRef]

20. Rogers, Y.; Lindley, S. Collaborating around vertical and horizontal large interactive displays: Which way is best? Interact. Comput. 2004, 16, 1133-1152. [CrossRef]

21. CommunityViz Software. Available online: http://communityviz.city-explained.com/communityviz/ index.html (accessed on 17 July 2017). 
22. Pelzer, P.; Geertman, S. Planning support systems and interdisciplinary learning. Plan. Theory Pract. 2014, 15, 527-542. [CrossRef]

23. Pelzer, P.; Geertman, S.; van der Heijden, R. A comparison of the perceived added value of PSS applications in group settings. Comput. Environ. Urban Syst. 2016, 56, 25-35. [CrossRef]

24. Shrestha, R.; Koeckler, H.; Flacke, J.; Martínez, J.A.; van Maarseveen, M. Interactive knowledge co-production and integration for healthy urban development. Sustainability 2017, under review.

25. Zonnekaart. Available online: https:/ / www.mapgear.nl/web/zonnekaart.html (accessed on 17 July 2017).

26. Aerial Photographs (Luchtfoto). Available online: https://geodata.nationaalgeoregister.nl/tiles/service/ wmts/lufolabels? (accessed on 18 October 2017).

27. Street Names, Regions, Districts (Luchtfoto Lables). Available online: https://geodata.nationaalgeoregister. $\mathrm{nl} /$ tiles/service/wmts/lufolabels? (accessed on 18 October 2017).

28. Available online: https://www.enschede.nl/sites/default/files/actieplan-duurzaamheid.pdf (accessed on 19 October 2017).

29. Energie in Beeld. Available online: http:/ / www.energieinbeeld.nl/ (accessed on 17 July 2017).

30. Energieonderzoek Centrum Nederland (ECN). Nationale Energieverkenning 2016; ECN Policy Studies: Amsterdam, The Netherlands, 2016.

31. Enschede Wekt Op. Available online: http://enschedewektop.nl/ (accessed on 17 July 2017).

32. Available online: https://www.enschede.nl/enschede-wekt-op-vertaald-naar-raadsvoorstel (accessed on 19 October 2017).

33. Pelzer, P.; Goodspeed, R.; Brömmelstroet, M.T. Facilitating PSS Workshops: A Conceptual Framework and Findings from Interviews with Facilitators. In Planning Support Systems and Smart Cities; Geertman, S., Ferreira, J., Goodspeed, R., Stillwell, J., Eds.; Springer: Heidelberg, Germany, 2015; pp. 355-369.

34. Rogers, J.; Simmons, E.; Convery, I.; Weatherall, A. Public perceptions of opportunities for community-based renewable energy projects. Energy Policy 2008, 36, 4217-4226. [CrossRef]

35. Barry, J.; Ellis, G. Beyond consensus? Agonism, republicanism and a low carbon future. In Renewable Energy and the Public: From NIMBY to Participation; Devine, W.P., Ed.; Earthscan: Milton Park, UK, 2011; pp. $29-42$.

36. Walker, G.; Devine-Wright, P. Community renewable energy: What should it mean? Energy Policy 2008, 36, 497-500. [CrossRef]

37. Walker, G.; Devine-Wright, P.; Hunter, S.; High, H.; Evans, B. Trust and community: Exploring the meanings, contexts and dynamics of community renewable energy. Energy Policy 2010, 38, 2655-2663. [CrossRef]

38. Goedkoop, F.; Devine-Wright, P. Partnership or placation? The role of trust and justice in the shared ownership of renewable energy projects. Energy Res. Soc. Sci. 2016, 17, 135-146. [CrossRef]

39. Harteveld, C.; Guimaraes, R.; Mayer, I.S.; Bidarra, R. Balancing Play, Meaning and Reality: The Design Philosophy of LEVEE PATROLLER. Simul. Gaming 2010, 41, 316-340. [CrossRef]

40. Voinov, A.; Bousquet, F. Modelling with stakeholders: Position paper. Environ. Model. Softw. 2010, 25, 1268-1281. [CrossRef]

41. Hettinga, S. Using a 3D Serious Game to Involve Citizens in Renewable Energy Transition Management; University of Twente: Enschede, The Netherlands, 2016.

(C) 2017 by the authors. Licensee MDPI, Basel, Switzerland. This article is an open access article distributed under the terms and conditions of the Creative Commons Attribution (CC BY) license (http:/ / creativecommons.org/licenses/by/4.0/). 


\title{
Article \\ The Governance Landscape of Geospatial E-Services-The Belgian Case
}

\author{
Maxim Chantillon ${ }^{1, *}$, Joep Crompvoets ${ }^{1}$ and Vassilios Peristeras ${ }^{2}$ \\ 1 KU Leuven Public Governance Institute, 3000 Leuven, Belgium; joep.crompvoets@kuleuven.be \\ 2 School for Science and Technology, International Hellenic University, 57001 Thermi, Greece; \\ v.peristeras@ihu.edu.gr \\ * Correspondence: maxim.chantillon@kuleuven.be; Tel.: +32-496-352-453
}

Received: 14 July 2017; Accepted: 21 August 2017; Published: 7 September 2017

\begin{abstract}
Geospatial data and geospatial e-services require governance and coordination between different governmental organisations. This article aims to understand what governance, and specifically what coordination, is used in Belgium for geospatial e-services and data. The Belgian case, with a focus on the regions and federal administration, is researched by making use of a document analysis, interviews with key stakeholders and an online survey. In contrast to the federal and Walloon administration, the Flemish administration and the Brussels Capital Region administration have a clearly developed governance model. Flanders combines hierarchy with network governance, whereas the Brussels administration is known for its hierarchical way of working. The transposition of the INSPIRE Directive had a strong influence: The Brussels Capital Region became more network-oriented, and the Walloon Region developed a form of network governance. The federal level, however, struggles to make the connection between geospatial data and e-services. From an inter-organisational perspective, the coordination can be labelled as a weak form of network governance: Cooperation exists, but only in a few areas. Nevertheless, geospatial data are exchanged within and between regions and the federal level. Geospatial e-services are also developed but there is a clear influence of the degree of organisational coordination on the development of geospatial e-services.
\end{abstract}

Keywords: e-services; geospatial data; governance; coordination; Belgium

\section{Introduction}

\subsection{Objective and Research Questions}

Geospatial data have high value for administrations, citizens and businesses. They have high potential for actors in various domains, and administrations often own a lot of data, sometimes without even realizing it [1]. Governments and administrations are today increasingly aware of the possibilities offered by technology and develop e-services for their internal relations and their relations with citizens and businesses. Those administrations often build on existing ways of working, and combine or build on existing technology. Affisco and Soliman [2], however, underlined that it is necessary to connect all the different e-services that have been developed since the beginning of the 21st century. Latre et al. [3] argue that 'the level of maturity or sophistication of e-government services is not improving in those areas that require geospatial information'. Furthermore, the authors underline that, although geospatial data are more and more available, 'their use and management is still more complex [ ... ] when compared to other kinds of data'. So, the focus of this article is on geospatial data and e-services, as the data are highly valuable and necessary for the development of geospatial e-services. 
In line with Affisco and Soliman [2], who argue that the islands of e-services need to be connected, the aim of the article is to understand what governance, and specifically what type of coordination, is used in the sector of geospatial data and e-services. Coordination is central as e-services have until now often been developed on an individual basis by organisations. In addition, the European Interoperability Framework highlights the importance of coordination: It underlines that organisational relations need to be clarified and formalised in order to develop and maintain e-services [4].

A number of specific research questions have been formulated on the basis of the research aim. A first research question is: "Who are the leading public sector actors with regards to geospatial e-services?" Based on this question, and bearing in mind that geospatial data are necessary for geospatial e-services, a second research question was formulated: "Who are the users and producers of geospatial data, and what is the source of origin of their data?" Thirdly, the coordination between the leading public sector actors will be analysed: "What types of coordination mechanisms are used in the field of geospatial data and e-services?" Finally, the fourth research question, "how can the current governance structures be explained?" aims to provide an explanation of the current situation concerning geospatial governance.

The Belgian administration has been selected as a case study. From a governance perspective, it is a highly interesting country to study as it has a dual federal structure whereby the creation of the federal structure was mainly the result of the unwillingness of two language groups (Dutch-speaking and French-speaking) to cooperate. The creation of a federal structure, however, reinforces this unwillingness, leading to a dual federal state. This makes the Belgian case interesting to study: A dual federal state needs to cooperate via instruments that focus on loyalty and coherence; however, this seems to be lacking [5].

The Belgian state has a federal structure. It is composed of a Federal State, three regions and three language communities. The three regions (Brussels Capital Region, Flemish Region and Walloon Region) are responsible for territorial policy areas such as urban development and environmental policy. Furthermore, there are three language communities (Flemish Community, French Community and German-speaking Community). The language communities are responsible for personal matters. So the regions are especially important from a geospatial perspective. Besides the Federal State, the regions and the language communities, there are also 10 provinces and 589 communities [6]. This article will, however, focus on the highest state structure that is mostly linked to geospatial e-services and data, namely the administrations of the Federal State and the three regions. Studying the language communities, the provinces and communities do not fall within the scope of this article.

The article starts with a theoretical overview of the three main concepts, e-services, geospatial data and governance. The methodology that was used to find an answer to the four research questions is explained. Thereafter the results are presented, answering the first three research questions. In the discussion the current governance status is analysed and explained, answering the fourth research question. Finally, some conclusions are drawn and further research in governance structures for e-services outlined.

\subsection{Theoretical Overview: E-Services, Geospatial Data and Governance}

\subsubsection{E-Services}

Tiwana and Ramesh [7] are among the first to define e-services and state that those are "[ ... ] Internet-based applications that fulfil service needs by seamlessly bringing together distributed, specialised resources to enable complex, (often real-time) transactions. Examples of e-services include supply chain management, customer relationship management, accounting, order processing, resource management, and other services that are electronically delivered through the Internet". The focus of their article lies, however, in software as a service. Scupola [8] defines e-services "as services that are produced, provided and/or consumed through the use of ICT-networks such as internet-based systems and mobile solutions". Another definition is provided by Lovelock and Wirzt [9]: An e-service is "an act or performance that creates value and provides benefits for customers through a process 
that is stored as an algorithm and typically implemented by networked software" $[9,10]$. Whereas the first two definitions can be used for both public and private perspectives on e-services, the perspective of Lovelock and Wirzt [9] is focused more on the private sector, with the reference to 'customers'. Furthermore, their definition also defines an e-service more from a technical perspective by making a reference to 'an algorithm' and 'networked software'. The main weakness of the Tiwana and Ramesh [7] definition is that it is written from a 'software as a service'-perspective, whereas the definition of Scupola [8] is more focused on the non-technical side of e-services. The Scupola [8] definition is more connected to governance, which is the focus of this research. Therefore, this definition has been chosen.

An important part of the academic discussion on the meaning of e-services is the distinction between public and private e-services. In the early days of defining e-services, a governmental perspective on e-services was lacking: This can partially be attributed to the fact that the 'e-service innovation' was launched in 2000 by Hewlett-Packard, a private sector actor [11]. Later, more specific attention was developed for the e-services developed in a governmental context [12,13].

Finally, the emergence of e-services has led to the disappearance of the division between goods and services. Goods that used to be sold to customers are, via digitalisation, converted into services [13,14]. A striking example of this convergence in the geospatial context is maps. As a result of the European Union INSPIRE Directive and the Directive on the re-use of public sector information [15-17], governmental agencies previously selling maps, as goods, are now increasingly offering the information via digital channels as a service, and no longer as a good. This can have an effect on governmental organisations, which are partially self-sustaining via the selling of goods such as maps, as they might have to review their business model.

\subsubsection{Geospatial Data}

Besides e-services, there is also the connection with geospatial data. The Oxford Dictionary does not define geospatial data, but spatial data are defined as "facts and statistics used for reference or analysis, relating to space" [18]. The INSPIRE Directive takes a very similar position and defines spatial data as "data with a direct or indirect reference to a specific location or geographic area" [15]. Finally, Masser and Crompvoets [19] state that "geographic information identifies or describes locations on the surface of the earth". Although the authors do not define geospatial data, the link between both is clear: Information is giving meaning to the data itself.

Public authorities are the main users and producers of geospatial data. It is essential that the data quality can be trusted and has a controlled source of origin, as many policies are making use of this type of data [3]. More and more, however, there are different stakeholders with a clear interest in this geospatial data. Geospatial data are no longer the sole territory of specialised mapping agencies and experts, but a tool that is becoming indispensable for modern governance. To ensure that various stakeholders have access to the data and see the added value of geospatial data, there has to be a creation of geospatial e-services and accompanying structures and processe, to govern the sharing of this geospatial data $[20,21]$. Furthermore, the data can be used to improve existing e-services with a geospatial component. Latre et al. [3] underline, however, that geospatial data are often 'difficult to create, maintain and exploit, it is expensive, and presents scale, resolution, thematic and jurisdictional problems when used'. Therefore, one of the critical points in developing geospatial e-services is the existence of governance structures with established lines of coordination.

\subsubsection{Governance}

Coordination "implies the bringing into a relationship [of] otherwise disparate activities or events". The question arises in what way coordination can be achieved [22]. Bouckaert et al. [23] brought together three theoretical approached of coordination: Markets, Hierarchies and Networks, based on (see Table 1): 
- Hierarchy-type mechanism: This type of mechanism is based on the idea that authority and power are the fundamental processes and resources. There can be bureaucratic hierarchical control: 'public organisations remain basic bureaucracies that are controlled by rules and internal authority', and political hierarchical control, public-sector organisations and their behaviour are ultimately controlled by political leaders'. This mechanism can work via a broad range of possible tools, ranging from legislation to procedural control mechanisms.

- Market-type mechanism: Using the markets as a coordination mechanism is based on the idea that bargaining is the basic process and resource. In markets buyers and sellers come together and bargain until they find a common agreement-in this way a balance is found between supply and demand. However, to establish well-functioning markets to supply governmental services, there is a need for a central authority that can ensure that the outcomes desired by the government are achieved.

- Network-type mechanism: Networks are considered to be '(more or less) stable patterns of cooperative interaction between mutually dependent actors around specific issues of policy (or management)'. So, between organisations there is cooperation based on voluntary collaborative actions as well as solidarity between organisations. There is bargaining, negotiation and co-operation between the participating organisations, based on trust, a certain level of information-sharing and time.

This remains, however, a theoretical perspective. In reality, there will always be a balance between the different mechanisms as 'administrative reforms represent a mixed order' [24].

Table 1. The features of hierarchies, markets and networks.

\begin{tabular}{llll}
\hline & \multicolumn{1}{c}{ Hierarchy } & \multicolumn{1}{c}{ Market } & Network \\
\hline Base of interaction & Authority and dominance & Exchange and competition & Cooperation and solidarity \\
\hline Purpose & $\begin{array}{l}\text { Consciously designed and } \\
\text { controlled design }\end{array}$ & Spontaneously created results & $\begin{array}{l}\text { Consciously designed purposes or } \\
\text { spontaneously created results }\end{array}$ \\
\hline $\begin{array}{l}\text { Guidance, control } \\
\text { and evaluation }\end{array}$ & $\begin{array}{l}\text { Top-down norms and } \\
\text { standards, routines, } \\
\text { supervision, inspection, } \\
\text { intervention }\end{array}$ & $\begin{array}{l}\text { Supply and demand, price } \\
\text { mechanism, self-interest, profit } \\
\text { and losses as evaluation, courts, } \\
\text { invisible hand }\end{array}$ & $\begin{array}{l}\text { Shared values, common problem } \\
\text { analysis, consensus, loyalty, } \\
\text { recipity, trust, information } \\
\text { evaluation-putation }\end{array}$ \\
\hline Role of government & $\begin{array}{l}\text { Top-down rule-maker and } \\
\text { steerer; dependent actors are } \\
\text { controlled by rules }\end{array}$ & $\begin{array}{l}\text { Creator and guardian of } \\
\text { markets, purchaser of goods; } \\
\text { actors are independent }\end{array}$ & $\begin{array}{l}\text { Network enabler, network } \\
\text { manager and network participant }\end{array}$ \\
\hline Resources needed & Authority, power & Bargaining, information, power & Mutual co-optation, trust \\
\hline Theoretical basis & Weberian bureaucracy & Neo-institutional economics & Network theory \\
\hline
\end{tabular}

\section{Materials and Methods}

A pragmatic approach, combining the three methods, was chosen to provide an answer to the four research questions. A first approach was a review of documents, mainly legal texts, that structure the relations between organisations, as well as the intergovernmental relations between the three regions and the federal administration. In order to illustrate the practical reality of the coordination between the different actors involved in the governance of geospatial data and e-services, the researchers also used qualitative analysis via interviews with the key actors, and a quantitative analysis in the form on an online survey. Adopting this approach allowed them not only to understand the formal governance structures, but also the importance of informal coordination.

The combination of these three methods provided answers to the research questions in an inclusive way. The document analysis, in combination with the interviews (both qualitative methods), answers the first ("Who are the leading public sector actors with regards to geospatial e-services?"), the third ("What types of coordination mechanisms are used in the field of geospatial data and e-services?") and the fourth ("How can the current governance structures be explained?") research question. The combined 
quantitative and qualitative approach creates the possibility to understand the governance structures and to explain them. The interviews are especially useful to understand the meaning of certain choices and events as well as to explain why and how a certain coordination approach emerged [25]. As geospatial e-services depend on geospatial data, it was important to understand who the users and producers of geospatial data are, the second research question. This question could only be answered via a large-scale survey among the users and producers of geospatial data and e-services in Belgium. Therefore the online survey was also used.

Firstly, the documents that define the governance landscape of geospatial e-services and data have been reviewed. Those texts are a valuable source of information as they provide an overview of the different tasks and roles of different organisations. The documents include a vast amount of question. Analysing documents has, however, one main weakness. They do not always represent the reality of the organisation. Therefore, interviews are especially useful as they allow us to get an insight into the way key actors experience reality [26,27].

Secondly, interviews were conducted with the various stakeholders between August 2016 and May 2017. The in-depth interviews allowed the researchers to collect information that would not be collectable via an online survey or via the document analysis. As Maxwell [25] underlines, qualitative exploratory research—such as the interviews that were conducted-helps to understand the phenomena and events in which the stakeholders are involved.

A list of the organisations visited and whose key representatives were interviewed can be found in Table 2. These organisations were selected on the basis of their link to geospatial data and e-services, and included the following administrative levels: Federal level, regional level, local communities and organisations representing their interests and the European Commission because of the INSPIRE Directive [15], the Directive on the re-use of public sector information $[16,17]$ and the ISA $\&$ ISA $^{2}$ programs [28]. The private sector was included via the AGORIA GEO-ICT Group, the main representative organisation of the private sector for geospatial data in Belgium, Proximus, the leading Belgian telecom operator, and BPOST, the main post company.

Table 2. Organisations interviewed between August 2016 and May 2017 (listed chronologically).

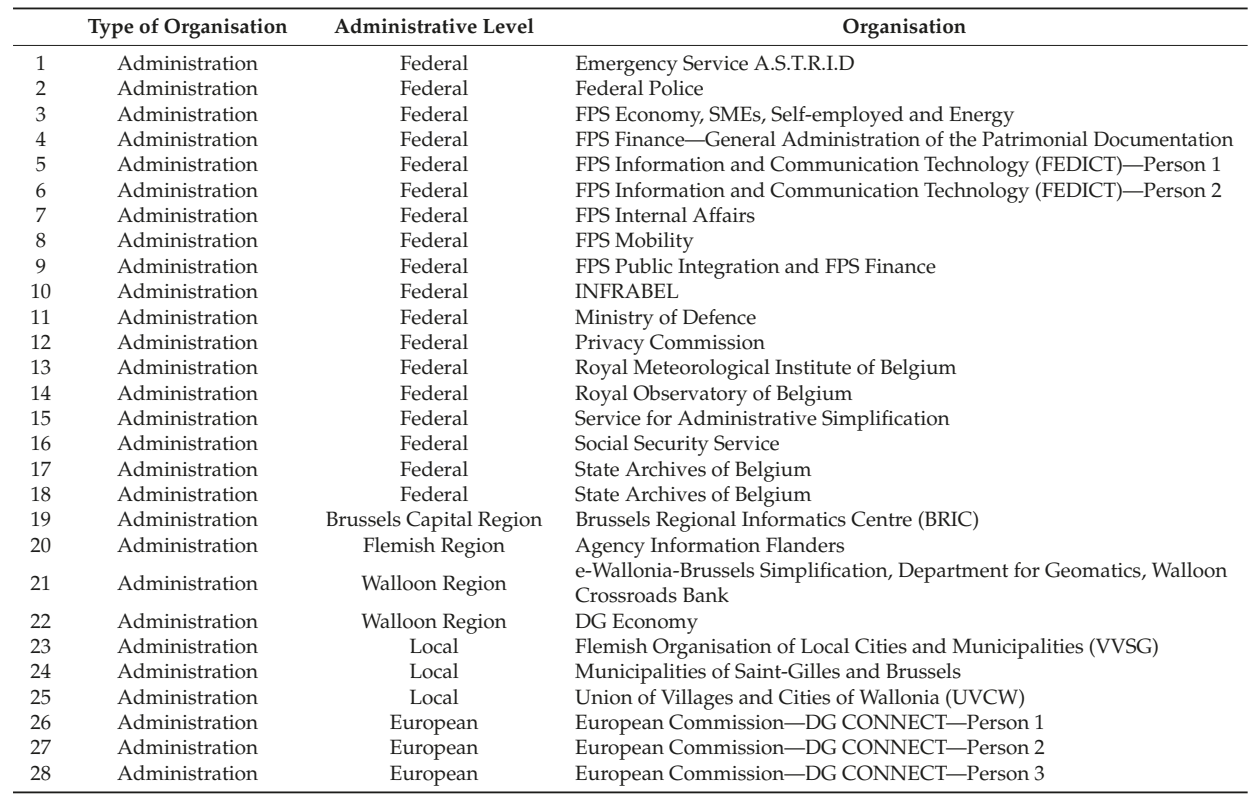


Table 2. Cont.

\begin{tabular}{|c|c|c|c|}
\hline & Type of Organisation & Administrative Level & Organisation \\
\hline 29 & Public-private sector & & $\begin{array}{l}\text { Intermunicipal Company for Informational and Organisational } \\
\text { Mutualisation (iMio) }\end{array}$ \\
\hline 30 & Public-Private Sector & & SMALS \\
\hline 31 & Private sector & & AGORIA GEO-ICT Group-Person 1 \\
\hline 32 & Private sector & & AGORIA GEO-ICT Group-Person 2 \\
\hline 33 & Private sector & & BPOST \\
\hline 34 & Private sector & & Proximus \\
\hline 35 & NGO & & EUROCITIES \\
\hline
\end{tabular}

The form that the interviews took can be considered as between the "interview guide approach" and the "standardised open-ended interview". All the topics to be discussed were decided in advance and some questions were predefined and standardised for all the respondents. Sometimes the questions differed slightly as not all topics were relevant for each organisation. In this way, it was ensured that the data were collected in a systematic way, while allowing for a certain level of flexibility [30,31].

The analysis of the interviews was conducted on the basis of the COBIT 5 enablers [32]. The description of each enabler was used to analyse the textual outcome of each interview. In this way an overview of the different respondent positions was obtained, structured on the basis of the COBIT 5 enablers. Making use of those enablers ensured that the research took an all-encompassing approach when analysing the research data. This approach fits within the research spirit as it underlines that geospatial e-services are not just technological objects but also have an important social element. The COBIT framework was developed by the Information Systems Audit and Control Association (ISACA) in 1992, and is internationally recognised as a framework for IT governance bringing together international best-practices. In 2012 ISACA released a new version of the framework, COBIT 5, which is currently the most recent version of COBIT [33]. The fact that the COBIT 5 framework offers an all-encompassing methodology is both its main strength and weakness. Based on the fact that the framework is originally developed for the private sector and the knowledge that is too all-encompassing to use as a whole, it has been decided to use COBIT 5 as a general stepping-stone while giving it an interpretation linked to the approaches used in the public sector. The following enablers are described within COBIT 5 [32];

- $\quad$ Processes

- Organisational structure

- Culture, ethics and behaviour

- Principles, policies and frameworks

- Information

- Services, infrastructure and applications

- People, skills and competencies

Besides the review of the legal texts and the interviews, a third research approach was used. An online survey was conducted in the period December 2016-February 2017. It was mainly used as an explorative and descriptive instrument to underpin the findings of the interviews related to the governance of geospatial data and e-services [34]. The survey data used in this article focused on the willingness of the federal level and the regions to collaborate, the users and producers of geospatial data, and the source of origin for different types of geospatial data.

As the online questionnaire is an exploratory tool, it was ensured that all the different layers of the Belgian administration as well as the private sector organisations with a connection to the administration were included. Organisations were selected based on their relation to e-services or geospatial data. Within those organisations, a new selection of possible respondents was made on the basis of their relevancy to the topic. The population for this research was selected on their direct 
connection to the development and maintenance of e-services and/or geospatial data. The following levels were contacted:

- Federal level: Federal Public Services, Public Planning Services, Scientific Institutions, Federal Institutions of Public Interest, Public Welfare Institutions, Federal Police and Ministry of Defence.

- Regional level: Flemish Region, Walloon Region and Brussels Capital Region.

- Provincial level: The administration of the 10 Belgian provinces.

- Communities: The administrative head of each community was contacted. Additionally, the Flemish and Walloon organisations representing the local entities were contacted.

- Private Sector: A random selection made via an online business directory for consumers, based on the provinces and the Brussels Capital Region was conducted for the following groups: Architects, building companies, land surveyors and notaries. Those groups can only execute their work by making use of geospatial data. Furthermore, the members of the Belgian private sector federation AGORIA GEO-ICT were contacted, as well as the four main consultancy companies (Deloitte Belgium, PwC Belgium, EY Belgium and KPMG Belgium).

- Public-Private Sector: The four main Belgian utility companies were contacted, as their functioning is strongly linked to geospatial data (Régie de l'Electricité de Wavre, Fluxys, ORES and EANDIS).

The questionnaire was sent to a total of 1317 respondents leading to an overall response rate of $15.1 \%$. Leaving out the communities, however, leads to a higher response rate of $23.3 \%$. A detailed overview of the response rate (in absolute numbers and percentages) can be found in Table 3.

Table 3. Online survey response data according to targeted group.

\begin{tabular}{cccc}
\hline Target Group & Sample Size & Number of Respondents & Response Rate $\%$ \\
\hline Federal administrations & 210 & 63 & $30.0 \%$ \\
Regional administrations & 293 & 67 & $22.8 \%$ \\
Provincial administrations & 120 & 18 & $15.0 \%$ \\
Private sector & 95 & 18 & $18.9 \%$ \\
Private-public partnerships & 7 & 3 & $42.8 \%$ \\
Sub Total & 725 & 169 & $23.3 \%$ \\
Communities & 592 & 30 & $5.1 \%$ \\
Total & 1317 & 199 & $15.1 \%$ \\
\hline
\end{tabular}

Source: FLEXPUB research project [35].

In order to increase the response rate, three reminders were sent. Institutions of the Belgian federal level with a strong impact on (geospatial) e-services that did not reply were contacted by telephone. The survey was managed by IVOX. It is important to mention the objective role of IVOX: this respected company conducts surveys for public and private actors and supported the online questionnaire via its technical expertise.

The results of the online survey were analysed via the program IBM SPSS Statistics 24 . A number of questions that included written text were analysed manually. Before starting the analysis, the quality of the data was examined: It was considered that for each of the respondents the data quality was sufficient to be used in the analysis. In the questionnaire a textbox was included at the end of the questionnaire in which the respondents were able to write down what they expect of future geospatial e-services: 66 out of the 201 respondents did not fill in anything in this textbox. Writing nothing in this textbox might mean that there was no interest in the survey, and could imply that the data were not correct. Therefore, the researchers checked for those 66 respondents if they wrote down what role they have in their organisation. Filling in this question with a clear function title also shows if the survey was filled in in a serious way, as it is one of the last questions and the researchers presume that the other questions were therefore answered in a serious and honest way. Of the 66 respondents, there were only four respondents who not write down a clear function title. Those four respondents were verified 
via their answers on the statements that were included in the questionnaire. Finally, it was agreed to include those four respondents in the analysis: two of them were known personally to the researchers and showed a strong interest in the project, and two others gave replies to other questions that were in line with the other respondents.

\section{Results}

In Section 3.1, the leading public sector actors with regards to geospatial e-services are presented. The main actors of the federal administration, as well as the three regional administrations, are discussed and their relations analysed. Section 3.2 gives a deeper look at the users and producers of geospatial data, and the source of origin for the geospatial data, based on a categorisation of 20 types of geospatial data. Finally, Section 3.3 analyses what types of coordination are used in the field of geospatial data and e-services.

\subsection{Leading Public Sector Actors at Different Administrative Levels}

\subsubsection{Federal Organisations}

At the Belgian federal level the National Geographic Institute (NGI) as well as the Federal Public Service (FPS) Finance and the newly created FPS Policy and Support are supposed to play a leading role in the creation of geospatial e-services: Those organisations are key as they all have a leading role in the creation of geospatial data or in the development of e-services.

- National Geographic Institute: This organisation takes the central governance position within the field of geospatial data at the federal level, both from a historical and judicial position [36,37]. However, the organisation seems to struggle with developing geospatial e-services: A digital topographic map, "CartoWeb.be" has been developed, but other geospatial data are often only available in formats that do not allow to be integrated in already existing e-services of the federal organisation responsible for e-government policy, the FPS Policy and Support [38]. Recently (March 2017) the federal geoportal "geo.be", was launched. This is, however, almost six years after the transposition of the INSPIRE Directive into law $[39,40]$. Finally, the NGI, the State Archives of Belgium, the Royal Library and the Africa Museum have developed an e-service for historical maps of Belgium and Central Africa [41].

- FPS Finance-General Administration for the Patrimonial Documentation: The General Administration is one of the six General Administrations of the FPS Finance. From a historical perspective, this organisation has been, together with the NGI and its predecessors, one of the cornerstones of the geospatial data via the creation and maintenance of cadastral plans and the organisation of the cadastral taxation—one of the key instruments of a country. Also today it remains responsible for conserving and updating the cadastral documentation and maps [42]. The General Administration has developed its own geospatial e-services for exchanging information with governmental and non-governmental users: "URBAIN" for the exchange of patrimonial information with the 589 communities, "MyRentPro" for the registration of tenancy agreements for housing by estate agents and "CadGIS" for consultation, by private individuals of the cadastral plan [43].

- FPS Policy and Support: Until early 2017, the FPS Information and Communication Technology (FEDICT) was responsible for the overall e-government policy of the federal administration. Besides the development of a common strategy, the aim was also to support other federal organisations in implementing the strategy and developing norms, standards and a basic architecture for e-services. However, since its founding in 2001, there has been no specific focus on using geospatial data within e-services, the organisation has witnessed strong budgetary decreases, and lacked the necessary power to position itself within the broader federal administration. In March 2017, the new FPS Policy and Support was created. The Directorate-General for Digital Transformation (DTO) within this FPS has taken over the tasks of the former FEDICT. Besides the DTO, a "G-Cloud" (Government Cloud) has been set-up: "The G-Cloud strives to 
a maximal cooperation between federal organisations in the field of basic ICT infrastructure" [44]. It remains to be seen how effective the DTO will be in relation to the other actors within the federal administration. Although the focus on geospatial data has been very limited within FEDICT, there are a few examples of e-services that make, to a limited extent, use of geospatial data. An example is the "4th Way", this e-service allows notaries and civil servant to collect debts when there is public sale or registration of real estate [45]. Another example of an e-service developed by FEDICT is "eBirth". When a baby is born, the birth is registered electronically way and the information is send digitally to the necessary governmental organisations, such as the community, for the registration of the birth place [46].

So, there are three main actors related to geospatial e-services at the federal level. It should, however, be underlined that there is currently a mismatch between the different capacities of the organisations. The organisation responsible for e-services does not have the necessary expertise to include the geospatial component in e-services, and the NGI lacks the necessary capacity to develop widespread geospatial e-services. Only FPS Finance combines its geospatial data and e-services in a proactive way.

\subsubsection{Brussels Capital Region}

In 1987 the Brussels Capital Region Government decided to create the "Brussels Regional Informatics Centre" (BRIC) and mandated it with all tasks related to the development and assistance of other actors in the Brussels Capital Region, concerning the topics of informatics, telematics or cartography [47]. As such, the region was the first in Belgium to make a clear connection between informatics and geospatial data. Besides the BRIC, however, other organisations have a clear connection with geospatial data. These are members of the "GeoBru Committee". This Committee, in charge of implementing the INSPIRE Directive, consists of six organisations: The Brussels Planning Office, the Brussels Institute for Environmental Management, the BRIC, the Brussels Urban Development and Heritage, Brussels Mobility and the Company for Interurban Transport in Brussels. Other governmental organisations contributing to the Brussels geoportal can be represented, but without voting rights. Although the different organisations still tend to develop their own geospatial e-services, there is a general acceptance and use of the geospatial data of the Brussels Urban Information System (UrbIS) offered by the BRIC. Examples of geospatial e-services developed with UrbIS are "fixmystreet.brussels", this e-service allows users to make an online mention of incidents in the public domain and to follow the actions taken by the administration to solve the incident, and the "Brussels Mobility Realtime e-service", this web service allows users to receive real-time mobility information $[48,49]$. Another example is the "Building Permit Viewer", it allows users to follow the granting of building permits on a map. There is general information available for all building permits granted in the region, and one can also log on and take actions on personal building permits [50]. As such, all organisations use the same basis for their geospatial e-services [51].

\subsubsection{Flemish Region}

The organisation responsible for the coordination, organisation and provision of services related to the Geospatial Data Infrastructure was founded in 2004 as the Agency for Geospatial Information Flanders. The organisation's mission was extended to include the overall promotion and use of geospatial data in Flanders [52,53]. Recently, it was decided to merge the previously separated Agency for Geospatial Information Flanders and the Department Information Flanders, into the new "Agency Information Flanders" (AIV). The agency aims "to build up a coherent government-wide information policy and to support and realise the transition of the Flemish administration towards an information-driven administration" [54]. Merging those two organisations was logical as location appeared in a wide range of policy areas. Also, the newly created organisation brings information and expertise together. Furthermore, there is a budgetary element included in the organisational reshuffling: Services existing in the two organisations can be merged. 
However, the new organisational structure has mainly created a policy steering and development agency that is not providing any IT tools. That is the task of the "Facility Company" of the Flemish administration. This has led to a certain level of friction and tensions, as it is not always clear who is responsible for the different tasks-especially concerning new IT-developments within the Flemish administration. Furthermore, the merging of the agency responsible for geospatial information and the organisation responsible for the non-geospatial information risks underestimating the importance of geospatial data in the overall policy of the Flemish administration. This would be the opposite of the original aim of creating more visibility and impact of all governmental information.

A first example of an e-service is the "Large-Scale Reference File", the topographic map of Flanders that is available as an e-service for all users active in the Flemish Region $[55,56]$. Furthermore, there is also the Flemish regional geoportal, "geopunt.be", created by the 2009 Geographic Data Infrastructure (GDI) Decree [53]. Another e-service is the "Central Address Reference File", created in 2009 by the Central Address Reference File (CRAB) Decree [57]. Together with the Large-Scale Reference File, the Central Address Reference File is one of the basic elements in defining the geospatial infrastructure and future geospatial e-services [58]. Finally, the Generic Information Platform Public Domain (GIPOD) Decree provides the legal basis for the "Generic Information Platform Public Domain" [59]. This e-service allows users of the public domain to inform other users of their actions in the public domain, for example when public works are planned or when there is a public event leading to the closure of roads [60].

\subsubsection{Walloon Region}

Two organisations are responsible for the overall coordination of geospatial data and e-services, the Department for Geomatics and e-Wallonie-Bruxelles Simplification. The Department for Geomatics is the leading Walloon organisation: It is responsible for shaping the optimal conditions to use geospatial data, both from a technical and judicial point of view. The organisation is expected to increase the visibility and knowledge on geospatial data towards governmental and non-governmental actors [61].

In executing those tasks, the Department for Geomatics is closely cooperating with e-Wallonie-Bruxelles Simplification: This organisation's task is to increase the digitalisation and overall simplification of the administration as it provides services to other organisations of the Walloon Region and the French Community—similar to the situation in Flanders, where AIV provides services to the Flemish Region and the Flemish Community. Specifically it is responsible for the provision of advice, the crossroads bank for data sharing, the operational implementation of e-services and the overall performance evaluation of e-government in Wallonia and the French Community $[62,63]$.

Even though the Department for Geomatics and e-Wallonie-Bruxelles Simplification are responsible for the horizontal policy coordination within the Walloon administration, there are a number of other departments and directions responsible for geospatial data within their specific, vertical policy domain. The most well-known example is the Directory of Geomatics within the Directory-General of Land Use and Urban Planning, which develops, in coordination with the abovementioned Department for Geomatics policies and consultation tools for geospatial data [64]. Besides e-Wallonie-Bruxelles Simplification, there is a second actor responsible for the development and maintenance of the IT infrastructure of the Walloon Region: the Department of Information and Communication Technologies, which falls under the responsibility of the Directory-General for Budget, Logistics and ICT. As such, there are four key actors involved in the development and maintenance of geospatial e-services [65]. Examples of geospatial e-services developed by those actors are "WalOnMap", the Walloon geoportal, and the "Central Inventory of Addresses and Streets in Wallonia" (ICAR), the Walloon counterpart of the Flemish CRAB e-service [66,67]. Another example is the "Ongoing Cartographic Information Project" (PICC): Just like in the Flemish Region, the Walloon Region also developed its own topographic map [68]. 


\subsection{Geospatial Data Users and Producers}

Besides the legal formal organisational structures, there is also the practical reality of sharing data. Understanding a governance structure implies more than analysing the main organisations and their relations from a legal point of view. It is necessary to understand the day-to-day exchange of geospatial data. Therefore, the second research question studies who the users and producers of geospatial data are, and what the source of origin of their data is. For 20 types of geospatial data-defined by the International Organization for Standardization in Standard 19115 (international standard to describe geospatial information and services) - the main users (those organisations that use the data at the moment of responding to the survey) and producers (those that produce the data at the moment of responding to the survey) were identified [69]. Those 20 types of geospatial data, defined by ISO Standards 19115, are described in Table 4.

The most commonly used type of data is "Location" with 74 users out of the 111 organisations that responded to the questionnaire. This is followed by "Planning Cadastre" used by 71 organisations and "Base Maps Earth Cover" used by 64 organisations. The types of data with the lowest number of user organisations are "Oceans", only nine users, and "Intelligence Military" with only 13 users.

For half of the different types of data, the leading public organisations described above play a key role. At the federal level, the NGI is one of the main actors concerning the more traditional types of geospatial data such as "Elevation", "Base Maps Earth Cover", "Earth Imagery", "Inland Waters", "Location" and "Structure". FPS Finance plays a key role for "Planning Cadastre". From a Flemish regional perspective, AIV overall has a strong position for sharing data with other organisations and is indicated for different categories as the main source or one of the main sources of origin. On the basis of the analysis of the leading public sector actors, it was expected that these actors would also play a key role in the network of users and data producers for the 20 types of geospatial data. The NGI and the FPS Finance indeed function as a producer, and as one of the main sources of origin for different types of data. AIV indeed acts as one of the key distributors of geospatial data and to a minor extent also produces data. For the Walloon Region, however, the Department for Geomatics does not appear as one of the key actors in the network of users and producers of data. Rather, the vertical organisations, focusing on specific policy areas, of the Walloon administration appear to be both responsible for the production and exchange of the data. No centralised system for exchanging data exists in the Walloon administration. The Department for Geomatics is nevertheless expected to "create the optimal conditions to use the geospatial data" and to "ensure the diffusion of Walloon geospatial data" [61]. This is in strong contrast to the Flemish Region, were AIV plays a key role in the distribution of the majority of geospatial data.

Another remarkable observation is that in types of data such as "Climate Meteorology", "Defence", "Economy", "Oceans" and "Transportation", the organisations described above have almost no function in the network of users and producers. Other, more specialised organisations are pointed to as the source of origin for the data. "Climate Meteorology" data, for example, are mainly the area of the Royal Meteorological Institute. The FPS Economy and the Departments responsible for the Economy in the regions have a prominent role for the "Economy" type of data, and for "Defence" the Ministry of Defence is the source of origin.

Finally, there were three types of data for which not a single key actor could be identified: "Health", "Society" and "Utilities Communication". "Health" and "Society" are not always associated with geospatial data; as such, there might not be enough focus on the key geospatial actors for this type of data. However, "Utilities communication", for which both the Flemish and federal administration developed geospatial e-services, is very much related to location: the Federal Cable and Pipe Information Checkpoint (KLIM) and the Flemish Cable and Pipe Information Portal (KLIP) [70,71]. Both are geospatial e-services and inform users on the precise location of cables and pipes that can be found in the public subsoil in areas where they, as users, plan works. The federal e-service can be used by users planning engineering works in any area in Belgium, the Flemish KLIP e-service only 
in Flanders. It is surprising that the organisations developing these types of e-services are not taking a prominent role in the source of origin for this type of data.

Table 4. Use-produce-origin description for 20 types of geospatial data.

\begin{tabular}{l} 
Type of Data \\
\hline \multicolumn{1}{c}{ Location (positional information and services, } \\
e.g., addresses, geodetic networks, control points, \\
postal zones and services, place names)
\end{tabular}

Planning Cadastre (information used for appropriate actions for future use of the land, e.g., land use maps, zoning maps, cadastral surveys, land ownership)

Base Maps Earth Cover (e.g., land cover, topographic maps)

Environment (environmental resources, protection and conservation, e.g., pollution, waste storage and treatment, nature reserves)

Earth Imagery (Images of the Earth, e.g., satellite imagery, aerial photographs, LIDAR)

Boundaries (legal land descriptions, e.g., political and administrative boundaries)

Structure (man-made construction, e.g., buildings, museums, religious buildings, factories, housing, monuments, shops, towers)

\section{Description Use-Produce-Origin}

- 74 user organisations

- 32 producing organisations

- The data mainly originate from the NGI, AIV and the private sector actors such as TomTom, Google Maps. The NGI takes a central role at the federal level. AIV is a key source for organisations with a link to Flanders.

- 71 user organisations

- 15 producing organisations

- The FPS Finance, responsible for Cadastral Information is the main source of origin: 48 organisations indicated that their information originates from FPS Finance.

- 64 user organisations

- 14 producing organisations

- The NGI plays a dominant role as a provider of data, shared with AIV. The PSW is also indicated as a source for this data, but to a lower extent than NGI and AIV.

- 56 user organisations

- 24 producing organisations

- A dominant role of the regions. Data mainly used by organisations with a link to the local level; AIV has a prominent but no dominant role, together with the Walloon DG for Agriculture, Natural Resources and the Environment.

- 56 user organisations

- 14 producing organisations

- At the federal level, the NGI is one of the main sources. AIV dominates the other categories. No key organisation indicated within the Walloon administration. Google Maps is also mentioned but only seven times.

- 55 user organisations

- 8 producing organisations

- $\quad$ AIV is often cited as source of origin, while it uses information of the FPS Finance. NGI, also cited as a source of data, produces the data themselves. Google Maps and TomTom data do not seem to be used on a regular basis: Only mentioned four times as source of origin.

- 51 user organisations

- 19 producing organisations

- $\quad$ AIV has a strong impact of the diffusion of the data. Role of the NGI is limited and related to the federal level. 
Table 4. Cont.

\begin{tabular}{l} 
Type of Data \\
\hline Transportation (means and aids for conveying \\
persons and/or goods, e.g., roads, airports, \\
tunnels, nautical charts, vessel location, \\
aeronautical charts, railways) \\
Economy (economic activities, conditions and \\
employment, e.g., commerce, industry, tourism, \\
exploitation of resources) \\
Farming (rearing of animals and/or cultivation \\
of plants, e.g., agriculture, plantations, \\
livestock, etc.)
\end{tabular}

Elevation (height above or below sea level, e.g., altitude, bathymetry)

Inland Waters (inland water features, drainage systems and their characteristics, e.g., rivers, water utilisation plans, dams, floods)

Society (characteristics of society and cultures, e.g., archaeology, education, demographic data, recreational areas and activities, crime and justice)

Utilities Communication (energy, water and waste systems and communications infrastructure and services, e.g., solar and nuclear sources of energy, water distribution, sewage, electricity and gas distribution, telecommunication networks)

Biota (flora and/or fauna in the natural environment, e.g., wildlife, vegetation, habitat)

Health (health, health services, human ecology, and safety, e.g., disease and illness, hygiene, health services)
Description Use-Produce-Origin

- 48 user organisations

- 21 producing organisations

- Only the federal railway company and the Flemish bus company are mentioned as source of origin

- 44 user organisations

- 19 producing organisation

- Less impact of the NGI and/or AIV. The FPS Economy, the Flemish Department of Innovation \& Entrepreneurship and the Walloon DG for Economy, Employment and Research have prominent roles.

- 41 user organisations

- 12 producing organisations

- Dominant role of the regions. Main distributors are AIV, receiving its data from the Department of Agriculture and Fisheries, and Walloon DG for Agriculture, Natural Resources and the Environment.

- 41 user organisations

- 13 producing organisations

- $\quad$ AIV is in a key position: 17 organisations indicate that that their data originates from them.

- 41 user organisations

- 11 producing organisations

- $\quad$ NGI is the main source at the federal level. AIV is highly consulted by other levels. A particular situation in Wallonia: three different DGs are mentioned as source of origin.

- 39 user organisations

- 21 producing organisations

- Clear sharing structure is missing: Not a single organisation emerges as a key source of origin.

- 30 user organisations

- 6 producing organisations

- No central distributor for this type of data.

- 27 user organisations

- 10 producing organisations

- $\mathrm{AIV}$ acts as distributor for data of the Flemish Agency of Nature and Forest, the Flemish Institute of Nature and Forest Research and the Flemish Department of Environment, Nature and Energy. Walloon organisations indicate that their data originates from the DG for Agriculture, Natural Resources and the Environment.

- 27 user organisations

- 9 producing organisations

- $\quad$ Although the majority of the social security organisations of the federal administration participated, they do not appear as a user. 
Table 4. Cont.

\begin{tabular}{|c|c|}
\hline Type of Data & Description Use-Produce-Origin \\
\hline $\begin{array}{l}\text { Geoscientific Information (information } \\
\text { pertaining to earth sciences, e.g., geophysics, } \\
\text { geology, earthquakes) }\end{array}$ & $\begin{array}{l}\text { - } 25 \text { user organisations } \\
\text { - } \quad 11 \text { producing organisations } \\
\text { AIV is mentioned five times as source of origin, the } \\
\text { PSW is indicated by three organisations as their } \\
\text { source of data. }\end{array}$ \\
\hline $\begin{array}{l}\text { Climatology/Meteorology (processes and } \\
\text { phenomena of the atmosphere, e.g., weather, } \\
\text { climate, atmospheric conditions) }\end{array}$ & $\begin{array}{l}\text { - } 24 \text { user organisations } \\
\text { - } 7 \text { producing organisations } \\
\text { - } \quad \text { Dominant role of the Royal Meteorological Institute. }\end{array}$ \\
\hline $\begin{array}{l}\text { Intelligence Military (military bases, structures, } \\
\text { activities, e.g., military buildings and } \\
\text { transportation) }\end{array}$ & $\begin{array}{l}\text { - } 13 \text { user organisations } \\
\text { - } 5 \text { producing organisations } \\
\text { - } \quad \text { Always linked to the Ministry of Defence. }\end{array}$ \\
\hline $\begin{array}{l}\text { Oceans (features and characteristics of saltwater } \\
\text { bodies, e.g., tides, coastal information, reefs) }\end{array}$ & $\begin{array}{l}\text { - } 9 \text { user organisations } \\
\text { - } 3 \text { producing organisations } \\
\text { Only type of data for which organisations indicated } \\
\text { that they use non-Belgian sources such as European } \\
\text { Commission, European Space Agency and NASA. } \\
\text { Flemish organisations use their own data. }\end{array}$ \\
\hline
\end{tabular}

Source: FLEXPUB research project [35].

\subsection{Coordination in the Field of Geospatial E-Services}

The section addresses the third research question: What types of coordination mechanisms are used in the field of geospatial data and e-services? The three regions and the federal administration all have their own means of coordination in the field of geospatial data and e-services, whereas the intergovernmental coordination between the four actors appears to be organised via a weak form of network governance. The INSPIRE Directive has been an active driver of cooperation and increased coordination in the field of geospatial e-services.

\subsubsection{Federal Administration}

In 2010 the three regions and the federal government reached an agreement on the coordination of the infrastructure for geospatial information [72]. As a result of the INSPIRE Directive the four actors were obliged to agree on the overall implementation of this directive. Although the agreement was reached in April 2010, it was only in December 2011 that the directive was transposed into federal law. The interviews with different actors of the federal administration learned that before the transposition of the INSPIRE Directive no strongly formalised structures existed for exchanging data or setting up geospatial e-services. Geospatial data are very often exchanged in an ad hoc way between organisations, sometimes even without official agreement of the senior level of the administration, as this is too time-consuming. Also, although the role of the NGI and the FPS Finance might be clear, it is difficult for other organisations to see the added value of geospatial data and e-services. Furthermore, there is still no official exchange mechanism for geospatial data. Although FEDICT could have acted as a data exchanger for geospatial data, this has never been the case [73]. Moreover, FEDICT has over the years only developed a few e-services, which include-to a minor extent-geospatial data. This is probably the result of a combination of different factors: At the time that FEDICT was founded, in 2001, the majority of the federal institutions already had their own internal ICT department and continued to use their own service for developing e-services-e.g., FPS Finance or NGI. Furthermore, the budget of FEDICT has decreased systematically as a result of the austerity measures of the federal government. Finally, SMALS, a private sector company owned by the federal social security actors, had already developed and maintained e-services for other—mainly social-security-related—organisations at the 
federal level. FEDICT was as such the extra actor that came into the field, and never had sufficient capacity to play the role that it was expected to play.

Therefore, it can be argued that before the INSPIRE Directive was transposed into law in 2011, there was no real governance of geospatial e-services: Each federal organisation was acting on its own, without taking a common vision or strategy into account. There was insufficient leadership in the field of e-services, and a total lack of it in the field of geospatial data. The INSPIRE Directive, however, forced the federal organisations to start cooperation in this area. The NGI was legally instructed to create a network of services related to the geospatial data referred to in the Annexes of the INSPIRE Directive, and to set-up a federal geoportal. Whereas cooperation was lacking before the implementation of the INSPIRE Directive, some form of a network was created as a result of the directive. Hierarchical governance was used to promote a network approach for geospatial data, but it remains to be seen what the impact of the newly created FPS Policy and Support will be on the overall coordination.

\subsubsection{Brussels Capital Region}

BRIC already had from 1987 the legal mandate to develop services and to provide assistance to other actors in the Brussels Capital Region concerning topics of informatics, telematics and cartography. When, at the end of the 20th century, BRIC had the opportunity to buy the legal rights for the geospatial data belonging, until then, to the local authorities of the Brussels Capital Region, it consolidated and strengthened its legal—and hierarchical—position for developing geospatial e-services. BRIC took this opportunity, and started to develop the UrbIS products. These digital 'cartographic' products are available for all governmental organisations of the Brussels Capital Region, citizens and private sector actors $[74,75]$. The products can be used by governmental organisations as a basis tool for the development of their geospatial e-services. Although governmental organisations started to use these UrbIS products, which created a certain level of coordination, it remained a weak form of cooperation that did not lead to an optimal functioning of geospatial e-services.

When in 2010 the GeoBru Committee was created via the transposition of the INSPIRE Directive, there was not much formalised cooperation between the different organisations of the Brussel Capital Region. The only form of coordination, besides informal and personal contacts between organisations, was semi-official events that aimed to bring together the different actors involved in geospatial e-services: It remained, however, rather informal and informative [76]. Since the creation of the GeoBru Committee in 2010, however, which was imposed hierarchically, coordination between governmental organisations has improved and it is also expected that cooperation goes beyond just implementing the INSPIRE Directive. However, there are complaints from the communities about the strong hierarchical and dominant position that is taken by BRIC towards them. New e-service tools are developed without taking the needs of the local authorities into account. This situation is also accentuated by the fact that UrbIS and its products have been legally consolidated as the digital cartographic reference databank [51].

It can therefore be argued that the Brussels Capital Region is characterised by a strong hierarchical dominance of BRIC - which is, according to BRIC, creating the necessary unity between the different governmental actors. This is, however, combined with a certain level of network governance in which the different actors of the Brussels Capital Region can have their say via the official GeoBru Comité.

\subsubsection{Flemish Region}

The governance of geospatial data and e-services of the Flemish Region appears to be characterised by a mixture of hierarchy and network governance. On one hand the subsequent Flemish governments and the administration, AIV and its predecessors, have worked in an active way on a set of legally binding instruments that created the overall framework for geospatial data sharing and e-services. There are multiple examples of this policy. In 2000 the Flemish Parliament agreed on the proposed GRB (Large-scale Reference File) Decree [57], and later also on the KLIP (Cable and Pipe Information 
Platform) Decree (2008) [71], the GDI (Geographic Data Infrastructure) Decree (2009) [53], the CRAB (Central Address Reference File) Decree (2009) [57] and the GIPOD (Generic Information Platform Public Domain) Decree (2014) [59]. This "legalisation" not only has an effect on the Flemish administration, but especially on the Flemish communities, which fall under the responsibility of the region. The Flemish administration aims, via these legally binding decrees, to ensure a high level of standardisation. The communities underline that the hierarchical focus of the Flemish administration, with its standards, supervision and inspection, is strong and often does not sufficiently involve the communities. They do, however, recognise that geospatial data and e-service require a high level of standardisation and as such might require certain hierarchical governance structures.

There is, however, a certain level of network governance present in the Flemish management of geospatial e-services. Although AIV and its predecessors were and are responsible for the development of (geospatial) e-government and accompanying e-services, they still had and have to obtain and maintain the necessary confidence and trust of the other organisations of the Flemish regional administration. Without the support of the other organisations AIV would not be able to position itself in the way it currently does. One of the respondents underlined in this respect that AIV and its predecessors have a strong and trustable reputation. This created an advantage in comparison to the organisations of the federal administration. Those federal organisations have a long history, interspersed with procedures and processes that are not well suited to the digital world. Furthermore, the Flemish Region has, since the start of its geospatial data infrastructure (GDI) in 2000, created a number of councils that allowed public entities to actively participate in the creation of the Flemish Geospatial Data Infrastructure. The Steering Group GDI Flanders, the GDI Council and the Working Group GDI Flanders, created for the implementation of the GDI Flanders, provide for a for all stakeholders to communicate their geospatial requirements [77].

\subsubsection{Walloon Region}

Similar to the federal administration, the transposition of the INSPIRE Directive appears to have been a driver of reform in the Walloon administration: After the agreement between the three regions and the federal government had been reached in April 2010, the INSPIRE Directive was only transposed into a decree, the so-called Geospatial Information Infrastructure Decree, in December 2010 [78]. With the transposition a framework for coordination was created in the Walloon Region. A Strategic Committee for Geomatics was founded, to be chaired by the Department for Geomatics. The Committee is responsible for the overall coordination of the different actors in Wallonia related to geospatial data and e-services, for the development of the Walloon geospatial information infrastructure and for drafting the Strategic Geomatics Plan. The Committee groups all the DGs of the Walloon administration, as well as the Walloon local level, the regional crisis centre, and the regional service providers. However, today there is still a lack of a harmonised view among the different actors of the Walloon administration. This might for example explain why it took the Walloon administration four years to draft a Strategic Geomatics Plan. An external consultant had to be called in because there was, apart from the lack of sufficient capacity, a lack of common understanding on what should be the priorities. The Strategic Geomatics Plan 2017-2019 is an exact copy of the previous plan, and it is only now that the Walloon administration is starting with the implementation of the first plan. Therefore the Committee has developed an Operational Geomatics Plan: It aims to bring more coherence into the geospatial data and e-services of the Walloon administration. The Operational Geomatics Plan shows a certain level of unity among the different partners of the Committee [79]. So, the Walloon administration seems to be characterised by a certain level of network governance that appeared after the transposition of the INSPIRE Directive. 
3.3.5. The Belgian Governance: Cooperation between Three Regional Administrations and the Federal Administration

As a result of the strong autonomy of the regions, the four actors have concluded a number of agreements that are legally binding. With these agreements the regions and the federal level aimed to establish a common basis for the future cooperation and development on the topics of e-government, geospatial data and e-services. The agreements were necessary as they are part of the legal backbone for the future development of geospatial e-services [80]. The agreements show that there is a certain willingness of the four actors to cooperate in a weak form of network governance.

Concerning e-government, there have been agreements in 2001 and 2006. Both expired, however. When the 2006 agreement expired, it took the four actors three years to define a new one. This is illustrative of the relationship between them. All three agreements led to the establishment of a Strategic Committee in which the four actors are represented [81]. The added value of those agreements is, however, questionable: There are no visible public results and there is almost no information on what the Strategic Committee does. One of the technical working groups, the Technical Working group on interoperability, has met in this respect for the last time in October 2016. From the reports it can be ascertained that the meetings are rather informal. These rather poor results are not surprising and seem to be the result of the lack of a common vision and strategy on e-government $[82,83]$.

Concerning geospatial data, three important agreements have been concluded. The first was the agreement for the coordination of the infrastructure for geospatial information. This agreement, which is a partial transposition of the INSPIRE Directive, aimed to ensure the cooperation of the three regional administrations and the federal administration. One of the main points of the agreement was the creation of the Coordination Committee: Representatives of the four actors are members, and it ensures the overall coordination of the INSPIRE implementation in Belgium. However, this Committee is also mainly an information-sharing platform. Nevertheless, the Committee occupies a unique position in the field of geospatial data: For the first time the three regions and the federal administration are communicating with each other in a formal way. This is an important achievement as it has led to a weak form of network governance. However, due to the fact that the Committee does not have individual staff or budget, its influence is rather weak.

The second agreement, focusing on the coordination structure for patrimonial information was concluded in 2014. This agreement aims to ensure a coordinated exchange and update of patrimonial information. This agreement is the direct result of a political recognition that cooperation is necessary [84,85]. A new and common organisation was created between the regions and the federal level that is responsible for improving the coordination. Although it took until 2017 before it became publicly visible it is expected to deliver concrete results. The three regions and the federal administration recognize the need for a common and properly functioning patrimonial documentation. Data will be exchanged free of charge among the governmental users, and external non-governmental users are offered a single digital point of contact [86]. So for this area of geospatial information an institutionalised form of network coordination has emerged, via an agreement between the regions and the federal level. It remains to be seen what the effect of the new organisation will be on overall cooperation.

Finally, an agreement has been reached on the topic of address data. As it is a pre-condition for well-functioning geospatial e-services to have a common address structure, the three regions have been working on a common address structure since the beginning of the 21st century. Although there are agreements on the meaning of an address from a judicial point of view, the regions still have different ways of approaching those agreements and implementing them. In this agreement the three regions agreed on an organisational structure to solve the common problems with addresses. Although a common structure was created in the form of an Address Committee-which has to report on a regular basis to the National INSPIRE Committee and the Strategic Committee on e-government-there is no agreement on the common problems. This was, however, to be expected: All that happened with this agreement is the formalisation of an informal negotiation structure, and the 
organisation responsible for facilitating the work, FEDICT, did not have a sufficient budget to work on the topic [87].

These agreements and the related coordination show that there exists only a weak form of cooperation between the four actors. Each actor has its own working procedures. The Flemish Region started to develop its geospatial data and e-services governance structure much earlier than the other regions or the federal level, and has taken a different and more hierarchical approach. The Brussels Capital Region also has a long history of making the connection between geospatial data and information technology via the BRIC. The Brussels Region is characterised by a strong hierarchy, which was influenced to a high extent by the transposition of the INSPIRE Directive and the creation of a stronger network governance with the GeoBru Committee. The Walloon and the federal administrations, however, have struggled much longer with putting in place a governance structure for geospatial data and e-services: The Walloon Region has seemed to embark, although slowly, in the direction of network governance, whereas the federal administration still appears to have difficulties in making the connection between geospatial data and e-services-even after the transposition of the INSPIRE Directive.

\section{Discussion}

The fourth research question seeks to explain the current governance structures. From an intergovernmental perspective, a clear governance model is lacking. Also, the individual actors appear to struggle with developing such a governance model, whereby the Brussels Capital Region and the Flemish Region are the only two actors with a clear view on their governance of geospatial data and e-services. The Walloon Region has slowly started to develop a vision, but the federal administration has major difficulties with developing any sort of governance, as a result of which the crucial link between e-government and geospatial data seems to be lacking. This lack of an intergovernmental governance structure can be explained by taking a broader perspective: As various respondents said, there is a problem of awareness and information sharing. Organisations, and especially the people working in the organisations, do not know each other and do not know what the other is doing.

Furthermore, the three regions only work together when they see a clear need. As the regions have a clearly determined geospatial area for which they are responsible, they seem to be convinced of the fact that they can function on their own. This is highly problematic, as especially the federal level needs data of the regions, and delivers data to the regions. In some cases cooperation is necessary: Patrimonial information and address data are clear examples of this. The regions and the federal administration recognise the importance in the form of the so-called Cooperation Agreements. The impact of these agreements has, however, been limited.

Another point, especially important for the federal administration, is the lack of political support for geospatial e-services, leading to a lack of vision and strategy. Recently the e-government organisational structure has been reformed, but it remains to be seen what the effect will be. One of the respondents was rather sceptical of the new structure, as the administration responsible for the e-government strategy is hidden within the FPS Policy \& Support, and considered it more a budgetary operation.

Finally, the federal administration and the regions (Flanders to a lesser extent) seem to be characterised by a strong organisational independence, leading to informal cooperation based on personal connections. An extra factor in the federal administration is the historical independence of the main organisations, which makes coordination more difficult. In the online survey respondents were asked whether, in the future, they were willing to collaborate more actively, both within the same governmental level and across different governmental levels. A scale ranging from "strongly disagree" to "strongly agree" was used. The results were, in light of the above, rather surprising as they show that there is a willingness to engage in future collaboration, both at the federal and regional level. Concerning collaboration within the same governmental level (Table 5), there was a large majority that supported future collaboration: 45 out of 67 federal respondents agreed or strongly agreed. For the 
regional respondents the majority was slightly higher, with 48 out of 66 regional respondent agreeing or strongly agreeing.

Table 5. Willingness to engage in more active future collaboration within the same governmental level.

\begin{tabular}{ccccc}
\hline & $\begin{array}{c}\text { Federal (Absolute } \\
\text { Numbers-Total N: 67) }\end{array}$ & Federal (\%) & $\begin{array}{c}\text { Regional (Absolute } \\
\text { Numbers-Total N: 66) }\end{array}$ & Regional (\%) \\
\hline Strongly disagree & 0 & $0 \%$ & 1 & $1.5 \%$ \\
Disagree & 0 & $0 \%$ & 0 & $0.0 \%$ \\
No agreement or disagreement & 16 & $23.9 \%$ & 11 & $16.7 \%$ \\
Agree & 26 & $38.8 \%$ & 28 & $42.4 \%$ \\
Strongly agree & 19 & $28.4 \%$ & 20 & $30.3 \%$ \\
No answer & 6 & $9.0 \%$ & 6 & $9.1 \%$ \\
\hline
\end{tabular}

Source: FLEXPUB research project [35].

Concerning future collaboration across different governmental levels (Table 6), a similar picture appeared. Both for the federal respondents and the regional respondents, the number of respondents who agreed and strongly agreed was high: 47 out of 67, and 48 out of 66 respondents, respectively. The regional level in Table 6 includes the three regions. Looking at the Flemish and Walloon Region in detail, however (the number of respondents from the Brussels Capital Region was only six, so this information is not useful for individual calculations at the regional level), shows that the respondents from the Walloon Region had a lower level of agreement than their Flemish counterparts. The number of respondents from the Flemish Region who agreed or strongly agreed was 21 out of 25 (84\%); for the respondents from the Walloon Region that number was only 24 out of 36 (67\%).

Table 6. Willingness to engage in more active future collaboration across different governmental levels.

\begin{tabular}{ccccc}
\hline & $\begin{array}{c}\text { Federal (Absolute } \\
\text { Numbers-Total N: 67) }\end{array}$ & Federal (\%) & $\begin{array}{c}\text { Regional (Absolute } \\
\text { Numbers-Total N: 66) }\end{array}$ & Regional (\%) \\
\hline Strongly disagree & 1 & $1.5 \%$ & 1 & $1.5 \%$ \\
Disagree & 1 & $1.5 \%$ & 1 & $1.5 \%$ \\
No agreement or disagreement & 15 & $22.4 \%$ & 11 & $16,7 \%$ \\
Agree & 27 & $40.3 \%$ & 28 & $42.4 \%$ \\
Strongly agree & 20 & $29.9 \%$ & 20 & $30.3 \%$ \\
No answer & 3 & $4.5 \%$ & 5 & $7.6 \%$ \\
\hline
\end{tabular}

Source: FLEXPUB research project [35].

\section{Conclusions}

This article attempted to uncover what governance, and specifically what type of coordination, is used in the sector of geospatial data and e-services in Belgium. The theoretical coordination model (hierarchy, market and network) of Bouckaert et al. [23] was used to analyse the current situation, with a focus on the three regional administrations and the federal administration. Intergovernmental coordination was also analysed. The transposition of the INSPIRE Directive had a strong effect on the governance model of the administrations in the Walloon Region, the Brussels Capital Region and at the federal level. The Flemish Region is an exception as a clear governance model had already existed since the start of the 21st century, and can be labelled as a mixture of hierarchical and network governance. The Brussels Capital Region administration, and especially BRIC, is characterised by for its hierarchical working methods, although INSPIRE also led to the creation of network governance via the GeoBru Committee. In the Walloon administration cooperation has slowly started to develop, but progress towards a common strategy has been made. A form of network governance can be observed. Although the federal administration was influenced by the INSPIRE Directive, it is still struggling with the strong separation between geospatial data and e-services. From an intergovernmental perspective, a clear governance model between these four actors is lacking. Agreements between the regions and the federal level have been concluded, but the only effective agreement seems to be the one 
on patrimonial information. The other agreements and related structures have resulted mainly in information-sharing groups.

Geospatial data are nevertheless exchanged between organisations within administrations and also between organisations of different administrations. The NGI and the FPS Finance play a key role in the more traditional types of geospatial data, whereas AIV takes a central position in sharing and exchanging almost all types of data between organisations. In the Walloon administration, however, there is no organisation that takes such a central position: Data exchange is much less centralised. The INSPIRE Directive has had a strong effect, as the transposition has led to governmental obligations to create geoportals. The transition to the development of geospatial e-services across different organisations, however, is still partially lacking at the federal and Walloon level, as the governance models of the Walloon Region and the federal administrations are still too immature. The administrations of the Brussels Capital Region and the Flemish Region have well-developed governance structures, however, and are thus able to develop and maintain well-functioning geospatial e-services.

The intergovernmental situation can be explained by the fact that there is a problem of awareness about what the other administrations and organisations within those administrations are doing. Furthermore, the three regions only work together when they see a clear need for this: There is a strong notion among the regions that they can function separately, without coordinating their policies. Particularly important at the federal level is the lack of political support for geospatial e-services and data, as it has led to a lack of vision and strategy. Finally, the federal administration seems to be characterised by strong organisational independence.

While this article is a first attempt at understanding the governance structures for geospatial data and e-services in Belgium, more research is nevertheless required concerning the specificities of the different Belgian regions and the federal administration in developing geospatial e-services.

Although Belgium was selected as a case study because of its complex dual federal structure, the authors believe that the research methodology could be useful for analysing the governance structure of geospatial e-services and data in other countries. This would allow for a comparison between countries. There are various possible case studies, three of which are presented hereafter. The first possibility is Spain. Being "one of the most decentralised countries in Europe", it has redistributed the administrative and political power among the central government and the autonomous authorities [88]. Although two main differences with regard to Belgium can immediately be identified-Spain has more autonomous authorities than Belgium; and the competences assigned to the Belgian regions are equal, while this is not the case in Spain-it could be useful to undertake a similar analysis of the Spanish system by making use of the methodology applied in this paper. This would be particularly relevant since a recently published UN study on good practices of geospatial governance shows that the Spanish National Geographic Institute developed partnerships with organisations within the same administration, as well as with autonomous authorities for the establishment of a National Plan for Land Observation [89].

Germany might also be an interesting case to study. It is a federal state, with a federal administration, autonomous regions-the Länder-and communities. From an e-government perspective, Germany seems to have difficulties in providing e-services to its users, as one of the main challenges is the mismatch between administrations. E-service initiatives are taken by the federal administration, whereas users often tend to use services at local level [90,91]. From a geospatial perspective, however, there seems to be cooperation that is stimulated by the INSPIRE Directive. The federal administration, the autonomous regions and the associations of communities are working together on the Geospatial Data Infrastructure Germany [92].

Finally, the authors believe that not only federal or decentralised countries could be studied with this methodology. Cooperation can also be difficult in more centralised states, as organisations within the same administration have direct hierarchical power over various actors at lower levels. This, however, requires coordination among both the hierarchically equal organisations at the higher 
level and between the organisations on the lower administrative levels [93]. The French governance of geospatial e-services and data might in this respect be a useful case study. It is also influenced by EU legislation, such as the INSPIRE Directive, and different lessons might be learned from a governance perspective.

The countries described above are only examples that aim to show that the methodology applied for this paper might also be relevant for studying other countries. Not only federalised and decentralised countries face coordination difficulties; centralised countries are also confronted with similar challenges. Further research is therefore required to help improve knowledge about different governance structures—-which is not only useful for academic purposes but also for policy makers.

Supplementary Materials: The following are available online at www.mdpi.com/2220-9964/6/9/282/s1. Reports of the conducted interviews and data of Table 4.

Acknowledgments: The authors would like to thank BELSPO, the Belgian Federal Science Policy office, for their support. The research pertaining to these results received financial aid from the Federal Science Policy according to the agreement of subsidy no. [BR/154/A4/FLEXPUB]. Furthermore those working on the FLEXPUB Research project, in particular Rink Kruk (National Geographic Institute), Anthony Simonofski (KU Leuven) and Thomas Tombal (UNamur), are thanked for their active cooperation in preparing and handling the online survey, as well as most of the interviews. Finally, the authors are grateful to Declan Deasy for conducting the language review of the article.

Author Contributions: The data of the online survey and the interviews was collected via the BRAIN-be FLEXPUB Research project (see Acknowledgments), for which Prof. Dr. Joep Crompvoets acts as Coordinator and Maxim Chantillon as PhD Researcher. The article was written by the first author, Maxim Chantillon, with the contribution of the two other authors, and extensively reviewed and rewritten by Maxim Chantillon, Prof. Dr. Joep Crompvoets and Prof. Dr. Vassilios Peristeras.

Conflicts of Interest: The authors declare no conflict of interest. The founding sponsors had no role in the design of the study; in the collection, analyses, or interpretation of data; in the writing of the manuscript, and in the decision to publish the results.

\section{References}

1. Crompvoets, J.; Bouckaert, G. Op Weg Naar een Performante Geodata Infrastructuur in Vlaanderen-Een. Multidisciplinaire Kijk, 1st ed.; KU Leuven-Faculteit Sociale Wetenschappen: Leuven, Belgium, 2009; p. 5.

2. Affisco, J.F.; Soliman, K.S. E-government: A strategic operations management framework for service delivery. Bus. Process. Manag. J. 2006, 12, 13-21. [CrossRef]

3. Latre, M.A.; Lopez-Pellicer, F.J.; Nogueras-Iso, J.; Béjar, R.; Zarazaga-Soria, F.J.; Muro-Medrano, P.R. Spatial Data Infrastructures for environmental E-government services: The case of water abstractions authorizations. Environ. Model. Softw. 2013, 48, 81-92. [CrossRef]

4. European Commission. New European Interoperability Framework-Promoting Seamless Services and Data Flows for European Public Administrations, 1st ed.; Publications Office of the European Union: Luxembourg, 2017; p. 29.

5. Popelier, P.; Sinardet, D. Stabiliteit en instabiliteit in de Belgische federale staatsstructuur. In België, quo Vadis? Waarheen na de Zesde Staatshervorming? 1st ed.; Popelier, P., Sinardet, D., Velaers, J., Cantillon, B., Eds.; Intersentia: Antwerpen, Belgium, 2012; pp. 3-31.

6. Alen, A.; Muylle, K. Compendium van Het Belgisch. Staatsrecht, 1st ed.; Wolters Kluwer: Mechelen, Belgium, 2012; pp. 142-149.

7. Tiwana, A.; Ramesh, B. E-Services: Problems, Opportunities, and Digital Platforms. In Proceedings of the 34th Annual Hawaii International Conference on System Sciences, Maui, HI, USA, 6 January 2001; p. 1.

8. Scupola, A. E-services: Definition, characteristics and taxonomy. JECO 2008, 6, i-iii. Available online: https:/ / www.igi-global.com/Files/Ancillary/JECO\%20preface\%206(2).pdf (accessed on 2 August 2017).

9. Lovelock, C.; Wirtz, J. Services Marketing: People, Technology, Strategy, 5th ed.; Prentice Hall: Upper Saddle River, NJ, USA, 2004; p. 9.

10. Hofacker, C.F.; Goldsmith, R.E.; Bridges, E.; Swilley, E. E-Services: A Synthesis and Research Agenda. In E-Services-Opportunities and Threats, 1st ed.; Evanschitzky, H., Iyer, G.R., Eds.; Deutscher Universitäts-Verlag: Wiesbaden, Germany, 2007; pp. 14-44. 
11. Technology Writers. HP E-Service Innovation Uses Intelligent-Agent Technology to Provide a Personalized Shopping Experience; Business Wire: New York, NY, USA, 2000; pp. 1-2.

12. De Bot, D. Wat is e-government? In E-Government in het Federale. België, 1st ed.; Uitgeverij Politeia: Brussel, Belgium, 2015; pp. 109-114.

13. Scupola, A.; Henten, A.; Nicolajsen, H.W. E-services: Characteristics, Scope and Conceptual Strengths. IJESMA 2009, 1, 1-16. Available online: http://forskning.ruc.dk/site/files/40350253/E_Services_ Characteristics_Scope_and_Conceptual_Strengths.pdf (accessed on 20 January 2017). [CrossRef]

14. Lindgren, I.; Jansson, G. Electronic service in the public sector: A conceptual framework. Gov. Inf. Q. 2013, 30, 163-172. Available online: http:/ / www.sciencedirect.com/science/article/pii/S0740624X13000026 (accessed on 20 January 2017). [CrossRef]

15. European Parliament; Council of the European Union. Directive of 14 March 2007 Establishing an Infrastructure for Spatial Information in the European Community (INSPIRE); 2007/2/EC; EUR-Lex: Brussels, Belgium, 2007; pp. L108/1-L108/14.

16. European Parliament; Council of the European Union. Directive of 17 November 2003 on the Re-Use of Public Sector Information; 2003/98/EC; EUR-Lex: Brussels, Belgium, 2003; pp. L345/90-L345/96.

17. European Parliament; Council of the European Union. Directive of 26 June 2013 Amending Directive 2003/98/EC on the Re-Use of Public Sector Information; 2013/37/EU; EUR-Lex: Brussels, Belgium, 2013; pp. L175/1-L175/8.

18. Pearsall, J.; Trumble, B.; Soanes, C.; Stevenson, A.; Elliott, J.; Bailey, C.; O'Connor, S.; Blaney, J.; Hayman, K.; Johnston, L.; et al. Oxford Concise English Dictionary, 9th ed.; Oxford University Press: Oxford, UK, 1999; pp. 365, 1376.

19. Masser, I.; Crompvoets, J. Building European Spatial Data Infrastructures, 3rd ed.; Esri Press: Redlands, CA, USA, 2015; p. 11.

20. Molenaar, M. Good Governance Requires Good Geoinformation. Available online: http://www.giminternational.com/content/article/good-governance-good-geo-info (accessed on 21 January 2017).

21. Macharis, C.; Crompvoets, J. A stakeholder-based assessment framework applied to evaluate development scenarios for the spatial data infrastructure for Flanders. Comput. Environ. Urban Syst. 2014, 46, 45-56. Available online: http://www.sciencedirect.com/science/article/pii/S0198971514000441 (accessed on 12 December 2016). [CrossRef]

22. Frances, J.; Levacic, R.; Mitchell, J.; Thompson, G. Introduction. In Markets, Hierarchies E Networks-The Coordination of Social Life, 1st ed.; Thompson, G., Frances, J., Levacic, R., Mitchell, J., Eds.; Sage: London, UK, 1991; p. 3.

23. Bouckaert, G.; Peters, B.G.; Verhoest, K. Resources, Mechanisms and Instruments for Coordination. In The Coordination of Public Sector Organizations-Shifting Patters of Public Management, 1st ed.; Palgrave Macmillan: Basingstoke, UK, 2010; pp. 34-50.

24. Christensen, T.; Laegreid, P. Governance and Administrative Reforms. In Oxford Handbook of Governance, 1st ed.; Levi-Faur, D., Ed.; Oxford University Press: New York, NY, USA, 2012; pp. 255-267.

25. Maxwell, J.A. Qualitative Research Design-An Interactive Approach, 1st ed.; Sage: Thousand Oaks, CA, USA, 1996; pp. 17-20.

26. Bryman, A. Social Research Methods, 5th ed.; Oxford University Press: Oxford, UK, 2016; pp. 552-553, 560-561.

27. Mortelmans, D. Interviewen. In Handboek. kwalitatieve Onderzoeksmethoden, 2nd ed.; Acco: Leuven, Belgium, 2009; pp. 188-189.

28. European Commission. ISA2-IT Solutions for Less Bureaucracy. Available online: https://ec.europa.eu/ isa2/home_en (accessed on 20 December 2016).

29. FLEXPUB. FLEXPUB Research Project, New Generation of Flexible Public Services-The Geospatial Case: Interviews, 2016-2017; FLEXPUB: Leuven, Belgium, 2017.

30. Mortelmans, D. Kwalitatieve databronnen. In Handboek. kwalitatieve Onderzoeksmethoden, 2nd ed.; Acco: Leuven, Belgium, 2009; pp. 216-217.

31. Patton, M.Q. Qualitative Research \& Evaluation Methods, 4th ed.; Sage: Thousand Oaks, CA, USA, 2015; pp. $438-442$.

32. ISACA. COBIT 5 Implementation, 1st ed.; ISACA: Rolling Meadows, IL, USA, 2012; p. 27.

33. De Haes, S.; Van Grembergen, W.; Debreceny, R.S. COBIT 5 and Enterprise Governance of Information Technology: Building Blocks and Research Opportunities. JIS 2013, 27, 308-324. Available online: http:/ / aaajournals.org/doi/10.2308/isys-50422 (accessed on 20 December 2016). [CrossRef] 
34. Billiet, J. Cycli in het empirisch onderzoek. In Een Samenleving Onderzocht: Methoden van het Sociaal-Wetenschappelijk Onderzoek, 2nd ed.; Billiet, J., Waege, H., Eds.; Uitgeverij de Boeck: Antwerpen, Belgium, 2012; pp. 33-64.

35. FLEXPUB. FLEXPUB Research Project, New Generation of Flexible Public Services-The Geospatial Case: Online Survey, 2016-2017; FLEXPUB: Leuven, Belgium, 2017.

36. Belgian Federal Parliament. Wet tot Oprichting van het Nationaal Geografisch Instituut; Belgisch Staatsblad: Brussels, Belgium, 1976; pp. 8299-8303.

37. Belgian Federal Government. Koninklijk Besluit tot Regerling van de Organisatie en de Werking van het Nationaal Geografisch Instituut en van de Vereffening van de Subsidies aan dit Instituut; Belgisch Staatsblad: Brussels, Belgium, 1985; pp. 3722-3725.

38. NGI. CartoWeb.be. Available online: http:/ / www.ngi.be/NL/NL1-19-1.shtm (accessed on 5 March 2017).

39. Belgian Federal Parliament. Wet tot Omzetting van de Richtlijn 2007/2/EG van het Europees. Parlement en de Raad van 14 Maart 2007 tot Oprichting van een Infrastructuur Voor Ruimtelijke Informatie in de Gemeenschap (INSPIRE); Belgisch Staatsblad: Brussels, Belgium, 2011; pp. 559-566.

40. National Geographic Institute. Geoportal of the federal state of Belgium. Available online: https://www. geo.be/\#/catalog?l=en (accessed on 15 May 2017).

41. National Geographic Institute; State Archives of Belgium; Royal Library; Africa Museum. Cartesius. Available online: https: / www.cartesius.be/CartesiusPortal/ (accessed on 15 May 2017).

42. FPS Finance. Patrimonial Documentation. Available online: https://financien.belgium.be/nl/over_de_fod/ structuur_en_diensten/algemene_administraties/patrimoniumdocumentatie (accessed on 16 May 2017).

43. FPS Finance. E-services. Available online: https:// financien.belgium.be/nl/E-services/overview (accessed on 16 May 2017).

44. Belgian Federal Government. Koninklijk Besluit houdende Oprichting van de Federale Overheidsdienst Beleid en Ondersteuning; Belgisch Staatsblad: Brussels, Belgium, 2017; pp. 30684-30686.

45. FPS Policy \& Support. 4de Weg. Available online: http://www.services.fedict.be/nl/Services/4de-weg (accessed on 19 May 2017).

46. FPS Policy \& Support. eBirth. Available online: http://www.services.fedict.be/nl/services/eBirth (accessed on 19 May 2017).

47. BRIC. Wet van 21 Augustus 1987-Officieuze Coördinatie van de Wetten en Organieke Ordonnantie Betreffende het CIBG. Available online: http:/ / cibg.brussels/nl/het-cibg/bestanden/wettelijke-basis / wet-van-21-augustus-1987 (accessed on 19 May 2017).

48. Brussels Mobility. Fixmystreet. Brussels. Available online: https:/ / fixmystreet.irisnet.be/about (accessed on 20 May 2017).

49. Brussels Mobility. Realtime Mobility. Available online: http:/ /www.mobielbrussel.be/ (accessed on 20 May 2017).

50. Brussels Urban Development. Building Permit Viewer. Available online: https://stedenbouw.irisnet.be/ vergunningen (accessed on 20 May 2017).

51. Brussels Parliament. Ordonnatie Betreffende de Oprichting en Organisatie van een Gewestelijke Dienstenintegrator; Belgisch Staatsblad: Brussels, Belgium, 2014; pp. 43665-43674.

52. Flemish Parliament. Decreet Houdende de Oprichting van het Publiekrechtelijk Vormgegeven Extern Verzelfstandigde Agentschap "Agentchap voor Geografische Informatie Vlaanderen"; Belgisch Staatsblad: Brussels, Belgium, 2004; pp. 43449-43451.

53. Flemish Parliament. Decreet Betreffende de Geografische Data-Infrastructuur Vlaanderen; Belgisch Staatsblad: Brussels, Belgium, 2009; pp. 33349-33360.

54. Flemish Government. Besluit van de Vlaamse Regering Houdende de Oprichting van het Intern Verzelfstandigd Agentschap Informatie. Vlaanderen, de Bepaling van Diverse Maatregelen voor de Ontbinding Zonder Vereffening van het AGIV, de Regeling van de Overdracht van de Activiteiten en het Vermogen van het AGIV aan het Agentschap Informatie Vlaanderen. en de Vaststelling van de Werking, het Beheer en de Boekhouding van het Eigen Vermogen. Informatie Vlaanderen; Belgisch Staatsblad: Brussels, Belgium, 2016; pp. 34028-34032.

55. Agency Information Flanders. Basiskaart Vlaanderen (GRB). Available online: https:/ / overheid.vlaanderen. be/producten-diensten/basiskaart-vlaanderen-grb (accessed on 22 May 2017).

56. Agency Information Flanders. Wat is het GRB? Available online: https:/ / overheid.vlaanderen.be/GRB-Watis-het-GRB (accessed on 22 May 2017). 
57. Flemish Parliament. Decreet. Betreffende het Centraal. Referentieadressenbestand; Belgisch Staatsblad: Brussels, Belgium, 2009; pp. 45068-45071.

58. Agency Information Flanders. CRAB-decreet en uitvoeringsbesluiten. Available online: https://overheid. vlaanderen.be/CRAB-CRAB-decreet-en-uitvoeringsbesluiten\#0 (accessed on 22 May 2017).

59. Flemish Parliament. Decreet Houdende de Uitwisseling van Informatie over een Inname van het Openbaar Domein in het Vlaamse. Gewest; Belgisch Staatsblad: Brussels, Belgium, 2014; pp. 51733-51736.

60. Agency Information Flanders. Wat is het GIPOD? Available online: https:/ / overheid.vlaanderen.be/GipodAlgemeen\#0 (accessed on 22 May 2017).

61. Walloon Administration. Guide des Institutions-Département de la Géomatique. Available online: http: //www.wallonie.be/fr/guide/guide-services/15972 (accessed on 24 May 2017).

62. E-Wallonie-Bruxelles Simplification. Promouvoir la Simplification et L'administration Électronique. Available online: http:/ / www.ensemblesimplifions.be/node/3 (accessed on 27 May 2017).

63. E-Wallonie-Bruxelles Simplification. Consultant interne du service public. Available online: http://www. ensemblesimplifions.be/node/160 (accessed on 27 May 2017).

64. Walloon Directory-General of Land Use and Urban Planning. Direction de la Géomatique. Available online: http://spw.wallonie.be/dgo4/site_amenagement/site/directions/dgeo (accessed on 28 May 2017).

65. Walloon Administration. Guide des institutions-Département des Technologies de l'information et de la communication (TIC). Available online: http:/ / www.wallonie.be/fr/guide/guide-services/16009 (accessed on 24 May 2017).

66. Walloon Administration. Finalités du Géoportail de la Wallonie. Available online: http://geoportail. wallonie.be/mentions-legales.html (accessed on 26 May 2017).

67. Walloon Administration. ICAR—La Source Authentique des Données D'adresses en Wallonie. Available online: http:/ /geoportail.wallonie.be/georeferentiel/icar (accessed on 26 May 2017).

68. Walloon Administration. Fiche descriptive-Projet Informatique de Cartographie Continue (PICC). Available online: http:/ / geoportail.wallonie.be/catalogue/b795de68-726c-4bdf-a62a-a42686aa5b6f.html (accessed on 26 May 2017).

69. International Organization for Standardization. ISO 19115-1:2014 Geographic Information—Metadata-Part 1: Fundamentals. Available online: https:/ / www.iso.org/standard/53798.html (accessed on 27 October 2016).

70. KLIM. Functie van KLIM. Available online: https://www.klim-cicc.be/klim2/home.jsp (accessed on 17 June 2017).

71. Agency Information Flanders. Kabel- en Leidinginformatieportaal (KLIP). Available online: https:/ /overheid. vlaanderen.be/producten-diensten/kabel-en-leidinginformatieportaal-klip (accessed on 17 June 2017).

72. Federal State; Flemish Region; Walloon Region; Brussels Capital Region. Samenwerkingsakkoord. van 2 April 2010 voor de Coördinatie van een Infrastructuur voor Ruimtelijke Informatie; Belgisch Staatsblad: Brussels, Belgium, 2010; pp. 23357-23365.

73. FPS Policy and Support. Wat zegt de Wet? Available online: http://www.fedict.belgium.be/nl/over_fedict/ nieuwsberichten/fedivers/fedivers_nov_2014/Item5 (accessed on 20 June 2017).

74. BRIC. Leidraad. voor de Gebruiker van UrbIS-Producten, 1st ed.; BRIC: Brussels, Belgium, 2015; pp. 3-5.

75. BRIC. UrbIS Solutions. Available online: http://cibg.brussels/nl/onze-oplossingen/urbis-solutions (accessed on 21 June 2017).

76. Dumortier, F.; BRIC, Brussels, Belgium. Personal communication, 2017.

77. Agency Information Flanders. Organisatie. Available online: http://www.geopunt.be/voor-experts/inspire/ organisatie (accessed on 28 May 2017).

78. Walloon Parliament. Décret. Relative à L'infrastructure D'information Géographique; Belgisch Staatsblad: Brussels, Belgium, 2010; pp. 9155-9160.

79. Walloon Administration. Plan Opérationnel Géomatique Pour la Wallonie. Available online: http://geoportail. wallonie.be/POGW (accessed on 28 May 2017).

80. Department Information Flanders. GDI-Jaarverslag 2014-2015, 1st ed.; Department Information Flanders: Brussels, Belgium, 2015; p. 8.

81. Federal State; Regional Authorities; Community Authorities. Samenwerkingsakkoord. voor het Harmoniseren en Uitlijnen van de Initiatieven die de Realisatie van een Gë̈ntegreerd E-Government Beogen; Belgisch Staatsblad: Brussels, Belgium, 2013; pp. 70727-70731. 
82. BELGIF. Belgian Interoperability Framework. Available online: http://www.belgif.be/nl/index.html (accessed on 30 May 2017).

83. De Bot, D. De impact van het grondwettelijk recht op de structuur van het interbestuurlijk gegevensverkeer. In E-Government in het Federale. België, 1st ed.; Uitgeverij Politeia: Brussel, Belgium, 2015; pp. 269-278.

84. FEDWEB. Coördinatiestructuur voor Patrimoniuminformatie: Website. Available online: https://fedweb. belgium.be/nl/nieuws/2017/co\%C3\%B6rdinatiestructuur-voor-patrimoniuminformatie-website (accessed on 1 July 2017).

85. Federal State; Flemish Region; Walloon Region; Brussels Capital Region. Samenwerkingsakkoord met Betrekking tot de Coördinatiestructuur voor Patrimoniuminformatie; Belgisch Staatsblad: Brussels, Belgium, 2014; pp. 76799-76817.

86. CSPI. Wat doen We? Available online: https://www.scip-cspi.be/wat-doet-het-cspi- (accessed on 1 July 2017).

87. Federal State; Flemish Region; Walloon Region; Brussels Capital Region. Samenwerkingsakkoord. met Betrekking tot de Eenmaking van de Wijze Waarop Gerefereerd Wordt aan Adressen en de Koppeling van Adresgegevens; Belgisch Staatsblad: Brussels, Belgium, 2016; pp. 11369-11373.

88. Gobierno de Espana. Spanish Institutions-The territorial organisation of the State. Available online: http:/ / www.lamoncloa.gob.es/lang/en/espana/spanishinstitutions/Paginas/index.aspx\#to (accessed on 2 July 2017).

89. United Nations Committee of Experts on Global Geospatial Information Management. Compendium of good practices for national institutional arrangement. Available online: http:/ /ggim.un.org/docs/meetings / GGIM7/Agenda\%207\%20Compendium\%20of\%20NIA\%20Good\%20Practices.pdf (accessed on 2 July 2017).

90. Naveed Baqir, M.; Iyer, L. E-government Maturity over 10 Years: A Comparative Analysis of E-government Maturity in Select Countries around the World. In Comparative E-Government, 1st ed.; Reddick, C.G., Ed.; Springer: New York, NY, USA, 2010; pp. 3-22.

91. Expertenkommission Forschung und Innovation. E-government in Germany: Much Room for Improvement. Available online: http:/ /www.e-fi.de/fileadmin/Chapter_2016/2016_B4_EN.pdf (accessed on 2 July 2017).

92. Geodateninfrastruktur Deutschland. Steering Committee. Available online: http://www.geoportal.de/EN/GDIDE/Organisation/Steering-Committee/gdi-de-steering-committee.html?lang=en (accessed on 2 July 2017).

93. Bouckaert, G.; Peters, B.G.; Verhoest, K. Coordination in France. In The Coordination of Public Sector Organizations-Shifting Patters of Public Management, 1st ed.; Palgrave Macmillan: Basingstoke, UK, 2010; pp. 170-186.

(C) 2017 by the authors. Licensee MDPI, Basel, Switzerland. This article is an open access article distributed under the terms and conditions of the Creative Commons Attribution (CC BY) license (http:/ / creativecommons.org/licenses/by/4.0/). 


\title{
Article
}

\section{Closing Data Gaps with Citizen Science? Findings from the Danube Region ${ }^{\dagger}$}

\author{
Josip Lisjak ${ }^{1, \ddagger}$, Sven Schade ${ }^{2, \ddagger}$ and Alexander Kotsev $2, *, \ddagger$ \\ 1 City of Požega, Department for Communal System and Management, Požega HR-34000, Croatia; \\ josip.lisjak@pozega.hr \\ 2 European Commission, Joint Research Centre, Digital Economy Unit, Ispra 21027, Italy; \\ s.schade@ec.europa.eu \\ * Correspondence: alexander.kotsev@ec.europa.eu; Tel.: +39-0332-78-9069 \\ + The views expressed are purely those of the authors and may not in any circumstances be regarded as \\ stating an official position of the European Commission. \\ $\ddagger$ All authors contributed equally to this work.
}

Received: 23 May 2017; Accepted: 11 August 2017; Published: 1 September 2017

\begin{abstract}
Although data is increasingly shared online and accessible for re-use, we still witness heterogeneous coverage of thematic areas and geographic regions. This especially becomes an issue when data is needed for large territories and including different nations, as, for example, required to support macro-regional development policies. Once identified, data gaps might be closed using different approaches. Existing — but so far non accessible—data might be made available; new public sector information could be gathered; or data might be acquired from the private sector. Our work explores a fourth option: closing data gaps with direct contributions from citizen (Citizen Science). This work summarizes a particular case study that was conducted in 2016 in the Danube Region. We provide a gap analysis over an existing macro-regional data infrastructure, and examine potential Citizen Science approaches that might help to close these gaps. We highlight already existing Citizen Science projects that could address a large part of the identified gaps, and suggest one particular new application in order to indicate how a-so far uncovered — gap might be approached. This new application addresses bioenergy as a particular field of the circular economy. On this basis we discuss the emerging opportunities and challenges for this particular way of public participation in regional development policy. We close by highlighting areas for future research.
\end{abstract}

Keywords: Citizen Science; data gaps; spatial data infrastructures; Danube region; European Union Strategy for the Danube Region

\section{Introduction}

During the past few years, Open Data policies reached a new level. Governments across the entire globe continue to release public sector information for re-use by the public and private sector, hoping for increasing uptake and the resulting growth and innovation [1]. Whereas the current achievements are remarkable in many countries, we still witness data gaps in many different thematic areas, ranging across all economic, social and environmental domains [2]. Such gaps become even more visible when addressing macro-regional questions, because different notations follow diverse policies and are at a different stage of implementation. Furthermore, for some we might never be in the position to provide the missing data sets. Assuming that better evidence leads to better policy making, and especially that more complete data is an asset for policy, new approaches are needed in order to close the existing gaps and to support macro-regional developments.

So far, approaches to close data gaps include efforts to (i) provide access to already existing data sets; (ii) collect new public sector information with classical tools, such as land surveys; and (iii) acquire 
suitable data from the private sector. All these developments could already be observed through the emerging spatial data infrastructures (SDI) [3] on multiple geographic scales (e.g., municipal, regional, national, and international), which deserves more attention.. However, there is a fourth option available. Citizen Science is increasingly seen as a complement, and even substitute, to data from such traditional sources [4]. The penetration of smart devices, combined with the widespread use of socially-enabled Internet platforms and the rapidly developing technological scenery are together leading to unprecedented advancements in the ways we collect, transfer and make sense of data [5]. Individuals are no longer passive users of data generated by a designated institution on their behalf. On the contrary, they play a far more direct role in the creation and utilisation of content.

From this perspective, citizens are increasingly in need of data, as they want to play a more significant role in forming policies, but also in their implementation and control. Data is therefore to be seen within the context of the direct democracy paradigm [6]. It is nowadays more accessible than ever which implicitly leads to a better insight on general and individual decisions and their consequences [7]. Today, citizens do approach governmental bodies and public administration more intensively with their demands, complaints and requests for protection of their rights. Those demands cover various fields such as communal issues, social rights, health, environment protection. There are multiple challenges associated with the citizen participation within the governance process (see e.g., [8,9]). Citizens use available data and are an increasingly active partner in public sector management. It is therefore meaningful that they participate in data collection as well. Realising the many potential benefits from engaging with citizens, we conducted a study in the Danube region with two interdependent objectives. On one hand, we analyse the possible data gaps within the study area, for example, related to areas such as environmental protection, energy production and air quality. On the other hand, we elaborate on how some of the most prominent gaps might benefit from some sort of community engagement, such as the voluntary measurement of the exhaust of cars, air quality parameters, or the mapping of the current production of renewable energy in neighbourhoods. In meeting our objectives we studied the pan-Danubian open data portal put in place within the Danube Reference Data and Services Infrastructure project-DRDSI [10]. Our intention was not to completely fill existing gaps with Citizen Science data, as this is unrealistic given the vastness of the areas addressed (including air, water, energy and many more). Instead, we (i) emphasised on the importance of citizen engagement as an alternative channel for acquisition of data, and (ii) provided a theoretical construct on how the identified data gaps may be addressed, and (iii) offer several concrete examples on how activities involving the active participation of citizens would improve the current situation.

The following sections first present the background underlying the core of our investigations (Section 2). After introducing dedicated activities in the Danube Region, we present the results of our initial gap analysis of data availability in the region (Section 3). This is the basis for a first matchmaking of these gaps with already existing Citizen Science activities, and a proposal to address one of the gaps, which is related to bioeconomy, in Section 4. Section 5 discusses our findings, especially considering the (i) emerging opportunities and (ii) challenges for this particular way of public participation in relational development policy. The article closes with our main conclusions and an outline of future work (Section 6) We particularly underlining that this is a promising baseline for more detailed investigations and actions for addressing data gaps using Citizen Science.

\section{Background}

Our study focuses on the Danube macro-region. We benefit from our past support to macro-regional data sharing, but can also tap into a wide range of ongoing Citizen Science activities only partly coming from within the region.

\subsection{Study Area}

Geographically our analyses cover the area of the European Union Strategy for the Danube region-EUSDR [11]. It spans over 14 countries-Austria, Bosnia and Herzegovina, Bulgaria, Croatia, 
Czech Republic, Germany (Baden-Württemberg and Bavaria lander.), Hungary, Moldova, Montenegro, Romania, Slovenia, Slovakia, Serbia and Ukraine (Oblasts of Chernivtsi, Ivano-Frankivsk, Odessa and Zakarpattia.) (Figure 1). As an initiative, endorsed by the EU Member States at the General Affairs Council on 13 April 2011, the EUSDR functions through the commitment of all 14 neighbouring countries for joint actions towards regional development, taking into consideration each region's competitive advantages. A governance body is also established to coordinate those activities on a macro scale [11]. The strategy is thematically subdivided into 11 priority areas (PA) that cover a broad range of topics with some relevance to macro-regional development, such as environmental protection, transportation, capacity building, and competitiveness.

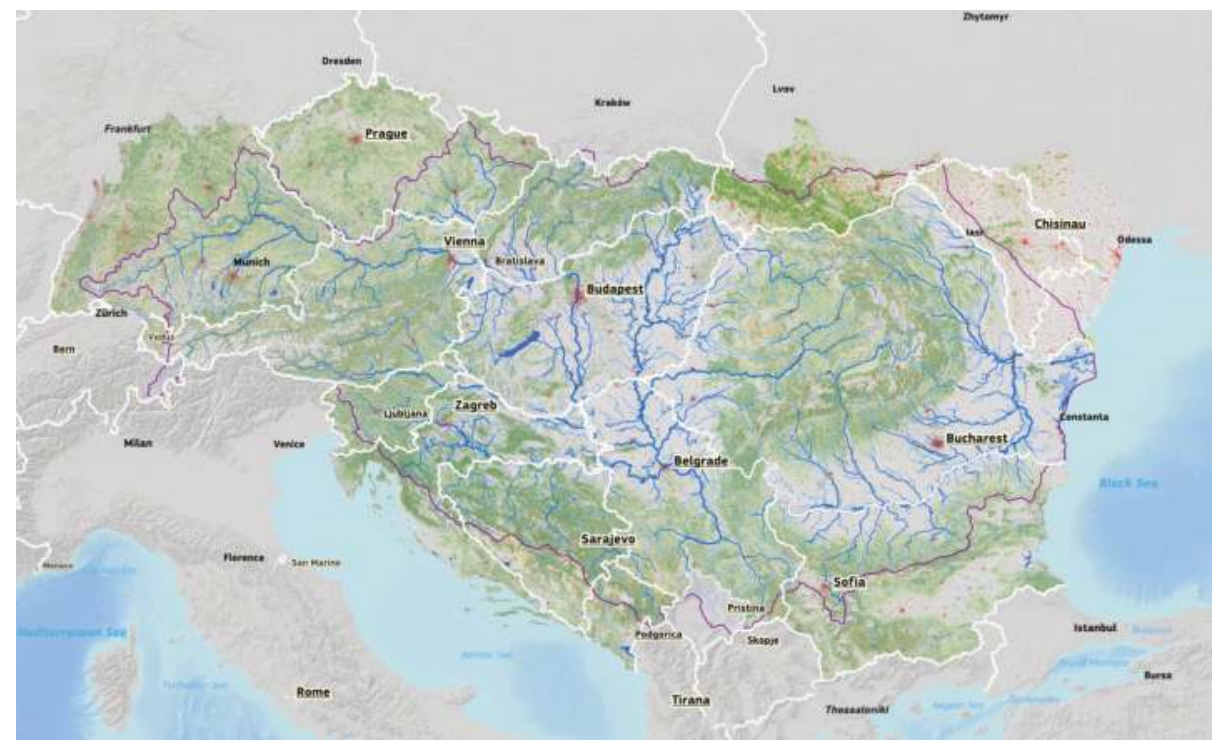

Figure 1. Territorial dimension of the EU Strategy for the Danube Region. Source: [12].

Within this broad context, the access to timely, accurate and comparable data for all 14 countries is a cross-cutting issue that is of critical importance for the overall implementation of the strategy. Benchmarking, monitoring progress towards predefined goals and identifying the advantages of each country, region or city in the study area are just a few examples of the possible use of data on the macro-regional level. At the same time, data infrastructures in the study area are heterogeneous, shaped by different cultures, traditions, languages and organisational settings.

\subsection{Danube Reference Data and Services Infrastructure (DRDSI)}

\subsubsection{Policy Context}

Data is of critical importance for the successful implementation of regional policy. In the absence of high quality (geospatial) data, it would hardly be possible for policy makers to identify the competitive advantages or disadvantages of a given region. Furthermore, as already mentioned, comparable territorially referenced data is needed in order to define baselines, and monitor progress in meeting the policy objectives against the baselines. At the same time, the identification, acquisition and use of data for the study area turned out to be a highly challenging task which required series of interdependent tasks (organisational, technological and legal) to be addressed in a coordinated manner. Considering the above, a project was put in place by the Joint Research Centre (JRC) of the European Commission. The project-Danube Reference Data and Services Infrastructure-was implemented in 
the period 2014-2016 with the overall objective to engage with stakeholders in the Danube region and work towards the establishment of a macro-regional data infrastructure addressing, at least in part, the challenges highlighted above.

The central access point of the data infrastructure was an open data portal that eases the access to various resources through a single entry point (Figure 2). A network of experts—Danube_Net—was also established with representatives in each country. They acted as 'ambassadors' of open data and worked with stakeholders on a national level.
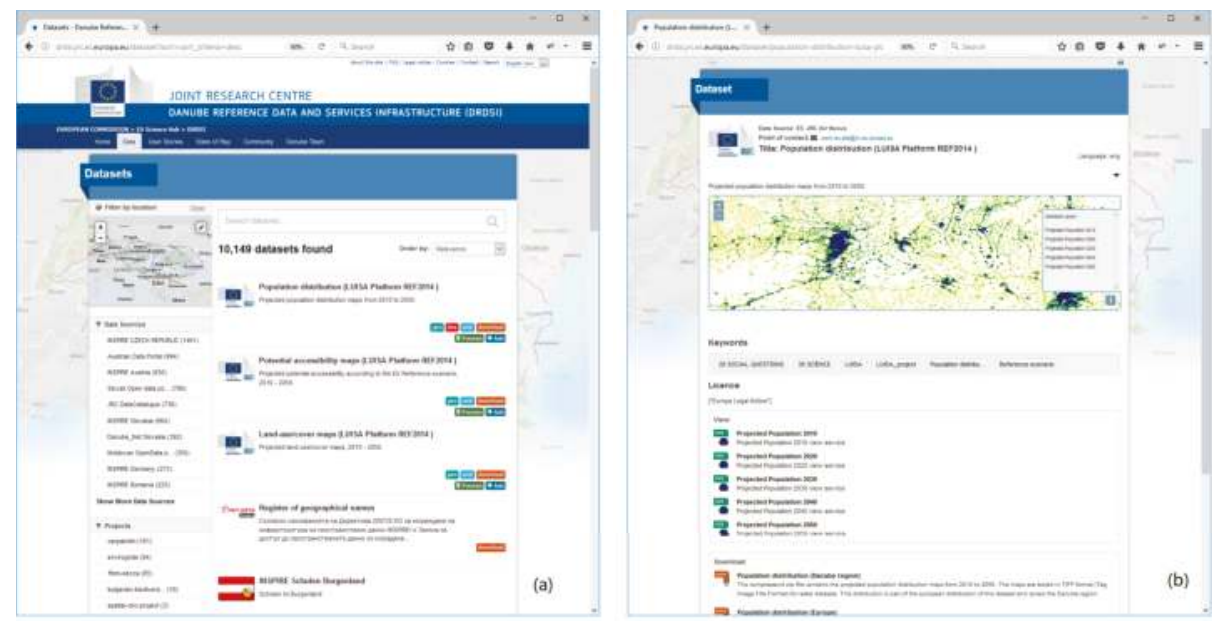

Figure 2. User interface of DRDSI. List of available datasets (a) and details about one particular entry (b). Source: [10].

\subsubsection{DRDSI Implementation}

The open data platform was metadata-driven. Metadata was (i) harvested from external sources, (ii) processed and stored internally, (iii) served through standardised web services, and (iv) exposed through a front-end. The software tools which were used included the open source CKAN (fronted), GeoNetwork open source (backend), and PostgreSQL (metadata storage). A semi-automated process was put in place for harvesting the Catalogue Services for the Web (CSW) provided by GeoNetwork, taking advantage of the CKAN geospatial plugin.

An Extract-Transform-Load (ETL) process was put in place in order to acquire, process, store and expose metadata records from heterogeneous sources (Figure 3.). The sources included standardised services (following the specifications of the Open Geospatial Consortium), proprietary solutions (ESRI RESTful services), as well as metadata collected by the Danube_Net network of experts. The acquired metadata was stored in a PostgreSQL relational database. An overview of the content is provided under Section 3.1.1 below. 


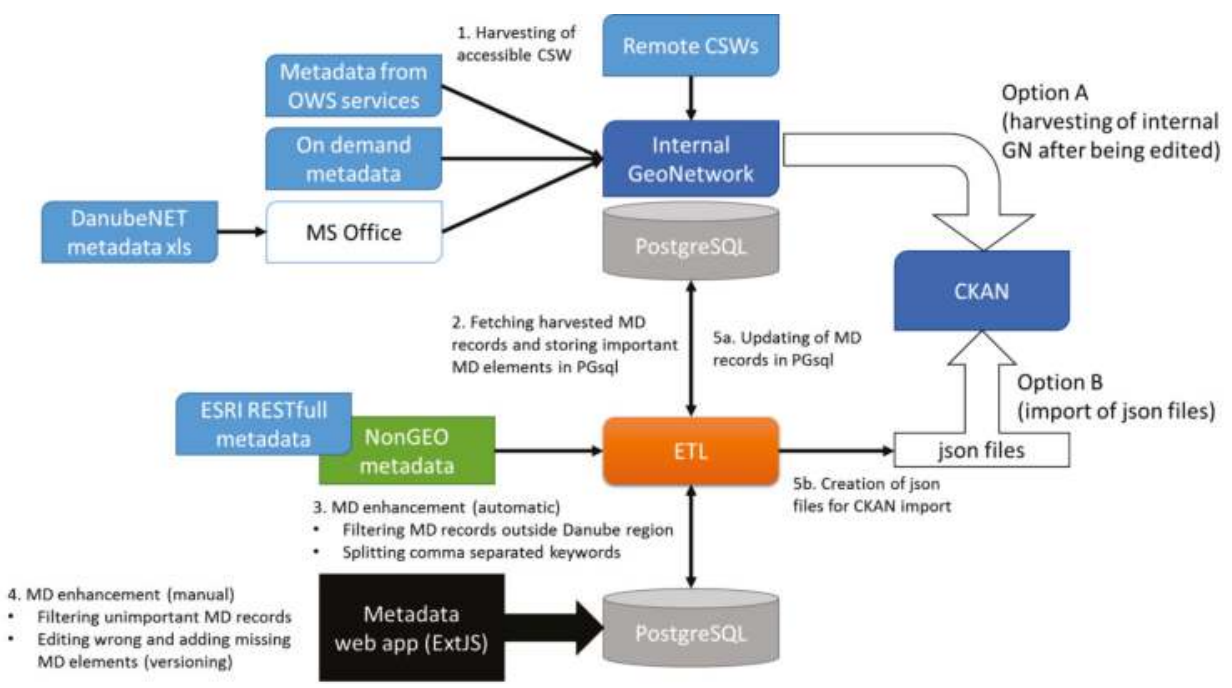

Figure 3. Architecture of the Danube Reference Data and Services infrastructure. Source: [13].

\subsection{Citizen Science}

\subsubsection{What Is Citizen Science?}

Citizen Science is a broad term, which considers that citizens can participate in the scientific research process in different ways: as observers, as funders, in identifying images or analysing data, or through providing data themselves [14]. This allows for the democratisation of science, and is also linked to stakeholders' engagement and public participation. The European Commission places it as part of Open Science [15], which is under the scope of the Digital Single Market through the 'Digital Economy and Society' priority of European Commission [16].

The notion of Citizen Science is often related to terms "crowd-sourcing" and "volunteer geographic information". For the purpose of clear understanding, crowd-sourcing is a method of mass data collection, while volunteer geographic information-VGI is limited to geographic/spatial Citizen Science only. These are clear distinctions, but the terms are nonetheless closely related. An analysis of the related terminology and its use in scientific publications has recently been published [17].

The history and rise of Citizen Science has already been well explained by authors such as Silvertown [18], and Bonney et al. [19]. In summary, the engagement of citizens in scientific activities has already a long tradition and only the term Citizen Science came to use relatively recently. Ongoing digital transformations, especially the evolution of mobile Internet and smart devices helped boosting the amount of Citizen Science activities in recent years [5].

In our work, we most often refer to the work of Craglia and Shanley [20] that integrates several of the previous categorisations, such as the one of Haklay [14] into a combined scheme. Most notably, Citizen Science is positioned into a space of Citizens' active contributions, collaborations or co-creations, which may have different motivations (see also Figure 4). 


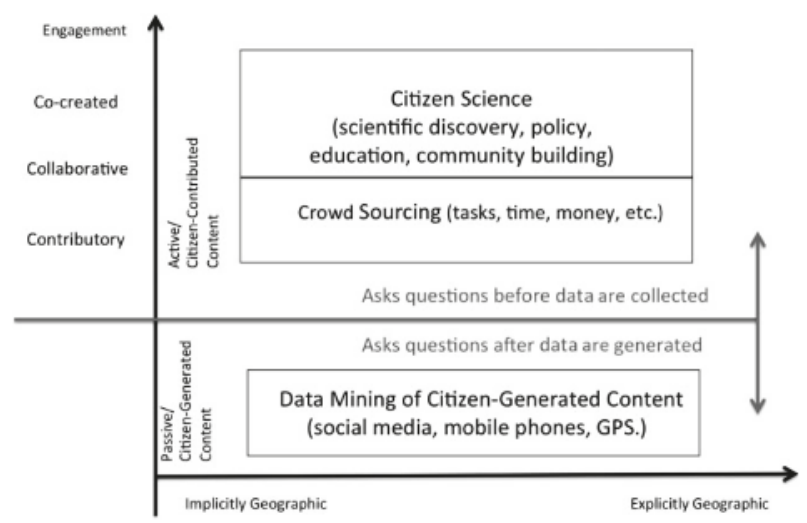

Figure 4. Schema positioning Citizen Science in the wider context of crowd-sourcing and data mining. Source: [20].

From our perspective Citizen Science is a manifestation of the collaboration of the public with researchers for common good. It is driven mainly by new technologies, and results in new knowledge and added value through the acquisition of new information. While the benefits and outcomes of specific Citizen Science activities can be manyfold, our work addresses only the narrow purpose of data gathering. Here especially following Citizen Science approaches to close data gaps, i.e., collecting data for a particular domain and inside a previously known geographic territory. We identify areas and approaches on how existing data gaps could be closed without any intention to replicate or replace existing sources.

\subsubsection{Emerging Organisational Structures for Citizen Science}

An increasing number of organisation relate themselves to Citizen Science. The League of European Research Universities (LERU) provides only one example [21]. Furthermore, a number of informal platforms are dedicated to Citizen Science activities (including, for example SciStarter [22], Atlas of Living Australia, Zooniverse, CitSci.org, or Österreich forscht). During the past few years, the continuously increasing Citizen Science activities were complemented with organisational structures. This included both thematic structures (e.g., the formation of a Citizen Science interest group within the network of European Environmental Protection Agencies, or the Citizen Science Domain Working Group of the Open Geospatial Consortium (OGC)) and geographic structures (such as national level networks in the UK, USA, Australia, Germany, Austria, Switzerland, Spain, etc., as well as a European and international network). The majority of Citizen Science activities in the Danube region occur in EU Member States. In Europe, thanks to funding from the EU, two research networks should be highlighted. One focusses on the concept of Citizens' Observatories, as a notion to include Citizens in data gathering (sensing) activities. Whereas five Citizens' Observatory projects already came to a close, four new ones started recently in order to deploy and scale up such observatories. Furthermore, project proposals to coordinate the already ongoing Citizens' Observatory initiatives are currently under evaluation. The other research network takes a slightly different approach. The Collective Awareness Platforms for Sustainability and Social Innovation (CAPS) seeks for new models to create and raise the awareness of emerging sustainability challenges. They are set up to address existing challenges through collective action. Several series of CAPs have already been funded (https://capssi.eu).

Last but not least, Citizen Science also receives much attention under the umbrella of Open Science [23]. Current research projects are funded under the notions of Responsible Research and Innovation (RII) [24] and Science with and for Society (SwfS) [25]. 


\subsubsection{Citizen Science Networks in the Danube Region}

The richest network that is relevant for the Danube Region is the European Citizen Science Association-ECSA (http:/ / ecsa.citizen-science.net). Established in 2015, ECSA gathers wide range of member and supporters in Europe and worldwide. It has a well-defined structured organisation schema, with clearly assigned roles.

ECSA conducts capacity building and training workshops and develops tools and resources for the Citizen Science community in accordance with research and coordination projects they are involved in, including the two Horizon2020 projects Doing it Together Science (DITOs) and Landsense. ECSA also actively works on forming partnerships with other Citizen Science associations, not only in Europe, but worldwide. This especially includes the US-based CSA and the Australian ASCA.

Österreich forscht is online since 2014, and acts as a project platform. It is run by a working group of the University of Natural Resources and Life Sciences in Vienna. The platform provides information on Citizen Science and bundles over 20 Austrian Citizen Science projects. Within this framework institutions are intensively working together to network Citizen Science actors in Austria and internationally, to further promote the quality of Citizen Science, and to further develop the method. The main partner organisation that supports Österreich forscht, and vice versa, acts with similar goals is the Zentrum für Citizen Science. Besides this cooperation, Österreich forscht organises an Austrian Citizen Science Conference which is supported by the Federal Ministry of Science, Research and Economy (BMWFW) - the founder of the Zentrum für Citizen Science. These two institutions also coordinate events that encourage Citizen Science activities.

The Citizen Science platform Bürgerschaffenwissen provides information about activities to support Citizen Science in Germany. The associated component programme "GEWISS" is responsible for skills development and the establishment of a "Citizen Science strategy 2020" for Germany. GEWISS is funded by the German Ministry for Education and Research (BMBF). Additional support for the online platform is provided by the Stifterverband Deutscher Wissenschaft.

GEWISS consists of two projects conducted to support each other: A capacity-building program is focused on the evolution of Citizen Science through events and development of a strategy and practical toolkit. An online platform seeks to connect current Citizen Science projects to each other and increase public awareness of Citizen Science. Bürgerschaffenwissen issued a Green paper-Citizen Science Strategy 2020 for Germany [26] which presents the understanding, the requirements and the potential of Citizen Science in Germany. It can, in addition, be considered as an overview of the current state-of-play of Citizen Science.

The Centre for Citizen Science was established at the Austrian Agency for International Cooperation in Education and Research (OeAD-GmbH) in 2015 by the Federal Ministry of Science, Research and Economy. It serves as an information and service centre for researchers, citizens and experts from different disciplines. Another task of the centre is the cross-linking of interested communities beyond Austria [27]. The organisation provides a large information library with links to projects, literature, calls for financing, etc. There is also list of helpful tools to support the creation of Citizen Science projects, smartphone apps, and do-it-yourself tools.

\section{Analysis of Existing Data Gaps}

Within the context outlined above, data infrastructures in the study area were analysed through a stepwise approach (Figure 5) in order to identify possible gaps that might be-at least partially-covered through the engagement of citizens. The steps included (i) identification of existing data from multiple channels; (ii) classification of identified data with respect to the priorities of the EU Strategy for the Danube region; (iii) identification and analysis of possible Citizen Science contributions; and (iv) uptake of the results in support of the EUSDR. 


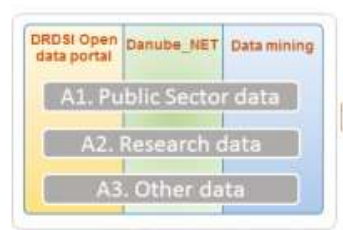

Step 1. Data discovery

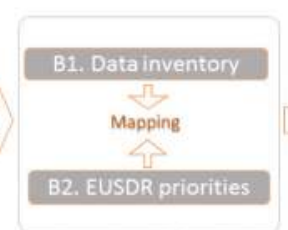

Step 2. Gap analysis

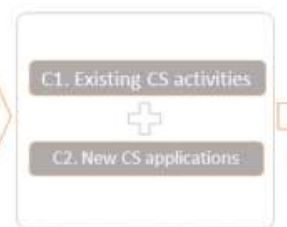

Step 3. Closing gaps

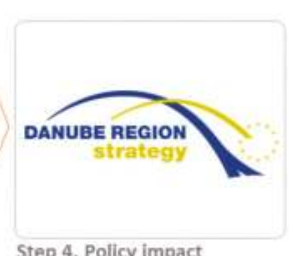

Step 4. Policy impact

Figure 5. Approach for the identification of possibly contribution of citizens.

\subsection{Data Discovery}

We investigated multiple channels (described below) in order to identify what exists in terms of thematic data relevant to the EUSDR. The sources we used are shown through Step 1 (Figure 5). The content that was discovered consisted of (i) public sector data, (ii) results from ongoing or past research projects, as well as (iii) others, such as pan-European data-related initiatives.

It is noteworthy to highlight that having a complete picture of existing data, considering the complexity and dynamism of the macro-region, combined with the broad thematic scope of the EUSDR is a task that goes far beyond our capacity. Nonetheless, we consider that the analysis of existing data gives us a fairly good indication of the possible role that Citizen Science can play. Any follow-up investigations would need a more detailed analysis of the data that is required in each of the priority areas, and a subsequent examination of the coverage by already available data sets. We suggest that such investigations are carried out separately for each priority area.

\subsubsection{Open Data Portal}

For a period of three years the DRDSI project documented and made discoverable over 10,000 datasets through a dedicated open data portal [10]. The portal is metadata driven and the content is collected through harvesting of distributed sources such as national open data portals, national geoportals and project repositories. The majority, if not all sources (public sector resources, national geoportals, open data portals and relevant project outputs), originate from the public sector.

The distribution of data between countries is uneven, with a noteworthy higher number of datasets in the western part of the study area (Figure 6). Thematically, the datasets correspond to one or more of the priorities defined under the EUSDR [11]. That is why they are relevant to a broad range of environmental, social and economic topics. More information on the open data portal and its content is provided by Dusart et al. [12].

From our perspective, the harvested content is comprehensive and provides a representative overview on the actual data availability within the study area. Furthermore, the same approach for collecting input metadata has been applied throughout the whole macro-region, and therefore provides a comparable overview of data availability. 


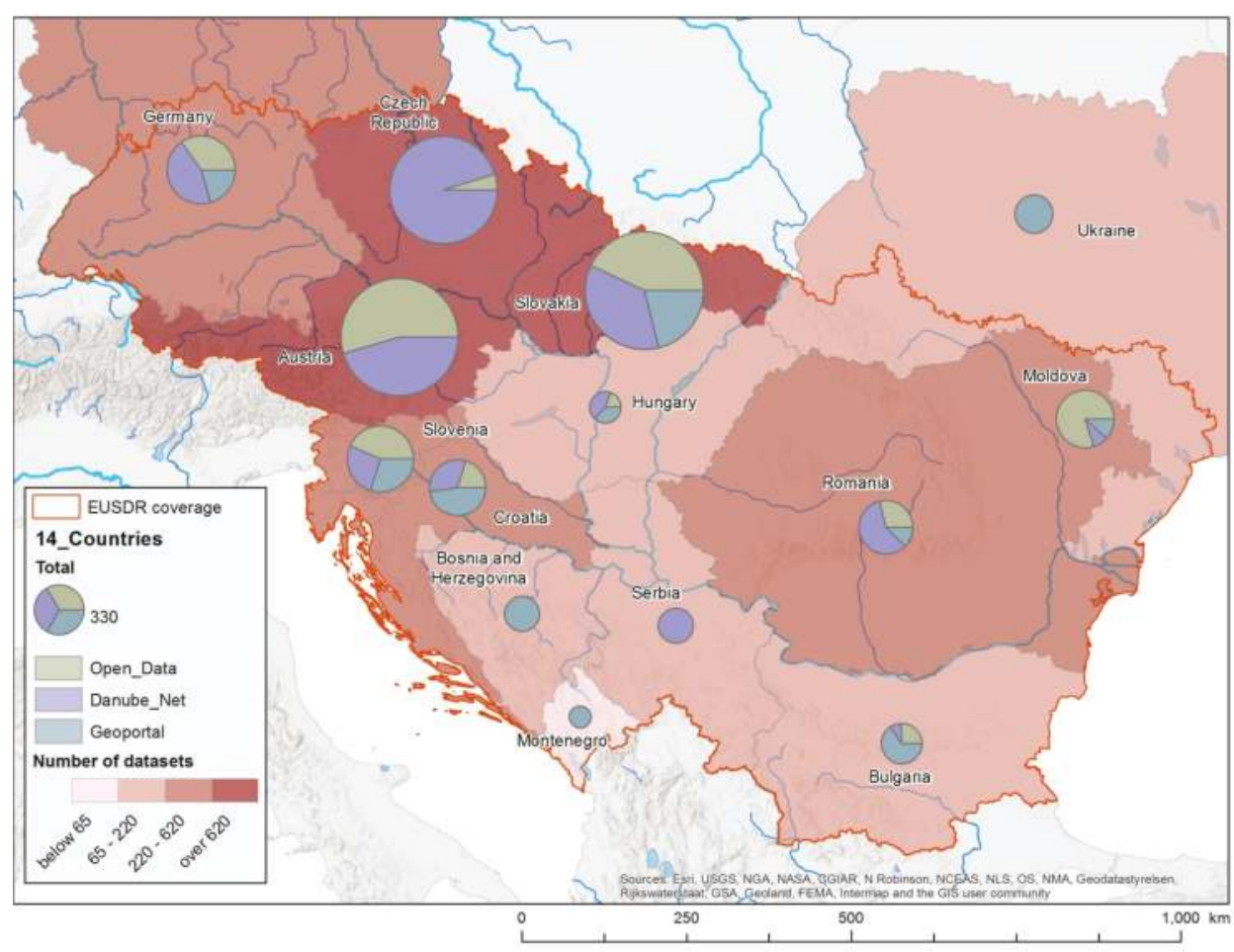

Figure 6. Data availability in the Danube region open data portal. Source: [12].

\subsubsection{Danube_Net}

In addition to the open data described above, we used the state-of-play reports on the national spatial data infrastructures that were produced by the Danube_Net-a network of 14 experts, representing each country in the study area [28]. The reports covered a broad spectrum of topics in a coordinated manner. They included an overview of tools used to serve data and metadata, licensing frameworks, metadata profiles and standards, together with noteworthy use cases for the application of data sets and services for policy making purposes. The country reports showed many commonalities and similar challenges associated with the establishment of usable spatial data infrastructures in the region. In general, they relate to the capacity of public sector actors to scope, implement and maintain data infrastructures that are best tailored to the evolving requirements of heterogeneous stakeholders.

While analysing the state-of-play reports we paid particular attention on the section dedicated to existing data gaps. We used this input information to validate the evidence on the availability of data obtained through the open data portal described in Section 3.1.1.

\subsection{Gap Analysis}

The analytical material described under Section 3.1.2, together with a cross-check in the Danube data catalogue (Section 3.1.1) helped us to identify data niches for each country that could possibly be addressed by Citizen Science activities. Those were split into nine categories (Table 1) in accordance with the requirements of the 'Scientific support to the EUSDR', defined by the European Commission [29]. It is worth highlighting that certain categories can overlap (e.g., energy production vs. bioenergy, irrigation vs. agriculture development, land vs. soil), but they are provided separately in the manuscript for simplicity reasons. It should also be noted that we did a first analysis on the level 
of those categories. Most—if not all—of them require a rich portfolio of datasets in order to be fully addressed by regional-development policy. However, such level of detail is out of the scope of our initial investigations that aim at a horizontal overview, i.e., as a baseline for future work.

Table 1. List of categories for identification of possible data gaps. Source [29].

\begin{tabular}{cl}
\hline Nr. & Category \\
\hline 1. & Environment protection \\
2. & Navigability \\
3. & Irrigation and agricultural development \\
4. & Energy production \\
5. & Air \\
6. & Water \\
7. & Land and Soil \\
8. & Bioenergy \\
9. & Others (none of the above) \\
\hline
\end{tabular}

The data gaps that were identified by each Danube_NET expert were extracted from a series of reports. They are summarised in Table 2.

Table 2. List of data gaps in the Danube region. Source: Danube_Net country reports [28].

\begin{tabular}{|c|c|c|}
\hline Country & Data Gaps & Category \\
\hline \multirow{2}{*}{ Austria } & Power plants & Energy production \\
\hline & Livestock farms & Irrigation and agriculture \\
\hline Bosnia \& Herzegovina & $\begin{array}{l}\text { (The country report does not contain substantial evidence } \\
\text { unknown that can to be used for identification of possible data gaps.) }\end{array}$ & \\
\hline \multirow{6}{*}{ Bulgaria } & Bio-heat on local scale & Bioenergy \\
\hline & Data on utilities & Energy production \\
\hline & Livestock farms & Irrigation and agriculture \\
\hline & Forest mills & Irrigation and agriculture \\
\hline & Data on health & Others \\
\hline & Land use master plans & Land and Soil \\
\hline Croatia & Data on bioenergy & Bioenergy \\
\hline Czech republic & Land use in rural areas & Land and Soil \\
\hline Germany & Human health & Others \\
\hline Hungary & unknown & \\
\hline Montenegro & Renewable energy sources & Energy production \\
\hline \multirow{3}{*}{ Moldova } & Bioenergy data & Bioenergy \\
\hline & Energy production data & Energy production \\
\hline & Data on transportation & Navigability \\
\hline Romania & Data on energy & Energy production \\
\hline Serbia & unknown & \\
\hline \multirow{3}{*}{ Slovakia } & Multi-modal transportation network & Navigability \\
\hline & Production and use of energy resources & Energy production \\
\hline & Culture and tourism & Other \\
\hline Slovenia & EUSDR priority areas well covered & \\
\hline Ukraine & unknown & \\
\hline
\end{tabular}

\section{Citizen Science Contribution}

After having identified data gaps in the region on a high level of abstraction we reviewed existing Citizen Science solutions that could be directly applied for closing or narrowing the existing shortcomings. Only as a second step, and where no match to an existing effort could be identified, we considered the establishment of a new activity (Figure 5). Again, we conducted this research as a first activity in order to approach the topic and did not get into as much detail as data quality needs and details of the data provisions from the individual Citizen Science projects. 


\subsection{Identification of Existing Activities}

We used heterogeneous channels in order to identify Citizen Science activities for the Danube region, such as web search, the CORDIS project repository database [30], initiatives as described under Section 2.3.3, and Danube_Net country reports. Priority was given, in accordance with the macro-regional dimension targeted, to national and international initiatives. Twenty relevant project initiatives were identified and further investigated for concrete examples where data can be used as input to policy making. An overview of the allocation of project data to individual countries and themes that are covered (Figure 7) shows that the majority of activities are available within EU Member States, however some isolated activities also cover the Western Balkans, Moldova and Ukraine.

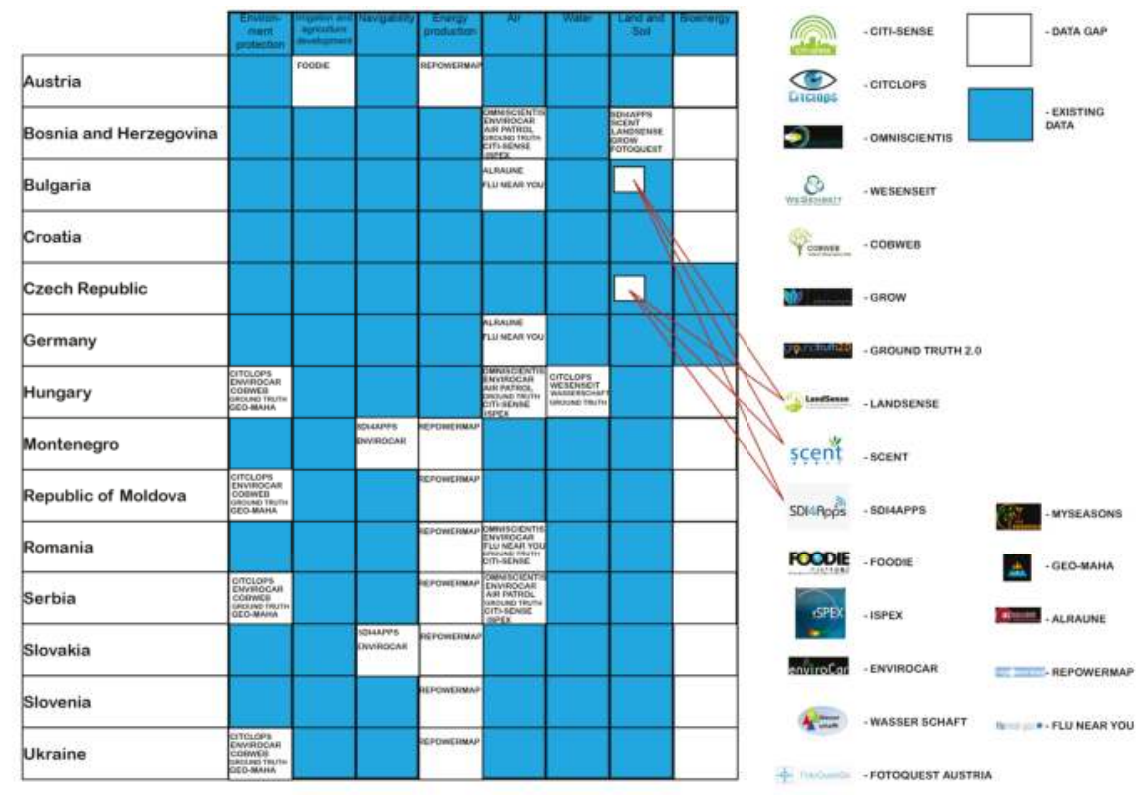

Figure 7. Thematic and geographic coverage of Citizen Science projects in the Danube region.

Thematically, there is a significant predominance of projects addressing environmental topics with the highest percentage addressing the quality of ambient air. This might be traced back to the origins of the term 'Citizen Science', which is rooted in the environmental domain, and to the recent focus of Citizen Science funding that concentrated on environmental pollution, and especially on air quality. Some reference projects that we investigated in relation to the category "Air" include CITI-SENSE, envirCar and iSPEX.

- The CITI-SENSE project [31] developed a rich web portal and toolbox (http://co.citi-sense.eu/) that can be re-used to measure air pollution and the human perception of air quality at any given occasion by using low-cost sensors and mobile phone applications. Methods and tools are provided to capture information about both, indoor and outdoor air quality.

- enviroCar is a Citizen Science platform for analysing and mapping crowd-sourced car sensor data [32]. The research project proposes an innovative approach towards the monitoring of car-related air pollution. Data is collected directly from the cars of volunteers. It is afterwards contributed to an open platform (https://envirocar.org/). An application programming interface (API) is made available to ensure easy access to the citizen-generated content. From our 
perspective this alternative approach to data collection is highly promising. Mashing up the resultant observations with other data sources (e.g., air quality models, data from monitoring stations, etc.) would lead to improved data coverage for air related matters.

- $\quad$ The iSPEX project [33] established a measurement network for particulate matter through the use of a smartphone app equipped with a specialised add-on. The project engaged with a vast number of volunteers, and illustrated the benefits of Citizen Science for obtaining a high resolution representation of the studied phenomenon.

\subsection{Development of a New Citizen Science Application}

We found that most gaps might indeed at least in parts benefit from the transfer and extension of already ongoing Citizen Science activities to a new geographic area. Only for the case of bioenergy, we could not find any even partially matching solutions involving citizens. Interestingly, exactly this topic is high on the European political agenda on the circular economy, an initiative to make the economy more sustainable and competitive [34]. In the case of bioenergy this refers to the re-use of biomass (as a renewable natural resource) to create energy, e.g., in the form of heat.

We decided to outline a new activity, also in order to illustrate with one concrete example how this last gap might be addressed. We used, an event organised in the study area, the DanubeHack 2.0 [35], as an opportunity to work on concrete ideas that could possibly fill existing data gaps related to bioenergy. The discussions resulted in the selection and initial development of a smartphone application (app) called 'Waste2Fuel'. The app is described below from a conceptual and technical point of view.

\subsubsection{App Rationale}

Agriculture has for long been an important source of income for many people in the Danube region. Agricultural production is diverse, but vineyards and orchards are traditionally well represented throughout the whole region. Those vineyards and orchards must be pruned twice a year-a well known agricultural practice which leads to many piles of residual branches (Figure 8). Usually, the owners directly burn the residual material in the field, not only creating environmental problems, but also missing opportunities for a better utilization of the biomass.

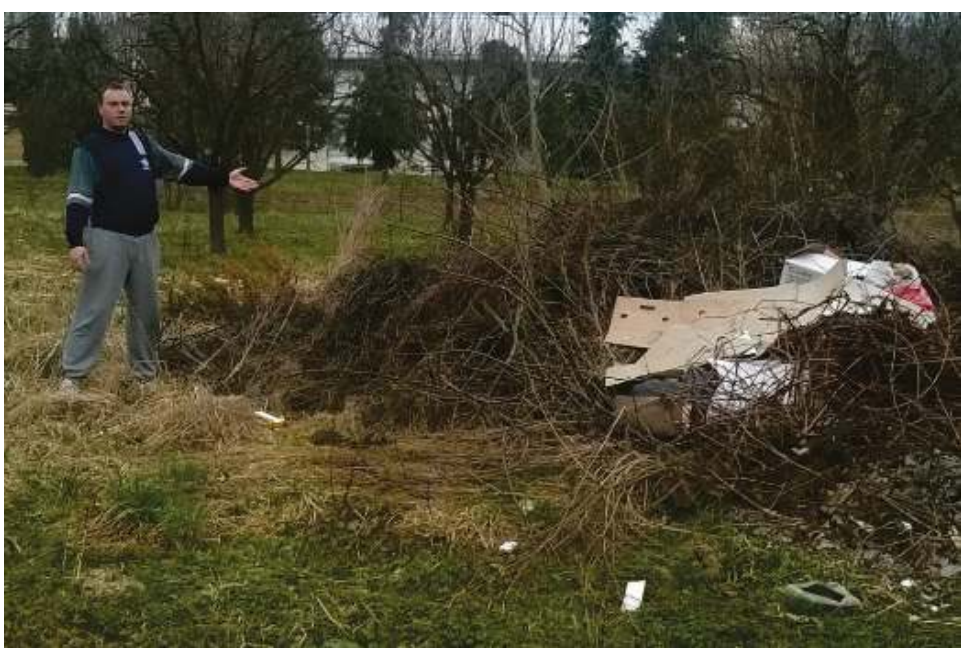

Figure 8. Example of a pile of residual branches in the Danube region. 
At the same time, the overall supply of biomass in the Danube countries (excluding non-EU countries where data was not available) is estimated for 2009 to be 1136.2 petajoule (PJ) with an agriculture contribution of $23 \%$ [36]. If seen from the perspective of bioenergy the residual branches provide an excellent raw material for the production of wood pellets for heating. Furthermore, it appears reasonable to assume that there is shared interest in utilising this resource between biomass producers and vineyard and orchard owners. However, information about the location and volume of the piles that are available for further consumption is not passed from one to the other and pick-ups cannot be organised.

\subsubsection{App Conceptualisation}

Within the context described above, an app was scoped that, based on the shared interest of different stakeholders, would enable (i) owners of vineyards and orchards to collect and share data on branch piles, including the volume and locations using smartphones, and (ii) biomass producers to be notified of the available biomass location(s) and estimated volume, see a photo as evidence, so that they can arrange the pick up of the branches for further processing.

In addition, it was considered important to share information about potential risks and to alarm owners in vicinity of forest areas in order to avoid wildfires. With this approach we hope to not only warn the owners of vineyards and orchards, but to also motivate them not to burn the piles.

With this setup, the application would benefit a whole set of stakeholders, including:

- Citizens (site owners) that do not have to organize burning activities.

- Industry (biomass producers) that get access to more biomass.

- Civil society for which (i) security is increased by less uncontrolled burning activities, and (ii) pollution from combustion is decreased.

- Research organisations that get access to one more spatial dataset about bioenergy in the Danube region.

- Governmental organisations that have less data gaps and can better support developments in the region.

\subsubsection{Waste2Fuel Initial Development}

An app was developed and tested in December 2016. It was developed entirely through the use of open source components. The source code is committed to GitHub [37]. A test instance is available at https://www.pg.geof.unizg.hr/biomass/. The current version of the application uses the following datasets:

- CORINE Land Cover 2012—Land cover inventory obtained through satellite image and in situ data processing [38].

- Land Parcel Identification Systems (LPIS)—systems, put in place by European Union Member States for identification of land plots based on high resolution aerial imagery.

- Open Land Use Map-Open, harmonised and seamless database of open land use in the Danube region obtained through combining input from heterogeneous data sources [39].

- Land Use/Cover Area frame statistical Survey (LUCAS)—sample statistical survey carried out by Eurostat every three years [40].

\subsubsection{App Functionality}

When a user is at the location of a pile of branches, (s)he can select 'Add biomass site', and a data form opens with fields to input a short description, contact number and estimated volume of the pile (Figure 9). In the end of the session, users can shoot and upload a photo. 


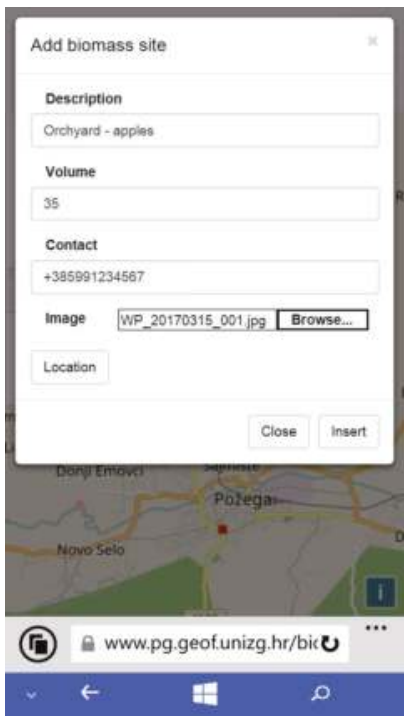

Figure 9. User interface of Waste2Fuel for adding a biomass sighting.

Data are uploaded to a server, and a new point is added to the 'Biomass sites' dataset which is also visible on the map. Biomass producers can use the interface (Figure 10) in order to find and select piles that they want to pick up.

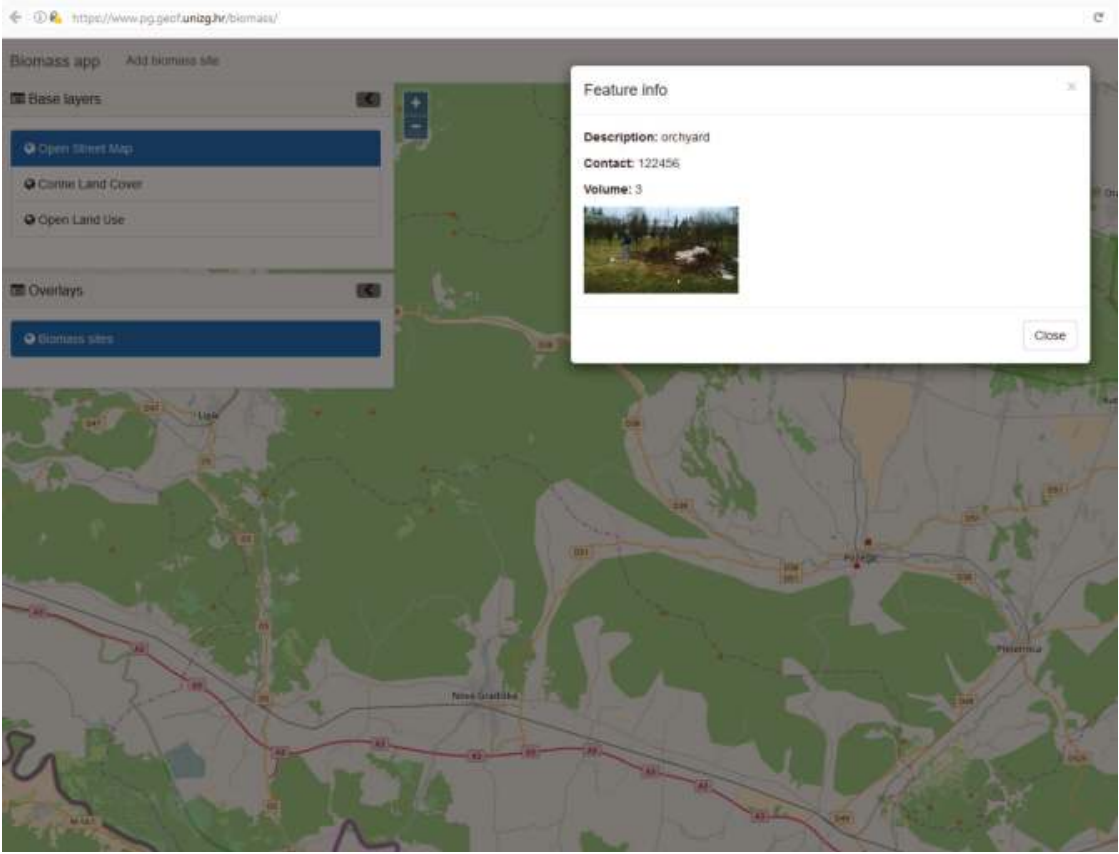

Figure 10. Web interface of Waste2Fuel. 


\section{Discussion}

Apart from the highly practical issues of enabling citizens to contribute to the closing of data gaps in a macro-region, the approaches indicated above introduce a particular way of public participation in relation to development policy. Members of the public start to get into a position in which they may contribute to the evidence base that is used for policy making-by directly providing data themselves, but also by taking actions related to policy targets. In addition to the projects presented in Section 4.1, the Waste2Fuel app described in Section 4.2 provides an illustrative example of how citizens may provide information about biomass that is available in the Danube region. At the same time, they help companies to arrange for the pick-up and support the re-use of branches that would have otherwise been wasted. Here we provide our perspective on the opportunities and challenges associated with the role of citizens, empowered by modern IT tools, throughout the policy cycle.

\subsection{Citizens' Impact on Policy Making}

The opportunities to get more citizens actively engaged are manifold, i.e., members of the public (including citizen as well as commercial enterprises) can be offered a rich portfolio of possibilities, which they might consider. The work presented here illustrates many of the already existing options to involve citizen in the closing of data gaps. We identified and listed a rich set of already existing solutions that could be deployed and offered to people living in, or visiting the Danube region. Notably, efforts would still be required in order to modify existing solutions (if necessary) to match the exact data needs; set-up the required data management infrastructures; prepare solutions in order to be ready for use in the region (e.g., including dedicated training material, as well as, language translations); and promote their existence to members of the public.

\subsection{Challenges}

Before engaging with citizens, it should also be noted that the emerging new options for increased public engagement do also come with a series of drawbacks. The pros and cons of collecting data through Citizen Science approaches are widely addressed in the literature (see for example [41-45]). The following critical issues should be recognized:

- Data coverage. The heterogeneous spatio-temporal coverage of citizen data might swamp any signal, or produce spurious signals of change where none exists [46]. At the same time, the coverage of data that fits policy makers' needs is (i) hard to define, and (ii) difficult to implement in practice. Data from Citizen Science apps, for example, is closely bound to where a community is involved for a particular reason. It often hardly exceeds the local dimension (e.g., bounds of a municipality). Community building activities are thus likely to be required in order to close a particular data gap on higher administrative levels or less-urban areas.

- Combined use of data. The integration (or mashing-up) of data, even if feasible and relatively easy from a technical point of view, should be based on solid theoretical foundations and where possible cross-checked with other data sources. This is important for Citizen Science approaches because it is, for example, very difficult to determine whether a particular high concentration (or lack) of data for a particular area, is objectively representing the studied phenomenon, or is related to a particularly active (or inactive) community. Notably, tools and methods from multiple projects might be combined to best address a data need. Also, in some cases, Citizen Science might be the only possible way to collect a particular data set, for example, for mapping uncharted territories (see for example [47]) that cannot be surveyed through traditional methods such because of military conflicts, dictatorships, or environmental crises.

- Data validation and quality. Validation and quality assurance of gathered data are a common issue for any data collection, but are frequently challenged in relation to Citizen Science activities. Related challenges and solutions are widely discussed in the literature (for example [48-51]). Whereas evidence shows that, for example, for species identification, non-professionals may reach 
a high level of expertise and eventually even outperform professional scientists. It might also be feasible to use Citizen input as a proxy for resource optimization, as, for example, done in a collaboration between the Scottish Environmental Protection Agency (SEPA) as part of the Anglers' Riverfly Partnership (http:/ / www.riverflies.org/rp-riverfly-monitoring-initiative).

- Fitness for purpose. Specific analysis of the appropriateness of a particular Citizen Science approach with respect to the concrete policy making needs would be needed when addressing any of the identified data gaps. The suitability of a solution that has already been developed will most essentially depend on two factors. The tools that are provided by the project, e.g., (i) Can a concrete air quality sensor meet the quality needs that are required in order to improve the model of environmental pollution at a regional level (also considering the density and costs of already existing measurement networks)? (ii) Does the smartphone for monitoring selected species deliver reliable occurrence records? And the methodology required by the project in order to mobilize or gather data, e.g., (a) Can the approach cover an entire region or country at a given resolution? (b) Can the data gathering be repeated in well-defined cycles in order to support monitoring? These investigations need to be carried out on a case-by-case basis (per required data set and per possible suitable Citizen Science project). They might be accompanied by a cost-benefit analysis.

- Business models. Following from the above mentioned assessment of cost-effectiveness, we also want to emphasise on the need for robust business models. Citizen Science activities require much more resources than possible technology (hardware and software). It also requires capacity building, community management and sustainability of the gathered results. Here, we should separate between the funding models of Citizen Science projects as such-see, for example [52] — from operational (and possibly long-term) use. While equal needs might be argued for other scientific and governmental approaches to data collection, analysis and dissemination, Citizen Science requires a different set of skills in order to, for instance, meet certain ethical requirements. However, as diverse as Citizen Science is in itself, as diverse are possible business models. Especially the embodied concept of shared responsibility offers a new range of possibilities, for example, Non-Governmental Organisations (NGOs) enter the scene, which might provide support in community outreach, and in some cases Citizen Science communities entail their community managers. Equally, a Citizen Science approach might help to optimise and concentrate available resources where they are most needed. Last but not least, Citizen Science approaches may also help reaching other goals of the involved parties, such as the modernisation of public services or the improved relationship between people and governments. Resource pooling is thus an option.

- Expectation management. Governmental support of a Citizen Science application (e.g., via a mobile phone app) raises expectations. Especially, citizens are likely to expect an immediate (re)action after having provided information. However, in regional policies across country borders, reactions are not always immediate, particular not if it is used as extended scientific advice in evidence based policy making. Decisions will take place along the policy cycle and diverse/heterogeneous political and cultural landscapes each add their own temporal constraints. The use of the data and according feedback mechanisms have to be clearly communicated from the beginning of each Citizen Science initiative.

- Participant incentives. The incentive of citizens to contribute to data collection initiatives beyond the initial curiosity is to be investigated. Not only need people be mobilized and attracted to participate in a Citizen Science activity, but active contributors have to be retained, too. Multiple mechanisms exists, but have to be selected carefully. One of the options would be to benefit from already active communities and engage with them in order to make a data collection exercise valuable for all participants in the process. 


\section{Conclusions}

Our initial investigations of the Citizen Science topic in relation to regional development set a rich baseline for future research. We wrap the most central messages, main lessons and areas for future work below.

\subsection{Summary}

The implementation of macro-regional policies relies on the availability and accessibility of data covering multiple topics. Whereas, also thanks to the growing popularity of open data policies, many of the required data sources do become available, gaps still exist. This holds particularly when multiple countries are involved, that all have their individual cultures and political priorities. We illustrated such a situation based on our experiences in the Danube macro-region and our involvement in the DRDSI project.

Among the four possible ways for closing, or at least narrowing data gaps, we highlighted several possibilities of involving citizens directly in data collection. We outlined that each of the data gaps that we identified for the Danube region could be addressed, at least partially. Surprisingly, almost all priority areas of the Danube Strategy may be addressed by transferring an already existing solution into a geographical area that was not covered so far. For the only topic that remained competently uncovered (bioenergy), we highlighted several possible solutions, situated in the circular economy, and especially related to energy production from organic material. We already succeeded to prototype an application thanks to a hackahton [35] that took place in Bratislava in 2016.

Whilst highlighting the many options that already exist today, we also underlined some of the critical issues that would need to be considered when allowing public participating in rational development policy following any of these Citizen Science approaches.

\subsection{Main Lessons}

The involvement of citizens not only provides an opportunity for closing data gaps, but also brings the policy making process closer to people. That is why the potential of Citizen Science to improve the dialogue between citizens and governments should not be underestimated. Within this context however, it is important to respond adequately to the raised expectations of citizens, and use appropriate communication channels. With our work we illustrated how data from citizens could play an important role in complementing other data sources. Nonetheless, there are numerous challenges that need to be addressed, for a real policy uptake of Citizen Science data. The questions below need an answer in order to decide whether an approach including citizens is at all feasible:

1. Are there existing data which are possible to 'open' in order to close the gap?

2. If yes, how much does it cost to open the data?

3. If other sources are too expensive, is there a Citizen Science activity (completed, ongoing, or planned) that might close the gap?

4. Would the quality of data from citizens be satisfactory?

5. How to ensure sustainability of the data collection process?

\subsection{Future Work}

In closing, citizen generated content is very likely to be an increasingly important channel for gathering policy relevant input. Furthermore, data from citizens might be more cost-effective and collected faster in comparison with other source of data. Trustworthiness and quality of the data generated through citizen engagement should still be investigated, and we will be addressing those issues as continuation of the work presented here.

Recognizing this article as a first approach to the topic, and considering the critical issues already raised in Section 5, there are several interdependent topics to be further investigated. These include: 
- Data gaps and possible Citizen Science contributions need to be further analysed on a case by case basis. This should include closer investigations of the data needs (e.g., in terms of coverage and quality), possibilities and limitations of using an already existing Citizen Science approach (transportability, need of community building etc.), but also a critical reflection on possibly underlying assumptions (e.g., on social needs).

- The potential of the app described in Section 4.2 is not explored to its full potential. Its possible use as a standalone tool, or in combination with one or more of the traditional approaches should be further investigated. Also, the deployment in the involved communities should be tested with a limited set of participants before approaching broader use.

- Methodologies for mobilizing and retaining citizens to contribute on a regular basis (i.e., beyond the initial curiosity) should be tested and then rolled out more widely. This will have to account for repeated promotion activities, but equally for feedback provision and ensured use of the inputs provided by the citizen.

- A scientifically sound methodological framework for utilisation of citizen contributions still needs to be developed and tested in real world conditions. Such investigations might need to reflect about the quality criteria to be applied and the relationship to e.g., official statistics and indicator-based assessment.

- Successful organizational settings to orchestrate the engagement processes need to be identified, shared and adopted where needed. When talking about regional development policy, the amount and diversity of involved stakeholders makes this exercise particularly channelling and highly interesting.

Acknowledgments: The manuscript is developed within the "New data sources and Citizens Science platform" project of the Joint Research Centre, European Commission. The authors would like to thank Saša Vranić, Hrvoje Tomić and Tomáš Kliment for their work on the Waste2Fuel prototype. We would also like to express our gratitude to Jean Dusart and Robin S. Smith for scoping relevant work within the DRDSI project, as well as to Mrs. Brooke Tapsall for proofreading the final draft of the text.

Author Contributions: J.L. worked on all chapters of the manuscript, analysed input from the Danube_Net reports and other sources of data, scoped and worked extensively on the Waste2Fuel prototype. S.S. contributed to the overall storyline, positioning of the specific work on Citizen Science into the wider research context, as well as the consolidation of the conclusions and shaping of future work. A.K. contributed to all chapters of the paper, including the literature review, as well as on defining the policy context, issues related to data management and the Danube Reference Data and Servies Infrastructure.

Conflicts of Interest: The authors declare no conflict of interest.

\section{Abbreviations}

The following abbreviations are used in this manuscript:

CKAN Comprehensive Knowledge Archive Network

CORDIS Community Research and Development Information Service

CS Citizen Science

DRDSI Danube Reference Data and Services Infrastructure

EUSDR European Union Strategy for the Danube Region

ECSA European Citizen Science Association

JRC Joint Research Centre, European Commission

OGC Open Geospatial Consortium

\section{References}

1. G8 Open Data Charter. Available online: https://www.gov.uk/government/publications/open-datacharter (accessed on 10 Feburary 2017).

2. Open Data Barometer. Available online: http:/ / opendatabarometer.org/ (accessed on 29 March 2017). 
3. Masser, I.; Crompvoets, J. Qualitative monitoring of information infrastructures: A case study of INSPIRE. Environ. Plan. B Plann. Des. 2016, doi: 10.1177/0265813516675871.

4. Butcher, G.S.; Niven, D.K. Combining Data From the Christmas Bird Count and the Breeding Bird Survey to Determine the Continental Status and Trends of North America Birds; National Audubon Society: New York, NY, USA, 2007.

5. Grey, F. Citizen Cyberscience: The new age of the amateur. CERN Courier 2011, Volume 51(7), 41-43.

6. Hemment, D.; Ellis, R.; Wynne, B. Participatory mass observation and citizen science. Leonardo 2011, 44, 62-63.

7. Chun, S.A.; Shulman, S.; Sandoval, R.; Hovy, E. Government 2.0: Making connections between citizens, data and government. Inf. Polity 2010, 15, 1-9.

8. Coglianese, C. Citizen participation in rulemaking: Past, present, and future. Duke Law J. 2005, 55, $943-968$.

9. Fung, A. Putting the public back into governance: The challenges of citizen participation and its future. Public Adm. Rev. 2015, 75, 513-522.

10. DRDSI Open Data Portal. Available online: http://drdsi.jrc.ec.europa.eu (accessed on 29 March 2017).

11. EUSDR Website. Available online: https://www.danube-region.eu (accessed on 29 March 2017).

12. Dusart, J.; Kotsev, A.; Smith, R.S.; Cetl, V.; Tapsall, B.; Divjak, D. Data Infrastructures in Support of Macro-Regional Development. Experiences and Lessons Learned From the Danube Region; European Commission: Brussels, Belgium, 2016.

13. Kotsev, A.; Dusart, J.; Smith, R. Reference Data and Services Infrastructure for the Danube Region. J. Entrep. Innov. 2015, 7, 143-147.

14. Haklay, M. Citizen science and volunteered geographic information: Overview and typology of participation. In Crowdsourcing Geographic Knowledge; Springer: Berlin/Heidelberg, Germany, 2013; pp. 105-122.

15. European Strategy for Open Science. Available online: https://ec.europa.eu/digital-single-market/en/ open-science (accessed on 29 March 2017).

16. European Actions on Citizen Science. Available online: https://ec.europa.eu/digital-single-market/en/ citizen-science (accessed on 29 March 2017).

17. See, L.; Mooney, P.; Foody, G.; Bastin, L.; Comber, A.; Estima, J.; Fritz, S.; Kerle, N.; Jiang, B.; Laakso, M.; et al. Crowdsourcing, citizen science or volunteered geographic information? The current state of crowdsourced geographic information. ISPRS Int. J. Geo-Inf. 2016, 5, 55.

18. Silvertown, J. A new dawn for citizen science. Trends Ecol. Evol. 2009, 24, 467-471.

19. Bonney, R.; Cooper, C.B.; Dickinson, J.; Kelling, S.; Phillips, T.; Rosenberg, K.V.; Shirk, J. Citizen science: A developing tool for expanding science knowledge and scientific literacy. BioScience 2009, 59, 977-984.

20. Craglia, M.; Shanley, L. Data democracy-increased supply of geospatial information and expanded participatory processes in the production of data. Int. J. Dig. Earth 2015, 8, 679-693.

21. Launch Event: Citizen Science at LERU Universities. Available online: http://www.leru.org/index.php/ public/calendar/citizen-science-at-leru-universities-trends-guidelines-and-recommendations (accessed on 29 March 2017).

22. SciStarter Website. Available online: https:/ / scistarter.com (accessed on 29 March 2017).

23. European Open Science Policy Platform. Available online: https://ec.europa.eu/research/openscience/ index.cfm?pg=open-science-policy-platform (accessed on 4 April 2017).

24. Responsible Research and Innovation. Available online: https:/ /ec.europa.eu/programmes/horizon2020/ en/h2020-section/responsible-research-innovation (accessed on 4 April 2017).

25. H2020 Science with and for Society programme. Available online: https://ec.europa.eu/programmes/ horizon2020/en/h2020-section/science-and-society (accessed on 4 April 2017).

26. Green Paper. Citizen Science Strategy 2020 for Germany. Available online: http://www.buergerschaffenwissen. de/sites/default/files/assets/dokumente/gewiss_cs_strategy_englisch.pdf (accessed on 26 July 2017).

27. Austrian Centre for Citizen Science. Available online: https://www.zentrumfuercitizenscience.at/en/thecenter (accessed on 22 May 2017).

28. DanubeNet State-of-Play Country Reports. Available online: http://drdsi.jrc.ec.europa.eu/state-of-play (accessed on 4 April 2017).

29. European Commission Memo. Scientific Support to the Danube Strategy, Brussels, 16 May 2013. Available online: http:/ / europa.eu/rapid/press-release_MEMO-13-441_en.htm (accessed on 26 June 2017).

30. CORDIS Database of European Research Projects. Available online: https://data.europa.eu/euodp/en/ data/dataset/cordisH2020projects (accessed on 28 April 2017). 
31. CITI-SENSE Project Website. Available online: http:/ / www.citi-sense.eu/ (accessed on 26 June 2017).

32. Bröring, A.; Remke, A.; Stasch, C.; Autermann, C.; Rieke, M.; Möllers, J. enviroCar: A Citizen Science Platform for Analyzing and Mapping Crowd-Sourced Car Sensor Data. Trans. GIS 2015, 19, 362-376.

33. Snik, F.; Heikamp, S.; de Boer, J.; Keller, C.; van Harten, G.; Smit, J.; Rietjens, J.; Hasekamp, O.; Stam, D.; Volten, H.; et al. iSPEX: The creation of an aerosol sensor network of smartphone spectropolarimeters. In Proceedings of the EGU General Assembly Conference Abstracts, Vienna, Austria, 22-27 April 2012; Volume 14, p. 12974.

34. European Commission Circular Economy Action Plan. Available online: http:/ /ec.europa.eu/environment/ circular-economy/index_en.htm (accessed on 4 April 2017).

35. DanubeHack 2.0 Website. Available online: www.danubehack.eu (accessed on 4 April 2017).

36. Banja, M.; Scarlat, N.; Dallemand, J.F.; Monforti-Ferrario, F.; Motola, V.; Bódis, K. Bioenergy Deployment in the Danube Region: Current Status And Progress According to National Renewable Energy Action Plans; European Commission: Brussels, Belgium, 2014.

37. Waste2Fuel GitHub Repository. Available online: https://github.com/danubehack/waste2fuel (accessed on 28 April 2017).

38. Corine Land Cover Dataset. Available online: http://land.copernicus.eu/pan-european/corine-land-cover (accessed on 28 April 2017).

39. Open Land-Use, SDI4Apps Project. Available online: http://sdi4apps.eu/open_land_use/ (accessed on 22 May 2017).

40. Land Use and Coverage Area frame Survey (LUCAS). Available online: http:/ /ec.europa.eu/eurostat/web/ lucas/overview (accessed on 28 April 2017).

41. Burgess, H.; DeBey, L.; Froehlich, H.; Schmidt, N.; Theobald, E.; Ettinger, A.; HilleRisLambers, J.; Tewksbury, J.; Parrish, J. The science of citizen science: Exploring barriers to use as a primary research tool. Biol. Conserv. 2017, 208, 113-120.

42. Ottinger, G. Buckets of resistance: Standards and the effectiveness of citizen science. Sci. Technol. Hum. Values 2010, 35, 244-270.

43. Roy, H.E.; Pocock, M.J.; Preston, C.D.; Roy, D.B.; Savage, J.; Tweddle, J.; Robinson, L. Understanding Citizen Science and Environmental Monitoring: Final Report on Behalf of UK Environmental Observation Framework; Centre for Ecology and Hydrology: Oxfordshire, UK, 2012.

44. Comber, A.; Mooney, P.; Purves, R.S.; Rocchini, D.; Walz, A. Crowdsourcing: It matters who the crowd are. the impacts of between group variations in recording land cover. PLOS ONE 2016, 11, e0158329.

45. Meentemeyer, R.K.; Dorning, M.A.; Vogler, J.B.; Schmidt, D.; Garbelotto, M. Citizen science helps predict risk of emerging infectious disease. Front. Ecol. Environ. 2015, 13, 189-194.

46. Isaac, N.J.B.; van Strien, A.J.; August, T.A.; de Zeeuw, M.P.; Roy, D.B. Statistics for citizen science: Extracting signals of change from noisy ecological data. Methods Ecol. Evol. 2014, 5, 1052-1060.

47. Perkins, C. Plotting practices and politics: (im)mutable narratives in OpenStreetMap. Trans. Inst. Bri. Geogr. 2014, 39, 304-317.

48. Freitag, A.; Meyer, R.; Whiteman, L. Strategies employed by citizen science programs to increase the credibility of their data. Citiz. Sci. Theory Pract. 2016, 1, 2, doi:10.5334/cstp.6.

49. Lukyanenko, R.; Parsons, J.; Wiersma, Y.F. Emerging problems of data quality in citizen science. Conserv. Biol. 2016, 30, 447-449.

50. Wiggins, A.; Newman, G.; Stevenson, R.D.; Crowston, K. Mechanisms for data quality and validation in citizen science. In Proceedings of the 2011 IEEE Seventh International Conference on IEEE e-Science Workshops (eScienceW), Stockholm, Sweden, 5-8 December 2011; pp. 14-19.

51. Sheppard, S.A.; Terveen, L. Quality is a verb: the operationalization of data quality in a citizen science community. In Proceedings of the 7th International Symposium on Wikis and Open Collaboration, Mountain View, CA, USA, 3-8 October 2011; pp. 29-38.

52. Schade, S.; Tsinaraki, C. Survey Report: Data Management in Citizen Science Projects; Publication Office of the European Union: Luxembourg, 2016.

(c) 2017 by the authors. Licensee MDPI, Basel, Switzerland. This article is an open access article distributed under the terms and conditions of the Creative Commons Attribution (CC BY) license (http:/ / creativecommons.org/licenses/by/4.0/). 
Article

\title{
Tensions in Rural Water Governance: The Elusive Functioning of Rural Water Points in Tanzania
}

\author{
Jesper Katomero ${ }^{1, *}$, Yola Georgiadou ${ }^{2}$, Juma Lungo ${ }^{3}$ and Robert Hoppe ${ }^{4}$ \\ 1 Department of Political Science and Public Administration, University of Dar es Salaam, P.O. Box 35042, \\ Dar es Salaam, Tanzania \\ 2 Department of Urban and Regional Planning and Geo-information Management (ITC), University of Twente, \\ Enschede 7500 AE, The Netherlands; p.y.georgiadou@utwente.nl \\ 3 Department of Informatics and Computer Sciences, University of Dar es Salaam, P.O. Box 35091, \\ Dar es Salaam, Tanzania; juma.lungo@zalongwa.com \\ 4 Faculty of Behavioral Management and Social Sciences, University of Twente, Enschede 7522 NB, \\ The Netherlands; r.hoppe@utwente.nl \\ * Correspondence: katomero.jesper@udsm.ac.tz; Tel.: +255-712-221-619
}

Received: 14 July 2017; Accepted: 21 August 2017; Published: 25 August 2017

\begin{abstract}
Public water services are still failing rural Tanzanians. Emboldened by advances in information communication technologies, the Ministry of Water has been developing computing, financial and administrative technologies to update and visualise the status of rural water points. This amalgam of technologies marks the emergence of an information infrastructure for rural water governance. The information infrastructure will enable the ministry to "see" the functionality status of all rural water points and to plan and budget for their repair and maintenance. In this paper, we examine three administrative technologies, which aim to standardise the functionality status of water points, and to prescribe how the information flows within the government hierarchy, and who is a legitimate recipient of this information. We analyze qualitative data, collected over a period of four years, in the framework of an interdisciplinary research program, funded by the Netherlands Organisation for Scientific Research—Science for Global Development (NWO-Wotro). In contrast to other researchers who study how information infrastructure evolves over time, we study what infrastructure evolution reveals about water governance. Our analysis of the practices of participants in rural water governance reveals tensions between formal and informal processes, which affect rural water services negatively.
\end{abstract}

Keywords: rural water governance; water points; functionality; information communication technologies (ICTs); administrative technologies

\section{Introduction}

In Tanzania, an estimated $70 \%$ of 44 million citizens live in 12,617 villages [1]. Population increases by 1.2 million people annually, one of the fastest growth rates in the world [2]. However, public water services are still failing rural Tanzanians, despite decades of efforts to improve them [3-7]. The 2015 Millennium Development Goal assessment for access to water is "limited or no progress" [8]. Citizens depend on traditional, unimproved water sources (e.g., ponds and streams) and endanger their health and well-being [3,4,8]. A 2016 report of the Ministry of Water (MoW) shows that out of almost 88,000 rural water points 60\% have "Functional", 31\% "Non Functional" and 8\% "Functional Needs Repair" status. Figure 1 illustrates how water points with a different functionality status may appear to a nearby observer. At first, a water point was simply defined as the point at which water emerges from a public improved water supply, such as a water tap [9]. Nowadays, the MoW's [10] definition is more precise: "a water point is a public tap or standpipe at which water emerges from a public 
'improved' water supply scheme. A water point can be a source by itself (e.g., a protected spring, a protected dug well or a borehole with hand pump, etc.) An 'improved' drinking-water source is one that, by the nature of its construction and when properly used, adequately protects the source from outside contamination, particularly fecal matter."

The country's rural water woes persist, despite substantial policy reforms and significant donor funding [2-5]. For instance, the National Water Policy (NAWAPO) of 2002 [11] decentralised rural water supply and transferred the ownership of water points to new village institutions, the so-called Community Owned Water Supply Organisations (COWSOs). Tanzania's Water Sector Development Program (WSDP), the largest water-sector program in Sub-Saharan Africa, attracted funding by development partners - as donors and lenders are now known-to the tune of US \$1.3 billion for its first phase (2007-2014) and is budgeted with US \$3 billion for the second phase (2015-2025). The size and organisational complexity of the WSDP makes the monitoring of the functionality status of rural water points particularly challenging $[12,13]$.
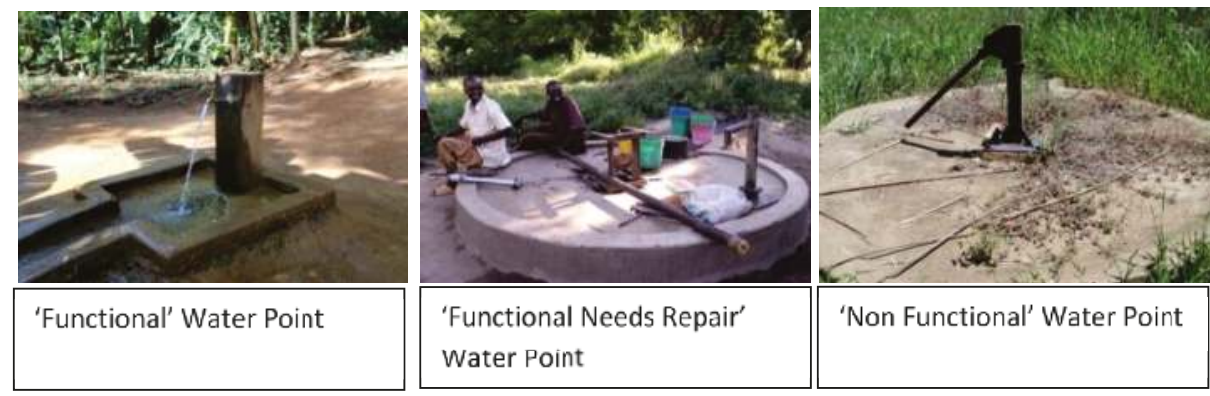

Figure 1. Images of rural water points with different functionality status adapted from [11].

In the past decade, advances in information and communication technologies (ICTs), particularly the high penetration of mobile phones, opened up new prospects for information collection and disclosure in water governance [14]. In particular, development professionals and researchers saw opportunities for quick, two-way SMS-based communication between citizens and water providers on the status of rural water points by using mobile phone-based platforms [15]. Emboldened by these prospects, the Ministry of Water developed the first ever, nation-wide, web-based information system in Sub-Saharan Africa, the so-called Water Point Mapping System (WPMS), with a World Bank loan of US \$4 million. At its most basic, a WPMS encompasses a database of baseline data on the location and status of all rural water points (Functional, Non Functional, Functional Needs Repair) at a reference epoch T, a mechanism for the regular updating of functionality status and visualisation software. The Ministry's ambition was to "see" from distant Dar es Salaam the status of all rural water points in the nation (Figure 2), to plan and budget for their maintenance and improve the equity of future investments in rural water infrastructure in all villages across Tanzania.

Collecting baseline data for each one of about 88,000 rural water points in the country was a highly complex undertaking akin to a national census. Over a period of three years (2010-2013), the official data collectors had to interact face-to-face with thousands local informants-district water engineers, village bureaucrats, traditional village chiefs, members of village COWSOs, individual villagers and non-resident water users, such as pastoralists - in order to collect attribute data about each rural water point. Tanzania covers an area almost twice the size of France and transportation is often slow, unreliable and costly. During the rainy season, reaching villages without a canoe or a motor bike was impossible. Walking on foot for up to eight hours in order to reach a water point to collect data was common. The daily schedule of a data collector was excruciating, as he (it was always a male) commenced early in the morning and terminated at sunset. 


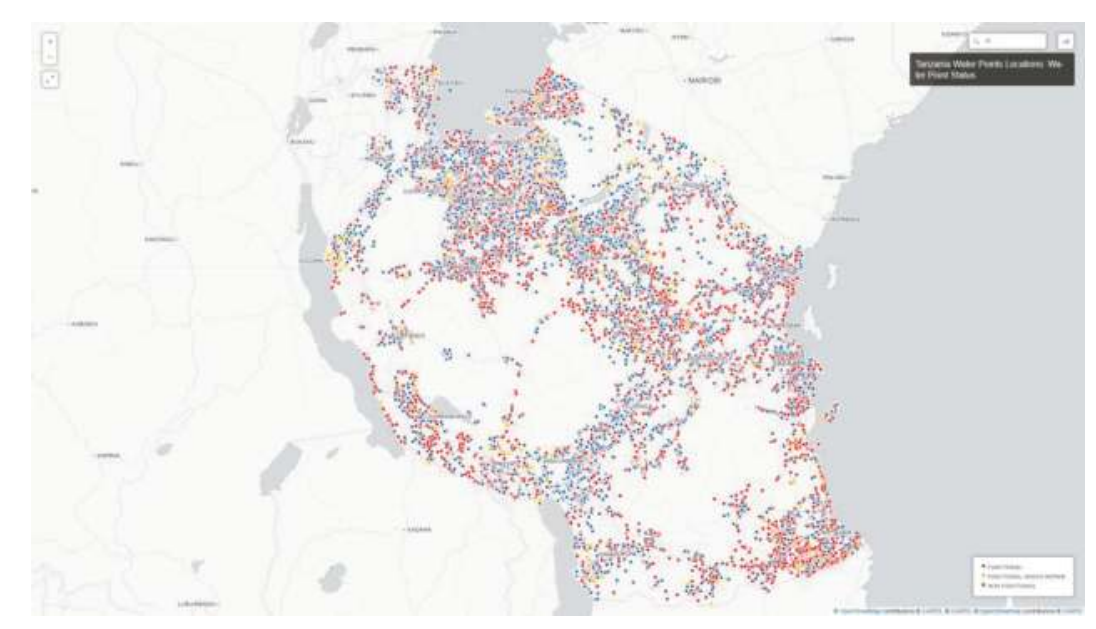

Figure 2. The current Water Dashboard of the MoW-"Seeing" the functionality status of all rural water points-Functional (blue), Non Functional (red), Functional Needs Repair (yellow) [16].

However, soon after the release of baseline data to public scrutiny in April 2013, it became clear that the data quality was far worse than the Government of Tanzania and donors had expected [17]. The water point data of entire wards within a district had either not been captured at all, or had a status of dubious quality. The other two components of the WPMS - a mechanism for regular status updating and the GIS-based visualisation software-were also developed, but were eventually cast aside, in the light of the "broken" baseline data. Ever since 2013 and to this day, the ministry, development partners, NGOs and consultants have been developing computing, financial and administrative technologies all geared towards the regular updating, the visualisation of the status and the repair of rural water points.

This amalgam of technologies-some tried and deserted, others persisting for the time being - marks the emergence of an information infrastructure for rural water governance in Tanzania. An example of computing technology is the Water Dashboard of the Ministry of Water, shown in Figure 2. An example of a financial technology is Payment-by-Results ( $\mathrm{PbR}$ ), a $£ 78$ million incentive to central and local governments of the United Kingdom Department for International Development (DFID) to repair and expand access to rural water points in 50 pilot districts. PbR will pay $£ 1500$ to local governments for each functioning water point but not for newly constructed ones. The hope is that local government will be motivated "to maintain existing water points in a sustainable manner and to fix broken water points instead of simply building new ones... Payments will be made upon an independent verification of results, building on the existing Water Point Mapping System" [18].

In this paper, we examine formal government processes embedded in three administrative technologies designed to update regularly water point (WP) functionality and inscribed in law or in official government documents. Specifically, we focus on processes aiming (1) to standardise the WP functionality status, (2) to prescribe how the information on WP functionality flows from the village to the district and, finally, to central government, and (3) to prescribe who is a legitimate recipient of this information. We collected qualitative data during a four-year period (2013 and 2017) in the framework of an interdisciplinary research program. Data include interviews with several actors in rural water supply-bureaucrats and politicians at all government levels, village leaders, data collectors, consultants and software developers. During this four-year period, our team was also developing, in cooperation with the MoW, an administrative technology-a mobile phone-based application, called the SEMA app - that enables villagers to report information on WP functionality to the district government. Thus, we were participant observers of these processes in a strong sense [19]. 
In contrast to other researchers who study how information infrastructure evolves over time, we contribute to recent STS literature, which focuses on what infrastructure evolution reveals about citizenship and governance-see [20] for an excellent overview. For example, Anand's [21] analysis of the formal and informal practices in municipal water supply in Mumbai reveals the social production of "hydraulic citizenship", a form of belonging to the city enabled by claims residents make to the city's water infrastructure. Richter's [22] study of formal and informal ways of recording information on land ownership reveals a blurred governance space between urban administration and urban society in Indian cities. Our research goal is to analyse the practices of actors, attempting to build an information infrastructure in rural water supply in Tanzania. This analysis reveals tensions between formal and informal processes, which affect rural water services negatively. We argue that the development of administrative technologies in the rural water sector should be viewed as an ongoing ecological change, where informal agency is dominant. African agency relies on informal behavior and institutions, which may either contradict the operations of formal institutions or make them more effective. The rest of the paper is organised as follows. Section 2 describes the three administrative technologies, which anchor this paper empirically. Section 3 summarizes relevant concepts and the methods used for data collection. In Sections 4 and 5, we analyze three specific processes relevant to the three administrative technologies, discuss them in view of the concepts and draw conclusions.

\section{Empirical Setting}

The release of the WPMS baseline data to public scrutiny in April 2013 unleashed a flurry of activities by the Ministry of Water, development partners (e.g., DFID and the World Bank), NGOs (e.g., WaterAid), consultants e.g., [23] and our research team. These activities focused on the development of administrative technologies geared towards the regular updating of the functionality status of rural water points as well as their repair. Three such technologies constitute our empirical setting-Big Results Now (BRN), Central Data Management Team (CDMT) and the SEMA app. We discuss them in terms of their position with respect to the Ministry of Water, the hierarchy and technology of information flow and their status (Table 1).

Launched in 2013, BRN was an attempt of the Government of Tanzania (GoT) and development partners to address the monitoring and equity of water supply, as well as of other priority areas, e.g., energy, agriculture, education, transport. In the water sector, BRN set the goal to sustain water supply to 15.2 million people, restore water supply to 5.3 million people, and extend it to 7 new million water users [24]. BRN installed a new hierarchy for the reporting of WP functionality, via new administrative units, the Ministerial Delivery Unit (MDU) and the Presidential Delivery Bureau (PDB). BRN designed a new technology for information flow, based on Google Docs [24] to simplify the reporting by the district water engineers (DWEs) to the MDU and PDB. However, the promised "synchronisation and harmonization with other monitoring systems so as to have a single source for the rural water supply sub-sector that will serve all the users" did not materialise (Water Sector Development Report [25]).

Every District Water Engineer had to send weekly updates of the WP functionality to the Ministerial Delivery Unit (MDU), without having any decision-making power within the BRN hierarchy [25]. His/her responsibility was limited to reporting WP functionality upwards. The rationale of hierarchies is to allow the rapid resolution of work-related conflicts by defining clear lines of authority. However, BRN's new hierarchy of reporting, imposed upon the existing hierarchy for monitoring rural water supply, caused confusion regarding who should do what, when and how, with what resources and authority, through which communication channels [26]. The lack of demonstrable progress and the 2015 presidential election led to the termination of BRN, when on 28 June 2017, the newly elected President of Tanzania declared the BRN defunct.

Launched in 2015, the CDMT represents yet another attempt to create a hierarchy of information flow to address the monitoring and equity of water supply. International donors in collaboration with the MoW established the CDMT under the Operations and Planning Section of the Department of Rural Water Supply (DRWS) of the MoW, to streamline and manage the flow of all data 
pertaining to the country's rural water sector [27]. Unlike the BRN, which was external to the MoW, CDMT is a new unit within the MoW. CDMT altered the existing MoW hierarchy by introducing a "project structure" [28]. It assembled old members from various MoW departments, as well as new members from outside the MoW, under a new goal—to streamline and manage the flow of all data pertaining to the country's rural water sector. The project structure enabled the ministry to resolve conflicts with respect to resources, power and authority between two former departments at the MoW—-the Information and Communication Technology (ICT) department and the DRWS—-with a history of tense relations. Originally, the DRWS hosted the WPMS because it manages data on rural water supply. However, officials in the ICT department felt that they should host the system because of their ICT capacities and expertise to manage it.

CDMT chose a preformatted and partly prefilled excel-sheet as the technology of choice for the information flow. District water engineers (DWEs) must complete this template, by adding only the current functionality status of water points in their district, once every month. This was a significant improvement compared to BRN's Google Docs [24], which DWEs had to fill out from scratch every week [24]. On the 15th of each month, a DWE receives the preformatted and partly prefilled excel template for data collection via email. If the DWE has problems with data submission, CDMT officials provide him/her with remote support by phone. During each monthly reporting period, a DWE receives two reminders. The information flow is top-down, designed to collect information from lower units of governance- the DWE in the district government. A significant innovation compared to the past is the external validation of district reports by an independent inspector [10].

Table 1. Summary of three administrative technologies for the regular updating of WP functionality.

\begin{tabular}{cccc}
\hline & BRN (2013-2017) & CDMT (2015-Present) & SEMA (2014-2017) \\
\hline $\begin{array}{c}\text { Position with respect } \\
\text { to the MoW }\end{array}$ & $\begin{array}{c}\text { New units (MDU and PDB), } \\
\text { external to MoW. }\end{array}$ & New unit, but internal to MoW. & $\begin{array}{c}\text { Hybrid (VEO and/or } \\
\text { COWSO members). }\end{array}$ \\
\hline $\begin{array}{c}\text { Hierarchy of } \\
\text { information flow }\end{array}$ & $\begin{array}{c}\text { District Water Engineer } \\
\text { (DWE) reports to MDU and } \\
\text { PDB. Weekly updates. }\end{array}$ & $\begin{array}{c}\text { DWE reports to MoW/CDMT. } \\
\text { Monthly updates. Independent } \\
\text { inspector verifies the report. }\end{array}$ & $\begin{array}{c}\text { VEO and/or COWSO member } \\
\text { reports to DWE. } \\
\text { Monthly updates. }\end{array}$ \\
\hline $\begin{array}{c}\text { Technology for } \\
\text { information flow }\end{array}$ & Google Docs & $\begin{array}{c}\text { Preformatted \& partly prefilled } \\
\text { excel-template (one entry). }\end{array}$ & $\begin{array}{c}\text { Via mobile phone, numerical } \\
\text { entries to digital interface. }\end{array}$ \\
\hline Current Status & Defunct & Ongoing in all districts & Ongoing in four districts \\
\hline
\end{tabular}

How would a District Water Engineer know the functionality status of hundreds of water points in his district, unless he could inspect all of them personally on a monthly basis? Neither the BRN nor the CDMT have explicit provisions for bridging the reporting gap between the village and the district level. Deployed in 2014-2017, the SEMA app aimed to fill it. The SEMA app is a mobile phone and Unstructured Supplementary Service Data (USSD)-based administrative technology that allows COWSO members to report to DWEs on a monthly basis the functionality status of WPs in their village. The reporter in the village (e.g., a COWSO member) must answer numerically (i.e., by entering 1, 2, 3, or 4) seven simple questions (seven rows of Table 2) about each WP in the village on the screen of a standard mobile phone. The software converts the numerical answers into a status of WP functionality (eighth row of Table 2). So far, the SEMA app has been deployed in four districts. An app simulator in Swahili can be accessed by typing on the web the following address, 41.86.162.35/simulator/. The information flow in SEMA is hierarchical. At first instance, the DWE has the authority to decide whether to accept or reject the report. Ultimately, the MoW/CDMT and the independent inspector have the final say and may overrule the DWE's assessment.

However, introducing the app to COWSOs is one thing, making sure that the report is deemed legitimate by village and district bureaucrats is quite another. Demonstrations of the SEMA mobile app in one of the districts unleashed a power struggle, between DWEs, Village Executive Officers (VEOs) and COWSOs. COWSOs, the new village institutions dictated by law (Water Supply and Sanitation Act, 2009) to manage and operate rural water points, are not only inexperienced to perform their tasks, 
but also too few. "Out of 2728 planned BRN COWSO establishments by June 2014, only 460 were registered $(17 \%)$. This slowness is due to a lack of funds allocated to [district governments] for undertaking registration" (Water Sector Development Report [25]).

Table 2. The software algorithm inscribed in the SEMA app.

\begin{tabular}{|c|c|}
\hline 1 & $\begin{array}{l}\text { Does the water point have any hardware problem? } \\
\qquad(1 . \text { Yes 2. No) }\end{array}$ \\
\hline 2 & $\begin{array}{l}\text { Is water flowing from water point? } \\
\qquad(1 . \text { Yes 2. No) }\end{array}$ \\
\hline 3 & $\begin{array}{l}\text { What is the quality of water? } \\
\text { (1. Soft Water 2. Colored Water 3. Salt Water 4. Contains Chemicals) }\end{array}$ \\
\hline 4 & $\begin{array}{l}\text { What is the quantity of water? } \\
\text { (1. Enough 2. Not Enough 3. Seasonal) }\end{array}$ \\
\hline 5 & $\begin{array}{l}\text { Reasons for non functional water point } \\
\text { (1.Broken 2. Stolen 3. No Fuel 4. Dry) }\end{array}$ \\
\hline 6 & $\begin{array}{c}\text { Alternative water sources } \\
\text { (1. Rainfall 2. Natural Source 3. Improved Source) }\end{array}$ \\
\hline 7 & $\begin{array}{c}\text { Water point maintenance option } \\
\text { (1. Machine Service 2. Parts replacements 3. Water Leakage) }\end{array}$ \\
\hline 8 & $\begin{array}{c}\text { Water point status } \\
\text { (1. Functional 2. Non Functional 3. Functional Needs Repair) }\end{array}$ \\
\hline
\end{tabular}

\section{Concepts and Methods}

\subsection{Concepts}

To conceptualise rural water governance, we use the systems approach to organisational studies [28]. At the heart of this approach are "organisational structures"-i.e., decisions that serve as premises upon which other decisions, however complex, are routinely made within organisations. For example, the decision of a water engineer to repair a water pump in a village is not a decision premise because it applies only to this particular water pump at that time. However, when the MoW decides that the district water engineer must repair any broken water pump in his district within ten days of a break down, a decision premise comes into play. Organisational structures refer to relatively lasting patterns of order within organisations [26]. They are formal when formally decided, and informal, when informally decided. Any organisation has three types of organisational structures-programs, communication channels and members-which can be either formal or informal.

In rural water supply, formal programs include legislative acts, policies, information systems (e.g., the water point mapping system) and official documents of the Ministry of Water. They determine which formal responsibilities organisational members have and, consequently, which of their actions are to be viewed as right or wrong, and rewarded or sanctioned, respectively. The National Water Policy (2002) and related legislative acts (United Republic of Tanzania, 1982, 1998, 2009) determine the responsibilities of district officials, councillors and COWSOs in rural water supply. For instance, district officials must provide information on the status of water services in the district. Councillors must access district public records and raise questions in water-related council meetings. COWSOs must follow up on non-functional water points and mobilize communities for their revival. Informal programs may take the form of well-established, customary routines and dictate informal responsibilities, such as citizens expecting councillors to contribute their own funds for water projects.

Formal communication channels establish legitimate points of contact, proper conduits for the flow of information and domains of responsibility. They are the only means of preventing communications overkill—everybody communicating with everybody else-within an organisation. For instance, Nganyanyuka [29] describes in minute detail the formal and informal channels and legitimate points 
of contact for the information flow between a village COWSO and the district council when a rural water pump breaks down. Informal communication channels develop when formal channels are routinely bypassed, or when informal hierarchies are set up based on political party or tribal affiliations. Examples are COWSO leaders bypassing the village assembly, and instead reporting their performance to leaders of civic associations during village feasts, or citizens contacting political figures or central government public officials (not necessarily involved in the water sector) to pressure district officials to respond to their needs.

Organisational members also constitute an organisational structure because decisions that affect the organisation always depend on who occupies the position responsible for making them [28]. A COWSO or village leader who belongs to the ruling political party may decide differently from a leader who leans towards the opposition party. In the late 1960s, when Julius Nyerere massively resettled peasants to newly formed villages, peasants often chose petty-capitalist farmers as village leaders "on the assumption that they were better equipped to deal with officials, including protecting them from government interventions that would threaten their livelihood. In places where there were no such petty-capitalists, villagers often chose individuals known not to be interested in change" [30], emphasis in original), but people whose interest in interfering with their life was small. Informal members are individuals and institutions outside the formal rural water hierarchy and include political patrons, the Church, Islamic institutions, and grassroots civic associations.

Informality may be either compatible with formality, or it may break the formal rules or it may break the law. The systems approach to the study of organisations teaches that informality cannot be suppressed by decree; it can take different forms only when changes are made to the formal structures themselves [28]. A change of formal rules and procedures will not supress informality. Instead, it may lead to new informal structures that are more (or less) conducive to improvement of rural water services at the district and village levels.

\subsection{Methods}

We used a qualitative case study design to examine how administrative technologies were used for the regular updating of WP functionality through space and time. We collected data on these processes during a four-year period (2013 and 2017), in the framework of an interdisciplinary research program, called Sensors, Empowerment, and Accountability (SEMA). Our qualitative data include interviews with bureaucrats at all government levels, politicians, village leaders, data collectors and software developers. During this period, we were also developing an administrative technology-a mobile phone-based application, called SEMA app-that enables villagers to report information on WP functionality to the district government. Thus, we were participant observers in the strong sense of these processes. A key element of the overall SEMA research design was action research, which included designing the SEMA app, deploying it in a district, learning from the deployment, redesigning and repeating the testing cycle in the same district.

We conducted interviews with political and administrative officials at the national and local government levels. We used a semi-structured interview guide, organised around the themes of rural water governance, information collection and flow, analysis and usage, the BRN programme, CDMT and the functionality of rural water points. Following [31], we organised the interview themes to accurately convey meaning to the respondents and motivate them to participate. At the MoW, we interviewed officials responsible for rural water supply, i.e., the department of rural water supply, officials in the ICT department, and officials responsible for managing the BRN programme and CDMT. At the district level, we interviewed politicians and bureaucrats in council meeting halls, district headquarters, ward and village offices, field sites and informal locations. We interviewed respondents immediately after a testing session of the SEMA app.

The second method for data collection was participant observation. Before embarking on data collection, using this method, we determined beforehand the type of information we needed to observe in the participant observation venues. We prepared a short list of things that would aid the 
observations. We observed four meetings: two in a (anonymized) district and two more at the MoW. In the district, we observed council meetings, council proceedings, district meetings and field-sites where bureaucrats interacted with politicians. We made similar observations during the introduction of the SEMA mobile app at a workshop that brought together councillors, ward officials, village officials and senior district administrative officials. At the MoW, we observed reactions to the SEMA app in workshops organised to solicit the views of MoW officials regarding its usefulness for updating the WPM system. Participant observation was useful in collecting the data because social practices are sometimes missed or hard to uncover in conventional interviews, for respondents may not mention them or may consider it silly to talk about them [32].

\section{Results}

Below we analyse three formal government processes relevant to the three administrative technologies BRN, CDMT and SEMA discussed in the previous section. These processes include national standardisation, the construction of new administrative hierarchies and the flow of WP information from reporters to recipients. The analysis reveal tensions in rural water governance, which affect rural water services negatively, and are discussed in Section 5.

\subsection{National Standardisation}

The first tension arose from efforts of the MoW to standardise the functionality status of a geo-located water point (WP), during the period 2010-2017. Standardisation is a process of simplification and abstraction that defines and communicates significant aspects of artefacts across time and space [33,34]. Standardisation enables any inspector of the water point, whether a ministry official, a district water engineer or a villager, to establish the status of the WP- "functional", "non-functional", "functional needs repair" - in exactly the same way, at any time. Without such a common standard across space and time, it would be impossible to "see" (see Figure 2) the status of all rural water points in the nation and plan and budget for their repair. Using the concepts in Section 3.1, we may say that a functionality standard combines a formal program, a communication channel and members. Together, these produce a functionality status for a WP, which remains the same across multiple, spatially distributed communities of practice.

Between 2010 and 2017, the MoW endorsed three different formal programs to standardise how a district water engineer must report the functionality status of a WP (Table 3). The first program (row 1) was recommended to the Ministry by SNV (2010)—an international NGO with substantial prior experience in water point mapping in Malawi and parts of Tanzania-and was used throughout the collection of baseline data for the WPMS, in 2010-2013, as well as for BRN. It was the least precise program of the three, but vague enough to be accepted by all. The second program (row 2) was recommended to the MoW by [23], the South African consulting company hired by DFID to assess the quality of the WPMS baseline data. We inscribed See/Saw's new formal program, which the ministry had endorsed, in the algorithm of the SEMA app (see Table 2). The Ministry announced the third program (row 3) in Dodoma in January 2017. This program is far more precise than the previous two, to ensure honest reporting of WP functionality. Honest reporting-i.e., reporting the status of water points functionality without fabrications [18] —enables the district water engineer to secure annual payments for each functional water point in his/her district and helps independent inspectors identify "gaming" by the district water engineer [10].

All three programs are conditional, "if ... , then ... " decision premises [28]. During the collection of WP baseline data for the WPMS (2010-2013), official data collectors and their local informants-district water engineer and village bureaucrats—-had to apply the formal "if . . , then ... " program in the first row of Table 1. For instance, if the WP has a hardware problem; or has been non-functional for less than six months; or non-functional for less than three months; or non-functional for more than three months, then the WP is "functional needs repair". 
However, the DWE and the village bureaucrats often applied an informal program in their interactions with the official data collectors: if a WP had been non-functional for less than three months and needed only small repairs, then they declared the WP "functional", because "small repairs usually take up to three months to fix" (interview with data collector). As a result, upon completion of the data collection in 2013, it was impossible to know whether water points recorded two to three years earlier and labelled "functional", had been actually repaired in the meantime. Village bureaucrats in several villages applied a further informal program. They often entirely concealed the existence of some water points in their villages: "The village [bureaucrats] often lied to me when I asked where the water points are. They reported having fewer water points than they actually did. They did not report water points that could be reached only by walking many hours. They hoped that by lying about existing water points, especially those far away, I would construct more water points closer to them. Obviously, they over-estimated my powers. I am only a data collector" (interview with data collector). The competition between the formal and informal programs was the root cause of the broken WPMS baseline. Data on hundreds of water points had either not been captured at all, or had a functionality status of dubious quality [18].

Table 3. Conditional formal programs for reporting the functionality status of a water point.

\begin{tabular}{|c|c|c|c|}
\hline Programs & Functional & Functional Needs Repair & Non Functional \\
\hline $\begin{array}{l}\text { 1st SNV } 2010 \\
\text { (used by BRN) }\end{array}$ & $\begin{array}{c}\text { WP yields water for at least six } \\
\text { months of the year and is being } \\
\text { used by people as a water source } \\
\text { on a day to day basis }\end{array}$ & $\begin{array}{l}\text { WP has a hardware problem; WP has } \\
\text { been non-functional less than } \\
6 \text { months; or WP has been } \\
\text { non-functional less than } 3 \text { months; or } \\
\text { WP has been non-functional more than } \\
\quad 3 \text { months. }\end{array}$ & $\begin{array}{l}\text { WP does not yield water for more } \\
\text { than six months of the year for any } \\
\text { reason (e.g., hardware problem, } \\
\text { source being dry, water quality } \\
\text { (too salty, or too much fluoride). }\end{array}$ \\
\hline $\begin{array}{l}\text { 2nd See/Saw } 2014 \\
\text { (used by SEMA) }\end{array}$ & $\begin{array}{l}\text { WP does not have a hardware } \\
\text { problem; water is flowing at the } \\
\text { time of inspection; acceptable } \\
\text { water quality (based on } \\
\text { users' perception) }\end{array}$ & $\begin{array}{l}\text { WP has a hardware problem; water is } \\
\text { flowing at the time of inspection; WP } \\
\text { abandoned due to water quality. }\end{array}$ & $\begin{array}{l}\text { The WP's source is seasonal; water } \\
\text { is not flowing at the time } \\
\text { of inspection. }\end{array}$ \\
\hline $\begin{array}{c}\text { 3rd } \\
\text { CDMT/MoW } 2017\end{array}$ & $\begin{array}{l}\text { WP does not have a hardware } \\
\text { problem; produces water within } \\
\text { five strokes for a pump or a user } \\
\text { can fill a } 20 \text { L bucket in } 2 \text { min; } \\
\text { acceptable water quality (based on } \\
\text { users' perception) and meets } \\
\text { national quality norms. }\end{array}$ & $\begin{array}{l}\text { WP has a hardware problem; does not } \\
\text { produce water within } 5 \text { strokes for a } \\
\text { pump, or a user is not able to fill a } 20 \mathrm{~L} \\
\text { bucket within } 2 \text { min; water quality is } \\
\text { not acceptable (based on users' } \\
\text { perception) or does not meet national } \\
\text { quality norms. }\end{array}$ & $\begin{array}{c}\text { WP does not provide users with } \\
\text { any water supply due to damage, } \\
\text { malfunction or restriction } \\
\text { of access. }\end{array}$ \\
\hline
\end{tabular}

Between 2014 and 2017, the Ministry and donors increased their efforts to fix the WPMS baseline. This meant increasing the pressure on district water engineers, who were already overwhelmed with existing upward-reporting requirements. A district water department must sustain vertical formal communication channels, upwards to the ruling party, the district and regional commissioners, all requiring non-harmonized reports that result in duplication. The ruling party demands water point information to explain to voters how the party is fairing in the water sector and how the election manifesto is being implemented in the district. The District and Regional Commissioners demand information on the status of rural water supply. To these, the Ministry added a new formal communication channel for WP reporting first to the BRN and, since 2016, to CDMT/MoW, a new unit within the Ministry. "We collect a lot of information, some of which is not even needed by the water department, but fulfils the requirements of the region and the MoW. [R]eporting to [several] higher levels derails [district water engineers] from focusing on other responsibilities" (interview district water engineer). At the same time, district water engineers must sustain horizontal formal and informal communication channels with other district departments, councillors and contractors as well as vertical channels downwards to village bureaucrats, COWSO members and water users, some of which display a staggering complexity. For instance, Nganyanyuka [29] describes how even the writing of a check-a tiny fraction of the entire process of detecting a failed water point and fixing it-within the district government to pay for the repair of a broken water pump may take a full week. "Usually it takes a week for the accountant to write the check. This is when I do frequent follow-ups. I have to go to [the district treasurer's] office every day and if the funds are urgently needed, I sometimes make multiple visits in a day" (District official, DWE's office). 


\subsection{New Administrative Hierarchies}

In 1998, the Government of Tanzania (GoT) promulgated a policy of decentralization by devolution ( $\mathrm{d}$ by $\mathrm{d}$ ) to give district governments the power and authority to manage their own administrative, fiscal, political and personnel affairs. The policy, often referred to as "eyes on, hands off", restricts central government, e.g., the Ministry of Water, to supervision, monitoring and coordination of national policies and priorities. Districts must act autonomously in making decisions pertaining to rural water supply, including ensuring the functionality of water points. The BRN was also supposed to be implemented within the context of decentralisation by devolution, but, in reality, it functioned informally as a centralization program, in tension with the formal decentralization program.

The new administrative hierarchies, created by BRN, overburden district officials, as respondents affirmed: "we feel overburdened by the information collection roles and reporting to higher levels ... the BRN programme introduced new reporting formats and information collection formats that are confusing and impossible to handle especially in the context where internet services are poorly available in the district. In addition, there are too many reporting levels that are not coordinated" [26]. Further, reporting the functionality status of rural WP upwards is one thing; ensuring that the reported information translates into repairs is quite another, and creates further competition between the decentralization and centralisation programs, and tensions at various levels of the hierarchy in the rural water sector. For instance, the formal decentralization program instructs COWSOs to cover O\&M costs when a water point is broken. In practice, COWSO members cannot meet the costs for operation and maintenance. In response, the MoW transfers resources to districts to help fix broken water points, which are often spent for other purposes [29].

As a result, informal centralization becomes the rule. A senior official in the MoW noted: "public officials in the MoW transfer a lot of responsibilities to district authorities without [them having] adequate resources. As a result, broken rural water points are not repaired on time, and, when they are repaired, they are not repaired effectively ... " Another senior respondent in the MoW explained that: "there are not enough qualified professionals at the village and ward levels in the districts posing challenges to the implementation of various programmes in the rural water supply sector." Echoing these remarks, a senior district official noted that "BRN is like a father, who refuses to give his children better health, education, and water but expects them to live a decent life ... instead of calling it a BRN Programme, I would call it a Small Results Now Programme ... you cannot have a cow producing a lot of milk, if you don't feed the animal properly" [26]. Respondents have mixed feelings regarding the financial resources required to sustain the functionality of rural water points. Central government, through the MoW, controls resources for managing rural water supply and deprives lower levels of government, including the district governments, of their autonomy. Furthermore, central government fails to disburse resources when and where needed.

Further tensions are evident between district water officials and Community Water Supply Organisations. COWSOs are formally responsible for the functionality of the water points in the village and must mobilize resources to sustain them. In reality, they lack organisational and financial management skills. A district water official explained: "A review of planning for OEM in the audit report of 2015 revealed that most of the COWSOs have not quantified their OEM costs and made no decisions on how much to charge for water to recover costs. The lack of a financial management plan to recover O\&M cost and insufficient sensitization negatively impact sustainability". As a survival strategy, district officials weaponize the formal decentralization policy to dump responsibilities to COWSOs through O\&M mandates. However, COWSOs insist that the district should intervene especially when the problems-e.g., the choice of water point technology and financial disbursements-emanate from the district. While dumping responsibility is largely prevalent, our fieldwork revealed an increasing focus on repairing newly constructed water points. This practice goes hand in hand with reporting upward information regarding newly constructed water points. Old water points do not get a lot of attention from district water officials because they do not attract funds from donors. Overall, in the midst of the described 
tensions, informal centralization between the MoW and districts and COWSO and district officials determines largely which actions are taken to repair a broken water point.

The CDMT administrative technology for information flow is top-down, designed to collect information from lower units of governance, the VEOs, WEOs, and DWEs. However, CDMT adds another layer of work to VEOs, WEOs and DWEs in addition to their daily reporting routines via the WPMS. This situation, at times, results in DWEs sending incomplete, inaccurate as well as unreliable information. For instance, a CDMT report of 2016 notes that "several challenges have been seen during analysis of the data received from every [local government]. This leads to either data being rejected, or being seen as (Data Error) or as partially updated. Additional water points have no name such as in [cites examples]. Several water points have no coordinates [or] are left unfilled with no proper explanation [cites example]. Copying and pasting the old template [cites examples]. The use of old template [cites example]. Filling up status with wrong data on water taps that are not conforming to approved standards hence (data error) like [cites examples]. Incomplete filling of the status and number of taps hence partially updated."

Although CDMT argues that the quality of data collected is improving, our interviews with district officials involved with BRN reporting structures, which is replicated by CDMT by involving VEOs and WEOs, confirm that the layer after layer of hierarchical upwards reporting is confusing and derails lower government officials from performing their daily tasks. Recognizing this shortcoming, our respondent(s) informed us that CDMT now uses an informal communication channels to communicate with VEOs and WEOs to verify and crosscheck the information reported by DWEs to the MoW.

\subsection{Recipients and Reporters of WP Information}

As noted in Section 2, the SEMA mobile app sought to bridge the reporting gap between the village and the district level, by empowering COWSOs to report to the district the status of water points in their respective locality. District water officials would use the reported information to report further upwards, to the MoW, the status of water points. However, reporting and receiving information using the SEMA app generates tensions. First, DWEs as the formal recipients of WP information, compete with the desire of other actors (e.g., Councillors and COWSOs) to informal receive the WP information. Second, the formal administrative mandates of VEOs to report information on functionality/non-functionality of water points compete with the informal mandate of COWSOs to report the information.

Regarding the first tension, district councillors argued that they are entitled to the information collected with the SEMA app: "We want to receive information from the SEMA app on rural water point functionality... We need this information in order to understand the status of water points in or respective wards so that we can take political action." Similarly, COWSO members wanted to receive the information. A COWSOs chairperson pointed out: "As an organisation responsible for managing rural water points in our villages, we certainly have a right to receive the information generated by the app ... This will enable us be sure that our problems regarding the rural water points in the villages have reached the district level." However, district officials were weary of a radical information transparency to all involved. A senior district official explained that the "SEMA mobile app is a working/administrative tool for the DWE and technical people in the water department. Politicians including councillors are therefore not part of this design. If councillors and COWSOs want information, they can get it at the Ward Development Committees (WDC) where councillors serve as chairpersons and COWSOs join as members of these committees. Hence, they have access to all the information, including water point status information" [29]. However, councillors insisted that they need information to be able to question the performance of the DWE in their respective wards. The fact that district officials wanted to exclude councillors and COWSOs from receiving information from the SEMA app raises questions with regard to the role of data transparency in monitoring rural water services using mobile phones. Councillors blocked from accessing information from the SEMA app cannot scrutinize the actions and inactions of public officials. COWSOs blocked from access will not be able to know whether water points with functionality problems are attended to by the district. 
As for the second tension, COWSOs and councillors felt that the secretary general of a COWSO should report, while district water officials were adamant that the Village Executive Officers (VEO) should report. Notably, the URT constitution of 1977 and the local government laws of 2000 formally recognize the role of the VEO. From a legal perspective, both entities draw their mandate from national laws. However, the district water officials were in favour of the Village Executive Officers because VEOs provide an important administrative link between the district officials and villages. VEOs are salaried officials and reporting is their basic responsibility. They are directly accountable to the District Executive Director (DED) and the DWE. Accordingly, from the point of view of district officials, VEOs should report. Relying on VEOs as the main reporters would make things easier for the DWE because, in practice, most of the VEOs are loyal to higher administrative ranks of the district and easy to control. In defending the VEOs as the main reporters in the SEMA app, a respondent explained: "In the rural water sector, the administrative hierarchy starts with the MoW, DED, DWEs, WEOs and VEOs. Bypassing these formal administrative arrangements in reporting information violates the local government legislation of 2000, including the local government Acts of 1982 and subsequent legislations... VEOs are not political officials, they are an important link of the administrative machinery of the district."

However, some district officials were against the idea of using VEOs as reporters on the grounds that VEOs have a lot of administrative roles and responsibilities. Respondents noted that "the district lacks funds to employ new VEOs, most of the VEOs, now working, in the district are serving in acting capacities in the villages. They are not employed by the district hence not directly accountable to the district. In some villages, VEOs are literally non-existent. The district does not have enough money to employ new VEOs." On the other hand, COWSO leaders were in favor of reporting themselves because: "COWSOs are autonomous legal entities; they are supposed to be independent to manage water points on their own without interference. Likewise, the councillors echoed this position by arguing that the roles of COWSOs and the VEO and the district are very clear ... COWSOs should send reports to VEO but should be able to report directly to the district ... the main reporter should be the COWSO secretary general." The technical staff of the department of the rural water supply challenged this idea: "Technical staff makes field visits to inspect water points and gets paid. Shifting this responsibility to COWSOs means no incomes for themselves and their families." This situation resulted in a clear tension between formal administrative mandates of VEOs to report information on functionality/non-functionality of water points and the informal mandate of COWSOs to report the information. Notably, VEOs are formerly recognized legally as part of the administrative hierarchy of the district. COWSOs are legal entities but not formally recognized in the administrative hierarchy of the district.

\section{Discussion}

The data analysis reveals five tensions in rural water governance in Tanzania caused by the competition of formal programs and communication channels with informal programs and informal communication channels. Table 4 summarizes tensions and their effects on rural water governance.

Below, we discuss the tensions and their effects on rural water governance as they pertain to standardisation, new administrative units, and, last but not least, recipients and reporters of WP information. The tensions are the following: (1) formal standardisation versus informal programs for determining WP functionality; (2) formal decentralization versus informal centralization of roles and responsibilities; (3) excessive top-down vertical communication versus indifference to complexity of horizontal communications; (4) DWEs as only formal recipients of WP information versus other actors (e.g., Councillors and COWSOs) as informal recipients of WP information; and, (5) formal administrative mandates of VEO to report functionality of water points versus the informal mandate of COWSOs to report the information. 
Table 4. Tensions between formal and informal programs and communication channels and their effects.

\begin{tabular}{|c|c|c|c|}
\hline & & Tensions & Effects \\
\hline Programs & (1) & $\begin{array}{l}\text { A series of formal standardisation } \\
\text { programs versus informal programs for } \\
\text { determining WP functionality } \\
\text { Formal decentralization versus informal } \\
\text { centralization of roles } \\
\text { and responsibilities }\end{array}$ & $\begin{array}{l}\text { "Broken" WPMS baseline Transferring of roles and } \\
\text { responsibilities to resource-less districts to manage the } \\
\text { rural water points, with unattended broken water } \\
\text { points as a result }\end{array}$ \\
\hline $\begin{array}{l}\text { Communication } \\
\text { Channels }\end{array}$ & $\begin{array}{l}(4) \\
(5)\end{array}$ & $\begin{array}{l}\text { Excessive, top-down vertical } \\
\text { communication versus indifference to } \\
\text { complexity of } \\
\text { horizontal communications } \\
\text { DWEs as only formal recipients of WP } \\
\text { information versus the desire of other } \\
\text { actors (e.g., Councillors and COWSOs) } \\
\text { to be informal recipients of } \\
\text { WP information } \\
\text { Formal administrative mandates of } \\
\text { VEO to report information on } \\
\text { functionality/non-functionality of } \\
\text { water points versus informal mandate } \\
\text { of COWSOs to report the information }\end{array}$ & $\begin{array}{l}\text { "Broken" WPMS baseline } \\
\text { Councillors are denied the opportunity to access } \\
\text { information to hold district officials to account } \\
\text { VEOs feel bypassed and powerless. Dump } \\
\text { responsibilities to COWSOs. }\end{array}$ \\
\hline
\end{tabular}

\subsection{National Standardisation}

The Ministry's repeated efforts to standardise water point functionality compete with informal programs used by district water engineers and villagers to label water points. They also compete with local interpretations of functionality, which the following example serves to illuminate. In 2014, See/Saw Consultants presented fictional WP scenarios (WPs with various hardware problems, differing water availability including seasonality, and at varying timescales) to district water engineers in four different districts and asked them to label each fictional WP. The exercise revealed a "considerable variation in district staff interpretation of WP functionality. Since the DWEs and their staff are currently responsible for updating the WPMS, these differences in understanding will have a significant impact on the data reported for the proposed PbR payments" [23].

The ministry's diverse efforts, either through the WPMS data collection exercise, or though BRN and finally through CDMT, to oblige district water engineers to report upwards downplay the complexity of the horizontal communications they have to sustain to perform their everyday work. As Georgiadou et al. [18] argue, the additional "premature load bearing" [35], or pressure on district water officials, driven by ignorance about their daily challenges, may lead to stress and a weakening or total collapse of district water capacity. A flexible standards approach to create a modular hierarchy of national, district and village-level water point datasets might release tensions between the national standardisation, required by the Ministry and development partners, and attention to local context is required [36]. Otherwise, the real functioning of rural water points will remain elusive and invisible to the government.

Standardisation is a reflexive process, constantly needing monitoring, revisions, and new standards (as we have seen in Table 3) in rural water supply. First, (in)formal programs, communication channels and members (donors, ministry, district officials, councillors, village bureaucrats, COWSOs, etc.) compete or converge with each other during the standardisation process. Second, it is important to understand how to allow each institutional level of members (ministry, or district or village level) a degree of autonomy and flexibility in order to define their own data standards while conforming to standards of the higher levels. Third, given the political nature of the standardisation process, it is important to negotiate and provide appropriate incentives to each member to engage in the process of standard setting and use. 


\subsection{New Administrative Hierarchies}

The administrative hierarchies introduced by the ministry to monitor water point functionality compete with existing ones. They create tensions at the district level-DWEs must report upwards and at the same time attend to their daily routines, which are at odds with upwards reporting. Furthermore, ensuring that the reported information is effective and enables the repair of broken water points complicates matters more because it reinforces the competition between the decentralization and centralisation programs in the rural water sector.

These tensions affect water point functionality in several ways. The WPMS baseline suffers from poor quality data, broken water points are left unattended and responsibilities are dumped to COWSOs. The MoW and district officials abdicate their technical and financial responsibilities to assist COWSOs manage rural water points. Instead, these roles and responsibilities are transferred to COWSOs, without providing them the technical and financial resources to do so. With no results to show to development partners, all actors engage in blame games. COWSOs blame the district government for failing to repair broken points, the district government blames the MoW for not transferring resources to repair broken water points, the MoW blames the central government and the development partners for delayed or insufficient disbursement of funds.

The concept of institutional bricolage can help illuminate these tensions by explaining how new administrative hierarchies interact with existing ones. In some cases, the interaction between old and new may result in total replacement or absorption of one by the other, but it may also produce a productive hybrid $[37,38]$. BRN and CDMT inserted new administrative hierarchies into a context where formal decentralisation already competes with informal centralisation. Informal centralisation became an instrument through which the MoW dictates to DWEs what they should do regarding reporting information on water point functionality as well as repairing broken water points. In effect, DWEs are deprived of their autonomy to make decisions and to use available resources within their localities to repair broken water points. Instead, they have to depend on technical and financial resources from the MoW, which are always in short supply.

Creating new administrative hierarchies may improve services if applied incrementally, reflecting on the existing institutional context and constantly adapting and adjusting to prevailing (in)formal programs, communication channels, and members and how they interact or compete. It is equally important to ensure that each institutional level of members enjoys a degree of autonomy and flexibility to manage rural water points, while at the same time conforming to policy and institutional directives at higher levels. This observation agrees with [4,5], who discuss challenges for water governance in the rural water supply and implementing pro-poor policies in a decentralized context.

\subsection{Recipients and Reporters of WP Information}

The introduction of the SEMA app to monitor functionality of water points created tensions with existing communication channels at the two ends of reporting and receiving information. The first tension involved DWEs as the presumably only formal recipients of WP information. This competed with the desire of other actors (e.g., Councillors and COWSOs) to be informal recipients of WP information. The second tension involved formal administrative mandates of the VEO to report information on functionality/non-functionality of water points and competed with the informal mandate of COWSOs to report the information. These tensions limit the accountability of councillors to citizens. Councillors are legally mandated to hold district officials to account. Excluding them from receiving information denies them an opportunity to access information, which they could use to hold the district officials to account. Equally, when VEOs are excluded from the district administrative links of information flows, they feel bypassed and powerless. This has a direct effect on their work for they are the formally designated administrative officials linking the district and the villages.

Administrative technologies such as the SEMA app are political in nature. They negotiate and renegotiate relations between members in organisations and introduce new communication channels. This observation is in line with $[39,40]$, who argue that apps are not free of politics, since they 
re-negotiate internal bureaucratic relationships, habits and unwritten rules. In this context, apps have a transformative power; they can transform existing communication channels by creating tensions between formal and informal recipients recipient of information versus as well as between formal and informal senders of information.

As noted by [41], any digital technology, including the SEMA app should be understood as part and parcel of a social context, both emerging out of that context, impacting upon it, and gradually acquiring new, frequently unintended meanings through anticipated and unanticipated use. In other words, apps are inscribed administrative or political preferences. The two tensions with regards to receiving and sending information via the SEMA app is a clear manifestation of this observation. As Fung et al. [42] argue, we need to understand administrative technologies as an intervention in a larger political system.

We suggest a cultivation approach for the development of an information infrastructure for rural water governance, a well-established approach in the STS scholarship of information infrastructures [43]. Cultivation is more conservative than 'construction', which privileges the power of human agency in "selecting, putting together, and arranging a number of objects to form a system" [44,45]. Cultivation emphasizes the power of the material: "the tomatoes themselves must grow, just as the wound itself must heal" [44]. A cultivation approach emphasizes improvisation and the work of people in situated action [45]. The development of administrative, as well as financial and computing technologies, should not be viewed as a well-defined process with pre-configured start and end states but as an ongoing process of ecological change of design and use, characterized by "unanticipated effects" [46] and "drift" [47]. Finally, informality is the mainstay of African life and how it operates is of both intellectual and strategic significance, especially as one turns to the link between politics and development in Africa [48].

Acknowledgments: We acknowledge the financial support of the research programme "Sensors, Empowerment and Accountability (SEMA) in Tanzania" funded by the Netherlands Organisation for Scientific Research-Science for Global Development (NWO-Wotro). Discussions with and readings of the work of Prof. Goran Hyden have significantly shaped our thinking on informality. We are grateful to our informants in Tanzania who provided us with invaluable information in rural water governance and to the two anonymous reviewers for insightful comments that improved the manuscript. We also acknowledge the contribution of Dr. Anna Wesselink, who worked in the SEMA research programme as a post-doc for two years and supervised the data collected by the first author.

Author Contributions: Jesper Katomero and Yola Georgiadou analysed, conceptualized the data and wrote the paper; Juma Lungo provided the software algorithm inscribed in the SEMA app; Robert Hoppe supervised the $\mathrm{PhD}$ thesis of the first author and critically read the paper.

Conflicts of Interest: The authors declare no conflict of interest.

$\begin{array}{ll}\text { Abbreviations } & \\ \text { BRN } & \text { Big Results Now } \\ \text { CDMT } & \text { Central Data Management Team } \\ \text { COWSOs } & \text { Community Water Supply Organisations } \\ \text { DFID } & \text { Department for International Development } \\ \text { DRWS } & \text { Department of Rural Water Supply } \\ \text { DWE } & \text { District Water Engineer } \\ \text { GoT } & \text { Government of Tanzania } \\ \text { ICTs } & \text { Information Communication Technologies } \\ \text { MDU } & \text { Ministerial Delivery Unit } \\ \text { MoW } & \text { Ministry of Water } \\ \text { NAWAPO } & \text { National Water Policy } \\ \text { NGOs } & \text { Non-Governmental Organisations } \\ \text { O\&M } & \text { Operations and Management } \\ \text { PbR } & \text { Payment by Results }\end{array}$




$\begin{array}{ll}\text { PDB } & \text { Presidential Delivery Bureau } \\ \text { SEMA } & \text { Sensors, Empowerment and Accountability } \\ \text { SMS } & \text { Short Message Service } \\ \text { SNV } & \text { Stichting Nederlandse Vrijwilligers_-Dutch NGO } \\ \text { USSD } & \text { Unstructured Supplementary Service Data } \\ \text { VEO } & \text { Village Executive Officer } \\ \text { WDC } & \text { Ward Development Committee } \\ \text { WEOs } & \text { Ward Executive Officers } \\ \text { WP } & \text { Water Point } \\ \text { WPMS } & \text { Water Point Mapping System } \\ \text { WSDP } & \text { Water Sector Development Programme }\end{array}$

\section{References}

1. Chidawali, H.; Chimbwete, R. CCM Beats Opposition Despite Decline. Available online: http:/ /www.thecitizen. co.tz/News/CCM-beats-Opposition-despite-decline/-/1840392/2560666/-/iviub/-/index.html (accessed on 25 August 2017).

2. United Nations Development Programme (UNDP). Human Development Report of 2014: Economic Transformation for Human Development. Economic and Social Research Foundation: Dar es Salaam, Tanzania; Available online: http:/ / hdr.undp.org/sites/default/files/thdr2014-main.pdf (accessed on 26 June 2017).

3. Carlitz, R. Money flows, water trickles: Understanding patterns of decentralized water provision in Tanzania. World Dev. 2017, 93, 16-30. [CrossRef]

4. Gine Garriga, R.; Perez-Foguet, A. Sustainability assessment of national rural water supply program in Tanzania. Nat. Resour. Forum 2008, 32, 327-342. [CrossRef]

5. Jimenez, A.; Perez-Foguet, A. Challenges for water governance in rural water supply: Lessons learned from Tanzania. Int. J. Water Resour. Dev. 2010, 26, 235-248. [CrossRef]

6. De Palencia, A.J.F.; Perez-Foguet, A. Implementing pro-poor policies in a decentralized context: The case of the rural water supply and sanitation program in Tanzania. Sustain. Sci. 2011, 6, 37-49. [CrossRef]

7. Therkildsen, O. Watering White Elephants: Lessons from Donor-Funded Planning and Implementation of Rural Water Supplies in Tanzania; Scandinavian Institute of African Studies: Uppsala, Sweden, 1988; Available online: http:/ / www.diva-portal.org/smash/get/diva2:277661/FULLTEXT01.pdf (accessed on 25 June 2017).

8. United Nations Children's Fund (UNICEF); World Health Organisation. Progress on Sanitation and Drinking Water: 2015 Update and MDG Assessment; World Health Organisation: Geneva, Switzerland, 2015; Available online: http:/ / files.unicef.org/publications/files/Progress_on_Sanitation_and_Drinking_Water_2015_Update_.pdf (accessed on 24 June 2017).

9. Stichting Nederlandse Vrijwilligers. Water Point Mapping: The Experience of SNV Tanzania. Available online: https://www.ircwash.org/resources/water-point-mapping-experience-snv-tanzania (accessed on 28 June 2017).

10. Government of Tanzania launches a nationwide scheme to improve access to water. Available online: https:/ / www.gov.uk/government/world-location-news/government-of-tanzania-launches-a-nationwidescheme-to-improve-access-to-water (accessed on 4 July 2017).

11. United Republic of Tanzania. National Water Policy; United Republic of Tanzania: Dar es Salaam, Tanzania, 2012. Available online: http:/ / www.tawasanet.or.tz/files/Tanzania\%20water\%20policy\%20-\%202002.pdf (accessed on 26 June 2017).

12. Mwamwaja, S.A. Mapping of Public Rural Water Service in Tanzania: A Case of Data Updating. Master's Thesis, University of Twente, Enschede, The Netherlands, 2014. Available online: https://www.itc.nl/library/ papers_2015/msc/upm/mwamaso.pdf (accessed on 28 June 2017).

13. United Republic of Tanzania (URT). Water Sector Status Report 2013; URT: Dar es Salaam, Tanzania, 2013.

14. Pedregal, B.; Cabello, V.; Hernández-Mora, N.; Limones, N.; Moral, L.D. Information and knowledge for water governance in the networked society. Water Altern. 2015, 8, 1-19.

15. Georgiadou, Y.; Bana, B.; Becht, R.; Hoppe, R.; Ikingura, J.; Kraak, M.J.; Lance, K.T.; Lemmens, R.L.G.; Lungo, J.H.; McCall, M.K.; et al. Sensors, empowerment and accountability: A digital earth view from East Africa. Int. J. Digit. Earth 2011, 4, 285-304. [CrossRef] 
16. United Republic of Tanzania. The United Republic of Tanzania-Government Open Data Portal. Available online: http:/ / opendata.go.tz/en/indicator/a2fab64e-47f7--11e5--847d-0e5e07bb5d8a\# (accessed on 1 July 2017).

17. Department for International Development (DFID). Phase Two: Rural Water Supply and Sanitation Programme, Tanzania: Annual Review: Department for International Development. Available online: https:/ / www.afdb.org/fileadmin/uploads/afdb/Documents/Project-and-Operations/Tanzania\%20\%20Rural\%20Water\%20Supply\%20and\%20Sanitation\%20Program\%20II\%20_AR_\%20doc\%20+Memo\% 5B1\%5D.pdf (accessed on 27 June 2017).

18. Janus, H.; Keijzer, N. Big Results Now? Emerging Lessons from a Result-Based Aid in Tanzania; German Development Institute: Bonn, Germany, 2015. Available online: https://www.files.ethz.ch/isn/192859/DP_ 4.2015.pdf (accessed on 5 July 2017).

19. Georgiadou, Y.; Verplanke, J.; Lungo, J.; Mbise, M. Water point mapping in Tanzania: Making the voices of data collectors audible. In Proceedings of the 7th Rural Water Supply Network (RWSN) Forum: Water for Everyone, Abidjan, Côte d'Ivoire, 29 November-2 December 2016.

20. Larkin, B. The politics and poetics of infrastructure. Annu. Rev. Anthropol. 2013, 42, 327-343. [CrossRef]

21. Anand, N. Pressure: The polytechnics of water supply in Mumbai. Cult. Anthropol. 2011, 26, 542-564. [CrossRef]

22. Richter, C. Digital Transformations in Indian Cities: Between Paper List and GIS Map; Faculty of Geo-Information and Earth Observation (ITC), University of Twente: Enschede, The Netherlands, 2014. Available online: http:/ / www.itc.nl/library/papers_2014/phd/richter.pdf (accessed on 25 June 2017).

23. See/Saw. Water point Mapping System Review and Data Verification, Draft Final Report, prepared in collaboration with the Ministry of Water, Government of Tanzania and DFID, Tanzania, with support from Crossflow Consulting. 2014.

24. United Republic of Tanzania, Ministry of Water. Tanzania Big Results Now! Road Map National Key Result Area Water 2013/14-2015/16. Available online: https:/ /www.pdb.go.tz/documents/Roadmaps/ 06.\%20Tanzania\%20BRN\%20Roadmap\%20-\%20NKRA\%20Water.pdf and Google Docs Form https:/ docs. google.com/forms/d/e/1FAIpQLScE5hLf3GFijCHX8xIqHLWiZq3Ok0Y5_it4q10m0a561aAr7A/viewform (accessed on 28 June 2017).

25. United Republic of Tanzania (URT). Water Sector Status Report 2014; Marking the End of WSDP Phase-I. Available online: http:/ / www.maji.go.tz/sites/default/files/u12/WSSR\%202014\%20FINAL_1.pdf (accessed on 7 July 2017).

26. Katomero, J.G. Accountability as an Element of Governmentality: An Investigation of National and Local Executive Accountability Practices in the Water Sector in Tanzania. Ph.D. Thesis, University of Twente, Enschede, The Netherlands, 2017. Available online: https:/ /www.narcis.nl/publication/RecordID/oai: ris.utwente.nl:publications\%2Fb772ad1c-860b-4df0-bc2b-9a2b06a0dc0d (accessed on 10 July 2017).

27. United Republic of Tanzania, Ministry of Water, Rural Water Supply Division. Processes \& Procedures for Updating Rural water point Data in Tanzania: User Manual. Available online: https://www.maji.go.tz/ sites/default/files/New_UPDATING\%20MANUAL\%20CDMT\%20SEPTEMBER\%202015.pdf (accessed on 11 July 2017).

28. Kühl, S. Organisations: A Systems Approach; Routledge: New York, NY, USA, 2013.

29. Nganyanyuka, K.O. Seeing like a Citizen: Access to Water in Urban and Rural Tanzania. Ph.D. Thesis, University of Twente, Enschede, The Netherlands, 2017. Available online: http://www.itc.nl/library/ papers_2017/phd/nganyanyuka.pdf (accessed on 8 July 2017).

30. Hydén, G. Beyond Ujamaa in Tanzania: Underdevelopment and an Uncaptured Peasantry, London; University of California Press: Berkeley/Los Angeles, CA, USA, 1980.

31. Denzin, N.K. The Research Act; Aldine: Chicago, IL, USA, 1970.

32. Bernard, H.R. Research Methods in Anthropology; Altamira Press: Lanham, MD, USA, 2006.

33. Bowker, G.; Starr, S.L. Sorting Things out: Classification and Its Consequences; MIT Press: Cambridge, UK, 1999.

34. Georgiadou, Y.; Puri, S.K.; Sahay, S. Towards a potential research agenda to guide the implementation of spatial data infrastructures: A case study from India. Int. J. Geogr. Inf. Sci. 2005, 19, 1113-1130. [CrossRef]

35. Pritchett, L.; Woolcock, M.; Andrews, M. Capability Traps? The Mechanisms of Persistent Implementation Failure Working Paper 234; Center for Global Development: Washington, DC, USA, 2010; Available online: https://www.cgdev.org/files/1424651_file_Pritchett_Capability_FINAL.pdf (accessed on 10 July 2017). 
36. Braa, J.; Hedberg, C. The struggle for district-based health information systems in South Africa. Inf. Soc. 2002, 18, 113-127. [CrossRef]

37. Cleaver, F. Development through Bricolage: Rethinking Institutions for Natural Resource Management; Routledge: London, UK, 2012.

38. Cleaver, F.; Franks, T.; Maganga, F.; Hall, K. Institutions, security, and pastoralism: Exploring the limits of hybridity. Afr. Stud. Rev. 2013, 56, 165-189. [CrossRef]

39. Maniatopoulos, G. E-Government movements of organisational change: A social shaping approach. In Proceedings of the 4th International Critical Management Studies Conference, Critique and Inclusivity, Cambridge, UK, 4-6 July 2005; Available online: http:/ / www.mngt.waikato.ac.nz/ejrot/cmsconference/ 2005/proceedings/movementsmoments/maniatopoulos.pdf (accessed on 11 July 2017).

40. Pelizza, A. Developing the vectorial glance: Infrastructural inversion for the new agenda on governmental information systems. Sci. Technol. Hum. Values 2016, 41, 298-321. [CrossRef]

41. Wesselink, A.; Hoppe, R.; Lemmens, R. Not just a tool. Taking context into account in the development of a mobile App for rural water supply in Tanzania. Water Altern. 2015, 8, 57-76.

42. Fung, A.; Russon Gilman, H.; Shkabatur, J. Six models for the Internet + Politics. Int. Stud. Rev. 2013, 15, 30-47. [CrossRef]

43. Hanseth, O.; Monteiro, E. Understanding Information Infrastructure. Available online: http:/ /heim.ifi.uio. no/ oleha/Publications/bok.pdf (accessed on 26 June 2017).

44. Dahlbom, B.; Janlert, S.; Department of Informatics, University of Gøteborg, Sweden. Computer future. 1996.

45. Suchman, L.A. Plans and Situated Actions; Cambridge University Press: New York, NY, USA, 1987.

46. Walsham, G. Interpreting Information Systems in Organisations; Wiley: Chichester, UK, 1993.

47. Ciborra, C.U.; Braa, K.; Cordella, A.; Dahlbom, B.; Failla, A.; Hanseth, O.; Hepso, V. From Control to Drift: The Dynamics of Corporate Information Infrastructures; Oxford University Press: Oxford, UK, 2000.

48. Hyden, G. African Politics in Comparative Perspective; Cambridge University Press: Cambridge, UK, 2004.

(C) 2017 by the authors. Licensee MDPI, Basel, Switzerland. This article is an open access article distributed under the terms and conditions of the Creative Commons Attribution (CC BY) license (http:/ / creativecommons.org/licenses/by/4.0/). 
Article

\title{
Evolving Spatial Data Infrastructures and the Role of Adaptive Governance
}

\author{
Jaap-Willem Sjoukema ${ }^{1, *}$, Arnold Bregt ${ }^{1}$ and Joep Crompvoets ${ }^{2}$ \\ 1 Laboratory of Geo-Information Science and Remote Sensing, Wageningen University \& Research, \\ Droevendaalsesteeg 3, 6708 PB Wageningen, The Netherlands; arnold.bregt@wur.nl \\ 2 Public Governance Institute, KU Leuven-University of Leuven, Parkstraat 45, 3000 Leuven, Belgium; \\ joep.crompvoets@kuleuven.be \\ * Correspondence: jaap-willem.sjoukema@wur.nl; Tel.: +31-317-481699
}

Received: 9 June 2017; Accepted: 10 August 2017; Published: 16 August 2017

\begin{abstract}
Spatial data infrastructures (SDIs) are becoming more mature worldwide. However, despite this growing maturity, longitudinal research on the governance of SDIs is rare. The current research examines the governance history of two SDIs in The Netherlands and Flanders (Belgium). Both represent decades-long undertakings to create a large-scale base map. During these processes, SDI governance changed, often quite radically. We analyse written accounts from geo-information industry magazines to determine if the SDI governance of these two base maps can be considered adaptive. We conclude that SDI governance was adaptive, as it changed considerably during the evolution of the two SDIs. However, we also find that most governance models did not hold up very long, as they were either not meeting their goals, were not satisfying all stakeholders or were not in alignment with new visions and ideas. In recent years, the policy instruments governing these base maps became increasingly diverse. In particular, more hierarchical instruments were introduced. Indeed, governance scholars increasingly agree that governance can better respond to changes when a broader mix of policy instruments is applied. Alas, this does not make SDI governance any less complex.
\end{abstract}

Keywords: spatial data infrastructure (SDI); governance; SDI development; self-organisation; complex adaptive systems; longitudinal analysis; large-scale base map; The Netherlands; Flanders

\section{Introduction}

\subsection{SDIs}

Spatial data infrastructures (SDIs) are becoming more mature worldwide. Their growing importance, increased connectivity and the greater participation of different public and private stakeholders have made appropriate governance essential for effective SDI development and management [1]. This is a challenge, however, due to the complex, multi-stakeholder, multi-level, technical and open nature of SDIs. As SDIs play an increasing role in society, more insight is needed into SDI governance.

In The Netherlands, Belgium and elsewhere, the governance of SDIs now often appears to be a matter of trial and error [2]. Hardly any evidence-based research exists on the effect of potential governance interventions, such as open data policy, changes in funding and coordination structures and participation of the private sector, on SDI effectiveness and efficiency. Formerly weak SDI components, such as standards, technology and data, have significantly improved over the years [3,4]. SDI governance might well be the "weakest link" in SDIs today.

A challenge in researching the relation between governance and SDIs is that ideas about both governance and SDIs are not stationary but change over time, place, culture and even discipline. 
This becomes clear in efforts to define these subjects, as there is a multitude of governance $[5,6]$ and SDI definitions $[7,8]$. How we think of governance or SDIs today could be very different from how we view these subjects in the future. This makes planning for future-proof SDI governance a challenge.

Though academia has no agreed governance definition [5,6], we use a holistic meaning in this research. We do not distinguish between 'hard government' and 'soft governance' [9]. Rather, we view all processes and structures for steering and managing SDIs as part of SDI governance [10]. These processes and structures can be governmentally or non-governmentally driven and can emerge from authoritarian [11], bottom-up or self-organising initiatives [12].

Kooiman [13] defines governance as follows:

Governing can be considered as the totality of interactions, in which public as well as private actors participate ... ; attending to the institutions as contexts for these governing interactions; and establishing a normative foundation for all those activities. Governance can be seen as the totality of theoretical conceptions on governing. (p. 4)

From this definition, we can distinguish three vital governance ingredients: 'actors' (public and private); 'institutions' (providing context and a foundation) and 'interactions'. In our holistic approach, these actors can be anyone. Institutions can be formal, such as laws and policies, or informal, such as culture, values and beliefs. Interactions can both be deliberate, such as hierarchical steering mechanisms or coincidental. Governance as a totality is more than the sum of these parts.

In this respect, SDIs resemble governance. Rajabifard et al. [14] define SDIs as made up of five components: 'people', 'policy', 'standards', 'data' and 'access network' (or 'technology'). As the sum of these interacting parts, the SDI itself is bigger than just the parts alone. This is also one of the features of complex adaptive systems [15]. Each SDI component, the interactions between them, as well as the SDI itself ('the sum of the parts') are in need of governance. It is therefore unsurprising that SDI governance is an incredibly complex subject that puzzles academics and practitioners alike. The current research, therefore, focuses on the evolutionary trajectory of SDI governance in the past, in the expectation that this might provide guidance for the future.

\subsection{Global Governance Trends and the Evolution of SDIs}

The concepts of governance and SDIs are continuously on the move, which only adds to their complexity. Within the governance domain, Verhoest et al. [16] observe 'an action-reaction pattern in which the solution to a problem turns into a problem itself' (p. 330). New solutions are proposed to deal with unintentionally created problems, and so a continuous pattern of improvement emerges. The same action-reaction pattern can be observed within the SDI domain.

Grus et al. [15] argue that SDIs can be seen as 'complex adaptive systems'. Adaptability, in fact, is considered a foremost SDI feature: 'A high degree of adaptability guarantees that an SDI can continuously develop by adjusting its structure, behaviour and goals to changing external circumstances' [15] (p. 457). Key features of complex adaptive systems are their unpredictability and self-organisation, which are influenced by external factors due to their openness and internal factors like their history (path-dependency).

Interestingly, governance developments appear to have partly shaped the preconditions for the development of SDIs. From the late 1970s, governance entered a transition phase from the 'golden age of planning', in which science and experts determined rationally and hierarchically the way to move forward, into a governance paradigm now widely known as 'New Public Management' (NPM). NPM stresses running governments like a business in order to save on costs and improve efficiency and effectiveness. Implementation of NPM strategies has varied widely, but NPM trends were certainly recognisable in the 1980s and 1990s in many western countries [6]. Hood [17] identifies several dimensions of change introduced by NPM, such as disaggregation and specialisation of public organisations, more competition, use of corporate management practices and a focus on measurable outputs and performance. 
The US executive order issued in 1994 by then-president Bill Clinton for a 'coordinated National Spatial Data Infrastructure' [18] (p. 1) marks for many academics and practitioners the official launching point for SDIs (e.g., [14,19]). The goal of the broader 'National Performance Review' policy in which it was embedded was 'a government that works better and costs less' [20]. This focus on performance and efficiency suggests that the order was inspired by NPM ideals.

Although the foundation of the US national spatial data infrastructure (NSDI) seems to rest on an NPM basis, the goal of the NSDI was actually to counterbalance NPM symptoms. As NPM advocated disaggregation of large bureaucracies into small specialised and competitive organisations (also known as 'agencification'), it led inevitably to fragmentation of governmental information [16]. Therefore, the US NSDI initiative sought to create cross-agency coordination, 'to avoid wasteful duplication of effort and promote effective and economical management of resources by Federal, State, local, and tribal governments' $[18,20]$.

Rajabifard et al. [21] observe a change in focus in SDI development around the start of 2000, which they call 'the second generation of National SDI initiatives' (p. 103). An important aspect of this SDI generation is a shift in emphasis from data integration to data dissemination by creating a link between data and data users. By making people an important component of an SDI, the value of the SDI increases. This realisation by SDI practitioners is an important aspect of what Rajabifard et al. [14] identify as a move away from product-based SDIs to process-based SDIs. Reasons for implementing an SDI changed from resource savings and increased productivity to the more holistic socio-cultural ideal of an SDI serving the interests of society as a whole [21,22].

Probably not coincidentally, ideas about governance also changed around the 2000s. While there seems no leading governance strategy such as NPM anymore, there is a general consensus that most western countries have moved away from a market perspective towards a network perspective on governance [6]. Indeed, in trying to achieve cross-agency coordination, it became apparent that the state is not unitary, but plural, and that not competition, but networks and relations are important for coordination. These insights can be seen as the core elements of New Public Governance (NPG), which is cautiously identified as NPM's successor [23]. While the NPG term itself is not embraced by all academics, the importance of network type mechanisms for coordination, next to market type mechanisms and hierarchy type mechanisms, is generally accepted [16].

In the 2000s, 'trust' and 'transparency' also became important notions within many public administrations, leading to the 'open government' concept. Freedom of information is here deemed important for increasing accountability, trust and public participation, which are seen as lubricants of the democratic process [6,24].

The open government concept is clearly visible within the SDI domain: concepts such as 'open standards', 'open source software' and 'open data' were already coined, but now became advocated by many governments (e.g., the European Union [25] and UK [26]). Open spatial data has resulted in growth in usage of spatial datasets [27,28], but also put pressure on data financing models [29].

The changing governance paradigms seem clearly interrelated with the evolution of SDIs. However, it would be inappropriate to think of these governance paradigms as the only agenda-setting factor. Of course, the emergence of information and communication technology (ICT) was particularly determinative in SDI evolution. Many scholars [14,19,30,31] note a technology push in SDI development. Without technology, an SDI would not be feasible. Even governance paradigms such as 'open government' are linked to ICT advancements such as the Internet [32].

Furthermore, the question arises as to why SDI developments fit the governance paradigms so well. Are they determined by these paradigms, or are SDI developments framed into these paradigms in order to gain budget and support? Again, given the complex adaptive nature of SDIs, the answer could be both. In order to better understand SDI evolution, a closer look is needed at SDI governance itself. 


\subsection{SDI Governance Dynamics}

SDI governance is clearly a main driver of SDI advancements, as it delivers in most cases the decisions and budgets needed for development. However, the way SDI governance has evolved and set the development direction of SDIs has not yet been studied in any detail. There appears to be various ways in which SDIs could come to life. Masser [19] distinguishes two groups in his description of the first SDI generation: 'those which are the result of a formal mandate from government and those which have largely grown out of existing geographical information coordination activities' (p. 75). Coetzee and Wolff-Piggott [12] find, based on the SDI literature, that 'SDIs are evolving from top-down, centralized government funded initiatives into decentralized and bottom-up initiatives, but most SDIs are not yet self-organizing and user-driven systems' [12] (p. 124). Lance et al. [33] conclude that in recent years more hierarchy has been introduced in the SDIs of Canada and the USA: 'Hierarchical controls may facilitate coordination to an extent that autonomy-seeking public managers need not automatically disparage such intervention; in fact, they may seek it' [33] (p. 265).

These two conclusions may seem contradictive, but could both be valid for specific SDI cases, given SDIs' complex, adaptive and path-dependent nature [15]. The question is can we qualify SDI governance as adaptive, and how does SDI governance evolve over time.

To answer this question, we assessed the governance evolution of two SDI cases: the Grootschalige Referentiebestand (GRB) of Flanders, Belgium, and the Basisregistratie Grootschalige Topografie (BGT) of The Netherlands. Both are large-scale base maps with all SDI components in place; that is, data, standards, technologies, policies and stakeholders. In both cases, standardised spatial data is collected by companies or governments, put into a central and authoritative database and disseminated via the web to users. This is all supported by an organisational and technical infrastructure. These cases also have very similar goals and objectives, resulting in similar products. However, their history, organisation and governance are very dissimilar. A key reason to choose these cases was their relatively long histories, as the BGT dates back to 1971. Each case will be further described in Section 3, after presentation of the data and research methods in Section 2. Section 3 then delves deeper into the SDI cases, tracing their histories and then synthesising and comparing the two. Section 4 discusses the results of our analysis, and Section 5 presents conclusions.

\section{Methods, Data and Cases}

\subsection{Data Collection}

The study of SDI governance dynamics could be approached using various methodologies, such as interviews, analysis of official documents and surveys. For our purpose of studying the long-term evolution of SDI governance, interviews and surveys were deemed less suitable, as memories can be altered, consciously or unconsciously. Instead, we chose to use written documents, as documents can be considered 'unobtrusive', 'non-reactive' and 'stable' [34] and are therefore suitable for longitudinal analysis [35] (p. 304). We used articles from geo-information and geodetic industry magazines. The benefit of using these magazines is that they are not owned by a specific party and therefore provide a platform for both SDI proponents and critics.

Six Dutch geo-information magazines were selected as research material: Nationaal Geodetisch Tijdschrift (NGT), Geodesia, Geo-info, Vi-Matrix, GeoInside and GeoPlatform (Table 1). The first three were digitally available via an online web archive. The magazines that also covered developments in Flanders (Vi-Matrix, GeoPlatform and GeoInside) had to be manually checked and scanned. 
Table 1. Overview of the Dutch geo-information magazines used as research materials.

\begin{tabular}{ccc}
\hline Magazine & Active Period & Coverage \\
\hline Nationaal Geodetisch Tijdschrift (NGT) & $1971-1979$ & The Netherlands \\
Geodesia & $1959-2003$ & The Netherlands \\
Geo-info & $2004-$ now & The Netherlands \\
Vi-Matrix & $1993-2010$ & The Netherlands and Flanders ${ }^{1}$ \\
GeoInside & $2011-2013$ & The Netherlands \\
GeoPlatform Vlaanderen & $2006-2013$ & Flanders \\
\hline
\end{tabular}

${ }^{1}$ Vi-Matrix described geo-information developments in Flanders until 2006, then GeoPlatform took over.

Scott [36] proposes four quality control criteria for assessing documentary sources: authenticity, credibility, representativeness and meaning. As we retrieved the magazines directly from the publisher, the documents' authenticity was a given. The credibility of the articles was ensured because major events were in most cases referenced in multiple articles. Furthermore, reactions or rectifications could be expected when authors or editors made a mistake or readers disagreed. As the articles were written in clear Dutch, and the researchers were native speakers of Dutch, there was no difficulty in identifying the meaning of each article, though of course there is always a risk of misinterpretation. We used the total population of available articles, so we can qualify the documents as representative. However, we must note that important governance developments, such as backroom politics, could have remained hidden from this research if they were not referenced in published accounts.

Although the coverage of the magazines was good, especially in The Netherlands, their frequency of appearance had recently diminished. In Flanders, coverage was sparser; the region-specific magazines even stopped publishing in 2013. Moreover, these magazines started a few years after the first large-scale base map developments. Luckily, later articles referred to the starting period, enabling us to form a picture from these secondary sources. As there is often a delay between an event happening and an account of it being published, this method was in effect used on multiple occasions.

As there was no active reporting on Flemish activities in geo-information (GI) magazines from 2013 and later, supplementary interviews were held with two staff members of 'Informatie Vlaanderen' (Information Flanders), which is the current e-government organisation for Flanders. Both staff members were policy advisors on the governance of the Flemish e-government structure, which also included the GRB. The interviews were unstructured. Questions were asked about the establishment of 'Information Flanders' and the current and future governance of the organisation. Because there were still magazines active in The Netherlands, interviews were not necessary to supplement data collection there.

Articles concerning the Dutch large-scale base map (BGT) were found by searching for keywords such as 'GBKN' (Grootschalige BasisKaart Nederland), 'BGT', 'Grootschalige BasisKaart' and 'GBK'. These represent either the name or abbreviation of the current large-scale base map or its predecessors. All articles containing these keywords were selected; only advertisements were ignored. In a similar fashion, articles related to the Flemish large-scale reference map (GRB) were selected by searching for the keywords 'GRB' or 'Cardib'. Because these articles were selected manually, the magazines were double-checked. In total, 877 articles were selected covering the history of the BGT and 176 covering the history of the GRB. Figure 1a,b show the distribution of the articles over time. 


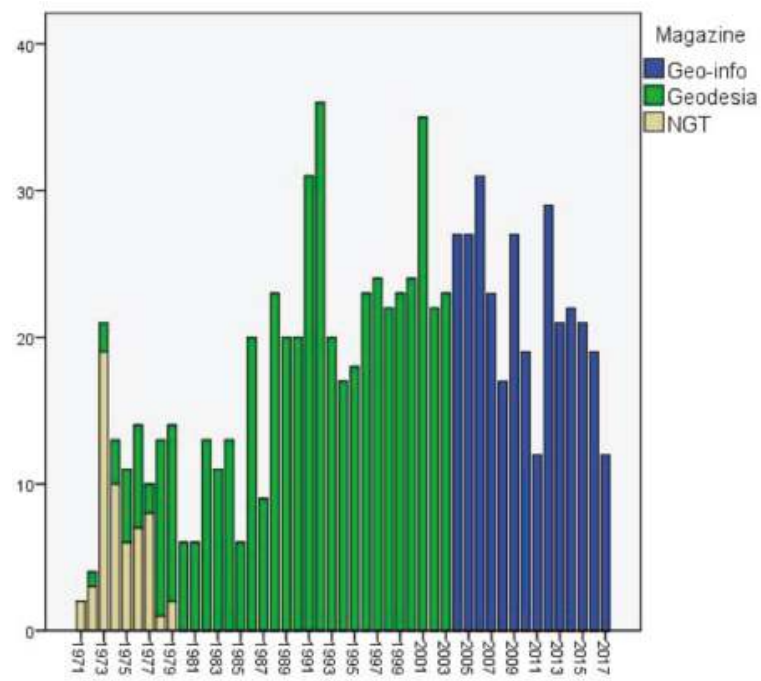

(a)

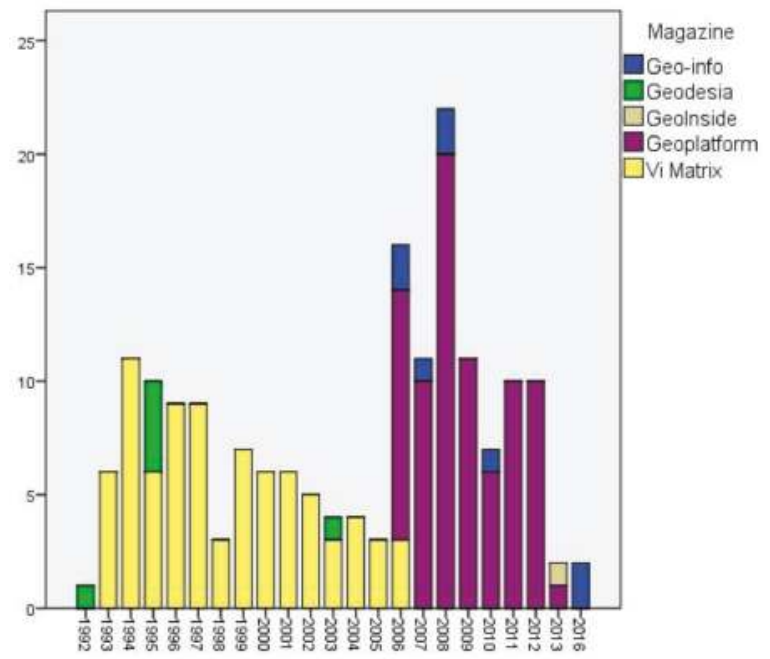

(b)

Figure 1. Distribution of found magazine articles over time: (a) distribution of articles containing BGT-related keywords (The Netherlands); (b) distribution of articles containing GRB-related keywords (Flanders).

\subsection{Data Analysis}

First, the articles were analysed at the meta level. For all articles, the title, publication date, page numbers, article type, authors and author organisations were noted. The author organisations were further aggregated into several higher stakeholder abstraction categories to assess whether the overall picture was overly distorted by one stakeholder group. These categories, in most instances, were naturally formed, based on the stakeholders represented in the articles. For example, all utility companies were categorised as 'utility', and all government entities, except central government organisations, were grouped in the 'local government' category. Organisations that were not aggregated 
were the Dutch 'Cadastre' for the BGT case and 'AGIV' (Agency for Geo-Information Flanders) for the GRB case, as these organisations were highly involved in the creation of the large-scale maps (see Section 3).

Associations and foundations were aggregated into three categories: 'associations', 'interest groups' and 'partnerships'. The category 'partnerships' includes official collaborations in which organisations worked closely together (or even joined up) to achieve their common goals. 'Interest groups' consist of lobby organisations for governmental organisations or private companies. 'Associations' comprise geo-information or geodetic associations for knowledge sharing.

Articles written by multiple authors from different stakeholder categories were classified as 'mixed'. Figure 2a,b present relative distributions of the author affiliations aggregated into case-specific stakeholder categories.

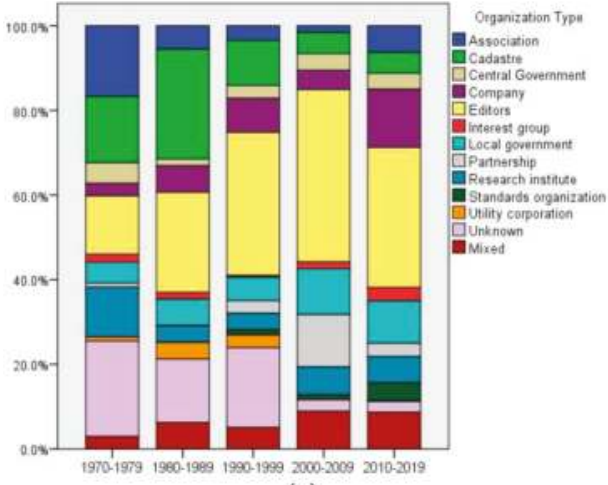

(a)

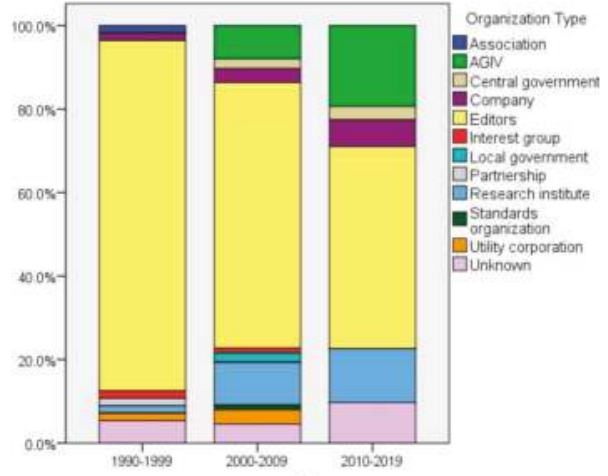

(b)

Figure 2. Relative distribution of article author affiliations, categorised into case-specific SDI groupings per decade: (a) distribution of BGT-related articles (The Netherlands); (b) distribution of GRB-related articles (Flanders).

It should be noted that the GRB-related articles were much more likely to be written by reporters and editors, as these magazines had a more journalistic character. Furthermore, the division seems balanced, as certain increases or decreases of particular stakeholder categories can be explained by the development of the SDI (described in Section 3).

Following the meta-analysis, the titles and content of articles were scanned and read in-depth if they contained organisational information on the SDI. This information provided the basis of the case descriptions, while simultaneously providing a window for the study of the SDI governance evolution in each case. To make the analysis transparent, references were documented in the case descriptions (Section 3). These refer to the list of articles used in Appendix A.

We then synthesised and compared our findings from the cases. Our analysis focused on two governance ingredients: actors and interactions. As stated in the introduction, institutions, both formal and informal, are also an important governance ingredient. However, informal institutions, such as cultures, values and beliefs, proved particularly difficult to distinguish from the magazine articles. Findings on formal institutions, such as laws, policies and organisations, are covered in the sections on interactions and actors. 


\section{Results}

\subsection{The Netherlands: Key Registry Large-Scale Topography (BGT)}

The history of The Netherlands' Key Registry Large-Scale Topography (BGT) dates back to the early 1970s. In 1971, a commission of scientists, governments and utility companies investigated the need for a uniform cable and pipe registration system (1971a). The conclusions of that study yielded a new commission, which studied the need for a uniform large-scale base map that could also serve as a reference map for the cable and pipe registry (1971b; 1972a; 1972b). In 1974, the report of this second commission was released, deeming the uniform base map feasible (1973a; 1974a). The commission made several proposals for realisation, suggesting among other things standards, techniques, stakeholders and a governance framework (1973a; 1973b; 1973c; 1974a). Although there were votes to create this map digitally (1973d; 1973e; 1973f), the maps and its production were ultimately analogue-based.

As often seen during the 'golden age of planning' [6], the advice of the experts and scientists was followed. In 1975, a Royal Decree launched the creation of the Grootschalige Basiskaart Nederland (GBKN; 'Large-Scale Base Map of The Netherlands') (1975a; 1975b). As proposed in the commission report, the Ministry of Housing and Spatial Planning gave the Dutch Cadastre the task of creating the map. The Central Mapping Board was officially installed in 1976, made up of stakeholders including utility companies, local government, the Cadastre, topographic bodies and ministries (1976a; 1976b). The goal of this Board was to determine priorities, allocate funds and develop standards and techniques (1974a; 1975a; 1975b; 1976a; 1976b). Provincial mapping boards, coordinated by the regional bodies of the Cadastre, were to facilitate regional collaboration and provide input to the Central Mapping Board (1974a; 1978).

In 1975, the first GBKN project began (1976c; 1976d; 1977). However, with the exception of a few regions, map production did not go well (1980). The first governance intervention came in 1983. A government ICT report advised greater focus on regulation, instead of consultation. Furthermore, it recommended that the Ministry create an organisation that could coordinate and facilitate all geo-ICT developments: the Board for Property Information (RAVI). The Central Mapping Board objected to the report's conclusions, noting that consultation remained crucial for such a big and expensive task (1983; 1984a; 1984b). The ministry listened: RAVI replaced the Central Mapping Board, but the original collaborative structure of the GBKN project remained at the level of the provincial mapping boards (1987a). Articles foreseeing further regulation were included in the preparation of a new Cadastre law (1985a).

Meanwhile, New Public Management (NPM) made its entrance. Government demanded that the Cadastre cover its own costs (1984c; 1984d; 1985b; 1989a). Budgets shrank (1986a), and local standards emerged to make the mapping feasible in regions where there were not enough partners (1986b). Criticism swelled from municipalities (1984d; 1989b; 1990a; 1990b) and the utility companies (1989c), as they considered the regional Cadastre offices as behaving too autonomously.

Around 1991, the Secretary of State of the Ministry of Spatial Planning and Environment intervened. The Cadastre's financial situation was poor and the Secretary of State demanded it make severe cuts (1991a). Creation of the GBKN was one of the reasons for the Cadastre's losses (1987b; 1988), and only 30\% of the country was covered (1992b). The Ministry determined that the GBKN would no longer be a primary Cadastre task (1991b; 1992a). GBKN articles were scrapped from the Cadastre law in 1992 (1991c; 1992a; 1992c). The national government was no longer willing to participate in the GBKN (1992b).

This could have been the kill switch, but it was not. Regional public-private partnerships were formed to create and maintain the GBKN in the regions (1992b; 1992d). The Cadastre became a partner instead of a coordinator. The national government provided 10 million guilders (4.5 million euros) for better organisation and collaboration for the GBKN. A foundation was set up which would coordinate GBKN activities nationwide: the National Partnership GBKN (1992e; 1993a; 1993b; 
1993d). The municipalities' position was strengthened, and as they could choose to either do the map production alone or operate in a public-private partnership mode (1993a). Moreover, a goal was set: the GBKN was to cover the entire country within 10 years (1993b; 1993c).

During the 1990s, GBKN production soared (1999a; 2000a). However, a fierce debate also emerged. The GBKN standard was line-oriented, for use in computer-aided design (CAD) systems, but users demanded object-oriented data, which worked better with geographical information systems (GIS) (1993e; 1995a). An object-oriented GBKN was promulgated as a cure for the regional diversity in GBKN data (1995a; 1995b). After some years of feasibility research and discussion (1996a; 1996b; 1997a; 1997b; 1997c; 1997d), the National Partnership decided not to invest in this, but to focus instead on completion and other ways to standardise the product (1998). In 2001, the GBKN was finished (2001a). Now that the map was complete, the National Partnership repositioned itself (1999b; 2000b; 2003a; 2003b). Goals were set for updating and standardising the product, conducted by the regional partnerships (2000b; 2001b; 2001c).

Meanwhile, the concept of 'authentic registries' emerged in government policy in The Netherlands (2002a; 2002b). An 'authentic register', later called a 'key registry', is a registration system formally appointed by government with legally mandated quality standards for use by government. The National Partnership saw it as an important goal that the GBKN become a key registry, as this would provide it a clear legal status and organisational and financial framework, while acting as an accelerator for standardisation (2002c). Although several other governmental spatial datasets were already considered 'key registries', the GBKN had to wait (2002d; 2003c). After all, creating a uniform GBKN would be quite costly (2006b) and support from many organisations was needed (2003c).

During the ensuing years, some municipalities independently created their own object-oriented large-scale base maps (2002e; 2003d; 2003e). However, becoming a key registry remained an important motivator for these organisations to join the National Partnership in its lobby (2003d; 2003e; 2003f). After an exploratory phase (2006a) and successful budget claim in 2008 (2009a), the mandate was given by the national government to transform the GBKN into the Basisregistratie Grootschalige Topografie (BGT; 'Key Registry Large-Scale Topography').

In 2009, a declaration of intention was signed by all partners creating the object-oriented BGT standard (2010). Interestingly, although the Cadastre and utility companies had done much in the past to create the GBKN, the BGT was created by government organisations alone (2009a; 2009b). However, because of the decentral organisation, some 450 governmental organisations were involved (2011; 2012a). The Cadastre was to continue to maintain the central database (2012b) and the National Partnership GBKN was transformed into the Partnership of BGT Key Registry Holders (2012c). Because key registries were created by government and because the BGT was declared open data, public utility companies no longer had to invest in the BGT (2009a; 2012a). However, as a main user, they did retain their position in steering groups (2009a).

In 2012, the BGT standard and law were finished (2013) and the key registry holders began to build the BGT (2014). The task was set for completion by the start of 2016 (2012a), but the second half of 2017 currently seems the likely completion time [37]. Now that the BGT is almost finished, efforts are being made to improve cohesion of the BGT with other datasets within and between organisations (2017a; 2017b).

\subsection{Flanders: The Large-Scale Reference Map (GRB)}

The origin of the GRB is two-pronged. One prong can be traced to the 'Cardib' initiative. Cardib was a public-private partnership erected in 1990 by four small public utility companies with the goal of creating a large-scale base map of Flanders. Together with its Walloon counterpart, Bicard, Cardib had agreed that the company Bicardib would do the data creation (Bicardib fulfilled this role for both partnerships) (1993f). One of the company's founders and shareholders was Eurosense, which was considered a monopolist in aerial photography (1993f; 1993g). 
Although some other public utilities joined, Cardib gained momentum in 1992, when it diminished the influence of Eurosense and two large private utility companies showed interest and joined (1993g; 1994a). At least three interested organisations in a region were needed to create a Cardib map (1994b). Although the initiative united some organisations, only $3.8 \%$ of Flanders was covered by a large-scale map at the start of 1997 (1997e). Another issue was that, despite agreements, these covered areas were not updated (1997f). This was reason for the two private companies to leave the initiative (1997f; 1997g). In 1999, the last Cardib project was finished and the initiative was declared bankrupt. 'GIS Flanders' took over all available data and aerial imagery (1999c).

GIS Flanders had started out at the end of the 1980s as a working group to study the GIS needs of federal government departments. It advised in 1991 putting in a huge order to Eurosense, to purchase aerial imagery for the whole Flanders region. This order was blocked, however, by the Financial Inspection department and later by the Flemish Parliament (1993g). GIS then became a politically sensitive issue and all investments were barred [38] (1993g; 1993h; 1994c). In 1993, after showing their dissatisfaction in local media, a group of GI professors was asked by the Flemish government to consult on the development of a Flemish spatial data infrastructure. The group designed a governance structure, with a technical centre, a geo-information board and a coordinating minister. It was to serve not only the federal level but interests at all administrative levels (1993i). After almost two years of meetings and negotiations (1994d; 1994e; 1994f; 1995c), the designed organisational structure was officially adopted in 1995 (1995d). The technical centre, now called 'Support Centre', expressed interest in joining the Cardib initiative (1997g), but, by the time it was fully operational, Cardib was defunct (1999c).

The Support Centre designed a new model for a large-scale base map: the Grootschalige Referentiebestand (GRB; 'Large-Scale Reference Map'). Feasibility was a key issue in the design choices for this map (1999d). After a long period of preparation (1999e), the Flemish parliament approved the GIS Flanders decree in 2000, which gave the Support Centre legitimacy (1999c; 2000c). With this decree, the preparations for the GRB also gained more solid footing, and design choices were made, pilot projects implemented and funding sought (2001d; 2002f).

In April 2004, the GRB decree was signed (2005; 2006c), setting out all the organisational preconditions and commitments needed to create and maintain the GRB, such as scope, standards, budgets and governance. Utility companies brought in around $50 \%$ of the funding, gaining considerable influence in return, as they were the only stakeholders in the GRB Board. The Flemish government funded the other half $(2004 ; 2005 ; 2006 \mathrm{~d})$.

In 2006, the Support Centre was reorganised into an independent entity: the Agency for Geo-Information Flanders (AGIV) (2006d). AGIV scaled up production of the GRB (2009c), and, in 2013, the GRB was successfully completed according to plan. In late 2015, the GRB was declared open data (2016). At the start of 2016, AGIV merged with several other e-government services to form the new agency 'Informatie Vlaanderen' ('Information Flanders'). Efforts are currently under way to further integrate governance of SDIs, such as the GRB, into a new governance model encompassing all e-government information (interviews).

\subsection{Comparing the Governance of the Two Cases}

When we compare the governance evolution of the GRB and its predecessor with the BGT and its predecessor, we must first conclude that SDI governance is definitely not static. From the Royal Decree in 1975 up to the BGT of 2017, the governance structure changed some six times, often quite radically (Table 2). Although the GRB initiative is younger, SDI governance also changed considerably in this case (Table 2). 
Table 2. Important governance transition moments in the Key Registry Large-Scale Topography (GBKN/BGT) case in The Netherlands and the Large-scale Reference Map (Cardib/GRB) case in Flanders, Belgium.

\begin{tabular}{|c|c|c|c|}
\hline Year & Governance Changes BGT & Year & Governance Changes GRB \\
\hline 1975 & Royal Decree GBKN & 1990 & Start of Cardib \\
\hline 1982 & End of the Central Mapping Board & 1992 & $\begin{array}{l}\text { GIS Flanders intervention } \\
\text { by Minister }\end{array}$ \\
\hline 1992 & $\begin{array}{c}\text { Cadastre and national government } \\
\text { pull-back, start of } \\
\text { public-private partnerships }\end{array}$ & 1999 & End of Cardib, start of GRB \\
\hline 2008 & Start of BGT programme & 2004 & GRB official decree \\
\hline 2012 & New governance for transition to BGT & 2007 & Start of AGIV ${ }^{1}$ \\
\hline 2017 & $\begin{array}{c}\text { New governance structure for greater } \\
\text { cohesion between spatial } \\
\text { key registries }\end{array}$ & 2015 & $\begin{array}{c}\text { Integration of GRB in e-government } \\
\text { services, establishment of } \\
\text { Information Flanders }\end{array}$ \\
\hline
\end{tabular}

\subsubsection{Interactions}

Interestingly, both large-scale base maps seem to have emerged from collaborative network activities rather than top-down coordination. The GBKN had formal top-down status in 1975 but lost that in 1992. The GRB only became official in 2004, 14 years after the first collaborative large-scale mapping activities.

Another similarity between the GRB and BGT is that both experienced a period in which the whole undertaking was in jeopardy. For the BGT, this was around the start of the 1990s, when the Ministry demanded that the Cadastre cut its GBKN outlays and revoked the GBKN's legal status. At around this same period, the Minister intervened in Flanders, blocking further GI investments. Both interventions seemed to act as a wake-up call for the interested parties, telling them that they needed each other to move forward.

The governance response to these interventions was opposite in the two different regions. In Flanders, the project evolved from governance with network and market type mechanisms to governance with more hierarchy and network type mechanisms. In The Netherlands, it moved from network and hierarchy type mechanisms to network and market type mechanisms in the 1990s. The later transition to the BGT, however, again brought hierarchy and network type mechanisms.

When the base maps became 'official authentic registries' and were incorporated into a larger digital national roadmap, the presence of hierarchical steering instruments increased. Figure 3 illustrates the rise and decline of hierarchical instruments in the cases. The graph was built as follows: for every hierarchical instrument found in the cases, a weight equal to 1 was added. The following hierarchical instruments were found: a law or decree, a central coordinating board, a central government with ultimate responsibility, a central government actively involved in decision-making, $50 \%$ or more of the SDI being centrally financed and mandatory standards. Although the graph should be interpreted schematically - as we would not suggest that our 'counting' of hierarchical instruments is complete-it nonetheless shows that over time hierarchical instruments became more prevalent in these SDIs.

Both large-scale base maps currently share a similar kind of interaction governance, with hierarchical steering such as a legal framework and a coordinating body in place, as well as network steering with the formation of several working groups and steering committees made up of all kinds of stakeholders. In addition, market type mechanisms are in place. The market is involved as a generator of the data and as a software provider, in most cases via tender procedures. However, hierarchical and network steering dominate in both SDI cases. 


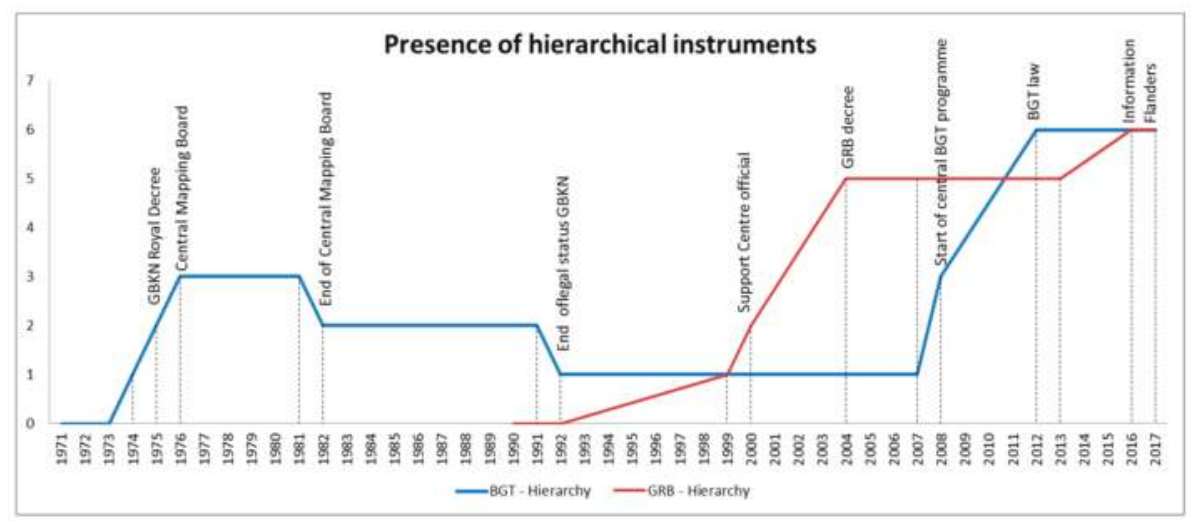

Figure 3. Presence of hierarchical instruments in the SDI cases: 1971-2017 BGT (The Netherlands) and 1990-2017 GRB (Flanders). Labels are in reference to key moments in the development of the specific large-scale base map.

\subsubsection{Actors}

Another remarkable finding is the constant repositioning of stakeholders. This is most obvious in the division of the budgets. For production of the GBKN, in 1975, the Cadastre provided 50\% (partly covered by a ministerial budget) and municipalities and public utilities together contributed $50 \%$. After 1992, this changed. The Cadastre provided only $20 \%$, municipalities provided $20 \%$ and public utilities contributed $60 \%$. After a reshuffle in 2003, the new division became $20 \%$ for the Cadastre, $30 \%$ for the municipalities and $50 \%$ for the public utilities, though a consultancy company calculated a fair division as $24 \%$ Cadastre, $41 \%$ municipalities and 35\% public utilities (2012d). With the BGT, the division between partners is less easily determined. The municipalities are responsible for the production process, and they get compensation from the central government, which also financed the necessary spatial data infrastructure. Together, they largely pay the bill for the BGT.

In Flanders, the Cardib initiative came mainly from public and private utility companies, sometimes with participation of interested municipalities. Before 1992, GIS Flanders was only for the central government, but the initiative was later opened to all government layers. When the GRB came about, the government needed input from the utility companies. They were mandated by law to pay some $50 \%$ of the budget. The Flemish government paid the other $50 \%$. Municipalities do not have to bring any money, but, in order to diminish the costs of the updating process, they are legally required to deliver feedback and as-built information from newly constructed areas.

In both large-scale mapping processes, we found a growing importance of municipalities in creating and updating large-scale maps. Furthermore, the SDI stakeholders in both cases clearly learned from their past experiences. This was mentioned in the articles too, as the past was sometimes used to highlight how things had improved. Furthermore, the two cases learned from each other. Recall that Figure $1 \mathrm{~b}$ showed articles about the GRB appearing in magazines covering only The Netherlands. Texts such as 'Let's finish the GRB quicker than the GBKN' and 'The Belgians do it better' enjoined SDI stakeholders to improve.

\section{Discussion}

\subsection{Self-Organisations}

The notion from Coetzee and Wolff-Piggott [12] that SDIs are not yet self-organising and are mainly top-down structured seems not to apply to these two cases. Stakeholders in both cases reorganised their governance from time to time, especially when challenges arose and frustration with the product or 
process reached a boiling point. However, Coetzee and Wolff-Piggott [12] also observe that 'the Dutch SDI development model is voluntary and its success lies in the strong self-organizing ability of the geospatial information community' (p. 124). Kok and Van Loenen [39] similarly stress the importance of self-organising abilities, characterising the Dutch community as 'active'. Adaptive governance capacity is probably much weaker if self-organising abilities are less prevalent within the geospatial community [15].

Culture could be an important factor in these self-organising abilities. However, it should be noted that, despite The Netherlands and Flanders sharing the same language, their cultures are rather different. The culture of Flanders can be seen as its own cultural cluster, seemingly most closely related to Sweden, though they do not share much history [40]. Further research on adaptive SDI governance in different countries and cultures could point out whether the reorganisation of SDI governance is culturally dependent, and if such a self-organising evolutionary trajectory is unique or a worldwide phenomenon.

The high cost of making a large-scale map is another possible reason why self-organisation emerged in these two cases, perhaps rendering network cooperation inevitable. Collaboration between public utility companies and local and central governments was necessary to make a large-scale map financially feasible. Other governmental spatial datasets, such as small-scale topography and land administration, are organised in a much more top-down fashion, both in Belgium and in The Netherlands.

Interesting in this respect is the relative absence of private parties in these initiatives, with the exception of privatised utility companies. The GRB did have a market-oriented start with the Cardib project, but that project failed to serve the interests of all stakeholders. The struggle for market collaboration in public-private partnerships is not unique to these SDIs. It has been documented in other financially costly initiatives, such as the European space programme Galileo [9,41]. More research on the market-government SDI relation may be helpful for improving collaboration or shedding light on potential problems. Furthermore, the influence of non-governmentally owned SDIs and their 'governance' could be an interesting research angle, as these bring (public) SDIs closer to end users.

Of course, the long history of GI collaboration in these regions could have fostered self-organisation. Note that it took from 1974 until 2001 to complete the GBKN. It took 23 years, from the first Cardib ideas in 1990 until 2013, to complete the GRB. In addition, it took 25 years to advance from the first ideas for an object-oriented GBKN, in 1992, to the slated completion of the object-oriented BGT, in 2017. In all cases, the last ten years were the most productive. These productive years were sparked by a shared realisation that the current path would ultimately lead to SDI failure.

This does not seem unusual for spatial data infrastructures. Koerten [31] studied, next to the GBKN, the development of the Dutch National SDI. At the time of his research, that project had suffered repeated failure, attributed to an overemphasis on technology and innovation. Upon the launch of yet another attempt, Koerten mused sceptically that 'the Dutch geoinformation sector is still not inclined to look back and learn from the past' [31] (pp. 175-176). Today, however, the Dutch National SDI is thriving, and its usage has grown almost exponentially in the years since 2014 [42]. Again, this success came 20 years after the first proposals for the project and repeated false starts. As SDIs do not come in dozens there is no 'survival of the fittest', but (impending) failure does seem to have a simulative effect. Alas, this trajectory costs time and money.

According to Jessop, 'given the growing structural complexity and opacity of the social world, failure is the most likely outcome of most attempts to govern it in terms of multiple objectives over extended spatial and temporal horizons-whatever coordination mechanism is adopted' [43] (p. 106). This suggests the need for further research on the possible fly-wheel effect of the threat of imminent SDI failure. 


\subsection{Mix of Governance Interactions}

This study's findings show remarkable resemblance to the conclusion of Lance et al. [33] in their study of two SDI cases in Canada and the USA. They found a growing importance of central coordination and a movement away from autonomous SDI stakeholders in favour of formal top-down recognition. Their conclusion is as follows:

The use of hierarchical controls ... runs contrary to the public management discourse on network governance, which purports that informal, horizontal networks are replacing formal, vertical/hierarchical organization. However, a shadow of hierarchy may actually facilitate the 'joining up' of government geospatial information systems. [33] (p. 265)

The fact that SDIs nowadays have more hierarchal controls, both in North America and in The Netherlands and Belgium, does not automatically mean that SDIs are now governed in an overtly authoritarian manner. Vancauwenberghe, in fact, notes an attempt to introduce more network coordination within the Flemish SDI [2]. The histories of the two large-scale base maps studied here suggest that harmonious collaboration is more important to move ahead than autonomy. Other coordination mechanisms such as markets and networks are also still present. Academics (e.g., [10,44,45]) increasingly agree that such a mixture of governance forms is important for achievements or results: 'Continuously steering towards interaction, participation and consultation tends to produce inertia; over-emphasis on hierarchical top-down control has the disadvantage of driving parties to dig in their heels, leading to resistance, delays and postponements of implementation' [45] (p. 185).

Not coincidentally, a mixture of governance forms is one of the three prescriptions of what is called 'adaptive governance' [44]. The other two are analytic deliberation and nesting. Analytic deliberation concerns formation of well-structured dialogue by including different kinds of actors with different interests and perspectives. By keeping them informed and around one table, trust is said to flow more easily and consensus is produced for dealing with conflicts. Nesting refers to the layering of institutional arrangements. This makes arrangements complex and redundant, but this is necessary, as simple governing strategies like 'command and control' often fail in complex systems [44].

Can the SDI cases in this research be considered perfect examples of adaptive governance? Probably not, as radical governance changes were sometimes needed to improve. However, both cases evolved towards use of a broader interaction mix, with more stakeholders involved and also the broadest set of laws, policies and standards applied. Therefore, it could be that, with the help of self-organisation, SDI governance automatically advances towards a more adaptive form. Further research is needed to confirm this.

\section{Conclusions}

Based on the key governance transitions found in the two cases, we can conclude that SDI governance is adaptive, as it changed considerably during the evolution of the two registries. However, we can also conclude that most governance models did not hold up very long, as they either were not meeting their goals, were not satisfying all actors or were not in alignment with new visions and ideas. Nothing, not even legal requirements, could withstand the need for a change in SDI governance.

The general notion that network governance is a contemporary phenomenon is contradicted by the origins of both our SDI cases, as both emerged from network collaboration. Their governance evolution thereafter differed. GBKN/BGT governance transformed from an hierarchy-network organisation towards a mainly market-network driven governance in the 1990s under the influence of New Public Management and poor financial and production performance. The GRB accumulated more and more hierarchical influences over the years as it gained legitimacy. This also later happened to the BGT when it gained the status of 'key registry'. This supports the finding of Lance et al. [33] that hierarchical controls are increasing within SDIs. 
This does not mean that SDIs are now governed in a purely top-down fashion, as other governance forms, such as networks and markets, are still present and important. It merely shows that central governments are taking SDIs more seriously and expanding their steering possibilities to govern SDIs more effectively, which also improves its adaptive capacity. However, self-organising abilities of SDI actors also seem an important precondition for successful adaptive SDI governance. By applying both in SDI governance, SDI's survival seems to be ensured for the future.

Acknowledgments: The authors thank Hollandse Cirkel, Geo-informatie Nederland (GIN) and VBK Content for providing access to their magazine archives. In addition, we would like to thank our reviewers for their elaborate feedback. This work was supported by the Nederlandse Organisatie voor Wetenschappelijk Onderzoek (NWO).

Author Contributions: Jaap-Willem Sjoukema conducted the research and wrote the paper. Arnold Bregt and Joep Crompvoets helped set up the research goals and design, provided suggestions and reviewed the paper.

Conflicts of Interest: Jaap-Willem Sjoukema was employed part time from October 2015 until June 2017 at the BGT Programme Office of the Dutch Ministry of Infrastructure and Environment. He is currently employed part time at Wageningen University, where this research was conducted. The BGT Programme Office exercised no influence on the research or its findings. The authors declare that no conflict of interest was involved.

\section{Appendix A}

Geo-information magazine articles referred to in the case descriptions (Section 3):

- $\quad 1971 a$, Studiecommissie Leidingenregistratie. Rapport Studiecommissie Leidingenregistratie. NGT, Vol. 1971, No. 05, pp. 91-105.

- $\quad$ 1971b, D.L. Rodrigues Lopes. De studiedag leidingenregistratie. NGT, Vol. 1971, No. 09, pp. 148-153.

- $\quad$ 1972a, G.A. van Wely. Grootschalige basiskaart van Nederland. Geodesia, Vol. 1972, No. 07, p. 200.

- 1972b, G.A. van Wely. Grootschalige basiskaart van Nederland. NGT, Vol. 1972, No. 09, pp. 144-145.

- $\quad$ 1973a, M.J.M. Bogaerts, G.F. de Witt, C. Koeman, G.A. van Wely, W.A. Claessen, S. Rienstra, J.A.C.E. van Roermund. Interimrapport Commissie Grootschalige basiskaart. NGT, Vol. 1973, No. 09, pp. 130-135.

- $\quad 1973 b, C$. Zeillemaker. Voorstellen voor de normalisatie van de bladindeling, het formaat en de nummering van grootschalige (1:2000 tot 1:500) topografische kaarten. NGT, Vol. 1973, No. 10, pp. 159-165.

- $\quad 1973$ c, C. Koeman. Voorstel voor bladindeling, het formaat en de nummering van de Nederlandse grootschalige kaart. NGT, Vol. 1973, No. 12, pp. 212-215.

- $\quad$ 1973d, J. Dubbeld. Digitaal kaarteren. NGT, Vol. 1973, No. 05, pp. 85-95.

- $\quad$ 1973e, Projectgroep '73. Digitale basiskaartering. Geodesia, Vol. 1973, No. 06, pp. 130-131.

- $\quad$ 1973f, Projectgroep '73. Het rapport 'Digitale Basiskartering' van de projectgroep '73 van de onderafdeling der Geodesie, TH-Delft. NGT, Vol. 1973, No. 09, p. 141.

- $\quad$ 1974a, M.J.M. Bogaerts, G.F. de Witt, C. Koeman, G.A. van Wely, P.A.M. de Vos, J.B. van Reij, W.A. Claessen, S. Rienstra, A. Waalewijn, J.A.C.E. van Roermund. Rapport van de commissie Grootschalige basiskaart. NGT, Vol. 1974, No. 11, pp. 219-237.

- $\quad$ 1975a, Editors. Grootschalige Basiskaart. Geodesia, Vol. 1975, No. 07, pp. 186-187.

- $\quad$ 1975b, Editors. Grootschalige Basiskaart. NGT, Vol. 1975, No. 09, pp. 145-146.

- $\quad$ 1976a, J.P. Gruijters, G.A. van Wely. Installatie centrale kaarteringsraad. Geodesia, Vol. 1976, No. 03, pp. 90-93.

- $\quad$ 1976b, J.P. Gruijters. Installatie centrale kaarteringsraad. NGT, Vol. 1976, No. 03, pp. 57-58.

- $\quad$ 1976c, W.A. Claessen. Grootschalige Basiskaart ‘het Bildt. Geodesia, Vol. 1976, No. 02, pp. 58-59.

- $\quad$ 1976d, W.A. Claessen. Grootschalige Basiskaart 'het Bildt. NGT, Vol. 1976, No. 02, p. 38.

- $\quad$ 1977, P. Plantinga. GBKN proefproject het Bildt. NGT, Vol. 1977, No. 06, pp. 97-109. 
- 1978, G.A van Wely. De vorming van Provinciale Kaarteringscommissies. Geodesia, Vol. 1978, No. 05, pp. 127-130.

- 1980, Unknown. Jaarverslag 1979 Voorlopige Centrale Kaarteringsraad. Geodesia, Vol. 1980, No. 11, p. 435.

- $\quad$ 1983, Unknown. Advies van de voorlopige Centrale Kaarteringsraad. Geodesia, Vol. 1983, No. 09, p. 283.

- 1984a, J. Mol. Heeft het Structuurplan Topografie en Leidingen van de BOCO zin? Geodesia, Vol. 1984, No. 01, pp. 9-11.

- $\quad$ 1984b, Unknown. Jaarverslag 1983 Voorlopige Centrale Kaarteringsraad. Geodesia, Vol. 1984, No. 09 , pp. 311-312.

- $\quad 1984 c$, P. van der Molen. Privatisering van overheidstaken op het gebied van de landmeetkunde en kartografie. Geodesia, Vol. 1984, No. 07, pp. 248-254.

- $\quad$ 1984d, A.J.G. Zinken. Decentralisatie kadastertaken. Geodesia, Vol. 1984, No. 10, pp. 345-347.

- 1985a, J.L.G. Henssen. De ontwerp-Kadasterwet. Geodesia, Vol. 1985, No. 11, pp. 386-390.

- $1985 b$, C.J. Remijnse. Het Kadaster als producent en verstrekker van vastgoedinformatie. Geodesia, Vol. 1985, No. 12, pp. 440-441.

- $\quad$ 1986a, F.B.. Uit de Nieuwjaarstoespraken. Geodesia, Vol. 1986, No. 03, pp. 102-103.

- $\quad$ 1986b, Adri den Boer. GBKN-B een haalbare kaart. Geodesia, Vol. 1986, No. 06, pp. 224-225.

- $\quad$ 1987a, Peter Miete. Het grote geld. Geodesia, Vol. 1987, No. 12, p. 526.

- $\quad$ 1987b, J.B. van der Veen. De ontwikkeling van de GBKN in Overijssel. Geodesia, Vol. 1987, No. 02, pp. $47-51$.

- 1988 , Editors. Onderzoek naar gebruik en kosten van de grootschalige basiskaart Nederland. Geodesia, Vol. 1988, No. 07, p. 348.

- $\quad$ 1989a, J.W.J. Besemer, F.v.d. Gaag, W. van Pijkeren, J.H.J.M. Vos. Het Kadaster op weg naar de formatie 1990. Geodesia, Vol. 1989, No. 04, pp. 166-170.

- 1989b, L.A.H. Boeije. De toekomstige rol van de grootschalige basiskaart bij de gemeente. Geodesia, Vol. 1989, No. 02, pp. 71-76.

- 1989 c, G.P.F. Pistorius. De relatie tussen de nutsbedrijven en de GBKN. Geodesia, Vol. 1989, No. 03, pp. 124-126.

- 1990a, J.G. Versteeg. Een pleidooi voor een betere bijhoudingsregeling GBKN. Geodesia, Vol. 1990, No. 03, pp. 114-118.

- $\quad$ 1990b, C. Zeillemaker. Gemeenten en topografie. Geodesia, Vol. 1990, No. 09, pp. 369-373.

- $\quad$ 1991a, Unknown. Privatisering Kadaster nu op een laag pitje. Geodesia, Vol. 1991, No. 01, p. 84.

- $\quad 1991 b$, J. Besemer, Wim van Pijkeren, Theo Scheele. De (onzekere) toekomst van het Kadaster. Geodesia, Vol. 1991, No. 06, pp. 258-261.

- $\quad$ 1991c, Editors. Kadaster. Geodesia, Vol. 1991, No. 12, p. 555.

- $\quad$ 1992a, Adri den Boer. Ministerraad akkoord met wetsvoorstel verzelfstandiging Kadaster. Geodesia, Vol. 1992, No. 07, pp. 310-311.

- $\quad$ 1992b, Berry van Osch. GBKN-overleg in impasse?. Geodesia, Vol. 1992, No. 04, pp. 160-163.

- $\quad$ 1992c, P. Schreuder, Z. Klaasse. Kadasterwet. Geodesia, Vol. 1992, No. 09, pp. 344-353.

- $\quad$ 1992d, R. Morrema. GBKN-PPP Op weg naar publiek private samenwerking. Geodesia, Vol. 1992, No. 04 , pp. $142-146$.

- $\quad$ 1992e, Unknown. Samenwerkingscontract Grootschalige Basiskaart van Nederland ondertekend. Geodesia, Vol. 1992, No. 12, p. 535.

- $\quad$ 1993a, Editors. De strijd om tien miljoen. Geodesia, Vol. 1993, No. 05, p. 227.

- 1993b, J. Kats. Grootschalige Basiskaart van Nederland: strijd om tien miljoen?. Geodesia, Vol. 1993, No. 09, p. 425. 
- $\quad$ 1993c, F. Molenaars, J.A. Schaart. GBKN een zorgenkind volwassen. Geodesia, Vol. 1993, No. 04, pp. 160-164.

- $\quad$ 1993d, W.H. de Vos. Landelijk Samenwerkingsverband GBKN. Geodesia, Vol. 1993, No. 11, pp. 558-564.

- $\quad$ 1993e, J.H. van Oogen. Terreinmodel Vastgoed. Een algemene classificatie voor ruimtelijke objecten. Geodesia, Vol. 1993, No. 10, pp. 486-490.

- 1993f, Peter Mom. Over jaar of 10 is gans Vlaanderen gecardibd. Vi Matrix, Vol. 1993, No. 12, pp. 10-13.

- $1993 g$, Peter Mom, Vera Dua. Gewest zal nooit over eigen basisgegevens beschikken. Vi Matrix, Vol. 1993, No. 10, pp. 36-37.

- 1993h, Editors. GIS in België: verdeeldheid troef. Vi Matrix, Vol. 1993, No. 12, p. 49.

- 1993i, Peter Mom. Tien profs tekenen bestek voor een Vlaams ‘GIS-huis. Vi Matrix, Vol. 1993, No. 10, pp. 34-35.

- 1994a, Peter Mom. Belgacom talmt met participatie Cardib. Vi Matrix, Vol. 1994, No. 03, p. 42.

- 1994b, Peter Mom. Cardib valt van de ene verbazing in de andere. Vi Matrix, Vol. 1994, No. 12, pp. 38-39.

- 1994c, Peter Mom. Slechten GIS-barrière plaatst gemeenten voor nieuw obstakel. Vi Matrix, Vol. 1994, No. 03, pp. 20-23.

- $\quad 1994 d$, Peter Mom. Weg vrij voor GIS-Vlaanderen. Vi Matrix, Vol. 1994, No. 06, pp. 44-44.

- $\quad$ 1994e, Peter Mom. Vlaamse GIS-werkgroep vergadert hevig voort. Vi Matrix, Vol. 1994, No. 10, pp. 2-3.

- 1994f, Peter Mom. Optimisme over GIS Vlaanderen moet men soms van verre zoeken. Vi Matrix, Vol. 1994, No. 10, pp. 6-7.

- $\quad$ 1995a, J.B. van der Veen, H.T. Uitermark. Naar een objectgerichte GBKN?! Van basiskaart tot basisbestand via het objectbegrip. Geodesia, Vol. 1995, No. 02, pp. 83-88.

- $\quad$ 1995b, C.H.J. Lemmen. Topologie en unike objectidentificatie. Enige aspecten bij het uitwisselen van ruimtelijke gegevens. Geodesia, Vol. 1995, No. 05, pp. 231-235.

- 1995c, Peter Mom. GIS-Vlaanderen krijgt stilaan de allure van een fata morgana. Vi Matrix, Vol. 1995, No. 01, pp. 6-9.

- 1995d, Peter Mom. Regeringsbesluit GIS-Vlaanderen. Vi Matrix, Vol. 1995, No. 06, p. 47.

- 1996a, Berry van Osch. Van de redactie: De objectgerichte GBKN: wanneer komt er schot in?. Geodesia, Vol. 1996, No. 04, p. 138.

- 1996b, Theo Scheele. Themadag Objectgerichte GBKN in Zeeland. Geodesia, Vol. 1996, No. 12, pp. 553-554.

- 1997a, Ad van der Meer. Van de redactie: Objectgerichte GBKN als religieus dispuut. Geodesia, Vol. 1997, No. 04, p. 154.

- $\quad 1997 b$, Jaap van der Veen. Objectgerichtheid en de GBKN. Een manier om tot standaardisatie te komen. Geodesia, Vol. 1997, No. 05, pp. 227-228.

- $\quad 1997$ c, Berry van Osch. Zijn we wel klaar voor een Objectgerichte GBKN?. Geodesia, Vol. 1997, No. 07, p. 298.

- $\quad$ 1997d, René van der Schans. We zijn niet klaar voor een objectgerichte GBKN. Een reactie op Berry van Osch' redactionele commentaar. Geodesia, Vol. 1997, No. 09, p. 397.

- $\quad 1997 \mathrm{e}$, Peter Mom. Cardib onvermoeid optimistisch over Grootschalige BasisKaart Vlaanderen. Vi Matrix, Vol. 1997, No. 02, pp. 33-35.

- $\quad$ 1997f, Peter Mom. Interelectra gaat nu met 'Cardib-kaart' eigen weg. Vi Matrix, Vol. 1997, No. 09, pp. 40-42.

- 1997g, Peter Mom. Cardib en OC optimistisch over één grootschalige basiskaart. Vi Matrix, Vol. 1997, No. 12, p. 43. 
- 1998, LSV-GBKN. Objectgerichte GBKN voorlopig geen haalbare kaart. Geodesia, Vol. 1998, No. 01, p. 42.

- 1999a, Landelijk Samenwerkingsverband GBKN. GBKN-vervaardiging bijna gereed. Geodesia, Vol. 1999, No. 06, p. 297.

- $\quad$ 1999b, J.C. Meerkerk, J.B. van der Veen. De GBKN, klaar voor de 21ste eeuw!?. Geodesia, Vol. 1999, No. 04, pp. 163-169.

- 1999 c, Peter Mom. OC start scanproject. Vi Matrix, Vol. 1999, No. 02, p. 36.

- 1999d, Peter Mom. Grootschalig Referentie Bestand voor Vlaanderen haalbare kaart. Vi Matrix, Vol. 1999, No. 12, pp. 38-40.

- $\quad 1999$ e, Peter Gorlé. Samenwerking GIS-Vlaanderen krijgt decretale basis. Vi Matrix, Vol. 1999, No. 09, pp. 34-37.

- 2000a, J. Polman. Hink, Stap, Sprong. De geschiedenis van het ontstaan van de GBKN. Geodesia, Vol. 2000, No. 07, pp. 319-326.

- 2000b, L.M. Murre. GBKN anno 2000. De stand van zaken en het perspectief voor de toekomst. Geodesia, Vol. 2000, No. 07, pp. 327-332.

- 2000c, Editors. GIS bij wet geregeld. Vi Matrix, Vol. 2000, No. 09, p. 41.

- 2001a, L.M. Murre. Laatste GBKN in Hardinxveld/Giessendam opgeleverd. Geodesia, Vol. 2001, No. 02, p. 83 .

- 2001b, J.C. Meerkerk, J.W.F.M. van Grunsven. GBKN, van aanbod naar vraaggericht. Geodesia, Vol. 2001, No. 03, pp. 117-121.

- 2001c, LSV-GBKN. Berichten uit de Stuurgroep GBKN. Geodesia, Vol. 2001, No. 12, p. 600.

- 2001d, Peter Mom. GRB Vlaanderen staat op de rails. Vi Matrix, Vol. 2001, No. 12, pp. 28-30.

- 2002a, Ad van der Meer. De GBKN een authentieke registratie? Geodesia, Vol. 2002, No. 06, p. 235.

- 2002b, Ad van der Meer. De GBKN-kip en het AR-ei. Geodesia, Vol. 2002, No. 09, p. 327.

- 2002c, N.J.M van Eekelen, E.J.M. Weesie. Instrumenten voor een uniforme GBKN. Geodesia, Vol. 2002, No. 03, pp. 108-110.

- 2002d, Adri den Boer. Geo-informatiebeleid in Tweede Kamer. Geodesia, Vol. 2002, No. 09, pp. 322-326.

- $\quad$ 2002e, Leen Murre. Topografie en gemeenten. Geodesia, Vol. 2002, No. 10, p. 387.

- 2002f, Peter Mom. Londerzeel prijst de dag dat GRB wordt opgeleverd. Vi Matrix, Vol. 2002, No. 06, pp. 30-31.

- 2003a, H. Schallenberg. De grootschalige basiskaart een gemeentelijke zorg. Geodesia, Vol. 2003, No. 01, pp. 4-9.

- 2003b, L.M. Murre. Nieuwe Stichting LSV GBKN van start. Geodesia, Vol. 2003, No. 09, pp. 342-345.

- 2003c, Adri den Boer. Eindrapportage Stroomlijning Basisgegevens. Geodesia, Vol. 2003, No. 05, pp. 210-212.

- $\quad$ 2003d, E. Scheltes, L.A. Smit, Ad van der Meer, Jan de Kruif. Gemeenten verantwoordelijk voor topografie'. Geodesia, Vol. 2003, No. 02, pp. 82-85.

- 2003e, L.M. Murre. Kunnen 'gemeenten verantwoordelijk zijn voor topografie'?. Geodesia, Vol. 2003, No. 04, p. 179.

- 2003f, E. Dolle. RSV en TPG sluiten aan. Geodesia, Vol. 2003, No. 11, p. 457.

- 2004, Peter Mom. GRB-primeur voor Geetbets. Vi Matrix, Vol. 2004, No. 11, pp. 47-48.

- 2005, Redactie. Minister Kris Peeters volgt realisatie van geo-basisbestanden met argusogen. Vi Matrix, Vol. 2005, No. 12, pp. 44-47.

- 2006a, Adri den Boer. Themabijeenkomst basisregistraties in trek. Geo-info, Vol. 2006, No. 07, pp. 314-316. 
- 2006b, L.M. Murre. Wordt de GBKN een basisregistratie?. Geo-info, Vol. 2006, No. 02, pp. 66-68.

- $\quad 2006 c$, Koen Vervloessem. Iedereen een gelijke manier van aanmeten en alle objecten in de juiste layer. Geoplatform, Vol. 2006, No. 09, pp. 6-9.

- 2006d, Peter van Es. GIS Vlaanderen: verleden, heden en toekomst. Geoplatform, Vol. 2006, No. 09 , pp. 10-15.

- 2009a, Adri den Boer, Martin Peersmann. Martin Peersmann: 11 maanden 'mister GBKN2BGT'. Geo-info, Vol. 2009, No. 10, pp. 4-6.

- $\quad 2009$ c, Nico vande Kerkhof. Vlaanderen moet leren omgaan met een gefaseerde GRB-realisatie. Geoplatform, Vol. 2009, No. 09, pp. 14-19.

- 2009b, Ronald Bokhove. Gemeenten kleuren de BGT in, maar hoe?. Geo-info, Vol. 2009, No. 11, pp. 30-32.

- 2010, Adri den Boer, Ruud van Rossem. Ruud van Rossem: nu mister BGT. Geo-info, Vol. 2010, No. 01, pp. 22-24.

- 2011, Adri den Boer. Bronhoudersoverleg BGT op naar uniformering. Geo-info, Vol. 2011, No. 07, pp. 21-22.

- 2012a, Ruud van Rossem. De BGT: van denken naar doen. Geo-info, Vol. 2012, No. 06, pp. 4-8.

- 2012b, Bart Maessen. Landelijke voorziening BGT. Geo-info, Vol. 2012, No. 06, pp. 22-24.

- 2012c, Ernst Koperdraat. Nut en noodzaak van een samenwerkingsverband van bronhouders. Geo-info, Vol. 2012, No. 06, pp. 26-29.

- 2012d, Martin Peersmann, Sieb Dijkstra. Van GBKN naar BGT in historisch perspectief. Geo-info, Vol. 2012, No. 6, pp. 38-42.

- 2013, Editors. Wet BGT door de Eerste Kamer. Geo-info, Vol. 2013, No. 08, p. 44.

- 2014, BGTweb. Valkenswaard als eerste helemaal in de BGT!. Geo-info, Vol. 2014, No. 06, p. 15.

- 2016, Roelof Keppel. Verslag FLAGIS-bijeenkomst 8 december 2015 te Lier (B). Geo-info, Vol. 2016, No. 01, p. 34

- 2017a, Roelof Keppel; Astrid van den Hoek, Nienke Zeijlemaker. Grip op data: de puzzel van Rijkswaterstaat. Geo-info, Vol. 2017, No. 03, pp. 24-27.

- 2017b, Marcel Rietdijk; Gerlof de haan; Sandra Leijten. Met de BGT op tijdreis door de openbare ruimte. Geo-info, Vol. 2017, No. 03, pp. 30-33.

\section{References}

1. Macharis, C.; Crompvoets, J. A stakeholder-based assessment framework applied to evaluate development scenarios for the spatial data infrastructure for flanders. Comput. Environ. Urban. Syst. 2014, 46, 45-56. [CrossRef]

2. Vancauwenberghe, G. Coordination within Spatial Data Infrastructures: An Analysis of Exchange and Use of Geographical Information in Flanders; KU Leuven: Leuven, Belgium, 2013.

3. Bregt, A.K.; Crompvoets, J.W.H.C. Geo-informatie in de netwerksamenleving, een tweeluik. Vi Matrix 2000, 55, 16-19.

4. Bregt, A.K. Value added services en de nationale geo-informatie infrastructuur. In Proceedings of the Promoting value-added GI services, Den Haag, The Netherlands, 27 January 2006; pp. 77-81.

5. Robichau, R.W. The mosaic of governance: Creating a picture with defintions, theories, and debates. Policy Stud. J. 2011, 39, 113-131. [CrossRef]

6. Pollitt, C.; Bouckaert, G. Public Management Reform. A Comparative Analysis: New Public Management, Governance, and the Neo-Weberian State; Oxford University Press: New York, NY, USA, 2011.

7. Vandenbroucke, D.; Crompvoets, J.; Vancauwenberghe, G.; Dessers, E.; Van Orshoven, J. A network perspective on spatial data infrastructures: Application to the sub-national sdi of flanders (Belgium). Trans. GIS 2009, 13, 105-122. [CrossRef]

8. Hendriks, P.H.J.; Dessers, E.; van Hootegem, G. Reconsidering the definition of a spatial data infrastructure. Int. J. Geogr. Inf. Sci. 2012, 26, 1479-1494. [CrossRef] 
9. Mörth, U. The market turn in eu governance-The emergence of public-private collaboration. Gov. Int. J. Policy Adm. Inst. 2009, 22, 99-120. [CrossRef]

10. Rijke, J.; Brown, R.; Zevenbergen, C.; Ashley, R.; Farelly, M.; Morison, P.; van Herk, S. Fit-for-purpose governance: A framework to make adaptive governance operational. Environ. Sci. Policy 2012, 22, $73-84$. [CrossRef]

11. Fukuyama, F. What is governance? Governance 2013, 26, 347-368. [CrossRef]

12. Coetzee, S.; Wolff-Piggott, B. A review of sdi literature: Searching for signs of inverse infrastructures. In Cartography_Maps Connecting the World; Sluter, C.R., Cruz, C.B.M., Menezes, P.M.L., Eds.; Springer International Publishing: Cham, Switzerland, 2015; pp. 113-127.

13. Kooiman, J. Governing as Governance; SAGE: London, UK, 2003.

14. Rajabifard, A.; Feeney, M.-E.F.; Williamson, I.P. Future directions for sdi development. Int. J. Appl. Earth Obs. Geoinf. 2002, 4, 11-22. [CrossRef]

15. Grus, L.; Crompvoets, J.; Bregt, A.K. Spatial data infrastructures as complex adaptive systems. Int. J. Geogr. Inf. Sci. 2010, 24, 439-463. [CrossRef]

16. Verhoest, K.; Bouckaert, G.; Peters, B.G. Janus-faced reorganization: Specialization and coordination in four oecd countries in the period 1980-2005. Int. Rev. Adm. Sci. 2007, 73, 325-348. [CrossRef]

17. Hood, C. The "new public management" in the 1980s: Variations on a theme. Account. Organ. Soc. 1995, 20, 93-109. [CrossRef]

18. The White House. Coordinating geographic data acquisition and access: The national spatial data infrastructure. In Executive Order 12906; Federal Register: Washington, DC, USA, 1994.

19. Masser, I.A.N. All shapes and sizes: The first generation of national spatial data infrastructures. Int. J. Geogr. Inf. Sci. 1999, 13, 67-84. [CrossRef]

20. Gore, A. Creating a Government that Works Better \& Costs Less; Report of the National Performance Review; Status Report; US Government Printing Office: Washington, DC, USA, 1994.

21. Rajabifard, A.; Feeney, M.E.; Williamson, I.; Masser, I. National sdi initiatives. In Developing Spatial Data Infrastructures: From Concept to Reality; Williamson, I., Rajabifard, A., Feeney, M.-E.F., Eds.; Taylor \& Francis: London, UK, 2003; pp. 99-114.

22. Crompvoets, J.; Bregt, A.; Rajabifard, A.; Williamson, I. Assessing the worldwide developments of national spatial data clearinghouses. Int. J. Geogr. Inf. Sci. 2004, 18, 665-689. [CrossRef]

23. Osborne, S.P. The New Public Governance: Emerging Perspectives on the Theory and Practice of Public Governance; Routledge: Abingdon-on-Thames, UK, 2010.

24. Worthy, B. More open but not more trusted? The effect of the freedom of information act 2000 on the united kingdom central government. Governance 2010, 23, 561-582.

25. European Parliament. Directive 2003/98/ec of the European Parliament and of the Council of 17 November 2003 on the Re-Use of Public Sector Information; European Union: Brussels, Belgium, 2003.

26. Geographic Information Panel. Place Matters: The Location Strategy for Het United Kingdom; Communities and Local Government: London, UK, 2008.

27. Hansen, H.S.; Hvingel, L.; Schrøder, L. Open government data-A key element in the digital society. In Proceedings of the Second Joint International Conference on Electronic Government and the Information Systems Perspective, and Electronic Democracy, Prague, Czech Republic, 26-28 August 2013; pp. 167-180.

28. Bregt, A.K.; Castelein, W.T.; Grus, L.; Eertink, D. De Effecten van een Open Basisregistratie Topografie (Brt); Wageningen University: Wageningen, The Netherlands, 2013.

29. Welle Donker, F. Public sector geo web services: Which business model will pay for a free lunch? In Sdi Convergence. Research, Emerging Trends, and Critical Assessment; Van Loenen, B., Besemer, J.W.J., Zevenbergen, J.A., Eds.; Optima Grafische Communicatie: Delft, The Netherlands, 2009; pp. 35-50.

30. Maguire, D.J.; Longley, P.A. The emergence of geoportals and their role in spatial data infrastructures. Comput. Environ. Urban Syst. 2005, 29, 3-14. [CrossRef]

31. Koerten, H. Taming Technology. The Narrative Anchor Reconciling Time, Territory and Technology in Geoinformation Infrastructures; Delft University of Technology: Amsterdam, The Netherlands, 2011.

32. Sanz, E. Open governments and their cultural transitions. In Open Government: Opportunities and Challenges for Public Governance; Gascó-Hernández, M., Ed.; Springer: New York, NY, USA, 2014; pp. 1-15.

33. Lance, K.T.; Georgiadou, Y.; Bregt, A.K. Cross-agency coordination in the shadow of hierarchy: 'Joining up' government geospatial information systems. Int. J. Geogr. Inf. Sci. 2009, 23, 249-269. [CrossRef] 
34. Bowen, G.A. Document analysis as a qualitative research method. Qual. Res. J. 2009, 9, 27-40. [CrossRef]

35. Bryman, A. Social Research Methods, 4th ed.; Oxford University Press: Oxford, UK, 2012.

36. Scott, J. A Matter of Record; Polity Press: Cambridge, UK, 1990.

37. Ministerie van Infrastructuur en Milieu. Monitorrapportage Juli 2017: Bgt Voortgang Transitie; Ministerie van Infrastructuur en Milieu: Den Haag, The Netherlands, 2017.

38. Vlaamse Raad. Handelingen 7-8-9-10-11, Vergaderingen van November 1992; Vlaamse Raad: Brussels, Belgium, 1992; pp. 237-254.

39. Kok, B.; van Loenen, B. How to assess the success of national spatial data infrastructures? Comput. Environ. Urban Syst. 2005, 29, 699-717. [CrossRef]

40. Minkov, M.; Hofstede, G. Clustering of 316 european regions on measures of values. Cross-Cult. Res. 2014, 48, 144-176. [CrossRef]

41. Oikonomou, I. The 'nationalisation' of the galileo programme. In Theorizing European Space Policy; Hoerber, T.C., Sigalas, E., Eds.; Lexington Books: Lanham, MD, USA, 2016; pp. 141-158.

42. Publieke Dienstverlening op de Kaart (PDOK). Available online: www.pdok.nl (accessed on 19 July 2017).

43. Jessop, B. Governance and meta-governance: On reflexivity, requisite variety and requisite irony. In Governance, as Social and Political Communication; Manchester University Press: Manchester, UK, 2003; pp. 101-116.

44. Dietz, T.; Ostrom, E.; Stern, P.C. The struggle to govern the commons. Science 2003, 302, 1907-1912. [CrossRef] [PubMed]

45. Edelenbos, J.; Bregt, A.; Broesie, R.; Dammers, E.; Meyer, H.; Neumann, D.; Warmerdam, M. An action perspective fot the delta. In New Perspectives on Urbanizing Deltas; Meyer, H., Bregt, A., Dammers, E., Edelenbos, J., Eds.; MUST Publishers: Amersfoort, The Netherlands, 2015; pp. 173-187.

(C) 2017 by the authors. Licensee MDPI, Basel, Switzerland. This article is an open access article distributed under the terms and conditions of the Creative Commons Attribution (CC BY) license (http:/ / creativecommons.org/licenses/by/4.0/). 
Article

\title{
Wicked Water Points: The Quest for an Error Free National Water Point Database
}

\author{
Jeroen Verplanke * and Yola Georgiadou \\ Faculty for Geo-Information Science and Earth Observation (ITC), University of Twente, \\ 7522 NB Enschede, The Netherlands; p.y.georgiadou@utwente.nl \\ * Correspondence: j.j.verplanke@utwente.nl; Tel.: +31-53-4874-532
}

Received: 5 June 2017; Accepted: 3 August 2017; Published: 8 August 2017

\begin{abstract}
The Water Sector Development Programme (WSDP) of Tanzania aims to improve the performance of the water sector in general and rural water supply (RWS) in particular. During the first phase of the WSDP (2007 to 2014), implementing agencies developed information systems for attaining management efficiencies. One of these systems, the Water Point Mapping System (WPMS), has now been completed, and the database is openly available to the public, as part of the country's commitment to the Open Government Partnership (OGP) initiative. The Tanzanian WPMS project was the first attempt to map "wall-to-wall" all rural public water points in an African nation. The complexity of the endeavor led to suboptimal results in the quality of the WPMS database, the baseline of the WPMS. The WPMS database was a means for the future monitoring of all rural water points, but its construction has become an end in itself. We trace the challenges of water point mapping in Tanzania and describe how the WPMS database was initially populated and to what effect. The paper conceptualizes errors found in the WPMS database as material, observational, conceptual and discursive, and characterizes them in terms of type, suspected origin and mitigation options. The discussion focuses on the consequences of open data scrutiny for the integrity of the WPMS database and the implications for monitoring wicked water point data.
\end{abstract}

Keywords: rural water supply; water point mapping; Tanzania

\section{The History of Water Point Mapping in Tanzania}

Tanzania has a rich history in rural water supply. Jiménez and Pérez-Foguet [1] describe how, before independence, rural water schemes were implemented mainly by national government, while local government was responsible for operation and maintenance through water fees and taxes. Shortly after independence, the new government of Tanzania decided that all costs should be borne by the government and public water should be free. During the 1980s, a new policy made water users responsible for operation and maintenance of water schemes, and donors contributed significant funding [1]. Over the course of the 1990s, new targets were set to achieve rural water supply service to within $400 \mathrm{~m}$ of all households by 2002 .

The Government of Tanzania and international Non-Governmental Organizations (NGOs) have faced many challenges in the devolution of responsibilities for rural water supply to local actors. Jiménez and Pérez-Foguet [1] observe that the practice of devolving responsibility for rural water supply without simultaneously devolving the necessary financial resources and instituting coherent policies to support this, has persisted since independence, despite the warnings of academic literature [2-4].

In 2009, the Ministry of Water and Irrigation (MoWI) released the Water and Sanitation Act [5], which promulgated a "demand-response approach," whereby "the central government plays the role of coordinator and facilitator in the water sector, and the district level holds the main responsibilities 
for implementation" [1]. This approach to service delivery depends on communities to demand, own, and maintain their water services and participate in their design, as well as to be responsible for operation and maintenance costs.

Securing the resources for operation and maintenance has been very difficult for most rural communities and nearly impossible without external funding. The sustainability of water services is further jeopardized by the low level of professionalism in the management of services [6], the difficult relationship between water users and elected representatives and the limited role that local and district governments play in the monitoring of water point functionality and the provision of technical support [1].

The purpose of the Water Point Mapping System survey [7] was to collect for the first time ever a baseline of accurate, reliable and up to date information on all water points (WPs) in rural Tanzania. Like all baselines, this particular one was supposed to underpin not only the monitoring of all functional and non-functional public rural WPs at any future time, but also to improve decision-making and allocation of resources, leading to improved water supply services in rural areas. Several databases preceded the WPMS. The German Development Agency-GIZ set up a Rural Water Supply (RWS) database in 2001. The purpose was to record information on existing water schemes in rural areas. The system worked well and tracked information at the district and ward levels and was used as input for national policy reports [8]. The data was updated through paper forms that were filled out in the field and manually entered into the database. The RWS database contained 2765 schemes when it was last updated in 2007. The World Bank also set up the Maji Management Information System (MIS) in 2004, which was used until 2008. The Maji MIS covered only 14 districts and was essentially a project management tool comprising the procurement, construction and financing of rural water schemes. Neither the Maji MIS nor the RWS systems are linked to the current WPMS.

Water point mapping (WPM) was initiated in Tanzania by Water Aid in $2004[9,10]$ to scale this NGO's previous positive experiences in Malawi. Upon seeing the outputs of the water point mapping exercise, the Permanent Secretary institutionalized the process within the MoWI. Water points in fifty-five out of 132 Tanzanian rural districts were mapped between 2005 and 2009 using broadly the Water Point Mapping (WPM) methodology championed by Water Aid, and adopted by other actors in the international water sector (SNV, Plan International, Concern Worldwide).

The outcomes of these WPM efforts were fed into discussions at national sector review meetings [11]. By 2008, stakeholders in collaboration with the MoWI had successfully legitimized WPM as a useful monitoring tool and revealed a $43 \%$ functionality rate among mapped water points in rural areas [12]. The results of four case studies [13] showed that the main constraints were the lack of updating mechanisms, lack of use as well as lack of integration of the system with the other systems in the decision-making and planning process [1]. SNV then carried out a Validation and Inquiry Process (VIP) [14] to investigate why so many water facilities were not functioning.

From 2010 to 2013, the MoWI commissioned a consultant to carry out a Water Point Mapping (WPM) project in all districts in Tanzania, to monitor the functionality performance of rural water supply schemes and water points [15]. The purpose was to build on existing experiences and benefits obtained from the Water Aid experience with the view of improving decision making and allocation of resources towards improvement of water supply services in rural areas. According to the specifications of the WPM project, the consultant had to: (1) locate each rural WP in Tanzania by Global Positioning System (GPS); (2) take pictures of each WP; (3) collect data on the functionality, management, specifications and water quality and quantity of each WP. The WPM project also included a web-based GIS system to produce and make publicly accessible maps and data relating to WP functionality and coverage. Further, the project should facilitate an increase of the capacity of the MoWI and local government staff to use and update the WPM database and other stakeholders in the country to understand the status of rural water supply services in terms of coverage and functionality [12]. 


\section{The Need for Water Point Mapping}

The Sector Programme for Rural Water Supply in Tanzania (2006) set goals for the percentage of the population in rural areas with sustainable and equitable access to safe water. The first goal of $65 \%$ coverage was to be achieved in 2010 [16], and should subsequently grow to at least $74 \%$ by mid-2015 to comply with the Millennium Development Goals (MDGs) for access to water.

In 2010, the MoWI set certain annual milestones such as "countrywide quarterly functionality monitoring of all water points in Tanzania" [15] in order to create a baseline that could be used for results-based reporting of outcomes. Until then, the monitoring of the MoWI depended on routine output data to calculate service coverage. In this data, water service coverage was based on the number of constructed water points per 1000 inhabitants to calculate an assumed number of persons served. However, the data did not record whether the water installations were functioning. The MoWI and the National Bureau of Statistics noticed this flaw and decided to adopt an outcome based monitoring approach: "actual access rates are likely to be less (and possibly much less) than those reported using routine data. The reason for this discrepancy is clear: routine data does not record functionality and assumes that investments do not fail. Outcome (access) surveys do record situations where water points (or entire schemes) have failed for technical, financial, management or any combination of shortcomings. Without a reliable baseline that takes into account functionality and (more importantly) a means to keep this updated, it is impossible to track the net progress in expanding rural water supply service coverage or, more importantly, to determine actual access rates" [15].

Non-conflicting data on the number of water points available and the rural population served fueled the need for Water Point Mapping [17]. Originally conceived as a planning and budgeting tool to encourage the transparent and evidence based allocation of resources, Water Point Mapping was later also seen as an excellent tool for communities and local leaders to visualize a rural water scheme and its challenges. It was therefore envisioned that the baseline data could be updated by Community Water Supply Organisation (COWSO) representatives using their mobile phones, similarly to the Human Sensor Web system tested on Zanzibar $[15,18]$.

The contract to collect baseline information was supposed to be completed by December 2011. By then, a functionality tool would be operational in all 132 LGAs. By the middle of 2012, the project had not yet finished due to internal delays in the disbursement of funding. By that time however, producing accurate and up-to-date data on rural water supply infrastructure was seen "as one of the most urgent challenges facing the sector" [19]. The MoWI had established that it could enable government and other stakeholders (if authorized to do so) to monitor and analyze functionality and other aspects of all water points in real time, via a web based interface and even establish "the status and reasons for non-functioning water supply and identify rehabilitation requirements" [19].

At the same time [19], the Government of Tanzania committed to the Open Government Partnership (OGP), a global initiative aiming to promote transparency and citizen empowerment, to fight corruption and to encourage the use of new technologies to improve governance, e.g. platforms to engage citizens through the internet and mobile phones to monitor and report water point functionality to government. The OGP demanded that the disaggregated data from the WPM become available online (in machine-readable format) in order for "local government authorities to use data to plan for new investments and NGOs to use these data for planning their own investments [and] researchers to increase understanding of sustainability and equity issues for the water sector in the country" [19]. Thus, WPM was framed as a tool to produce accurate and timely data that could be disseminated through user-friendly maps and reports.

The consultant was eventually able to fulfill his contract mid-way through 2013 [17]. By then, a total of 75,777 water points had been mapped, of which 46,697 water points were found functional $(62 \%)$ and 29,080 were found not functional (38\%), as reported on the MoWI website. At the same time, only 200 COWSOs had been established in the 132 Local Government Authorities-a tiny fraction of the total number of COWSOs required nation-wide to update the water point data in the future. 


\section{How Are Water Points Wicked?}

"Wicked problems" is a popular concept in policy and information sciences. Several characteristics of wicked problems, defined by Kunz, Rittel and Webber [20,21], are relevant for rural water services. First, the framing of policy problems is not universal- "public water service" in France is roughly similar but discretely different from that in Tanzania. Second, it is difficult to achieve consensus regarding the solution of wicked problems-some may claim that constructing more public water points will improve water service, while others counter that genuine decentralization of public services is the solution. Third, solutions to wicked problems can only be subjectively better or worse, not objectively true or false-water service provision should be incrementally improved, rather than solved at one stroke forever. Fourth, many cause-effect stories can be advanced for a wicked problem, depending on the individual perspective of the stakeholder. As Rittel and Webber put it: "the information needed to understand the problem depends on one's idea for solving it" [21], where access to water can be improved from a health care or sanitation perspective but also from the point of view of a basic human right. Fifth, every wicked problem is a symptom of another problem-reduced school attendance for girls in many African countries is connected to the time required to collect water [22,23]. Sixth, proposing a solution to a wicked problem frequently prevents incremental design because most interventions change the original problem-introducing payment for (improved sources of) water in Tanzania to finance the maintenance of water points has caused many people to resort to the use of unimproved (free) water sources [24].

Aligning public water services with wicked problems is done in a different way by Rottenburg [25] in what he calls the "technical game". Rottenburg discusses in his parable of development aid the irresolvable internal contradiction in international development cooperation. He describes the "accountable, predictable and obviously conditional transfer of resources from the North to the South versus the facilitation of sustainable and self-determined development of target countries", which requires vast amounts of quantitative data to be supplied in order to provide proof of progress and achievement. This is reflective of the mentioned characteristics of wicked problems. To resolve this contradiction, development partners from the North and the South play a "technical game" that brackets the local social and cultural frames of reference. Development partners no longer focus on the wicked problem of improved rural water supply but only on the (seemingly) tame problem of mapping the distribution of that rural water supply or the mere "production" of water points in villages without considering the availability of other water sources.

As this research is part of a larger investigation funded by the Dutch Science Foundation, we also use the framework of Pritchett and Woolcock [26] and the World Bank [27] as adapted by Nganyanyuka et al. [24], which distinguishes between discretionary and transaction-intensive elements in key services to citizens. Transaction-intensive elements, like mapping or monitoring all rural water points in Tanzania, require a large number of transactions, involving face-to-face contacts between district officials, village water technicians, COWSO members, and citizens-for example, a water technician detecting a broken water point and reporting the breakdown to the COWSO secretary. Discretionary elements involve decisions based on information that "is important but inherently imperfectly specified and incomplete, and entails extensive professional or informal context-specific knowledge" [26] (p. 194). Collecting and digitizing data about transaction-intensive elements of water services is relatively easy, while collecting data about discretionary elements is fraught with insuperable difficulties [25]. It is precisely the discretionary nature of water point mapping that renders the water points "wicked" and their mapping a "wicked problem."

\section{The Water Point Mapping Data}

We analysed the various attributes of WPs captured during water point mapping (WPM) in Tanzania from 2010 to 2013 and recorded in the online database of rural water points dated 25 April 2013 (APR.2013). In mid-February 2014, a new version of the WPM data was published on the Ministry of Water's website and denoted FEB.2014. Both versions were officially available on the government website on 21 May 2014. The version FEB.2014 is different from the previous version 
(APR.2013) in several ways. The FEB.2014 version was organized in spreadsheets, one spreadsheet per Tanzanian region, and contained close to 68,000 water points-about 7500 fewer water points compared to APR.2013. In the new version, however, one region with 6293 water points was excluded. The total number of mapped water points in Tanzania including this region therefore amounted to 74,250; 1500 less than the original data set. The FEB.2014 version had, however, been considerably cleansed of duplicate records. The APR.2013 version featured over a thousand duplicate records of which only around 100 duplicate records (coordinates) remained in the FEB.2014 version. Database cleansing has most likely led to the reduction of the total number of water points. The new data also contained information on the geographic coordinates. The previous version lacked metadata regarding the map datum used to collect the GPS coordinates of the water points. The table headers in the new spreadsheets indicate that the data were collected using the Arc.1960 map datum. As geographic overlays of water point (WP) information and administrative boundaries show some strange overlaps (water points positioned in neighboring districts), the map datum information can be used to correct these map errors. In 2015, several updates of the WPM data were made. The data, however, became less accessible to the general public due to the transfer of the database under the OGP as the raw data tables were no longer downloadable. Only pdf files and data per administrative region could still be visualized on an interactive website. As most evaluations of the Tanzanian Rural Water Supply have been based on the WPM data, initially made available (APR.2013 version), this paper is basing its argumentation on this dataset as well.

\subsection{Errors in WPM Data}

To analyse the errors in the WPM data and to assess the issues arising from these errors, we examined the attributes of the WPM data (spreadsheet columns), and catalogued and classified the anomalies in the data according to error types. If we see the WPM survey as an experiment, a common way to look at errors is to classify them as systematic, random and gross errors [28-32]. Systematic errors, e.g., due to wrong calibration of instruments (e.g., settings in a GPS), can be eliminated through recalibration; random errors may be estimated statistically [31,32]; blunders or gross errors, made when values are incorrectly selected or marked [29]. Besides deletion, no other solution exists for the correction of gross errors. Deletion of gross errors therefore leads to loss of data and the only way to get the data cleaned is to repeat their collection in the field.

Nevertheless, errors encountered in the WPM data, cannot be classified in this way since a mapping project is unlike a scientific experiment. The variables measured by an instrument lack metadata regarding the applied method and procedure and make it difficult to assess whether an error is systematic. Secondly, the effect of random errors on the data cannot be quantified easily because the individual water points are unique, independent features in the landscape and their attributes are uncorrelated. Of course, there will be some form of correlation between some of the recorded attributes, like the water quality of water points connected to the same aquifer. However, these errors mostly occur in unrelated elements like the order in which water points are named, the number of people using a water point, the quantity of water measured, the type of pump technology, and the level of point improvement. Even the donor agency (another WP attribute) cannot be deduced from neighboring water points. Many water points are either donated by individuals or by multiple donors active in a village consecutively or together for several years. Thirdly, many errors seem to arise during data entry or from ambiguity. Spelling errors and contradicting columns suggest the existence of significant gross errors. Much of the analysis of the data and a consequent judgement on the integrity and usability of the data therefore comes down to studying these gross errors.

Allchin [33] provides a classification of errors that is dependent on observational benchmarks derived from both fact and theory as well as local cultural context. As this classification also resonates with our theoretical framework of transactions and discretion $[25,26]$, we have chosen to adopt it. It creates a contextual spectrum of errors that can be classified into material, observational, conceptual and discursive errors: 
- Material errors can be caused by improper procedures (violation of protocol or poor technical skills) and involve "aspects of getting the phenomenon right" [33]. In WPM, this encompasses (a) the filling of the data entry form, (b) the use of GPS for water point location, (c) the use of water quality testing kits and (d) data processing.

- Observational errors occur when insufficient controls exist to establish domain observation or an incomplete theory of observation exists, reflected by the poor choice of instruments or field methods. Observers can also exhibit a perceptual bias that is either "theory-laden" [33] or a problem of framing of the phenomenon. In WPM, this error type is reflected in (a) the choice of field equipment, (b) experience of the Water Point Collector (WPC) and (c) the management of the WPC team.

- Conceptual errors are commonly miss-specified assumptions or boundary conditions. They involve theoretical interpretations common in philosophy. The possible cognitive bias due to theoretical entrenchment is important. In WPM, this error type is due to (a) the rigidity of the data entry form, (b) changes over time in the WPM approach and (c) the framing of rural water service problems by stakeholders at different levels of the Water Point Mapping System.

- Discursive errors can originate from communication failures (incomplete reporting, translation) or mistaken judgments of credibility but also from unchecked sociocultural cognitive biases and public misconceptions. In WPM, these problems arise with (a) the intelligence sources for the different WPM attributes, (b) misunderstanding of WPM concepts by local water users, (c) misinterpretation of local knowledge by the WPC and finally (d) fraudulent data manipulation.

This classification, although conceived to analyze scientific results, enables a narrower interpretation of the WPM survey results. Particularly, the assumption that the benchmarks of observation have a local cultural aspect is important when scrutinizing data from a field experiment such as WPM. This is linked to what Allchin [33] calls "second-order errors". It involves the ability of local (scientific) institutions to warrant claims and produce knowledge effectively with the ability for error remediation.

In Appendix A, 36 of the collected attributes in the WPM data are displayed in relation to the intelligence sources and their potential problem manifestations (Table 1). We identified potential problems with 26 of the 36 attributes. These problems were categorized according to the error typology we adapted from Allchin [33]. We defined 14 different root causes within these four error types that corresponded with suspected errors. Many of these cases occur, however, in combinations of different error types derived from the manifestation of the errors:

1. material errors

a. filling of the data entry form (in 19 attributes)

b. use of GPS (in one attribute (for GPS, there are many attributes $(>20)$ recorded with the WPM data, as these are all automatically recorded they have been grouped as one. In the open WPM dataset lat-lon coordinates (two attributes) and GPS height (one attribute) are presented without their error values, making it impossible to calculate systematic or random errors in the location measurements. The quality of GPS data therefore in this analysis depends only on the proper use of the device (1b), the choice of equipment (2a) and experience of the operator $(2 \mathrm{~b})$ )

c. use of water quality testing kits (in one attribute)

d. data processing (three attributes)

2. observational errors

a. choice of field equipment (four attributes)

b. experience of the Water Point Collector (WPC) (seven attributes)

c. management of the WPC team (consistency and training) (two attributes) 
3. conceptual errors
a. rigidity of the data entry form (nine attributes)
b. changes over time in the WPM approach (three attributes)
c. framing of rural water service problems by stakeholders at different levels of the Water Point Mapping System (five attributes)

4. discursive errors
a. intelligence sources for the different WPM attributes (eight attributes)
b. misunderstanding of WPM concepts by local water users (three attributes)
c. misinterpretation of local knowledge by the WPC (seven attributes)
d. data manipulation (two attributes)

Table 1. Broadly suspected causes of error in Water Point Mapping data categorized according to error typology adapted from Allchin [33].

\begin{tabular}{|c|c|c|c|}
\hline $\begin{array}{c}\text { Error Type } \\
\text { (Allchin, 2001) }\end{array}$ & Suspected Origin & Manifestation & Mitigation Options \\
\hline material error & $\begin{array}{l}\text { human computer } \\
\text { interaction (office) }\end{array}$ & duplication of records syntax error & Can be solved relatively easily \\
\hline observational error & $\begin{array}{l}\text { human computer } \\
\text { interaction (field) }\end{array}$ & $\begin{array}{l}\text { missing data, duplication, ambiguity } \\
\text { through miss typing or touch/tap } \\
\text { error in preformatted fields }\end{array}$ & $\begin{array}{l}\text { Difficult to solve. Hard to } \\
\text { establish whether the chosen } \\
\text { option was correct or not }\end{array}$ \\
\hline conceptual error & $\begin{array}{l}\text { human-human } \\
\text { interaction (office) }\end{array}$ & $\begin{array}{l}\text { changes over time, procedural } \\
\text { rigidity, definition of functionality }\end{array}$ & $\begin{array}{c}\text { Hard to solve after data collection } \\
\text { has commenced. Requires database } \\
\text { adaptation or changes in data } \\
\text { collection strategy }\end{array}$ \\
\hline $\begin{array}{l}\text { discursive } \\
\text { conceptual }\end{array}$ & $\begin{array}{l}\text { human-human } \\
\text { interaction (field) }\end{array}$ & $\begin{array}{l}\text { subjective information. information } \\
\text { not matching between columns } \\
\text { (functional and breakdown) }= \\
\text { conflicting information }\end{array}$ & $\begin{array}{l}\text { Difficult to solve. Hard to } \\
\text { establish whether the source was } \\
\text { authoritative or not }\end{array}$ \\
\hline $\begin{array}{c}\text { material and } \\
\text { observational error }\end{array}$ & $\begin{array}{l}\text { pure human error } \\
\text { (e.g., forgetfulness) }\end{array}$ & $\begin{array}{l}\text { regular, repetitive mistakes in } \\
\text { numbering or misspelling (field) }\end{array}$ & $\begin{array}{l}\text { Can be solved, but may require } \\
\text { considerable resources }\end{array}$ \\
\hline discursive error & malicious intent & forgery of records (field and office) & $\begin{array}{l}\text { Difficult to solve. Unless } \\
\text { geographical coordinates are } \\
\text { forged badly or unnatural } \\
\text { patterns are visible in the data }\end{array}$ \\
\hline
\end{tabular}

When translating the manifestations of error into Allchin's error types, it becomes clear that very few of the errors pertaining to specific attributes can be uniquely classified. In most attributes, errors are of mixed types if not all four types. If only one type would be found, the root cause would likely be either a person, a tool, a method or a line of reasoning. In reality, however, these errors are due to a cascade of causes starting with a wrong line of reasoning that leads to a poor choice of method, which, in the end, leads to ambiguity in the collected information, as the WPC is unable to fit the observations into the possible options provided in the data collection form. The ambiguity in the resulting information could be the starting point for new or poorer lines of reasoning resulting in a vicious circle. Another example could be a faulty tool that leads an inexperienced WPC to believe he is operating within margins.

Most of the errors identified in the Tanzanian WPMS are neither intrinsic to Water Point Mapping nor to the Tanzanian cultural context. The material and observational errors may occur in any large spatial data collection survey, particularly those conducted at a national scale. The discursive errors may be attributed to a wider developing country setting where local capacity is insufficient to provide the required support or information. Only the conceptual errors originating from the framing of water service issues have the specific local context as a root cause. The rigidity of the data collection form appears to be the result of the many requirements set by the MoWI for the WPMS, which left little 
space for the consultant to maneuver. The Tanzanian framing of what constitutes a functional water point (see Section 4.2.6) and the rearrangement of local government authorities during the duration of data collection are causes of error that can only be attributed to the specific national context.

\subsection{Manifestation of Errors}

As shown in Table 1, errors in the data are due to a number of reasons. These are usually combinations of the four error types. The causes and effects of these errors can be inferred by discussing the errors based on their manifestation: changes that have happened over time, syntax error in the input of the data, missing data and ambiguous values, subjective observations by field operators, duplicate records created at different occasions during data handling and the definition of functional water points.

\subsubsection{Changes over Time}

WPM data was collected over a three-year period from 2011 to 2013. Around 33,300 points were collected in 2011, 5200 points in 2012 and the remaining 27,000 in 2013. The data also includes 37 water points recorded as early as 2004. The first WPM exercise (by SNV, Water Aid, ISF and Concern) contained around 24,500 water points recorded between 2002 and 2009. These points were revisited and updated in the period 2011-2013. This implies that the information for almost half of the water points $(33,300$ out of 68,000$)$ was already three years old at the moment of publication.

The fact that the information was collected over a period of three years does not seem to have affected the consistency of the approach. The data collection form used for WPM was adapted from the form used in the first exercise led by SNV [14] by adding a few categories to the form, and removing none (Box 1). This could have allowed for seamless updating of the pre-recorded water points.

Serious challenges for the consistency of the data, however, occurred during the survey time span (2011-2013). These were caused by the renaming and numbering of local government authorities (LGA) in 2012 [34] and the related merging of administrative wards within LGAs and resulted in the disconnection of whole villages in the database. These errors in the data can only be removed by updating the water point records taking the unique identifiers of the water points as a starting point. Checking these against the actual ward and LGA names could correct this problem. These unique identifiers, the water point codes, are, however, one of the major challenges in the data as explained in the next section.

Box 1. Changes made to the Water Point Mapping data collection form between 2010 and 2013.

Added attributes in the WPM data collection field form:

- $\quad$ Local Government Authority name, Village population, Village photo, WPT code, Population served by WP, Catchment name, Existence of Water permit, Year of construction.

- $\quad$ Existing Attributes with added options are:

- Source type; added two options for "rain water harvesting, roof or ground", previously only rain water harvesting

- Extraction system; added "SWN 81" and "India Mark III"

- Status; added four classes of functionality: "Functional needing repair, not functional $>6 \mathrm{~m}$, not functional $<6 \mathrm{~m}$, not functional $<3 \mathrm{~m}$ "

- Hardware problem; added "Hand-Pump broken" and "on rehabilitation". The option "other reasons for not functional" was renamed to "reason for not functioning"

- Water quantity; added "others"

- Water Payments; added "amount Tsh"

\subsubsection{Syntax Error}

Each water point (WP) has a unique identifier (WPCODE). The syntax of the WPCODE is created by consecutively combining the numbers of Region-District-LGA-WARD-VILLAGE (11 digits) + a WP 
number, e.g., "01020030405WP001", totaling 16 characters. The added "WP001" is created by the WPC: the first WP encountered in a village receives \#001 [12]. The data shows that the 16-digit syntax is only observed for about $50 \%$ of the water points. In wards with less than $100 \mathrm{WP}$ (which is most of them), the first WP is numbered WP01 creating a code with 15 characters only. While this error can be easily mitigated in the database, other "zeroes" in the identifier were also omitted (e.g., when a LGA, Ward or Village was numbered " 012 "). As a consequence, the location (up to village level) of about $50 \%$ of the water points cannot be logically inferred anymore from this unique identifier. Once the WPC has formulated the WP code, it was physically recorded on the WP with either paint or a tag. The data does not allow the analyst to assess whether the syntax errors are replicated on the water point tags. Only a revisit in the field of all the points with wrongly formatted codes could provide a conclusive answer. Furthermore, the data contained many duplicate records. In most attributes, it seems that these duplications occurred when the WPC moved to another village or ward and restarted numbering WP001 without changing the ward or village numbers accordingly.

\subsubsection{Missing Data and Ambiguous Values}

The data contains several fields that raise questions. It is not always clear whether a "zero" (0) actually represents a value of zero or whether it reflects lack of data. The data for instance contains information on available PRIVATE CONNECTIONS, but only 952 records are available. Without metadata, it cannot be assessed whether the missing value " 0 " represents the fact that no private connections exist or whether no data was available. As many rural areas are also serviced by urban water supply schemes, it is possible that many more private connections exist nationwide than those recorded.

Further, many data fields are empty. Out of 25,209 non-functional water points, only 16,546 points provide information on BREAKDOWN YEAR. Collecting this attribute obviously requires local knowledge. Apparently, either nobody knew when those water points had broken down or the WPC was unable to consult anyone who knew. Additionally, the data features several records where the breakdown year precedes the year of construction. In addition, 1010 WP in Mwanza are missing GPS coordinates. If some of these WP also have wrongly formatted ID Codes, they can be presumed "lost" and cannot be retrieved for updating.

Other data is completely missing. The FEB.2014 dataset no longer contains the information on the recording date of the WP, making it harder to assess which WP should be prioritized in the updating. One piece of information that was originally missing in the data (APR.2013) was the metadata on the map datum used for the GPS recordings. Mapping the WP data in a GIS without datum information lead to challenges caused several WPs to be located in the wrong administrative unit or even within water bodies (e.g., lakes) when using the default map datum settings of the GPS devices. The FEB.2014 dataset fortunately provided this information in the column headings, indicating that the map datum used was Arc.1960.

Ambiguity is evident in the information provided with FUNDER, INSTALLER and YEAR_OF_CO. These attitudes are commonly recorded (painted) on the WP base/slab upon completion of installation and are copied by the WPC on the spot [12]. Very often, the information had worn off or was damaged and had to be provided by a member of the COWSO. Whether copied from the WP or recorded from the COWSO member, the WPC entered this information manually. Since many WPC were involved in the water point mapping, a multitude of spellings of names under FUNDER and INSTALLER were used. For instance, WP funded by the German Government may have been recorded as either: "Germany, german, ger or G". "G", however, may represent the Government of Tanzania. Such different spellings are common in the database for every donor, rendering much of this information useless.

In some attributes, the information leads to suspicion about conflicting information between the observations made by the WPC and the information provided by his local informants. The attribute HARDWARE_P ("Main hardware problem") was recorded based on predefined reasons for WP breakdown. The next attribute on the list "REASON_WPT" was originally defined in the 2010 SNV Data Collection Form as "other reason WP not functional". During the WPM data collection, however, 
the WPCs interpreted this as either "the reason for the recorded hardware problem" or, if the WP was judged as functional, but other problems were evident, as "additional reasons" [12]. There also was a final attribute to record "General comments". These were provided by the WP collectors themselves and are general statements about the WP. These comments (Figure 1) sometimes give valuable insight into the situation on the ground, indicating whether management of the WP was poor or describing the "actual" problem, from the point of view of the WPC, if the available options of the data collection form did not include it.

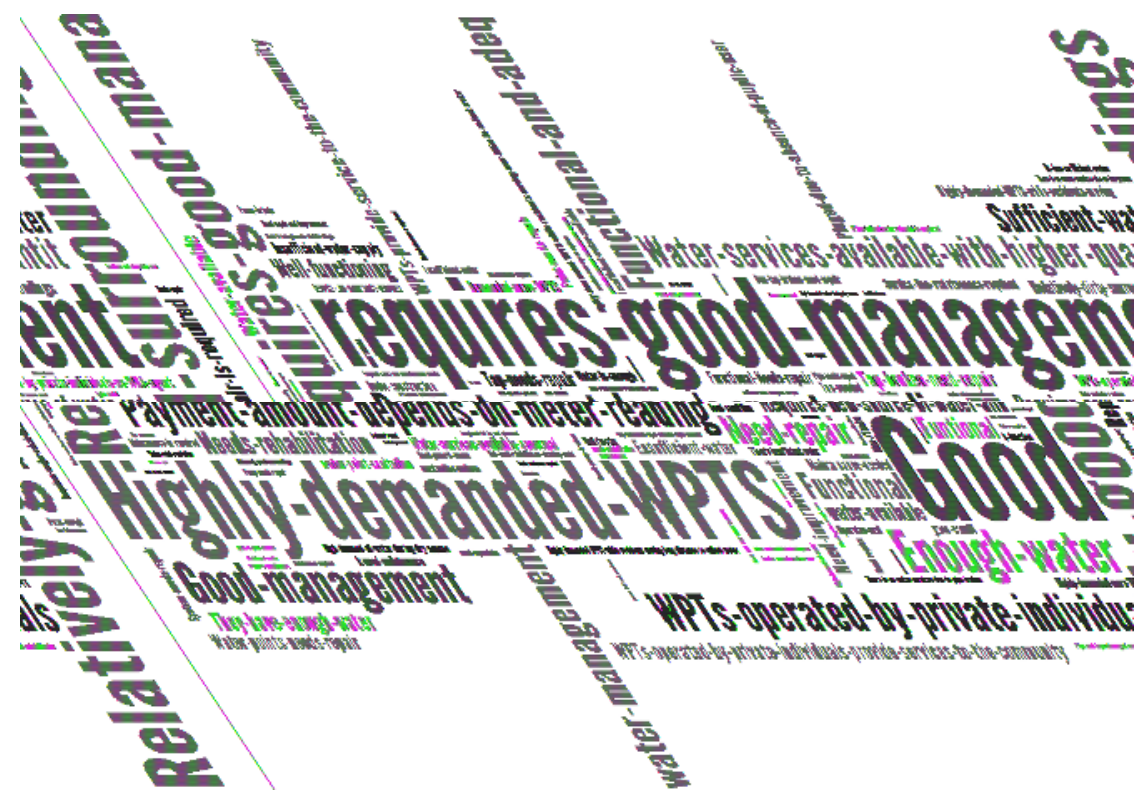

Figure 1. Word-cloud of the APR.2013 water point data constructed from 47,903 general comments. The comments were not corrected for spelling errors or variations.

\subsubsection{Subjective Observations}

The general comments field on the data collection form allowed the WPC to express his personal insights of the WP situation. The subjectivity of the observer presented a problem, most prominently reflected in the attributes on water quality and quantity. WATER_QUAL was observed by the WPC by tasting, visually inspecting, or by using a testing kit. Testing kits were used for fluoride and salinity assessment. "Soft" means good, well tasting water, "Milky" was a visual observation, "Salty" was a tasted or tested qualification and finally "Fluoride" was also tested. "Abandoned" was an attribute the WPC used for extreme quantities of salt or fluoride or "other" issues with water quality that led to abandonment of the WP. The practice of visually inspecting or tasting the water leads to great uncertainty and subjectivity in the data. Similarly, the judgement whether WATER_QUAN (quantity) was sufficient or not was highly subjective. No actual flow measurements were done and the qualification was given based on local knowledge of individual users. It is therefore likely that the quantity of water was subjectively judged in connection to the estimated population served.

\subsubsection{Duplicate Records}

Because of field recording mistakes or data processing errors, the APR.2013 version contained 3637 duplicate WPTCODEs. Many of these came from duplicate (GPS) records, which were partly removed in the FEB.2014 data. Still, 1862 duplicate WPTCODEs remained in the FEB.2014 data. 
The pictures taken of the WP at the time of recording should have a unique ID as well. The WPTPHOTOID column however shows: 1316 duplicates. The FEB.2014 data also includes two new columns GID and OBJECTID. The OBJECTID column includes 1447 duplicate identifiers of which 771 exist in the Tanga region alone. As a consequence, some sort of duplication was evident in about five percent of the total data.

\subsubsection{The Definition of Functional Water Points}

Functionality of a water point is represented in the data by the attributes STATUS and STATUS2. The STATUS of a WP was recorded in seven classes:

- Functional;

- Functional needing repair;

- Non-functional <3 months;

- Non-functional $>3$ months;

- Non-functional <6 months;

- Non-functional $>6$ months;

- Non-Functional.

STATUS 2 is an aggregate done by the consultant during data processing, when he merges these seven classes into only two classes:

- Functional (including Functional and Functional Needing Repair) and,

- Non-functional (including all other classes).

Based on the number of functional water points, the rural water supply coverage can be calculated.

The Second National Strategy for Growth and Reduction of Poverty (MKUKUTA II) required the national government to increase the access to clean and safe water supply from $58.7 \%$ in 2009 to $67 \%$ in June 2015 [16]. The first Rural Water Supply and Sanitation Programme (2006) established much higher targets for the population in rural areas with sustainable and equitable access to safe water: $65 \%$ by 2010 (MKUKUTA), at least 74\% by mid-2015 (MDGs), and $90 \%$ by 2025 [1]. Table 2 shows that the improvements over the last years have, however, been small and coverage seems to decline since 2009. In 2013, however, the Baseline for Rural Water Service Coverage (RWSC) was downgraded from $57 \%$ to $40 \%$ [35], which leaves an even more considerable gap to cover in the remaining years.

Table 2. No. of people with access to water supply service in rural areas between 2009-2012.

\begin{tabular}{cccc}
\hline Year & $\begin{array}{c}\text { District } \\
\text { Population (Dp) }\end{array}$ & $\begin{array}{c}\text { No. of People with Access to } \\
\text { Water Supply in Rural Areas (Ps) }\end{array}$ & $\begin{array}{c}\text { \% of Rural Water Service } \\
\text { Coverage } \mathbf{W}_{\mathbf{C}}=\mathbf{P}_{\mathbf{S}} / \mathbf{D}_{\mathbf{p}} \times \mathbf{1 0 0}\end{array}$ \\
\hline 2005 & $30,995,135$ & $16,308,651$ & 53.74 \\
2006 & $33,767,106$ & $18,798,723$ & 55.7 \\
2007 & $38,337,892$ & $21,675,360$ & 57.10 \\
2008 & $39,105,062$ & $22,790,460$ & 58.3 \\
2009 & $33,536,205$ & $19,685,659$ & 58.70 \\
2010 & $35,569,876$ & $20,545,945$ & 57.76 \\
2011 & $36,474,939$ & $20,634,227$ & 56.57 \\
2012 & $39,413,223$ & $22,443,769$ & 57 \\
\hline
\end{tabular}

The reduction in the baseline of 2012 from $57 \%$ to $40 \%$ can be partly explained based on the variability of the number of improved water supply infrastructures that are currently functional. The variation is caused by the multiple interpretations of Functional Water Supply Coverage. For starters, the formula for calculating functional coverage in Tanzania assumes one functional water point for every 250 people. Hence, four functional water points per 1000 people results in $100 \%$ water supply coverage. The problem with this formula is to agree on the definition of "functional", a problem 
shared by all specific indicator definitions. Proper definitions should involve issues of affordability, quality, reliability and non-discrimination-"exactly identifying what should be measured remains challenging" [36]. Finally, the calculation of the Rural Water Service Coverage depends on whether to include only fully functional water points or also those needing repairs.

\section{Conclusions}

The Open Data policy of Tanzania created space and opportunity for data analysts to scrutinize the database of the water point mapping system and raised doubts about the integrity of data collected in projects funded by development partners. Data previously (before the Open Government Initiative) considered undisputed can no longer be taken for granted as input for achieving the new Sustainable Development Goal for access to water.

The material, observational and discursive errors identified in the WPMS database are not intrinsic to either Water Point Mapping or the Tanzanian context. These errors may occur in any data collection project in the global South, particularly those projects conducted at a national scale or with a mind-set from the global North expecting an enabling environment for any sort of enumeration. Countries that lack the resources or the benefit of decades and centuries of dedicated mapping and monitoring at a national scale cannot easily enumerate infrastructural elements in remote areas. On the other hand, the root cause of conceptual errors is the specific local context. Notably, a consensual definition of water point functionality in a database is fundamentally contextual and cannot be addressed as a universal challenge to Water Point Mapping. Neglecting the local context-in other words, neglecting the discretionary nature of water point mapping — rendered the water points "wicked" and their mapping a "wicked problem."

The rationale for neglecting the local context is well established in the literature of development aid, most recently in Rottenburg's parable of development aid [25]. International development cooperation requires an accountable, predictable and conditional transfer of resources from the global North to the South [25] as well as vast amounts of quantitative data in order to provide proof of progress and achievement in the water sector. To resolve the paradox of accountability to the North and project effectiveness in the South, development partners are inclined to transform the wicked problem of improving rural water supply to the more manageable problem of mapping the geographical distribution and attributes of water points. However, wickedness can strike back, as we have seen, no matter how diligently it is avoided. Thus, the representation of water points in the database turned out to be "wicked"-water points were duplicated, obfuscated, disappearing and often useless. As a result, the database construction became an end in itself instead of a means for the future monitoring of all rural water points and rural water supply.

Surveying, mapping and recording the 75,777 rural water points in Tanzania was a formidable task for the consultant. It required employing and training of many data collectors, dealing with changing policies, international politics and local administrative shifts, as well as interacting with a wide range of stakeholders-multiple levels of government, (international) NGOs, donor agencies, data collectors, COWSOs and local water users. Ambiguity, issues of authority and subjectivity, changes over time, procedural changes versus rigidity, and multiple definitions of the same concept (e.g., functionality) all fit the characteristics of wicked, or messy problems, as Horn and Weber [37] prefer to call them.

The question remains as to whether our findings are applicable in other policy domains. For instance, while the health and sanitation sector is similar to the water sector in terms of data collection requirements, the organization of data collection is inherently different. Health and sanitation professionals are required to conduct daily monitoring and reporting. Their data collection skills have been honed over years of continued and constantly improved monitoring protocols and alleviate many of the hurdles shown here for water point mapping. It is precisely for this purpose that the SEMA research project [24] focused on using reporters who are embedded in the local context of rural water supply to do the monthly monitoring of functionality. 
A further parallel may be drawn to efforts like Humanitarian Open Street Map (OSM). Many individuals, some with little training, are tasked to add features to maps available online. These maps are becoming increasingly important in the global South, as they often contain more detailed information than maps of national mapping agencies. However, the types of errors discussed in this paper are usually detected or avoided before the information is published online. OSM data collection undergoes a strict verification of mostly transaction-intensive data. All map entries are verified by the mapping community and follow globally applicable and well-documented guidelines of data entry and verification. Although efforts are under way to agree on a global definition of water point functionality [38], a verification system comparable to OSM is not likely to be available any time soon.

Acknowledgments: This study analysed the Water Point Mapping database, made available online by the Government of Tanzania, as well as interviews with and reports written by national and international consultants involved in the Tanzanian Water Sanitation and Heath sector. Particular thanks go to Mr Singolile Mwamwaja who gave us an eye-witness report of practices of data collection from the Water Point Mapping in Tanzania in his capacity as a water point collector. We also acknowledge the insights into global experiences of water point mapping and the contextual explanations of these experiences provided by the consultants, technicians and academics interacting through the Rural Water Supply Network (RWSN). Research for this paper was part of an integrated research project, titled "Sensors, Empowerment and Accountability in Tanzania (SEMA)" and funded by the Netherlands Organisation for Scientific Research (NWO-WOTRO).

Author Contributions: Jeroen Verplanke analysed the data; Jeroen Verplanke and Yola Georgiadou wrote the paper.

Conflicts of Interest: The authors declare no conflict of interest. 


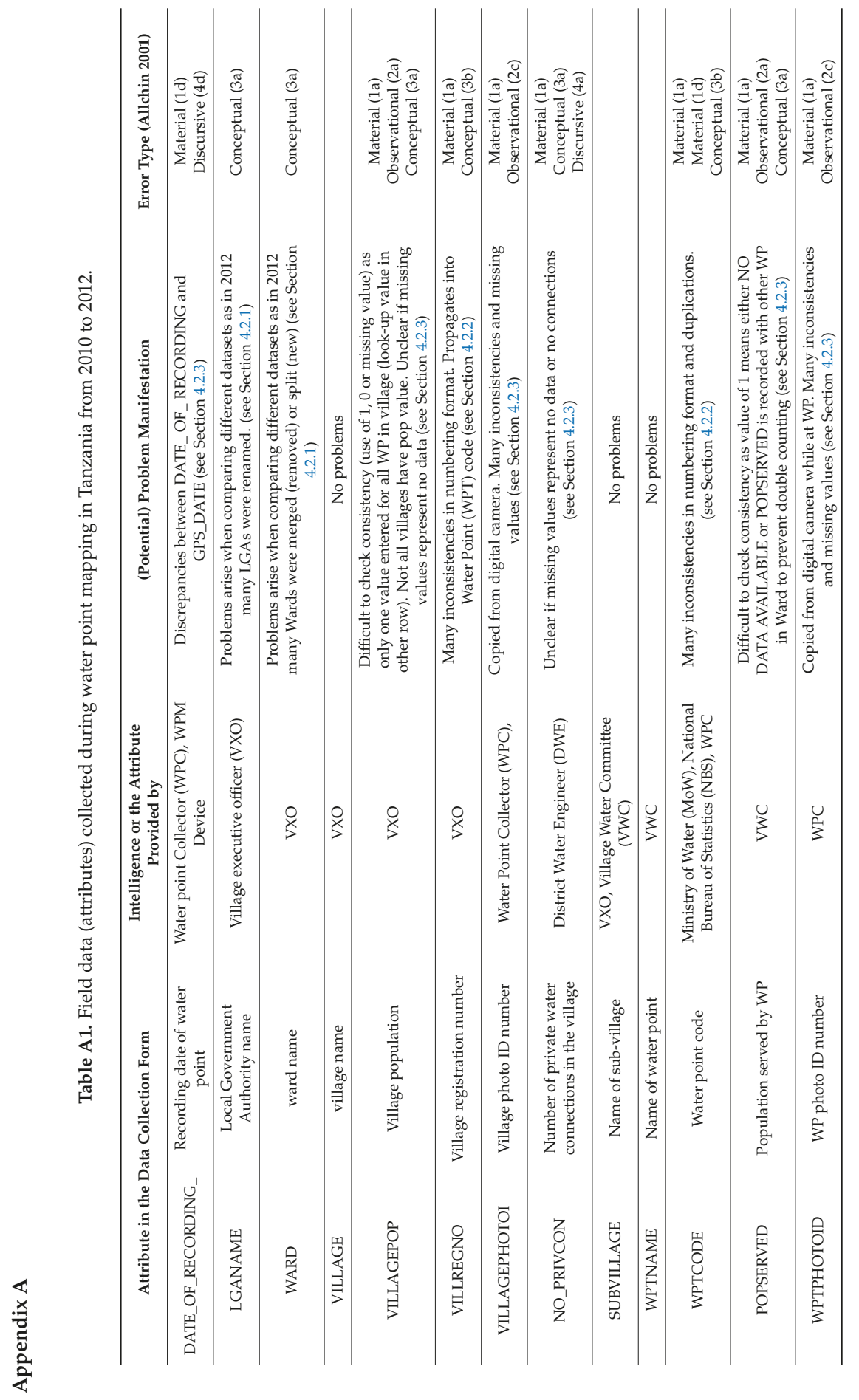




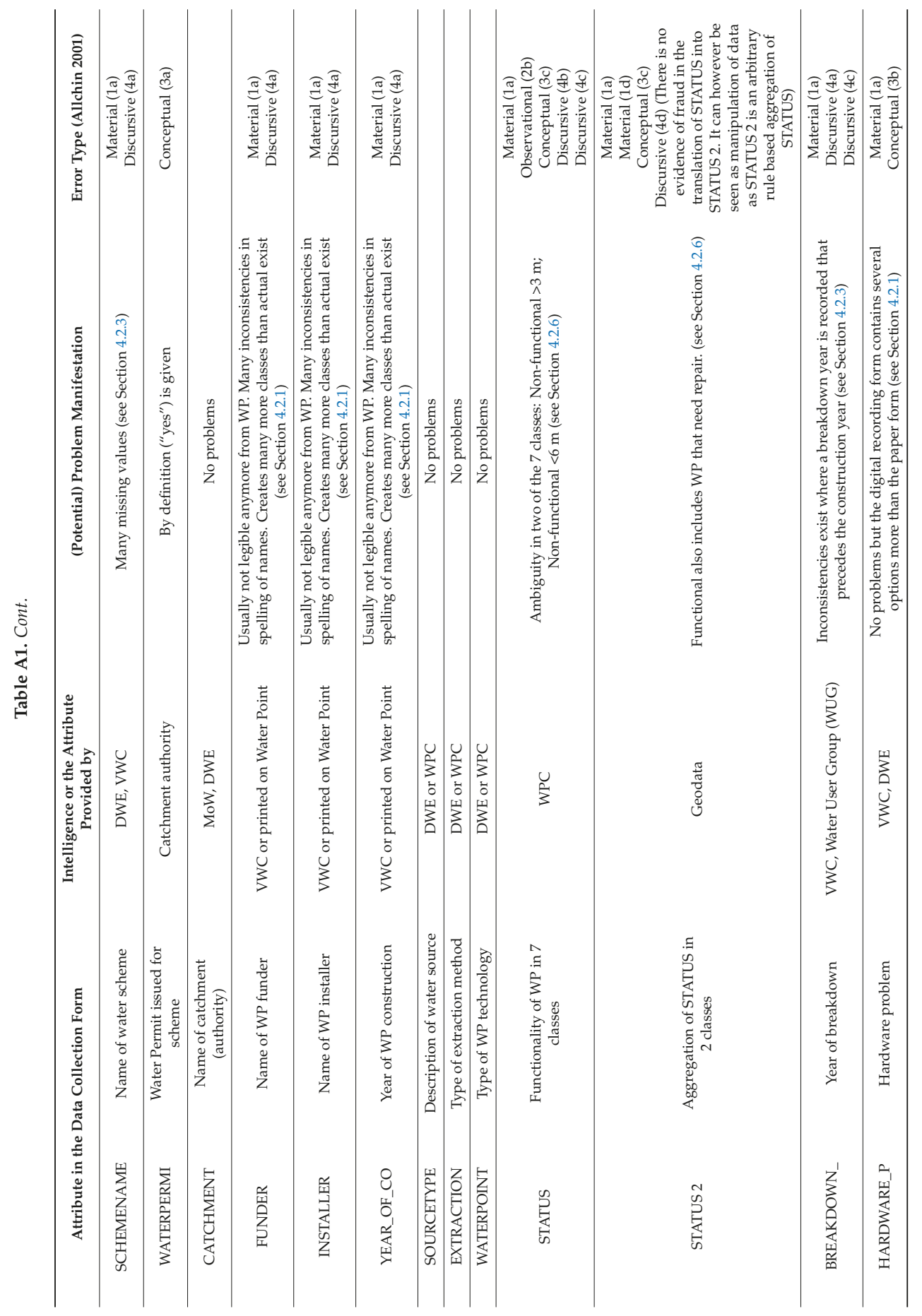




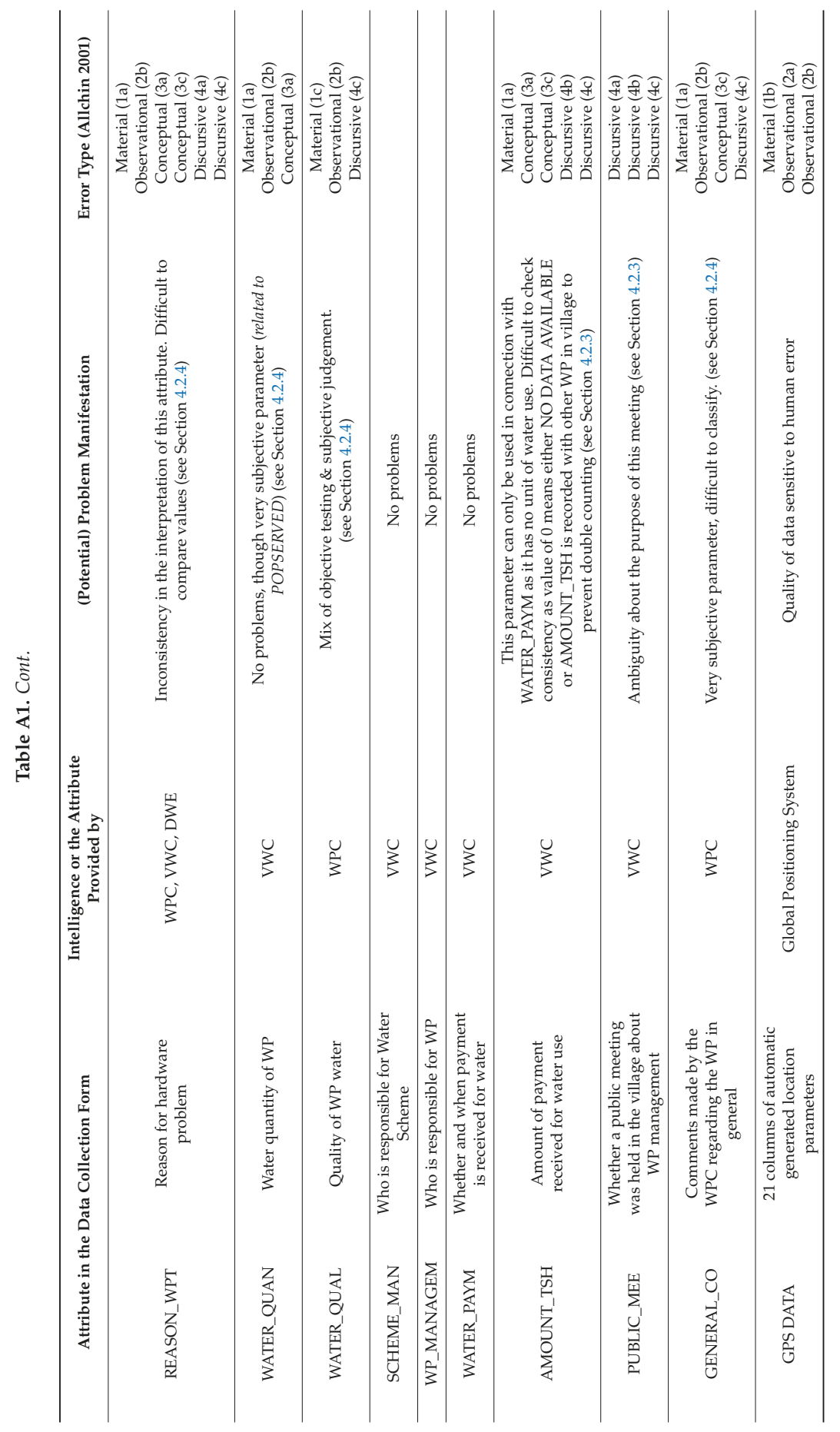




\section{References}

1. Jiménez, A.; Pérez-Foguet, A. Challenges for Water Governance in Rural Water Supply: Lessons Learned from Tanzania. Int. J. Water Resour. Dev. 2010, 26, 235-248. [CrossRef]

2. Christopher Brown, J.; Purcell, M. There's nothing inherent about scale: political ecology, the local trap, and the politics of development in the Brazilian Amazon. Geoforum 2005, 36, 607-624. [CrossRef]

3. Smoke, P.; Lewis, B. Fiscal decentralization in Indonesia: A new approach to an old idea. World Dev. 1996, 24, 1281-1299. [CrossRef]

4. Smith, N. Homeless/global: scaling places. In Mapping the Futures: Local Cultures, Global Change; Bird, J., Ed.; Routledge: New York, NY, USA, 1993.

5. Ministry of Water and Irrigation. The Water Supply and Sanitation Act, No. 12-2009; Ministry of Water and Irrigation: Dar es Salaam, Tanzania, 2009.

6. Giné, R.; Pérez Foguet, A. Sustainability assessment of national rural water supply program in Tanzania. Nat. Resour. Forum 2008, 32, 327-342. [CrossRef]

7. Welle, K. Water Point Mapping in East Africa; WaterAid: London, UK, 2010.

8. Ministry of Water and Livestock Development (MoWLD). Water and Sanitation in Tanzania-Poverty Monitoring for the Sector Using National Surveys; Government of Tanzania: Dodoma, Tanzania, 2002.

9. Welle, K. Strategic Review of WaterAid's Water Point Mapping in East Africa Based on a Review of Ethiopia, Tanzania, Kenya and Uganda; WaterAid: London, UK, 2010.

10. Welle, K. Learning for Advocacy and Good Practice-WaterAid Water Point Mapping, Report of Findings Based on Country Visits to Malawi and Tanzania; WaterAid: London, UK, 2005.

11. United Republic of Tanzania (URT). Water Sector Status Report 2009; URT: Dar es Salaam, Tanzania, 2009.

12. Mwamwaja, S.A. Mapping of Public Rural Water Service in Tanzania: A Case of Data Updating; University of Twente: Enschede, The Netherlands, 2014.

13. Taylor, B. Waterpoint Mapping, Planning and Obstacles to Equity in Rural Water Supply: A Review in Mpwapwa, Kongwa, Iramba and Nzega; WaterAid: Dar es Salaam, Tanzania, 2009.

14. SNV Netherlands Development Oiganization. Water Point Mapping: The Experience of SNV Tanzania; SNV: The Hague, The Netherlands, 2010.

15. United Republic of Tanzania (URT). Water Sector Status Report 2010; URT: Dodoma, Tanzania, 2010.

16. United Republic of Tanzania (URT). National Strategy for Growth and Reduction of Poverty II; Ministry of Finance and Economic Affairs: Dar es Salaam, Tanzania, 2010.

17. United Republic of Tanzania (URT). Water Sector Status Report 2013; URT: Dar es Salaam, Tanzania, 2013.

18. Hutchings, M.T.; Dev, A.; Palaniappan, M.; Srinivasan, V.; Ramanathan, N.; Taylor, J.; Ross, N.; Luu, P. mWASH: Mobile Phone Applications for the Water, Sanitation, and Hygiene Sector; Pacific Institute: Oakland, CA, USA, 2012.

19. United Republic of Tanzania (URT). Water Sector Status Report 2012; URT: Dar es Salaam, Tanzania, 2012.

20. Kunz, W.; Rittel, H.W.J. Information science: On the structure of its problems. Inf. Storage Retr. 1972, 8, 95-98. [CrossRef]

21. Rittel, H.W.J.; Webber, M.M. Dilemmas in a general theory of planning. Policy Sci. 1973, 4, 155-169. [CrossRef]

22. Graham, J.P.; Hirai, M.; Kim, S. An Analysis of Water Collection Labor among Women and Children in 24 Sub-Saharan African Countries. PLoS ONE 2016, 11, 1-14. [CrossRef] [PubMed]

23. Hemson, D. The Toughest of Chores: policy and practice in children collecting water in South Africa. Policy Futures Educ. 2007, 5, 315-326. [CrossRef]

24. Nganyanyuka, K. Seeing Like a Citizen: Access to Water in Urban and Rural Tanzania; University of Twente: Enschede, The Netherlands, 2017.

25. Rottenburg, R. Far-Fetched Facts: A Parable of Development Aid; MIT Press: Cambridge, MA, USA, 2009.

26. Pritchett, L.; Woolcock, M. Solutions when the solution is the problem: Arraying the disarray in development. World Dev. 2004, 32, 191-212. [CrossRef]

27. World Bank. World Development Report 2015: Mind and Society; World Bank: Washington, DC, USA, 2014.

28. Taylor, J.R. An Introduction to Error Analysis: The Study of Uncertainties in Physical Measurements; University Science Books: Herndon, VA, USA, 1997.

29. Narasimhan, S.; Jordache, C. Data Reconciliation and Gross Error Detection; Elsevier: Amsterdam, The Netherlands, 1999. 
30. Florinsky, I.V. Digital Terrain Analysis in Soil Science and Geology; Elsevier: Amsterdam, The Netherlands, 2012.

31. Latifovic, R.; Pouliot, D.; Dillabaugh, C. Identification and correction of systematic error in NOAA AVHRR long-term satellite data record. Remote Sens. Environ. 2012, 127, 84-97. [CrossRef]

32. Lintz, H.E.; Gray, A.N.; McCune, B. Effect of inventory method on niche models: Random versus systematic error. Ecol. Inform. 2013, 18, 20-34. [CrossRef]

33. Allchin, D. Error types. Perspect. Sci. 2001, 9, 1-16. [CrossRef]

34. National Bureau of Statistics (NBS). 2012 Population and Housing Census; NBS: Dar es Salaam, Tanzania, 2013.

35. United Republic of Tanzania (URT). Big Results Now Brings Clean Water Supply to 752,000 Villagers in Three Months; URT: Dar es Salaam, Tanzania, 2013.

36. Giné-Garriga, R.; Jiménez-Fernández de Palencia, A.; Pérez-Foguet, A. Water-sanitation-hygiene mapping: An improved approach for data collection at local level. Sci. Total Environ. 2013, 463-464, 700-711. [CrossRef] [PubMed]

37. Horn, R.E.; Weber, R.P. New Tools for Resolving Wicked Problems: Mess Mapping and Resolution Mapping Processes. Available online: http://www.strategykinetics.com/New_Tools_For_Resolving_Wicked_ Problems.pdf (accessed on 3 August 2017).

38. Global Water Challenge. Available online: www.globalwaterchallenge.org (accessed on 4 August 2017).

(C) 2017 by the authors. Licensee MDPI, Basel, Switzerland. This article is an open access article distributed under the terms and conditions of the Creative Commons Attribution (CC BY) license (http:/ / creativecommons.org/licenses/by/4.0/). 
Article

\title{
What do New Yorkers Think about Impacts and Adaptation to Heat Waves? An Evaluation Tool to Incorporate Perception of Low-Income Groups into Heat Wave Adaptation Scenarios in New York City
}

\author{
Sadra Matmir*, Diana Reckien and Johannes Flacke \\ Department of Urban and Regional Planning and Geo-information Management, ITC Faculty, University of \\ Twente, 7500 AE Enschede, The Netherlands; d.reckien@utwente.nl (D.R.); j.flacke@utwente.nl (J.F.) \\ * Correspondence: smatmir@gmail.com; Tel.: +31-(0)626-155-771
}

Academic Editors: Yola Georgiadou, Diana Reckien, Jason K. Levy and Wolfgang Kainz Received: 31 May 2017; Accepted: 10 July 2017; Published: 25 July 2017

\begin{abstract}
Low-income residents are among the most vulnerable groups to climate change in urban areas, particularly regarding heat stress. However, their perceptions about heat and the impacts they face go often undocumented, and are seldom considered in decision-making processes delivering adaptation. This paper presents a robust tool to allow the integration of perception, concerns and impacts of different income groups in urban adaptation planning and governance, using the City of New York as a case study. Employing online interviews-a solid method to reach poorer households-and Fuzzy Cognitive Mapping, we compare impacts and adaptation perception to heat and simulate adaptation scenarios. Results reveal that lower income groups are more concerned about impacts of heat waves than middle- and high-income populations. All income groups see citizens more in charge of adaptation, although more people from the lower income groups regard it necessary to do much more to protect themselves, proportionately more people from the higher income groups think they are doing the right amount. The scenario analysis shows that, compared to investments in the water/electricity and health system, improvements in the transit system would yield the largest decrease in negative impacts during heat, benefitting all income groups jointly.
\end{abstract}

Keywords: climate change; climate governance; vulnerability; heat wave; FCM (Fuzzy Cognitive Mapping); New York City; income groups

\section{Introduction}

Climate change increases the stress on urban areas through increasing the number of extreme events and hazards such as heat waves, inland floods, and storm surges which are affecting inhabitant's lives and property, essential infrastructure and ecosystems [1]. Among these hazards, heat waves are the most deadliest, as in many countries they cause more fatalities than floods and hurricanes combined [2,3].

Globally there is strong evidence that heat waves will increase in duration and frequency over most land areas [4]. Impacts of heat waves on human and natural systems include direct effects caused by the direct exposure to higher temperatures and indirect effects, such as those on urban sectors such as water, energy, transportation and telecommunication [5]. Such indirect impacts may include a reduction of drinking water supply, increasing energy demand as well as heat-related mortality (death) and morbidity (illness) [6]. Furthermore, psychological health problems can occur and cause increasing violence and crime during heat events [7].

Heat wave impacts are stratified across the population, with certain socio-demographic groups being stronger affected than others. These vulnerable groups include infants, elderly, people with 
disabilities and health problems $[2,6,8-10]$ and poor people and low-income groups. Low-income groups are among the most vulnerable to heat events due to their limitation to meet energy costs, their dependency on public facilities and problems in access to proper health care services [6]. Moreover, vulnerable and low-income populations may be concentrated in areas with increased exposure to risk. For instance, compared to higher-income populations, low-income communities tend to live in lower-standard or older buildings without the capacity to regulate temperature and humidity $[8,11]$.

Whereas the relation between heat vulnerability and socio-demographic factors, such as age, race, gender, and poverty, is well examined [12-16], the role of economic factors such as different income levels (not only considering the poor and low-income, but also middle- and high-income people) is under-researched. Being a prominent vulnerability factor, income may play an important role in how citizens experience heat waves. It is the aim of this research to close this research gap, and compare the impacts and adaptation perceptions of different income groups in New York City. This information is then used to deduce socially sensible adaptation options, evaluating the effect of different adaptation scenarios on income groups.

The vulnerability concept is useful to understand and evaluate impacts and adaptation of climate change on human and environment system [6]. According to the IPCC Fifth Assessment Report (AR5), vulnerability is generally defined as "The propensity or predisposition to be adversely affected. Vulnerability encompasses a variety of concepts and elements including sensitivity or susceptibility to harm and lack of capacity to cope and adapt" [17] (p. 5). Vulnerability is also generally seen from two perspectives [17], described as:

\section{- $\quad$ Contextual vulnerability (starting-point vulnerability)}

- $\quad$ Outcome vulnerability (end-point vulnerability)

Contextual vulnerability assumes that certain socio-economic groups in society are more vulnerable than others even before an event happens. According to that understanding, groups such as the elderly, children, women, the poor and people with health issues belong to the most vulnerable, due to their existing circumstances making them more vulnerable than others. Outcome vulnerability assumes people only becoming vulnerable after a hazard occurred [18]. This can affect different groups in society and is not necessarily confined to the groups mentioned. Focusing on differences across income groups this research is based on the contextual vulnerability (starting-point vulnerability) concept, which is defined as: "A present inability to cope with external pressures or changes, such as changing climate conditions. The contextual vulnerability is a characteristic of social and ecological systems generated by multiple factors and processes" [19] (p. 1762).

For example, Rosenthal et al. [15] evaluated the socio-economic and build environment characteristics of places with high heat-related mortality in New York City. According to their results, there is a significant positive association between heat-related mortality and neighborhood characteristics, comprising less access to air conditioning (A/C), poor housing conditions, and poverty status. Energy costs associated with the use of air conditioning are also one of the major concern for low-income families during heat events. Low-income households who have access to A/C, do not use it due to the concerns about energy costs [20].

Air conditioning is one of the major and most frequent adaptation strategies to the impacts of heat waves in North American cities. However, to improve the effectiveness of air conditioning as an adaptive measure it is important to ensure access to functional air conditioners and sufficient energy for vulnerable groups [21]. Lemmen and Warren [21] suggest monetary support of low-income populations and programs for peak load and or voltage reduction. However, important to note, as long as traditional, non-renewable sources of energy are used to run A/Cs it is not a sufficient nor a sustainable solution, but has to be regarded as mal-adaptation instead [22] —as it may increase the vulnerability of natural and human systems over the long term. Nonetheless, the subsidization of air conditioning for low-income urban residents may entail new financial outlays and be offset by health-related cost savings due to the reductions in heat-related morbidity and mortality [6]. 
Adaptation in the context of climate change is defined as "Initiatives and measures to reduce the vulnerability of natural and human systems against actual or expected climate change effects" [12] (p. 69). Adaptation practices can take place at a different level from individual and household level to the community and institutional level. According to Jian Zuo et al. "The common mechanisms to deal with heat waves and the associated consequences include: structural/institutional, technological and cultural/behavioral" [10]. However, as Bolitho and Miller [23] argue, responses to extreme heat reflect a tension between a risk management paradigm (heat as an emergency) and a social vulnerability perspective (heat as chronic stress), whereas adaptation policy and planning that appreciates the interconnections between the two perspectives would likely reduce vulnerability and contribute to more urban sustainability [23]. Table 1 summarizes their views.

Table 1. Heat wave adaptation measures with respect to risk management and vulnerability approaches. Source: [23] (p. 13).

\begin{tabular}{ll}
\hline Approaches & \multicolumn{1}{c}{ Heat Wave Adaptation Measures } \\
\hline \multirow{2}{*}{$\begin{array}{l}\text { Risk } \\
\text { management } \\
\text { approaches }\end{array}$} & $\begin{array}{l}\text { Identification and mapping of at-risk groups } \\
\text { Cromotion of behavioral modification } \\
\text { Education and awareness programs on minimizing harm from heat } \\
\text { Coordinated responses within and between agencies for preparedness planning and emergency response }\end{array}$ \\
\hline & $\begin{array}{l}\text { Direct engagement with vulnerable people through support of social networks and partnerships } \\
\text { Improve housing quality, for example, retrofitting }\end{array}$ \\
Vulnerability & $\begin{array}{l}\text { Improve access to healthcare and social services } \\
\text { Improve access to cool public and private spaces, for example, air-conditioning concessions }\end{array}$ \\
& $\begin{array}{l}\text { Integrate thermal considerations, shading, and vegetation into urban design and planning } \\
\text { Address access and mobility considerations, for example, shade at bus stops } \\
\text { Coordinated responses within and between agencies in planning and emergency and long-term responses }\end{array}$ \\
\hline
\end{tabular}

In addition to these measures, infrastructure investments, particularly in vulnerable urban areas, urban greening programs such as green roofs, and building codes requiring reflective exterior surfaces are among the most effective and sustainable adaptation options, and should-according to the First Assessment Report of the Urban Climate Change Research Network (UCCRN)—therefore be strongly considered [1].

However, adaptation cannot be delivered by a top-down process, particularly in vulnerable urban communities, where residents' views to impacts and adaptation needs and perceptions go often unheard and unrecognized [14]. Much in contrast the perception and views of vulnerable populations have to be integrated and made a vital part of adaptation planning, as citizens' act on their beliefs and perceptions [24], which is vitally important for the success of adaptation on all levels-individual to community. To this end, it is also important to scientifically assess the residents' views, making them part of urban research and community science for sustainable adaptation.

Innovative governance forms can help integrating vulnerable populations in research as well as the urban adaptation decision-making processes. The Organization for Economic Cooperation and Development (OECD) defines governance as "the formal and informal arrangements that determine how public decisions are made and how public actions are carried out, from the perspective of maintaining a country's constitutional values in the face of changing problems" [25] cited in [26] (p. 5). Accordingly, climate change governance includes a broad spectrum of navigating mechanisms, which may include the collaboration of different actors and institutions according to hierarchical forms of principles and regulation [27]. Thereby, urban climate governance describes the ways in which private, public, and civil society actors articulate climate goals, exercise influence and authority, and organize urban climate planning and the process of implementation [28]. More precisely, as Chanza and De wit [29] argue, decentralization, autonomy, accountability, transparency, responsiveness, flexibility, participation and inclusion are basic elements of climate change governance. 
Reviewing the state of the art on climate change governance, it is realized that the majority of studies focus primarily on mitigation and mitigation planning, set by the international and national levels of government. The more local dimension of adaptation and adaptation planning is not yet covered comprehensively $[28,30,31]$.

We aim to assess the social sensibility and effectiveness of adaptation options by evaluating the potential consequences of adaptation scenarios on the reduction of detrimental impacts mentioned by the respondents. Respondents are distinguished by four groups: poverty, low-income, middle-income and high-income. To assess the consequences of adaptation scenarios across income groups, we use Fuzzy Cognitive Mapping (FCM) [32-35]. The importance of mental models and cognitive maps in identifying and evaluating the key elements of climate change impacts has been highlighted in adaptation research [32-34,36,37]. Cognitive maps are a representation of external reality by using individual's perceptions, experiences, and knowledge structured by the respondents' reasoning. Capturing groups or individual's cognitive maps regarding climate change impacts clearly illustrates how individuals understand climate problems [36], which can be used to develop adaptation strategies. FCM is able to deduce socially sensible adaptation options by way of manipulations of the network denoting if-then-connotations, e.g., by way of adding elements—exemplifying new policies, cutting relations or lowering their link weight—exemplifying ceased or lowered influence, or by changing concept weight-exemplifying reduced importance of an element.

It should be highlighted that, by using perception data (not focusing on scientific facts) and by using online questionnaires to collect those, "hard to reach" populations such as people in poverty and low income groups are included as active stockholders in the research on adaptation planning. By that, we also hope to give these groups a voice in the climate change adaptation and planning process.

The main objective of this research is to develop an evaluation tool to simulate heat wave adaptation according to different income group's perceptions especially hard to reach population such as in poverty group and low-income citizens. The research is structured along the following research questions in order to reach the main objective.

- What are the main differences across income groups in regards to their concerns about future impacts of heat waves?

- What are the main differences across income groups in regards to their opinion about citizens' responsibility in heat wave adaptation and urban sector(s) most in need of adaptation actions during future heat waves in NYC?

- What are the main differences between different income groups' cognitive maps in regards to impacts of heat waves in NYC?

- How do prominent adaptation options affect different income groups in NYC, i.e., lower the impacts of heat waves for each group?

\section{Materials and Methods}

This research focuses on New York City (NYC), for which heat events are projected to approximately triple in frequency by the end of the century [12,38]. Nevertheless, municipal climate change plans in NYC, such as PlaNYC (PlaNYC is a plan released first by New York City Mayor Michael Bloomberg in 2007 to prepare the city for one million more residents, strengthen the economy, combat climate change, and enhance the quality of life for all), focus more on the impacts of floods and coastal storms, as compared with the impacts of heat waves. Furthermore, New York City is one of the socially most unequal cities in the world and the third most unequal city in the U.S. regarding economic issues [39]. There is a huge difference between different income groups in New York City and economic characteristics of citizens seem to play an important role in how New York citizens experience impacts of heat waves, e.g., by changing the way residents' can access adaptation options. 


\subsection{Data}

The main data used in this research are the output of an online questionnaire conducted in November/December 2013 in New York City (the online interview was part of a research project sponsored by the Center for Research on Environmental Decisions (CRED), Columbia University under the direction of Dr. Diana Reckien (more info in: http://cred.columbia.edu/research/allprojects/socially-different-climate-change-impacts-and-adaptation-options-in-nyc/)). The interview includes individuals who are 18 years of age or older, living in the five boroughs. The interviews were conducted by using the professional survey provider Qualtrics and their survey software. More than 1200 attempts (complete and incomplete questionnaires) were initially registered. The final number of valid, fully completed questionnaires comprises 762 after rigorous automated and manual quality control, which should reduce concerns about the quality of the online questionnaire data to a minimum. The questionnaire lasted for approximately $30 \mathrm{~min}$. Respondents were compensated with 4 US\$ per completed questionnaire Automated quality control included IP address check, captcha code, attention questions, and valid ZIP code check, and completeness. Manual quality control comprised checking the understanding, truthfulness and reliability of the responses.

The distribution of dataset records across boroughs and NYC zip/postal codes is presented in Figure 1. The dataset includes participants from all over New York City; there are only few zip-codes without any participant. The dataset includes seven main dimensions, and each dimension includes different variables, which is presented in Figure 2.

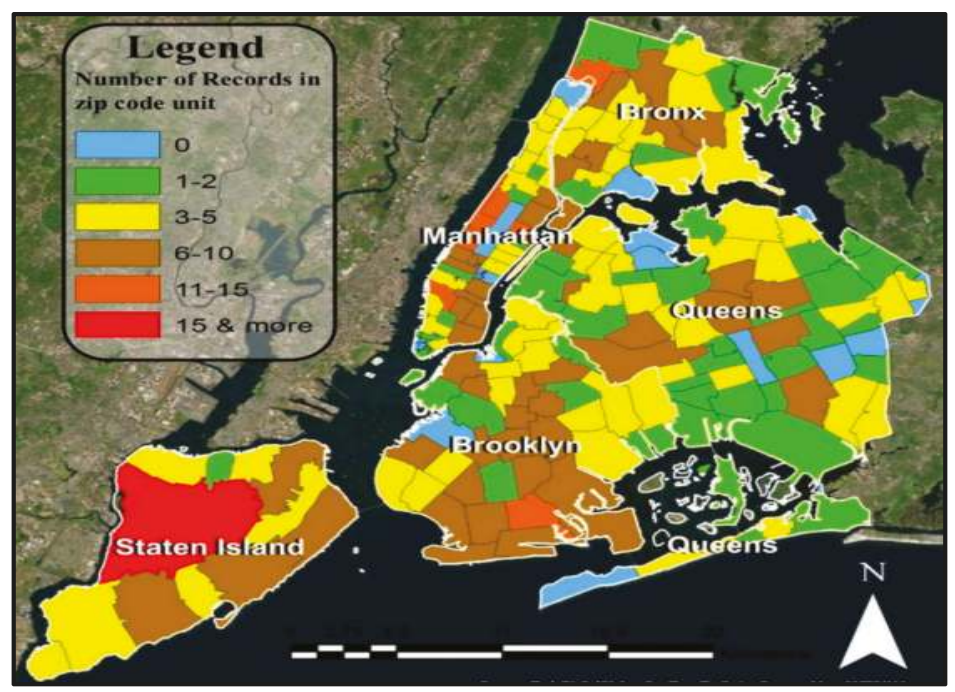

Figure 1. The distribution of dataset records across New York City on zip/postal code level. 


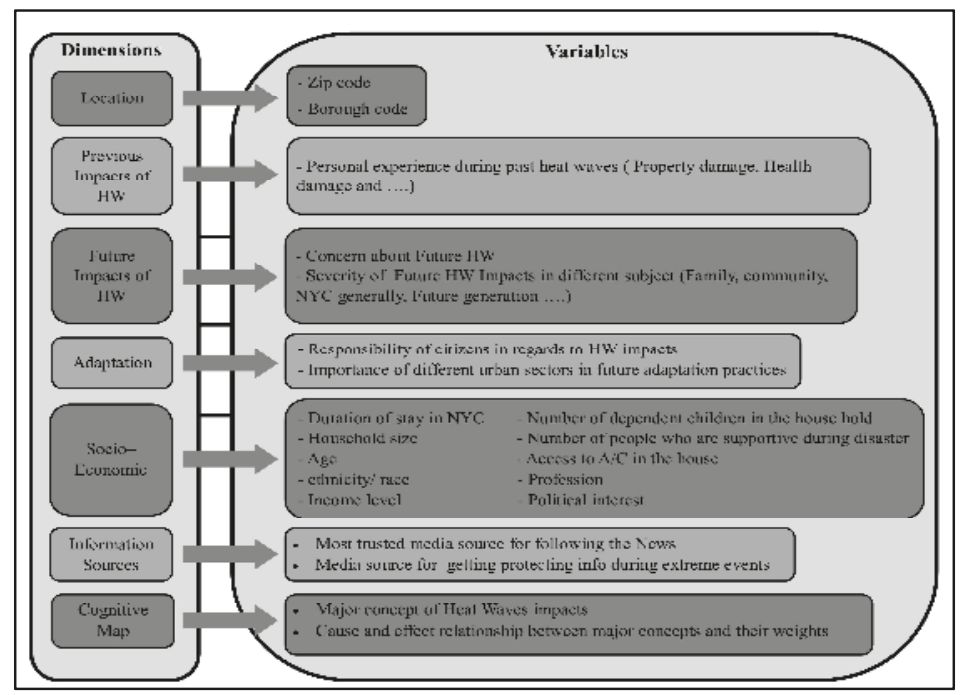

Figure 2. Structure of the dataset.

\subsection{Methods}

An overview of the applied research methodology is presented in Figure 3. To identify differences across income, the research defines four income groups:

- $\quad$ People living in poverty

- Low-income group

- Middle-income group

- $\quad$ High-income group

The group of people living in poverty is defined based on suggested poverty thresholds by DeNavas-Walt and Proctor [40], using household income and household size variables available in the dataset. To define the other three groups, at least the threshold for the middle-income group had to be defined. It is important to consider that "there is no official government definition of who belongs to the middle class. The middle class may refer to a group with a common point of view or to those having similar incomes" [41] (p. 4). Accordingly, there are different methods to define the middle class. In this study, we used the method introduced in the Congressional Research Service report [41] and formulated by the Pew Research Center. Similar to Kiersz and Kane [42] using the Pew Research Center method and applying it to data of median income from the US Census Bureau's American Community Survey 2013, we define the thresholds for middle-income groups in New York City based on our dataset.

Data analysis is split in two main parts. The first part is a statistical analysis to find significant differences across the four defined income groups with regard to future impacts of heat waves and related adaptation issues in New York City. We use non-parametric statistics, i.e., the Kruskal-Wallis $\mathrm{H}$-Test, as the dataset mainly consists of nominal and ordinal variables [43,44]. To identify the particular differences between sample pairs, the Mann-Whitney U-test was selected.

The second section focuses on the FCM analysis. FCM is a semi-quantitative analysis method that is based on casual reasoning. The FCM method translates stakeholder knowledge, experience or perception to a network consisting of nodes as main concepts and weighted connections representing their causal relations in a system. By using this method, the cause-effect relationships between main concepts of a system can be quantified and simulated-important for adaptation decision making [32]. Olazabal and Reckien [32] provided a step by step guide to do so. 


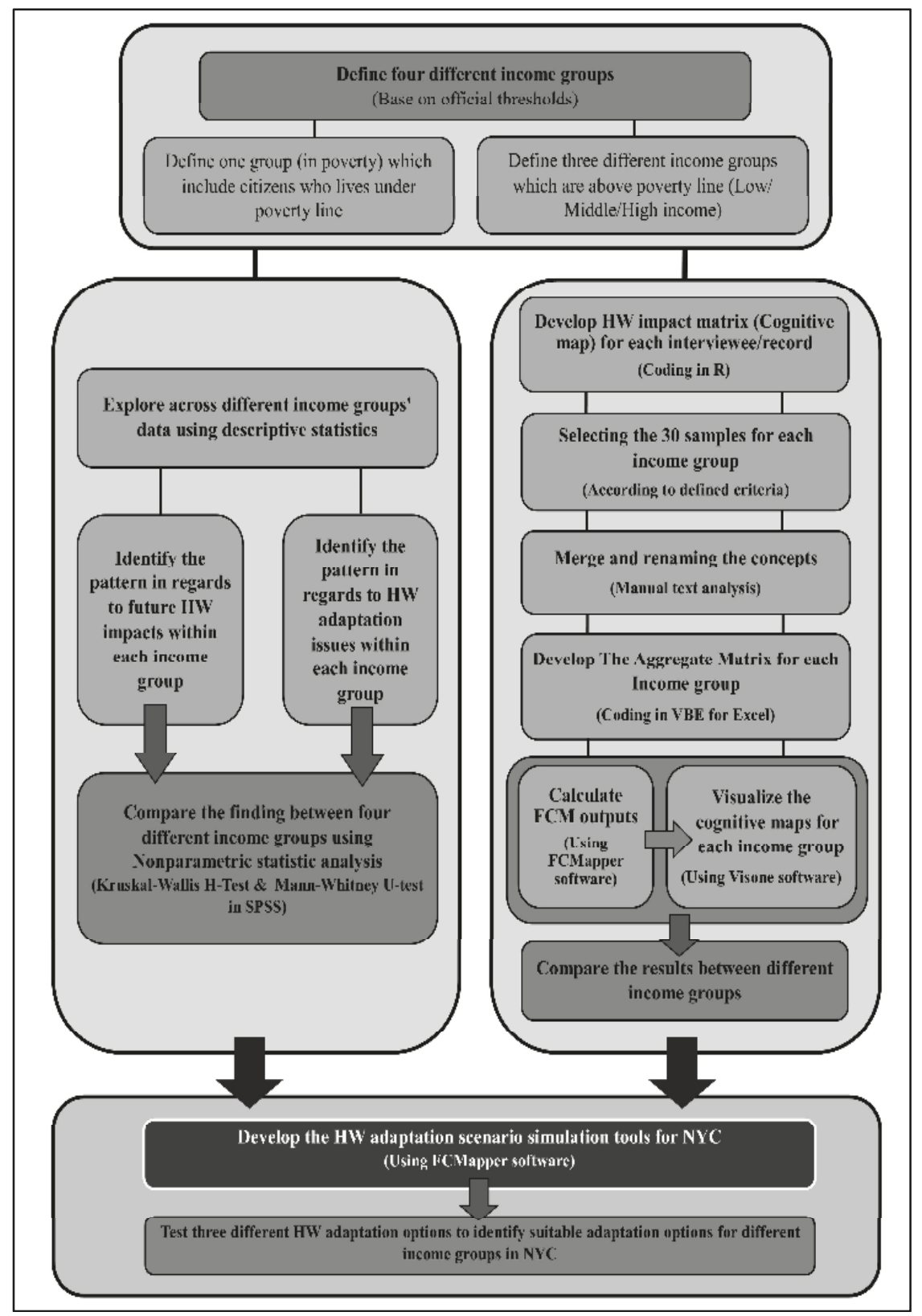

Figure 3. Flowchart of research methodology.

The FCM analysis starts with a transformation of the FCM data of each interviewee (record), i.e., impact networks of heat waves, into impact matrices using R programing language. As a next step, the sample for the FCM analysis is selected based on the socio-demographic characteristics of interviewees (records). In order to achieve a sufficient level of validity and reliability of the results 
accumulation curves are used, such as those suggested by Özesmi and Özesmi (2004). This resulted in samples of 30 records for each income group. The main criteria for selecting the sample are given below (from highest to lowest priority):

1. Highest number of stated concepts (minimum 4 concepts must be stated)

2. Equal distribution in different boroughs (according to database availability)

3. Equal composition in age groups (according to database availability)

4. Equal composition of gender (according to database availability)

In the next step, the FCM matrix of each interview analyzed was coded into one united format using manual text analysis. After that, the 30 individual cognitive maps in each income group were aggregated to one social cognitive map for each income group. Then, the social maps were visualized using Visone, analyzed by way of network statistics and structure analysis and simulated using FCMappers software (open access software accessible in www.FCMAPPERS.net).

FCM scenario simulation analysis focuses on the effect that each concept has on the other concepts in the network over a number of iterations or time steps (k) (normally 20-30 iterations) [45]. "Scenario generation has been recognized as one of the most valuable applications of FCM in general and in environmental management in particular" [45,46] cited in [32] (p. 158). To test the developed tools, three different scenarios are simulated and tested for each income groups:

1. Investment in and development of the NYC public health sector

2. Investment in and development of the NYC water and electricity system

3. Investment in and development of the NYC transit sector

To conduct the scenario analysis, the concepts in the network belonging to each scenario ( 1 , concepts regarding health; 2 , concepts regarding water and electricity; and 3, concepts regarding public transportation) are fixed to one value throughout all iterations of the matrix multiplication. That means that after an initial value of 1 for all concepts, fixed concepts remain at 1, i.e., denoting steady increase, or are put to lower values or 0 for a particularly low or no influence. The change and effect on non-fixed concepts in the network is then compared to the matrix multiplication without an intervention (usually until a steady state is reached) [32].

The selected fixed value for concepts in scenario simulation must be between 0 to 1 (Olazabal and Reckien, 2015). The concepts with regard to health issues is mainly set to 0.1 , which means the effect of that concept would be reduced to a minimum but still affect the system. For the other scenarios, i.e., the water and electricity scenario and transit sector scenario, the related concepts are mainly put to 0 , which means that the effect of those concepts is completely removed. It should be considered that all these numbers are relative. For instance, a value of 0.9 compared to 0.1 does not mean that the effect of the first value is 9 times bigger than the smaller one-it is just "much stronger" or "a lot larger". Detailed information to the selected values for each scenario is presented in the Appendix A.

\section{Results}

\subsection{Perceived Extent of Climate Change Impacts in the Future}

Figure 4 shows the residents' worry about heat waves in the future, i.e., the next 20 years. According to our results, more people living in poverty and of low income than residents of middle and high income are very worried about future impacts of heat waves-the highest category. In contrast, more middle- and high-income residents are (only) somewhat worried.

To gain a better understanding about the nature of concern regarding future impacts of heat waves the extent of perceived future impacts are evaluated. The question is "How much do you think the impacts of future heat waves will harm: you personally, your family, your community/ neighborhood, your borough, NYC in general, future generation, plant and animal, public property, people's private property?" 


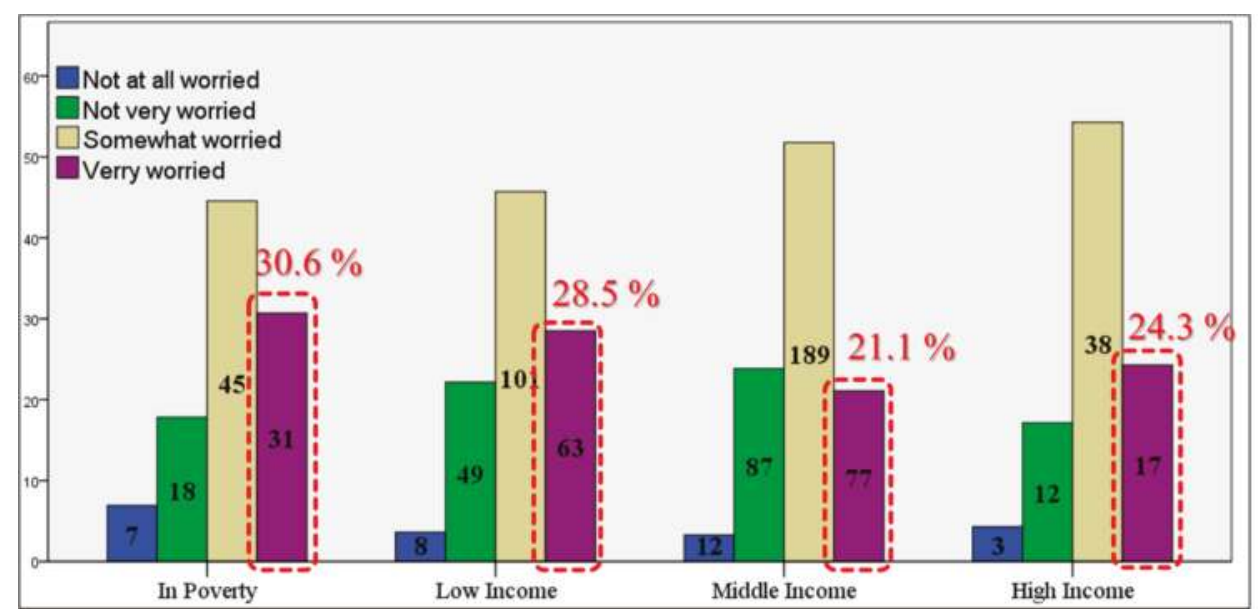

Figure 4. Concern about future impacts of heat waves across income level. The heights of the bars represent percentages, whereas numbers inside the bars represent number of respondents.

Respondents expressed their views on a scale of: very severe, somewhat severe, not very severe, and not at all severe. Table 2 shows the results, with significant differences marked in red. The perception of income groups differ with regard to five aspects, i.e., future impacts on:

- Personal life

- Family

- New York City in general

- Future generation

Table 2. Results of Kruskal-Wallis H-Test regarding the sector of future impacts of heat waves. The underlined text shows aspects for which significant differences between income groups exist, i.e., the $p$-value is lower than 0.05 .

\begin{tabular}{lcc}
\hline Subject & Chi-Square & Asymp. Sig. \\
\hline Personal life & $\underline{12.661}$ & $\underline{0.005}$ \\
Family & $\underline{10.283}$ & $\underline{0.016}$ \\
Community/neighborhood & 5.033 & 0.169 \\
Borough & $\underline{16.184}$ & $\underline{0.001}$ \\
NYC in general & $\underline{\underline{16.724}}$ & $\underline{0.001}$ \\
Future generations & $\underline{16.782}$ & $\underline{0.001}$ \\
Plant and animal species & 1.584 & 0.663 \\
Public property (e.g., roads, schools, public buildings) & 5.082 & 0.166 \\
\hline People's private property (e.g., homes, cars, boats) & &
\end{tabular}

The Mann-Whitney U-test reveals which groups differ with respect to the five aspects mentioned (Table 3). There are no significant differences between the middle-income group and the high-income group. All significant differences identified are found between the lower income groups (in poverty and low income group) and the higher income groups (middle income and high income group). People living in poverty and of low income perceive future impacts on their personal life, their family, NYC in general, future generations and plant and animal species a lot more as "very severe" and "severe", as compared with the middle and high income groups. In contrast, middle- and high-income residents perceive future impacts more often as being "not very severe" (see Appendix B). 
Table 3. Results of Mann-Whitney U-test regarding perceived extent of future impacts of heat waves. The underlined text shows the location of significant differences between income groups with $p$-values less than 0.05 .

\begin{tabular}{|c|c|c|c|c|c|}
\hline Subject & $\begin{array}{r}\text { Location of Significan } \\
\text { Income }\end{array}$ & $\begin{array}{l}\text { ifferences (between } \\
\text { oups) }\end{array}$ & $\begin{array}{c}\text { Mann- } \\
\text { Whitney-U }\end{array}$ & Z-Score & $\begin{array}{l}\text { Asymp. } \\
\text { Sig. }\end{array}$ \\
\hline \multirow{6}{*}{ Personal life } & \multirow{3}{*}{ In poverty } & Low Income Group & 9981.000 & -0.130 & 0.896 \\
\hline & & Middle Income Group & $14,616.500$ & -2.154 & $\underline{0.031}$ \\
\hline & & High Income Group & $\overline{2751.500}$ & $\overline{-1.862}$ & $\overline{0.063}$ \\
\hline & \multirow{2}{*}{ Low Incomeguifen 1} & Middle Income Group & $32,334.000$ & -3.019 & $\underline{0.003}$ \\
\hline & & $\frac{1}{\text { High Income Group }}$ & 6085.000 & -2.214 & 0.027 \\
\hline & Middle Income Group & High Income Group & $\overline{12,034.500}$ & $\overline{-0.282}$ & $\overline{0.778}$ \\
\hline \multirow{6}{*}{ Family } & \multirow{3}{*}{ In poverty } & Low Income Group & 9150.000 & -0.376 & 0.707 \\
\hline & & Middle Income Group & $14,061.500$ & -2.104 & $\underline{0.035}$ \\
\hline & & High Income Group & $\overline{2348.500}$ & $\overline{-2.380}$ & $\overline{0.017}$ \\
\hline & \multirow{2}{*}{ Low Income } & Middle Income Group & $31,587.000$ & -2.154 & 0.031 \\
\hline & & High Income Group & 5313.000 & $\overline{-2.265}$ & $\overline{0.023}$ \\
\hline & Middle Income Group & High Income Group & $10,291.000$ & -1.067 & 0.286 \\
\hline \multirow{6}{*}{$\begin{array}{l}\text { New York City } \\
\text { in general }\end{array}$} & \multirow{3}{*}{ In poverty } & Low Income Group & 9621.000 & -0.007 & 0.995 \\
\hline & & Middle Income Group & $13,882.000$ & -2.612 & $\underline{0.009}$ \\
\hline & & High Income Group & 2490.000 & $\overline{-2.500}$ & $\overline{0.012}$ \\
\hline & \multirow{2}{*}{ Low Income } & Middle Income Group & $\overline{31,329.500}$ & $\overline{-3.175}$ & $\overline{0.001}$ \\
\hline & & High Income Group & $\overline{5667.0008}$ & -2.555 & $\overline{0.011}$ \\
\hline & Middle Income Group & High Income Group & $11,523.500$ & $\overline{-0.689}$ & $\overline{0.491}$ \\
\hline \multirow{6}{*}{$\begin{array}{l}\text { Future } \\
\text { generation }\end{array}$} & \multirow{3}{*}{ In poverty } & Low Income Group & 7672.500 & -0.260 & 0.795 \\
\hline & & Middle Income Group & $11,739.500$ & -2.502 & $\underline{0.012}$ \\
\hline & & High Income Group & $\overline{1906.500}$ & $\overline{-2.924}$ & $\overline{0.003}$ \\
\hline & \multirow{2}{*}{ Low Income } & Middle Income Group & $28,845.500$ & $\overline{-2.898}$ & $\overline{\underline{0.004}}$ \\
\hline & & High Income Group & $\underline{4730.5}$ & -2.995 & $\underline{0.003}$ \\
\hline & Middle Income Group & High Income Group & $\overline{10,084.0}$ & $\overline{-1.284}$ & $\overline{0.199}$ \\
\hline \multirow{6}{*}{$\begin{array}{c}\text { Plant and } \\
\text { animal species }\end{array}$} & \multirow{3}{*}{ In poverty } & Low Income Group & 8328.5 & -2.076 & 0.038 \\
\hline & & Middle Income Group & $\overline{12,830.5}$ & $\overline{-3.782}$ & $\overline{0.000}$ \\
\hline & & High Income Group & 2445.0 & -2.803 & 0.005 \\
\hline & \multirow{2}{*}{ Low Income } & Middle Income Group & $32,844.0$ & $\overline{-2.178}$ & $\underline{0.029}$ \\
\hline & & High Income Group & $\overline{6238.5}$ & $\overline{-1.402}$ & $\overline{0.161}$ \\
\hline & Middle Income Group & High Income Group & $12,071.0$ & -0.077 & 0.938 \\
\hline
\end{tabular}

\subsection{Perceived Responsibility of Citizens' Regarding Heat Wave Adaptation}

In NYC, air conditioning represents the major personal adaptation means to address heat in home during heat waves. However, as noted above many residents living in poverty or of low incomes might not be able to support air conditioning, because either investment costs or running costs are too high. Figure 5 shows the distribution of air conditioning across our sample, broken down by income groups. As one can see, most people have $\mathrm{A} / \mathrm{C}$ in their house or apartment, particularly in the middle and high income groups. However, almost $20 \%$ of the respondents living in poverty or of low income have no A/C. The prevalence of A/C might influence the perception and views on citizen's responsibility regarding adaptation to heat waves, which is shown below.

The question was "Do you think citizens themselves should be doing more or less to protect themselves from the impacts of heat waves?"

According to the results presented in Figure 6, the majority of citizens in each income group (more than $68 \%$ counting "more" or "much more") state that citizens should be doing more or much more to prevent themselves from the impacts of heat waves in the future. However, proportionately more people from the higher incomes groups think they are doing the right amount, whereas proportionately more from the lower income groups regard it necessary to do much more to protect themselves. 


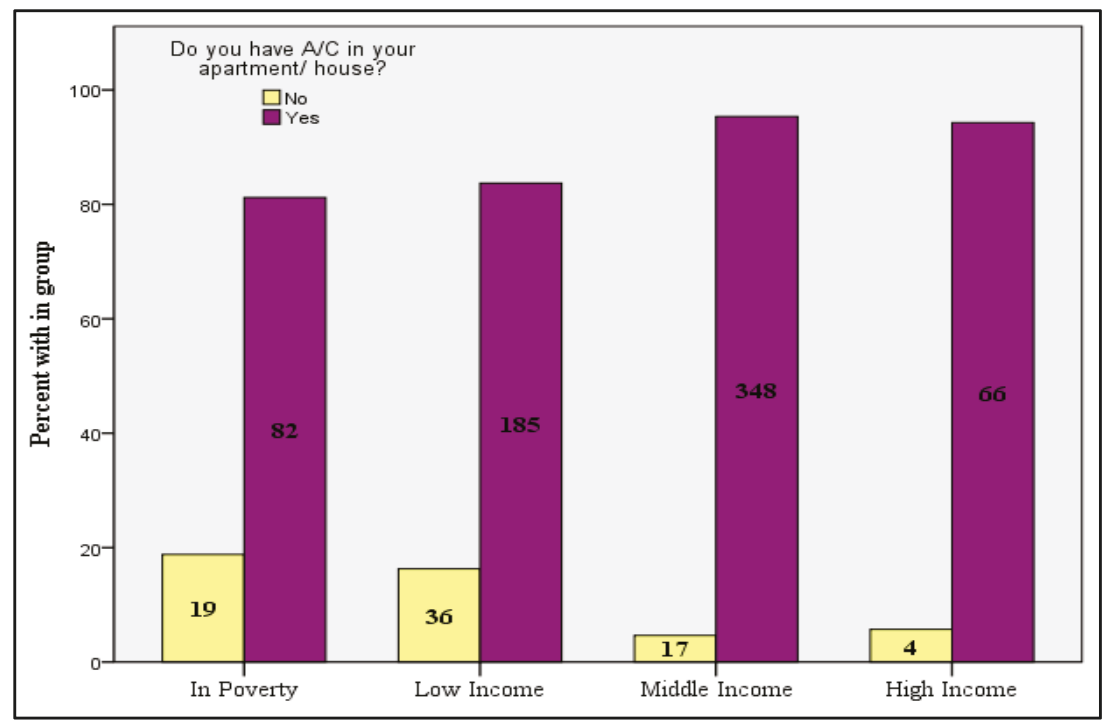

Figure 5. Access to air conditioning (A/C) devices across different income groups. The numbers inside the bars represent the number of total respondents in the respective group.

Table 4 shows which of the urban sectors respondents saw most in need of adaptation for future heat waves. Our results show that the majority of citizens across all income groups regard it as very important or somewhat important to invest in all adaptation sectors investigated. However, for almost all evaluated sectors, people living in poverty and of low income stated in higher shares that it adaptation is very important (see Appendix C). Despite this similarity, there are also differences across income groups, as shown in Table 3. The four income groups significantly differ in regard to the perceived importance of "Urban greenery and parks" (highlighted in red in Table 4).

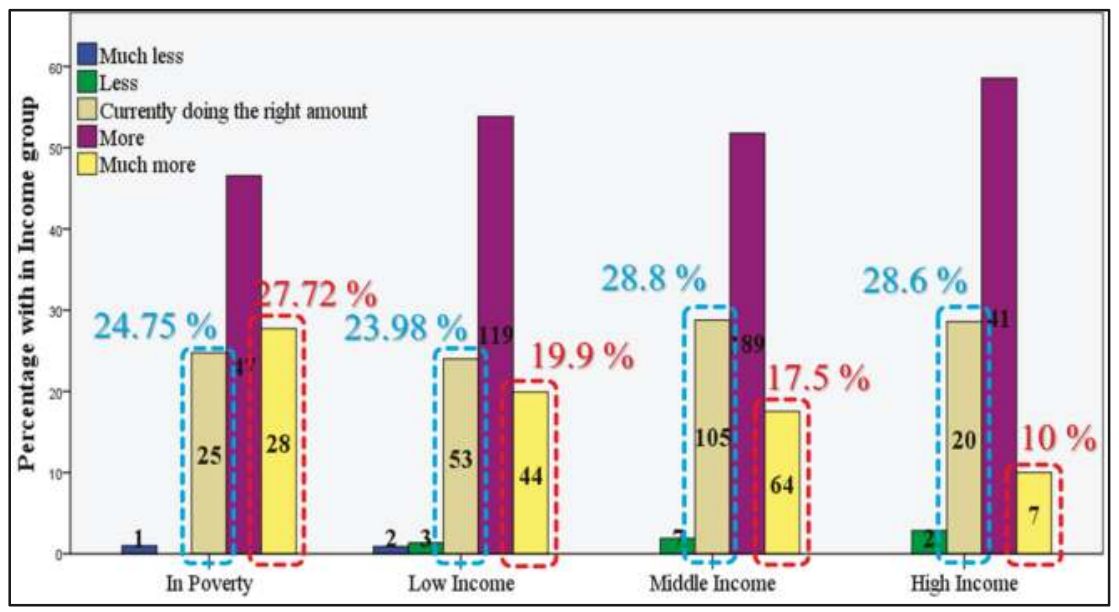

Figure 6. Different income groups expressions about citizens' responsibility with regard to adaptation issues. The numbers inside the bars represent number of respondents. 
Table 4. Results of Kruskal-Wallis H-Test in regard to the importance of adaptation to heat waves for different urban sectors. The underlined text shows the significant differences between income groups with $p$-value less than 0.05 .

\begin{tabular}{ccc}
\hline Urban Sectors & Chi-Square & Asymp. Sig. \\
\hline The water supply & 4.542 & 0.209 \\
The public's health & 6.561 & 0.087 \\
The drainage and sewer system & 2.001 & 0.572 \\
The subway and rail system & 2.683 & 0.443 \\
The electricity system & 2.530 & 0.470 \\
The building stock, e.g., through insulation & 1.782 & 0.619 \\
Urban greenery and parks & $\underline{8.384}$ & $\underline{0.039}$ \\
\hline The road system & 7.675 & 0.053 \\
\hline
\end{tabular}

According to the results of the Mann-Whitney U-test (Table 5) significant differences regarding the perceived importance "Urban greenery and parks" as adaptation strategy exist between the low and middle income group. The low income group regards it as significantly more important than the middle income group to invest in urban greenery and parks as adaptation strategy.

Table 5. Results of Mann-Whitney U-test in regard to the importance of urban sectors in heat wave adaptation. The underlined text shows the location of significant differences between income groups with $p$-value less than 0.05 .

\begin{tabular}{|c|c|c|c|c|c|}
\hline Urban Sector & $\begin{array}{l}\text { Location of Sigr } \\
\text { (Between In }\end{array}$ & $\begin{array}{l}\text { icant Differences } \\
\text { me Groups) }\end{array}$ & $\begin{array}{c}\text { Mann- } \\
\text { Whitney-U }\end{array}$ & Z-Score & $\begin{array}{l}\text { Asymp. } \\
\text { Sig. }\end{array}$ \\
\hline \multirow{6}{*}{$\begin{array}{l}\text { Urban greenery } \\
\text { and parks }\end{array}$} & \multirow{3}{*}{ In poverty } & Low Income Group & $10,627.0$ & -0.023 & 0.981 \\
\hline & & Middle Income Group & $16,054.5$ & -1.773 & 0.076 \\
\hline & & High Income Group & 2999.5 & -1.473 & 0.141 \\
\hline & \multirow{2}{*}{ Low Income } & Middle Income Group & $34,670.0$ & -2.462 & 0.014 \\
\hline & & High Income Group & 6466.0 & -1.777 & 0.076 \\
\hline & Middle Income Group & High Income Group & $12,256.5$ & -0.305 & 0.761 \\
\hline
\end{tabular}

\subsection{FCM Analysis Results}

Following the perception on future impacts and impact sectors as well as adaptation responsibility and adaptation sectors we now present the results of the adaptation scenarios, asking which adaptation scenario would reduce the impacts for which income group the most. To do so we first present the cognitive maps of impacts of heat waves in New York City and respective statistics for each income group. Figure 7 shows the cognitive maps of each income group.

One can see that, e.g., the cognitive map of the people of middle income has a few larger concepts, depicting higher centrality. This means that a few concepts are very important for the network and have many in-going and out-going connections. Middle income people perceive a few aspects of being very central and important to the impact situation during heat waves in NYC. In contrast, the respondents living in poverty reported many concepts of smaller centrality, showing that many but small cause-effect relations determine the situation of heat wave impacts for this income group. Regarding sector it appears that people of low income mentioned aspects of energy and natural resources more often and more important than others. With regards to the other sectors, the picture seems mixed. Figure 8 brings clarity, showing the number of concepts per sector in each map. Health aspects are the most numerous in each cognitive map, although they have a larger share in the cognitive map of people living in poverty. Energy and natural aspects rank second. It shows that health, energy and other natural resources are the aspects that respondents most associate with impacts during heat waves. 


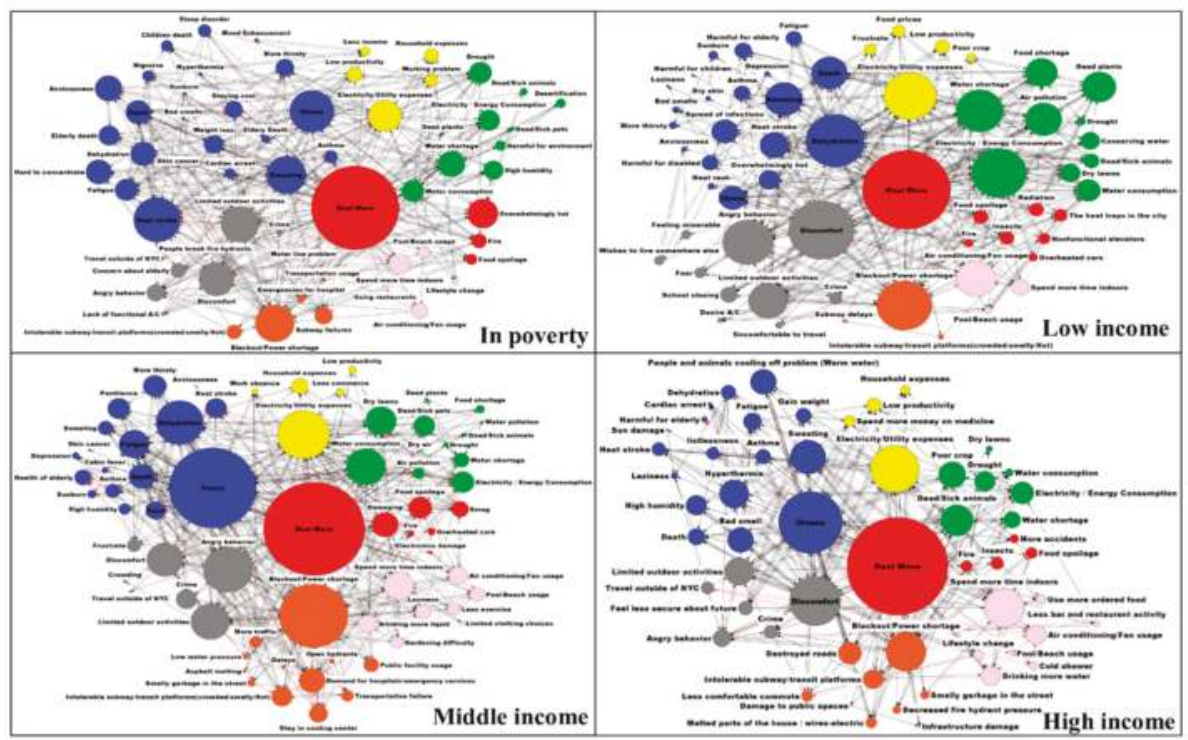

Figure 7. Visualization of the cognitive map of each income group. Legend: The size of the nodes depict centrality. The colors refer to sectors, such as health, economic aspects, social aspects, energy and natural resources, infrastructure, hazard and damages, life style.

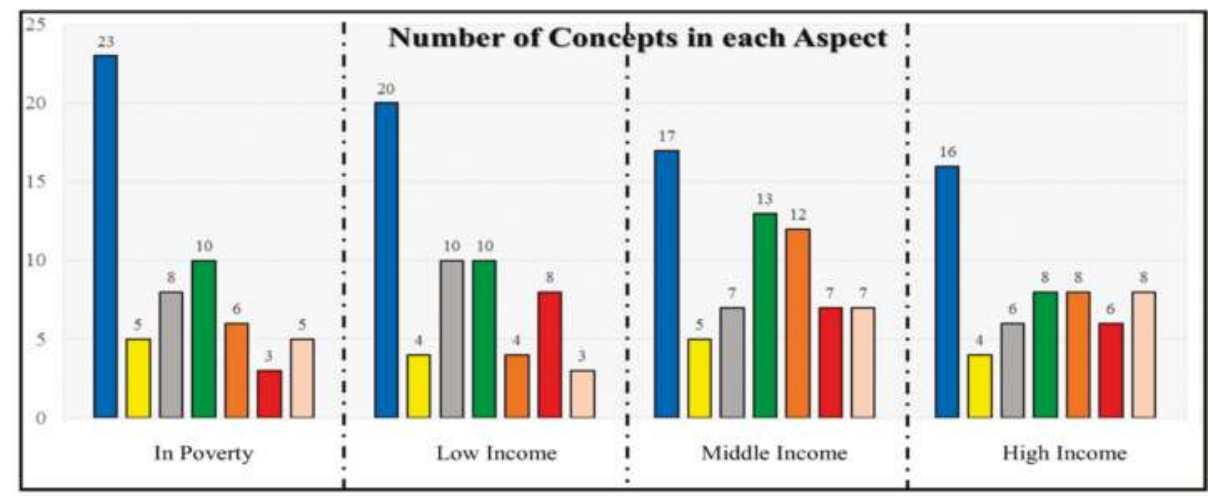

Figure 8. Frequency of concepts per sector in cognitive maps per income group. The colors refer to sectors as follows health, economic aspects, social aspects, energy and natural resources, infrastructure, hazard and damages, life style.

Figure 9 shows which of the concepts have the highest centrality per sector and network, depicting concepts of the largest influence. Centrality is the sum of the weight of in-going and out-going factors and therefore stands for both an aspect highly influenced and highly influential in the network. 


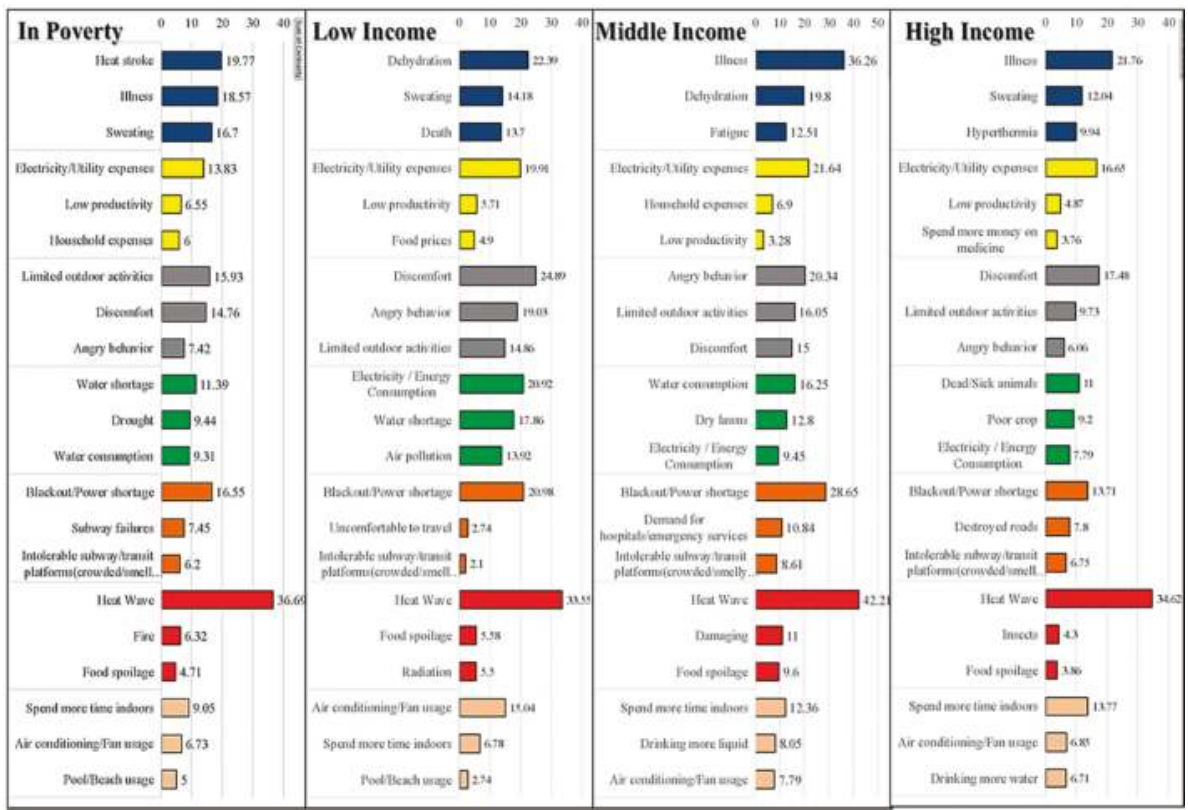

Figure 9. Concepts of highest centrality in the network per sector and income group. The colors refer to following sectors: health, economic aspects, social aspects, energy and natural resources, infrastructure, hazard and damages, life style.

There are some concepts which are similarly important in the maps such as illness in the health sector, electricity/utility expenses and low productivity among economic aspects, limited outdoor activities and angry behavior among social aspects, water and energy consumption among natural resources, blackout/power shortage and intolerable transit platforms as regards city infrastructure, food spoilage as concerns hazards/damages, air conditioning/fan usage and spending more time indoors with regard to lifestyle aspects. These similar and very important concepts can be considered as main drivers when developing and prioritizing general adaptation options to heat waves for all citizens. Other important concepts may be considered when developing income group specific adaptation options, especially for lower income groups which are regarded as more vulnerable than others. Some of these important concepts are: dehydration as regards health aspects, household expenses and food prices as economic aspects, water shortage and air pollution among natural resources, subway failure and uncomfortability to travel in city infrastructure, and fire hazards.

\subsection{FCM Scenario Simulation Results}

The results of three sample scenarios-investments in the public health sector, the water and electricity systems, and the transit sector-are presented in Figure 10, which shows the effect of each scenario on major concepts in the cognitive map of each income group.

Figure 10 shows that investments in the transit sector compared to the other two tested scenarios would result in the strongest positive change (decrease in negative concepts) in most of the aspects. The result of this scenario in regards to health and natural resource aspects should be highlighted. With respect to the four income groups, the group of people living in poverty and of low income experience stronger negative impacts (increase in negative concepts) throughout all tested scenarios as compared with the middle class and high income group. 


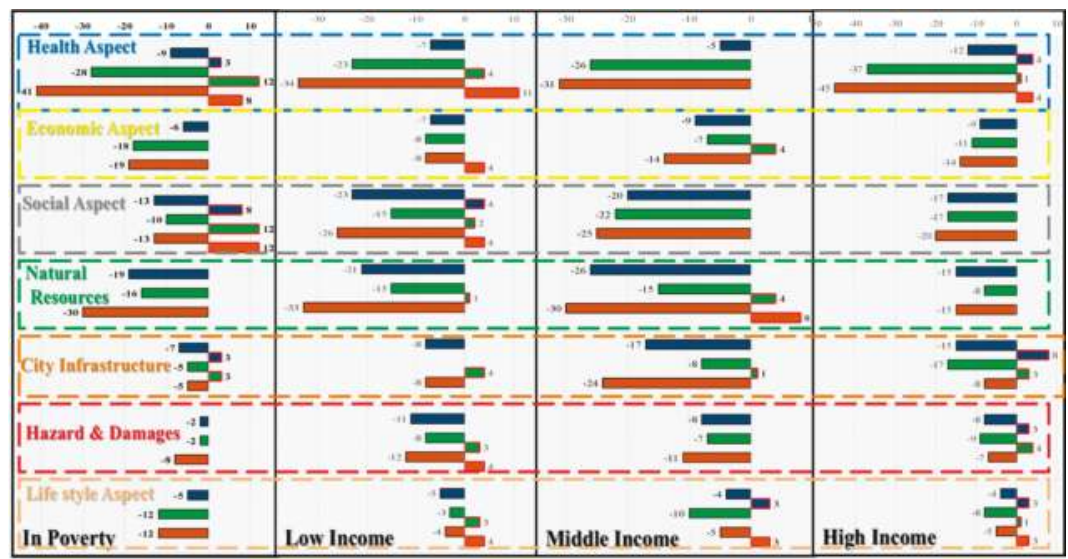

Figure 10. Comparing the effect of different scenarios on concepts per sector and income group. It should be highlighted that the negative numbers show the decrease in negative impacts (concepts) and positive numbers shows the increase in negative impacts. Legend: Blue bar represents the scenario: public health; green bar represents the scenario: water and electricity system; orange bar represents the scenario: transit system.

To provide a general overview of the effect of each scenario on the entire sample population, i.e., all income groups, and to compare them, all positive change of positive concepts and negative change of negative concepts are merged separately. The results are presented in Figure 11.

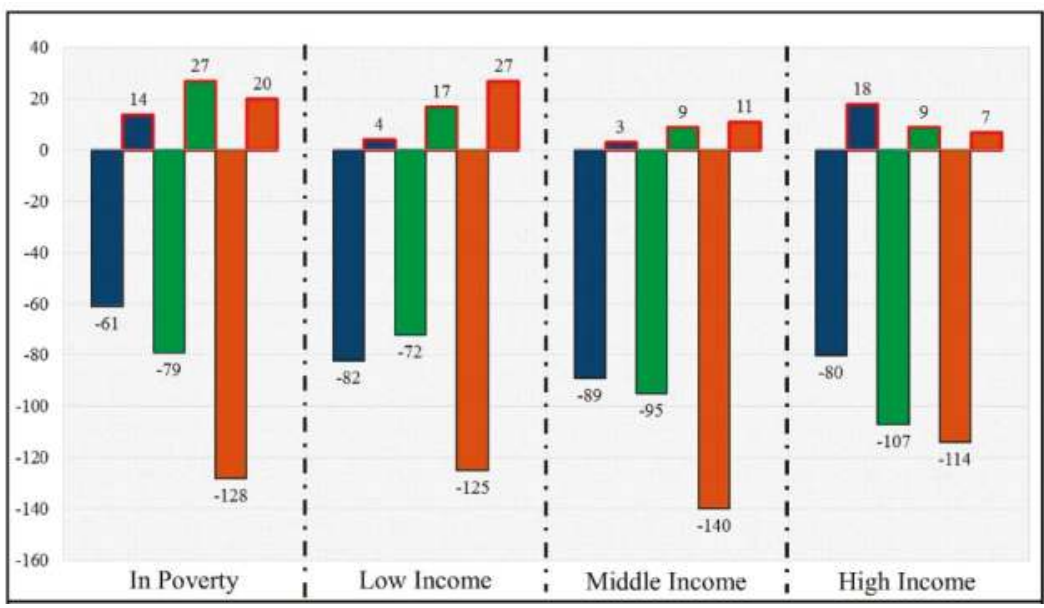

Figure 11. Comparison of the joint impact of the three scenarios on all income groups. It should be highlighted that the negative number shows the decrease in negative impacts (concepts) and positive numbers shows the increase in negative impacts. Legend: Blue bar represents the scenario: public health; green bar represents the scenario: water and electricity system; orange bar represents the scenario: transit system.

The results of the scenario simulations show that all three scenarios have overall a positive impact on all income groups, as negative impacts are lowered by every scenario for each income group. The scenario "investment in the transit sector" shows the strongest positive effects for all income groups. 
Investments in the water and electricity system are the second most effective in reducing negative impacts for people living in poverty, middle and high income respondents, while for low income respondents the public health sector ranks second.

\section{Discussion}

The aim of this research was to assess the perception of NYC residents' regarding impacts of heat waves and aspects of adaptation. By using citizen's perception we aimed to concentrate on the local level and to develop relevant information for socially sensible adaptation options to heat waves as bottom-up process-and in contrast to top-down approaches in the governance hierarchy. Doing so this study also aimed to use and prioritize non-scientific local knowledge as the main driver in developing adaptation options for the local level. Using perception data and citizen's cognitive maps with regard to the impacts of heat wave, residents' understanding about heat waves become apparent, which is vitally important for individual and autonomous adaptation.

Moreover, using online interviews to collect residents' perception data has proven to be a useful method and channel to reach in particular people of low incomes and people living in poverty-usually regarded as hard to reach. Using paid questionnaire surveys their views and perceptions can be elicited and theoretically be integrated and respected in the urban planning process. By that, people of lower income (could) become systematically involved as active stockholders in the urban governance and decision making processes. The developed tool is therefore useful, as considers the views and perception of vulnerable groups alongside other citizens, e.g., those belonging to higher income classes. Only if views of all income groups are respected adaptation measures can hypothetically be fully effective.

Our results show that residents living in poverty and of low income are more worried by heat wave impacts than higher income groups. They also perceive impacts to be larger in the future and a larger adaptation responsibility with themselves. The scenario analyses showed that investments in the transit sector show the highest positive impacts for all income groups, but for the lower income groups most. These results should be very useful for the decision makers in New York City, allowing aligning adaptation options with regard to future heat waves. According to the results of FCM analysis, focusing on the transit sector would have a potentially positive effect on concepts related to the health sector and water and electricity sectors as well and will lead to more effective and comprehensive answers to citizens needs when they face the negative impacts of heat waves.

There are also some limitations of the study. Compared to the population size of NYC (according to the American Community Survey projected to be at 8,405,837 in 2013) the sample size of 762 respondents is relatively small. However, for a social study it is quite comprehensive and particularly rich, with more than 60 variables to different subjects which can provide a useful overview of differences between various income groups in New York City.

The other limitation is in regards to gathering the FCM data through an online questionnaire. Eliciting networks via questionnaires is a complex task, increasing the risk of misunderstandings and mistakes, especially about the relation between concepts. According to Özesmi and Özesmi (2004) and Olazabal and Reckien (2015) face to face interview method should be favoured. However, using online questionnaires has also advantages, as it allows to reach more participant in a shorter timeframe and selected participants of particular characteristics or large diversity. Online FCM samples can therefore provide a more comprehensive sample, e.g., increasing the spatial scope of sampling from all New York City.

\section{Conclusions}

Our results show that lower income groups are more concerned about future impacts of heat wave than middle class and high income populations. They also see a larger adaptation responsibility with themselves. However, as regards sectors, residents of different income levels do not significantly 
disagree, apart from urban greenery and parks. Lower income households see a larger need for adaptation using urban greenery and parks, as compared to higher income respondents.

The FCM analysis shows that respondents are most concerned with health-related aspects, as health-related concepts have the highest share in the cognitive maps of all income groups' cognitive maps. However, according to the results of the scenario simulation, investments in the transit sector shows the strongest positive effect for all income groups. Investment in the transit sector is a mediator and lowers the negative impacts on people's health.

This research mainly concentrates on citizens' perception and on local knowledge. Future study may combine these results with expert knowledge, especially climate change scientists and New York City decision makers, which could be a useful exercise increasing efficiency and validity of our results and ensuring that adaptation measures are fit for purpose.

Author Contributions: S.M. conducted the research and wrote most parts of the paper. D.R. conceptualized the study, gathered the data, guided the data analysis and supported the writing of the paper. J.F. contributed to the analysis and to writing.

Conflicts of Interest: The authors declare no conflict of interest.

\section{Appendix A. Detailed Information about Concepts' Fixed Value in Scenario Simulation}

Table A1. Selected concepts and their fixed values for scenario simulation in FCMAPPERS.

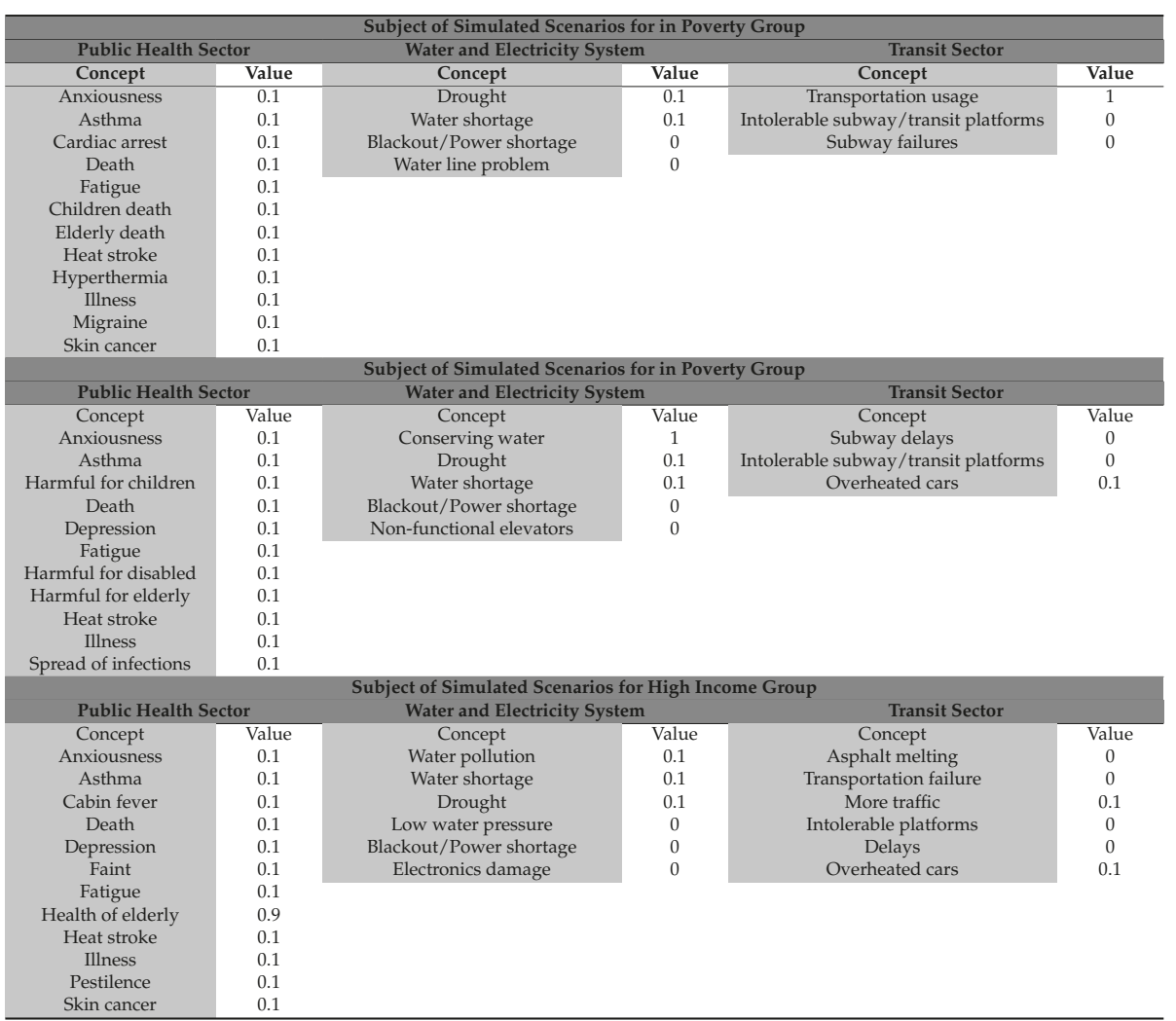


Table A1. Cont.

\begin{tabular}{|c|c|c|c|c|c|}
\hline \multicolumn{6}{|c|}{ Subject of Simulated Scenarios for in Poverty Group } \\
\hline Concept & Value & Concept & Value & Concept & Value \\
\hline Asthma & 0.1 & Draught & 0.1 & Destroyed roads & 0 \\
\hline Death & 0.1 & Water shortage & 0.1 & Infrastructure damage & 0 \\
\hline Fatigue & 0.1 & Blackout/Power shortage & 0 & Intolerable subway/transit platforms & 0 \\
\hline Harmful for elderly & 0.1 & Decreased fire hydrant pressure & 0 & Less comfortable commute & 0 \\
\hline Cardiac arrest & 0.1 & & & More accidents & 0.1 \\
\hline Heat stroke & 0.1 & & & & \\
\hline Hyperthermia & 0.1 & & & & \\
\hline Illness & 0.1 & & & & \\
\hline $\begin{array}{l}\text { People and animals } \\
\text { cooling off problem }\end{array}$ & 0.1 & & & & \\
\hline
\end{tabular}

\section{Appendix B. Perceived Extent of Climate Change Impacts in the Future}

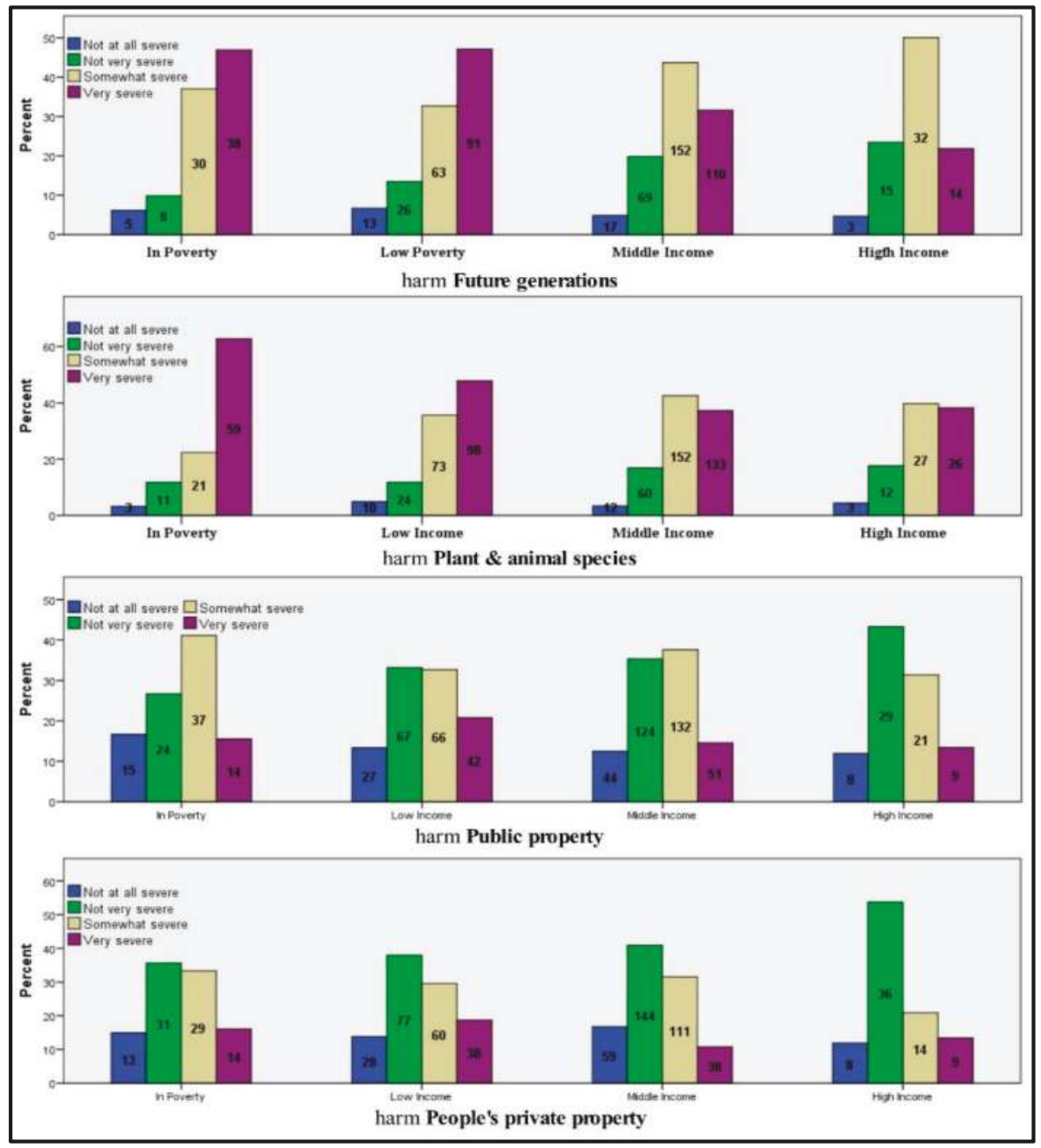

Figure A1. Different income groups concerns about future impacts of heat waves based on different subjects. 


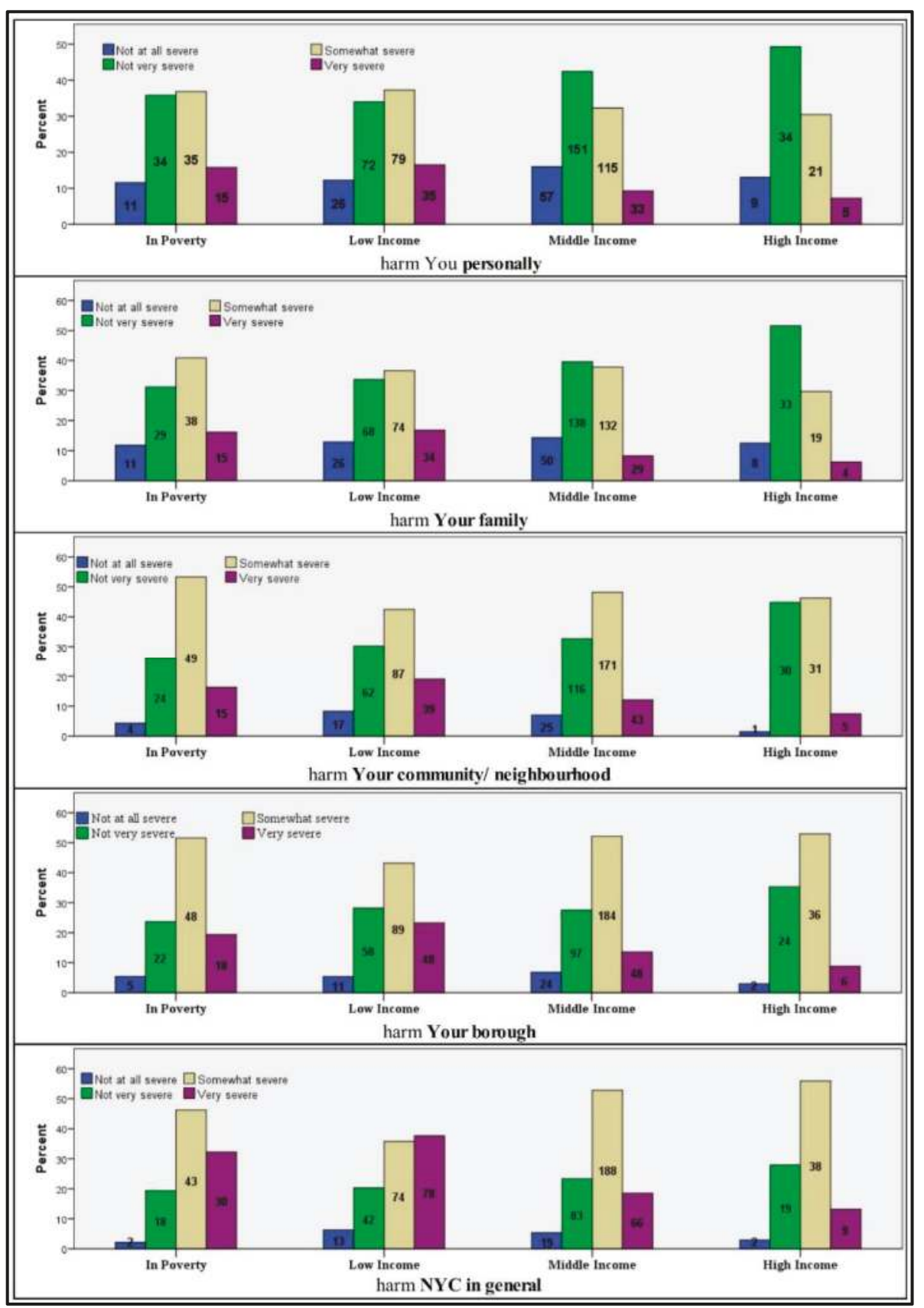

Figure A2. Different income groups concerns about future impacts of heat waves based on different subjects. (the numbers inside the bars represent the number of responses in the data base). 
Appendix C. Importance of Different Urban Sector in Future Heat Wave Adaptation

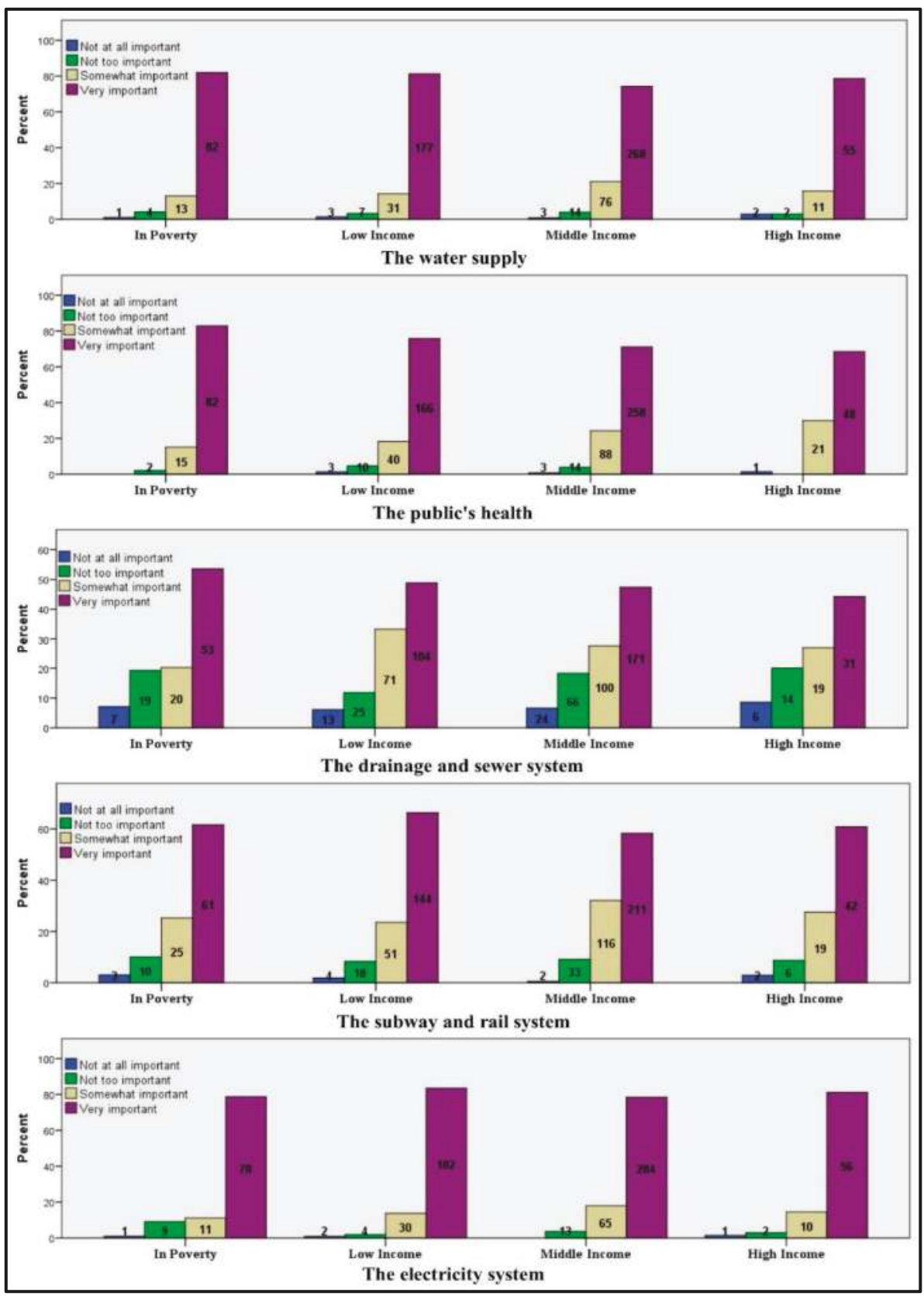

Figure A3. Importance of different urban sectors in heat wave adaptation based on income groups' perception (the numbers inside the bars represent the number of responses in the data base). 


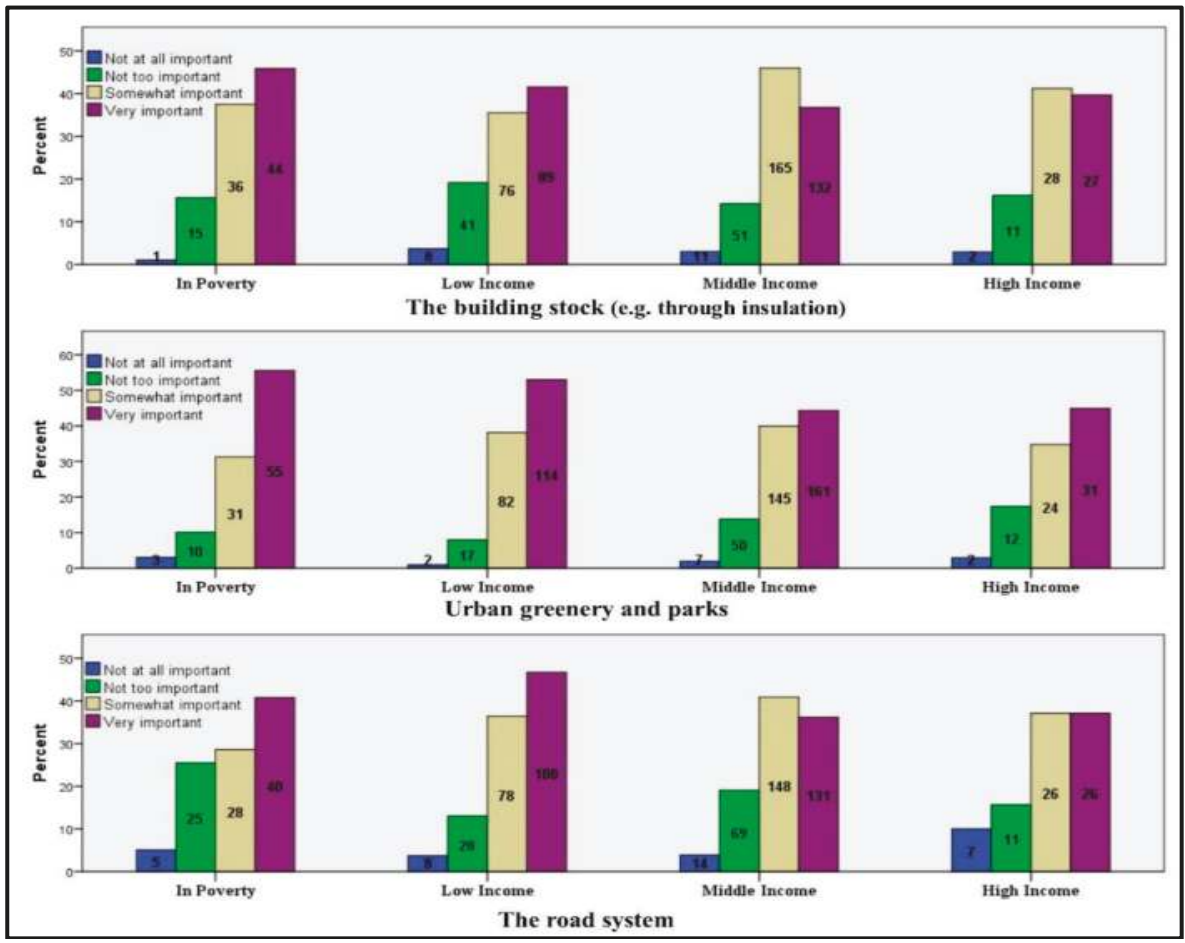

Figure A4. Importance of different urban sectors in heat wave adaptation based on income groups' perception (the numbers inside the bars represent the number of responses in the data base).

\section{References}

1. Rosenzweig, C.; Solecki, W.D.; Hammer, S.A.; Mehrotra, S. Climate Change and Cities First Assessment Report of the Urban Climate Change Research Network(Executive Summary); Columbia University: New York, NY, USA, 2011; pp. 1-23.

2. Klinenberg, E. Heat Wave: A Social Autopsy of Disaster in Chicago; University of Chicago Press: Chicago, IL, USA, 2003; p. 305.

3. Satterthwaite, D.; Huq, S.; Pelling, M.; Reid, H.; Lankao, P.R. Adapting to Climate Change in Urban Areas: The Possibilities and Constraints in Low and Middle Income Nations; Human Settlments; IIED: London, UK, 2007; Volume 58, p. 124.

4. Intergovernmental Panel on Climate Change (IPCC). Managing the Risks of Extreme Events and Disasters to Advance Climate Change Adaptation; Cambridge University Press: New York, NY, USA, 2012; p. 594.

5. Goodess, C.M. How is the frequency, location and severity of extreme events likely to change up to 2060? Environ. Sci. Policy 2012, 27, S4-S14. [CrossRef]

6. Rosenzweig, C.; Solecki, W.; Degaetano, A.; Grady, M.O.; Hassol, S.; Grabhorn, P.; Buonaiuto, F.; Hammer, S.A.; Kinney, P.L.; Wolfe, D.W.; et al. Responding to Climate Change in New York State: The Climaid Integrated Assessment for Effective Climate Change Adaptation in New York State; Final Report; Annals of the New York Academy of Sciences: New York, NY, USA, 2011; pp. 2-149.

7. Wamsler, C.; Brink, E. Urban climate interfacing citizens' and institutions' practice and responsibilities for climate change adaptation. Urban Clim. 2014, 7, 64-91. [CrossRef]

8. Williams, D.R.; Collins, C. Association of schools of public health racial residential segregation: A fundamental cause of racial disparities in health. Public Health Rep. 2001, 116, 404-416. 
9. Cutter, S.L.; Boruff, B.J.; Shirley, W.L. Social vulnerability to environmental hazards. Soc. Sci. Q. 2003, 84, 242-261. [CrossRef]

10. Zuo, J.; Pullen, S.; Palmer, J.; Bennetts, H.; Chileshe, N.; Ma, T. Impacts of heat waves and corresponding measures: A review. J. Clean. Prod. 2015, 92, 1-12. [CrossRef]

11. Evans, G.W.; Kantrowitz, E. Socioeconomic status and health: The potential role of environmental risk exposure. Annu. Rev. Public Health 2002, 23, 303-331. [CrossRef] [PubMed]

12. Kinney, P.L.; Matte, T.; Knowlton, K.; Madrigano, J.; Petkova, E.; Weinberger, K.; Quinn, A.; Arend, M.; Pullen, J. New York City Panel on Climate Change 2015 Report Chapter 5: Public Health Impacts and Resiliency; Annals of the New York Academy of Sciences: New York, NY, USA, 2015; pp. 67-88.

13. Reckien, D.; Creutzig, F.; Fernandez, B.; Lwasa, S.; Tovar-Restrepo, M.; Mcevoy, D.; Satterthwaite, D. Climate change, equity and the sustainable development goals: An urban perspective. Environ. Urban. 2017, 29, 159-182. [CrossRef]

14. Reckien, D.; Lwasa, S.; Satterthwaite, D.; McEvoy, D.; Creutzig, F.; Montgomery, M.; Schensul, D.; Balk, D.; Khan, I. Equity, environmental justice, and urban climate change. In Climate Change and Cities: Second Assessment Report of the Urban Climate Change Research Network; Rosenzweig, C., Solecki, W., Romero-Lankao, P., Mehrotra, S., Dhakal, S., Ibrahim, S.A., Eds.; Cambridge University Press: Cambridge, UK, 2017.

15. Rosenthal, J.K.; Kinney, P.L.; Metzger, K.B. Intra-urban vulnerability to heat-related mortality in new york city, 1997-2006. Health Place 2014, 30, 45-60. [CrossRef] [PubMed]

16. Sampson, N.R.; Gronlund, C.J.; Buxton, M.A.; Catalano, L.; White-Newsome, J.L.; Conlon, K.C.; O'Neill, M.S.; McCormick, S.; Parker, E.A. Staying cool in a changing climate: Reaching vulnerable populations during heat events. Glob. Environ. Chang. 2013, 23, 475-484. [CrossRef]

17. Intergovernmental Panel on Climate Change (IPCC). Summary for Policymakers; Climate Change 2014: Impacts, Adaptation and Vulnerability-Contributions of the Working Group II to the Fifth Assessment Report; Cambridge University Press: Cambridge, UK; New York, NY, USA, 2014; pp. 1-32.

18. Füssel, H.M. Vulnerability: A generally applicable conceptual framework for climate change research. Glob. Environ. Chang. 2007, 17, 155-167. [CrossRef]

19. Intergovernmental Panel on Climate Change (IPCC). Glossary. In Climate Change 2013: Impacts, Adaptation and Vulnerability. Contribution of Working Group II to the Fifth Assessment Report of the Intergovernmental Panel on Climate Change; Cambridge University Press: Cambridge, UK; New York, NY, USA, 2014; pp. 1757-1776.

20. Tonn, B.; Eisenberg, J. The aging us population and residential energy demand. Energy Policy 2007, 35, 743-745. [CrossRef]

21. Lemmen, D.S.; Warren, F.J. Climate Change Impacts and Adaptation: A Canadian Perspective; Natural Resources Canada: Ottawa, OTT, Canada, 2004; p. 174.

22. Barnett, J.; O’Neill, S. Maladaptation. Glob. Environ. Chang. 2010, 20, 211-213. [CrossRef]

23. Bolitho, A.; Miller, F. Heat as emergency, heat as chronic stress: Policy and institutional responses to vulnerability to extreme heat. Local Environ. 2016, 1-17. [CrossRef]

24. Slovic, P. The Perception of Risk; Routledge: London, UK, 2000.

25. The Organisation for Economic Co-operation and Development (OECD). Modernising Government: The Way Forward; OECD: Paris, France, 2005.

26. Pollitt, C.; Hupe, P. Talking governance: The role of magic concepts. Public Manag. Rev. 2011, 13, 641-658. [CrossRef]

27. Bernauer, T.; Schaffer, L.M. Climate change governance. In The Oxford Handbook of Governance; OUP: Oxford, UK, 2012; pp. 9-27.

28. Anguelovski, I.; Carmin, J. Something borrowed, everything new: Innovation and institutionalization in urban climate governance. Curr. Opin. Environ. Sustain. 2011, 3, 169-175. [CrossRef]

29. Chanza, N.; De wit, A. Enhancing climate governance through indigenous knowledge: Case in sustainability science. J. Sci. 2016, 112, 1-7. [CrossRef]

30. Sippel, M.; Jenssen, T. What About local Climate Governance? A Review of Promise and Problems. 2009, pp. 1-51. Available online: https:/ / ssrn.com/abstract=1514334 (accessed on 31 May 2017).

31. Urwin, K.; Jordan, A. Does public policy support or undermine climate change adaptation? Exploring policy interplay across different scales of governance. Glob. Environ. Chang. 2008, 18, 180-191. [CrossRef] 
32. Olazabal, M.; Reckien, D. Chapter 7: Fuzzy cognitive mapping: Applications to urban environmental decision-making. In Handbook of Research Methods and Applications in Environmental Studies; Ruth, M., Ed.; Edward Elgar Publishing: Cheltenham, UK, 2015; pp. 148-176.

33. Reckien, D. Weather extremes and street life in india-implications of fuzzy cognitive mapping as a new tool for semi-quantitative impact assessment and ranking of adaptation measures. Glob. Environ. Chang. 2014, 26, 1-13. [CrossRef]

34. Reckien, D.; Wildenberg, M.; Bachhofer, M. Subjective realities of climate change: How mental maps of impacts deliver socially sensible adaptation options. Sustain. Sci. 2013, 8, 159-172. [CrossRef]

35. Reckien, D.; Wildenberg, M.; Deb, K. Understanding potential climate change impacts and adaptation options in indian megacities. In Resilient Cities: Cities and Adaptation to Climate Change-Proceedings of the Global Forum 2010; Otto-Zimmermann, K., Ed.; Springer: Dordrecht, The Netherlands, 2011; pp. 15-34.

36. Gray, S.R.J.; Gagnon, A.S.; Gray, S.A.; O’Dwyer, B.; O’Mahony, C.; Muir, D.; Devoy, R.J.N.; Falaleeva, M.; Gault, J. Are coastal managers detecting the problem? Assessing stakeholder perception of climate vulnerability using fuzzy cognitive mapping. Ocean Coast. Manag. 2014, 94, 74-89. [CrossRef]

37. Moser, S.C.; Ekstrom, J.A. A framework to diagnose barriers to climate change adaptation. Proc. Natl. Acad. Sci. USA 2010, 107, 22026-22031. [CrossRef] [PubMed]

38. Horton, R.M.; Gornitz, V.; Bader, D.A.; Ruane, A.C.; Goldberg, R.; Rosenzweig, C. Climate hazard assessment for stakeholder adaptation planning in new york city. J. Appl. Meteorol. Climatol. 2011, 50, 2247-2266. [CrossRef]

39. Long, H. America's 10 Most Unequal Cities. Available online: http://money.cnn.com/2014/12/14/news/ economy/america-inequality-10-worst-cities/index.html (accessed on 14 December 2014).

40. De Navas-Walt, C.; Proctor, B.D. Income and Poverty in the United States: 2013 Current Population Reports; Current Population Reports; U.S. Government Printing Office: Washington, DC, USA, 2014; pp. 60-249.

41. Elkwell, C.K. The Distribution of Household Income and the Middle Class; Library of Congress, Congressional Research Service: Washington, DC, USA, 2014; Volume 7-5700, pp. 1-10.

42. Kiersz, A.; Kane, L. What 'Middle Class' Means in 50 Major US Cities. Available online: http://www. businessinsider.com/what-middle-class-means-in-50-major-us-cities-2015-4 (accessed on 2 April 2015).

43. Carver, R.H.; Nash, J.G. Doing Data Analysis with Spss ${ }^{\circledR}$; Version 18; Cengage Learning: Boston, MA, USA, 2011.

44. Corder, G.W.; Foreman, D.I. Nonparametric Statistics for Non-Statisticians: A Step by Step Approach; Wiley: Hoboken, NJ, USA, 2009; Volume 264.

45. Kok, K. The potential of fuzzy cognitive maps for semi-quantitative scenario development, with an example from brazil. Glob. Environ. Chang. 2009, 19, 122-133. [CrossRef]

46. Jetter, A.; Schweinfort, W. Building scenarios with fuzzy cognitive maps: An exploratory study of solar energy. Futures 2011, 43, 52-66. [CrossRef]

(c) 2017 by the authors. Licensee MDPI, Basel, Switzerland. This article is an open access article distributed under the terms and conditions of the Creative Commons Attribution (CC BY) license (http:/ / creativecommons.org/licenses/by/4.0/). 
MDPI

St. Alban-Anlage 66

4052 Basel

Switzerland

Tel. +41616837734

Fax +41 613028918

www.mdpi.com

ISPRS International Journal of Geo-Information Editorial Office

E-mail: ijgi@mdpi.com

www.mdpi.com/journal/ijgi

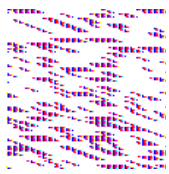



MDPI

St. Alban-Anlage 66

4052 Basel

Switzerland

Tel: +41 616837734

Fax: +41 613028918

www.mdpi.com 